ANNE KARRASS

\title{
Die EU und der Rückzug des Staates
}

\author{
Eine Genealogie \\ der Neoliberalisierung
} der europäischen Integration 
Anne Karrass

Die EU und der Rückzug des Staates 
Dr. Anne Karrass ist Volkswirtin und Sozialökonomin. Zurzeit arbeitet sie als wissenschaftliche Mitarbeiterin im Deutschen Bundestag. Ihre Arbeits- und Forschungsschwerpunkte sind europäische Wirtschafts- und Sozialpolitik. 
Anne Karrass

\section{Die EU und der Rückzug des Staates}

Eine Genealogie der Neoliberalisierung

der europäischen Integration

[transcript] 


\section{(a) $(1 \otimes \Theta$}

Dieses Werk ist lizenziert unter der Creative Commons AttributionNonCommercial-NoDerivs 4.o Lizenz (BY-NC-ND). Diese Lizenz erlaubt die private Nutzung, gestattet aber keine Bearbeitung und keine kommerzielle Nutzung. Weitere Informationen finden Sie unter https://creativecommons.org/licenses/by-nc-nd/4.o/deed.de/.

Um Genehmigungen für Adaptionen, Übersetzungen, Derivate oder Wiederverwendung zu kommerziellen Zwecken einzuholen, wenden Sie sich bitte an rights@transcript-verlag.de

\section{(C) 2009 transcript Verlag, Bielefeld}

Die Verwertung der Texte und Bilder ist ohne Zustimmung des Verlages urheberrechtswidrig und strafbar. Das gilt auch für Vervielfältigungen, Übersetzungen, Mikroverfilmungen und für die Verarbeitung mit elektronischen Systemen.

\section{Bibliografische Information der Deutschen Nationalbibliothek}

Die Deutsche Nationalbibliothek verzeichnet diese Publikation in der Deutschen Nationalbibliografie; detaillierte bibliografische Daten sind im Internet über http://dnb.d-nb.de abrufbar.

Umschlaggestaltung: Kordula Röckenhaus, Bielefeld Lektorat \& Satz: Anne Karrass

Druck: Majuskel Medienproduktion $\mathrm{GmbH}$, Wetzlar Print-ISBN 978-3-8376-1067-3 PDF-ISBN 978-3-8394-1067-7

Gedruckt auf alterungsbeständigem Papier mit chlorfrei gebleichtem Zellstoff.

Besuchen Sie uns im Internet: http://www.transcript-verlag.de Bitte fordern Sie unser Gesamtverzeichnis und andere Broschüren an unter: info@transcript-verlag.de 
INHALT

1 Einleitung 9

1.1 Problemstellung und Relevanz 9

1.2 Zielsetzung und Aufbau der Arbeit 13

2 Eingrenzungen und Definitionen 17

2.1 Definition von Staatsverständnis, staatlicher

2.2 Eingrenzung der zu untersuchenden Politikfelder 21

Überblick über die Ziele staatlicher Ausgabenpolitik 22

Ausgabenpolitische Vorgaben in den Europäischen Verträgen $\quad 26$

Zusammenfassung: Untersuchungsgegenstand 32

3 Theoretischer Rahmen 35

3.1 Entwicklung idealtypischer Staatsverständnisse 35

Gegenüberstellung: Liberale und interventionistische

Staatsverständnisse $\quad 37$

Das Staatsverständnis in der Keynes'schen Theorie $\quad 39$

Das Staatsverständnis in der monetaristischen Theorie 51

Das Staatsverständnis in der Angebotsökonomie/

Neuen Klassischen Makroökonomie $\quad 61$

Synopse der drei idealtypischen Staatsverständnisse $\quad 71$

3.2 Entwicklung möglicher Strategien zur

Beeinflussung von Handlungsfähigkeit $\quad 72$

Hinführung $\quad 73$

Die kritische Strategie $\quad 77$

Die affirmative Strategie $\quad 80$

Die revisionistische Strategie $\quad 82$

Fazit $\quad 85$ 
4 Untersuchung der intendierten Beeinflussung von Handlungsfähigkeit sowie des Staatsverständnisses in den verschiedenen Phasen des Integrationsprozesses

4.1 Durchführung und Methoden

Eingrenzung des Datenmaterials

Durchführung der Untersuchung der intendierten

Beeinflussung von Handlungsfähigkeit

Methodisches Vorgehen bei der Analyse der den Vorgaben zugrunde liegenden Staatsverständnisse

4.2 Phase I (1957-1973) 100

Umfeldbeschreibung

Intendierter Einfluss der europäischen Vorgaben auf die

Interventionsmöglichkeiten der Mitgliedstaaten und

ihre Handlungsfähigkeit

102

Staatsverständnis

114

Fazit

4.3 Phase II (1974-1982) 120

Umfeldbeschreibung

Intendierter Einfluss der europäischen Vorgaben auf die Interventionsmöglichkeiten der Mitgliedstaaten und ihre Handlungsfähigkeit

Staatsverständnis

Fazit

4.4 Phase III (1983-1989) 140

Umfeldbeschreibung

Intendierter Einfluss der europäischen Vorgaben auf die Interventionsmöglichkeiten der Mitgliedstaaten und ihre Handlungsfähigkeit

Staatsverständnis

Fazit

4.5 Phase IV (1990-2004) 158

Umfeldbeschreibung

Intendierter Einfluss der europäischen Vorgaben auf die Interventionsmöglichkeiten der Mitgliedstaaten und ihre Handlungsfähigkeit

Staatsverständnis 178

Fazit 
5.1 Entwicklung in den drei Interventionsbereichen $\quad 183$

Interventionsbereich Allokation: Beihilfen 183

Interventionsbereich Allokation: Öffentliche Güter

mit allokativer Funktion 186

Interventionsbereich Distribution 191

Interventionsbereich Stabilisierung 196

5.2 Entwicklung der Beeinflussung von Handlungsfähigkeit 201

5.3 Entwicklung des Staatsverständnisses 205

5.4 Entwicklung der Beziehung zwischen den Staatsverständnissen und der Beeinflussung staatlicher Handlungsfähigkeit 209

6 Der Wandel im Spiegel der europäischen Vorgaben und Verfahren

6.1 Kurze Darstellung des Wandels anhand des Inhalts der Vorgaben

6.2 Darstellung des Wandels anhand der europäischen Vorgaben und Verfahren

Blütezeit des alten Paradigmas 218

Anomalien und Politikexperimente:

Der Beginn des Wandlungsprozesses 220

Herausbildung des neuen Paradigmas 222

Durchsetzung und Institutionalisierung des neuen Paradigmas 224

6.3 Fazit 228

7 Schlussbetrachtungen 231

$\begin{array}{ll}\text { Literatur } & 235\end{array}$

$\begin{array}{ll}\text { Abbildungsverzeichnis } & 267\end{array}$

$\begin{array}{lr}\text { Abkürzungsverzeichnis } & 269\end{array}$

$\begin{array}{ll}\text { Kategoriensystem } & 271\end{array}$

$\begin{array}{ll}\text { Danksagung } & 277\end{array}$ 



\subsection{Problemstellung und Relevanz}

Zu ihrem 50. Geburtstag im März 2007 hat die Europäische Union nicht nur Glückwünsche bekommen - im Gegenteil: Die Krise des Integrationsprozesses war allgegenwärtig. Festgemacht wird sie insbesondere am Scheitern des Verfassungsprojekts durch die französische und niederländische Ablehnung in den entsprechenden Ratifizierungsreferenden. Der bisher vorherrschende >permissive Konsens` der europäischen Bürgerinnen und Bürger ${ }^{1}$ scheint im Schwinden begriffen (vgl. Bieling/Steinhilber 2000: 118). Ein wesentlicher Kritikpunkt ist, die $\mathrm{EU}^{2}$ sei einseitig marktschaffend und würde in den Mitgliedstaaten zu einer Rückdrängung des Staates führen (vgl. Hrbek 2005: 486). Diese Position findet sich nicht nur in der Bevölkerung, auch in der Wissenschaft wird die (allerdings bei Weitem nicht nur negativ konnotierte) These vertreten, die EU trage dazu bei, in den Mitgliedsländern den Staat zugunsten des Marktes zu schwächen. Dies sei im Integrationsprozess angelegt, sowohl von seinen großen Integrationsprojekten - Zollunion, Binnenmarkt, Währungsunion - als auch von der Integrationsweise her, die seit Mitte der 1980er insbesondere über das Prinzip der gegenseitigen Anerkennung und damit wettbewerblich verläuft (vgl. z.B. Huffschmid 1994; Ziltener 1999; Donges/Freytag 2001).

1 Aus Gründen der Lesbarkeit wird im Folgenden meist nur die männliche Form benutzt, sie soll aber geschlechtsneutral verstanden werden.

2 In der Alltagssprache wie auch der Wissenschaft hat sich der Begriff der Europäischen Union weitgehend durchgesetzt, ich verwende ihn in dieser Arbeit teilweise synonym zu 〉Europäische Gemeinschaft $<$, da diese die zentrale Säule der Europäischen Union ist. 
Ist die Europäische Union somit einfach ein Teil der ökonomischen Globalisierung, der die wirtschaftliche Verflechtung zwischen den nationalen Volkswirtschaften verstärkt, damit die Möglichkeiten der Mitgliedstaaten, in die Wirtschaft $\mathrm{zu}$ intervenieren, einschränkt und die marktliche Koordination in den Vordergrund rückt? Diese These kann so nicht gehalten werden: Die EU ist nicht nur ein ökonomisches, öffnendes Projekt, sie ist - wenn auch in geringerem Maße - regulierend, ein Projekt >politischer Globalisierung wirtschaftliche Verflechtung hinaus und führt auch im ökonomischen Bereich nicht nur zu einer Einschränkung nationalstaatlicher Interventionsmöglichkeiten. Die EU ist somit Teil der ökonomischen Globalisierung, unterscheidet sich aber auch davon - man spricht in diesem $\mathrm{Zu}$ sammenhang auch vom Phänomen der Regionalisierung. Regionalisierung bedeutet, dass sich Nationalstaaten in bestimmten Regionen der Welt zusammenschließen, um Ziele gemeinsam (besser) zu erreichen, Probleme koordiniert anzugehen etc. Während die ökonomische Verflechtung die wirtschaftspolitischen Interventionsmöglichkeiten - dies ist weitgehend Konsens in der Wissenschaft - immer einschränkt, kann eine solche politische Zusammenarbeit, die in der Lage ist, auf ein deutlich breiteres Instrumentarium zurückzugreifen als Zollsenkungen, den Abbau nicht-tarifärer Handelshemmnisse sowie die Reduzierung von Transaktionskosten, auch zu einer Ausweitung dieser Möglichkeiten führen (vgl. hierzu ausführlicher Kapitel 3.2).

Um diesen Fragenkomplex - europäische Regionalisierung und deren Einfluss auf staatliche Interventionsmöglichkeiten - soll es in der vorliegenden Arbeit gehen. Die Beantwortung der Frage fällt je nach Politikfeld unterschiedlich aus, für diese Arbeit wird die Wirtschaftspolitik herangezogen. Dies ist nicht nur sinnvoll, weil sie in der öffentlichen Diskussion sehr präsent ist, sondern vor allem, weil der Einfluss der EU auf das Verhältnis von Markt und Staat in der Europaforschung deutlich seltener untersucht wird als die Frage nach dem Verhältnis EU - Nationalstaat, obwohl »der Großteil der europäischen Entscheidungen genau die Frage betreffen [...] welche Rolle der Staat in der Wirtschaft spielen soll« (Genschel 1998: 57). ${ }^{3}$ Schließlich ist das Verhältnis von Markt und Staat auch einer der Grundstreitpunkte der Wirtschaftswissenschaft, aus der die Autorin kommt. Die leitende Frage dieser Arbeit lautet demnach: Schränkt die Europäische Union die wirtschaftspolitischen Interventionsmöglichkeiten ihrer Mitgliedstaaten ein oder baut sie sie aus?

3 Die Fragen sind allerdings nicht völlig unabhängig voneinander, so kann z.B. eine Übertragung von Zuständigkeiten auf die europäische Ebene sowohl zu einer Schwächung als auch zu einer Stärkung des (National-)Staates führen, wie im Empirieteil der Arbeit deutlich werden wird. 
Die Beeinflussung nationalstaatlicher Interventionsmöglichkeiten (im Folgenden immer bezogen auf die Wirtschaftspolitik) kann auf zwei Wegen vonstatten gehen: Zum einen kann innerhalb der Europäischen Union die ökonomische Verflechtung weiter intensiviert werden, was wie gesagt - die Interventionsmöglichkeiten der Mitgliedstaaten mittelbar einschränkt. Die EU kann jedoch zum anderen auch direkt und intentional - über Vorgaben für die nationale Wirtschaftspolitik, in Form von Richtlinien, Verordnungen, Leitlinien etc. - Einfluss nehmen. Durch diese Art und Weise der politischen Zusammenarbeit können die Interventionsmöglichkeiten sowohl eingeschränkt als auch ausgebaut werden. In der vorliegenden Arbeit wird die intentionale Form der Einflussnahme genauer untersucht. Dies hat mehrere Gründe: Erstens lassen sich bei der mittelbaren Form die inzwischen recht zahlreichen Ergebnisse der Globalisierungsforschung übertragen. Zweitens ist es schwierig, bei der mittelbaren Beeinflussung die Absicht klar herauszuarbeiten: Die Einschränkung der Interventionsmöglichkeiten lässt sich als mehr oder weniger intendierter Nebeneffekt der integrationspolitischen Großprojekte wie Zollunion oder Binnenmarkt deuten. Hingegen ist die Absicht bei der intentionalen Beeinflussung deutlicher, da die europäischen Vorgaben jeweils mit einer (wenngleich immer auch kritisch zu sehenden bzw. zu hinterfragenden) Begründung versehen werden. Schließlich handelt es sich drittens um ein erst ansatzweise erforschtes Feld: Insbesondere die wirtschaftswissenschaftliche Forschung zur EU beschäftigt sich überwiegend mit den besagten Großprojekten, insbesondere der Schaffung des Gemeinsamen Marktes und damit der mittelbaren Form der Einflussnahme.

Präzisiert werden kann die Forschungsfrage demnach in: Wurde mit den europäischen Vorgaben die Absicht verfolgt, die mitgliedstaatlichen Interventionsmöglichkeiten einzuschränken oder auszubauen?

Spätestens an dieser Stelle sollte deutlich geworden sein, dass es sich bei der vorliegenden Arbeit nicht um eine Europäisierungsstudie handelt, d.h. es wird nicht untersucht, welchen Einfluss die europäischen Vorgaben tatsächlich hatten. Vielmehr geht es um die Intention, die mit ihnen verfolgt wurde. Da die Umsetzung der europäischen Vorgaben durch eine Vielzahl von Faktoren beeinflusst wird (politisches System der Länder, Vetospieler, Misfit etc.), können hieraus keine Rückschlüsse auf den beabsichtigten Einfluss bei der Verabschiedung gezogen werden. ${ }^{4}$ Der tatsächliche Einfluss wird jedoch insofern mit einbezogen, als dass in den Vorgaben auch (durchaus selbstkritisch) Bezug darauf ge-

4 So kann z.B. aus der Nicht-Umsetzung einer Vorgabe nicht darauf geschlossen werden, dass diese bereits von Beginn an nicht ernst gemeint war. 
nommen wird, was mit ähnlichen vorangegangenen Vorgaben geschehen ist, ob das angestrebte Ziel also grundsätzlich erreicht wurde.

Die Absicht, die sowohl mit der Einschränkung als auch mit dem Ausbau von Interventionsmöglichkeiten durch die europäischen Vorgaben verfolgt wurde, kann grundlegend in einer Stärkung nationalstaatlicher Handlungsfähigkeit gesehen werden. An dieser Stelle kommt ein weiterer - für diese Arbeit zentraler - Begriff ins Spiel: das Staatsverständnis. Von diesem hängt es ab, ob die Handlungsfähigkeit der Nationalstaaten durch einen Ausbau oder eine Einschränkung von Interventionsmöglichkeiten gestärkt wird: Ein interventionistischer Staat wird in seiner Handlungsfähigkeit gestärkt, wenn seine Möglichkeiten zu intervenieren ausgebaut werden. Ein zurückhaltender Staat hingegen, der nicht in die Wirtschaft eingreifen soll, wird durch eine Einschränkung dieser - nicht erwünschten - Interventionsmöglichkeiten in seiner Handlungsfähigkeit gestärkt (vgl. dazu ausführlicher Kapitel 2.1). Das Staatsverständnis ist dabei bezogen auf die Nationalstaaten, es soll nicht untersucht werden, inwiefern die Europäische Union ein Staat geworden ist. Daraus lassen sich nun die beiden Hauptfragen der Arbeit herleiten:

- Auf welche Weise sollte mit den europäischen Vorgaben Einfluss auf die nationalstaatliche Handlungsfähigkeit genommen werden, durch einen Ausbau oder eine Einschränkung von Interventionsmöglichkeiten?

- Welches Staatsverständnis - bezogen auf die Nationalstaaten - lag den Vorgaben zugrunde?

Grundlegend gibt es - wie eben dargestellt wurde - zwei Möglichkeiten, auf welche Weise die Vorgaben die Handlungsfähigkeit beeinflussen können: durch eine Einschränkung und durch einen Ausbau von Interventionsmöglichkeiten. Zur Zeit scheint die erste Möglichkeit im Vordergrund zu stehen: Mit den europäischen Vorgaben wird die Absicht verfolgt, die wirtschaftspolitischen Interventionsmöglichkeiten der EUMitgliedstaaten einzuschränken, was auf die Stärkung der Handlungsfähigkeit eines zurückhaltenden Staates zielen würde. Dies ist jedoch zu überprüfen, da sich diese - in der Öffentlichkeit und Wissenschaft verbreitete - These vor allem auf die mittelbare Form der Einflussnahme bezieht. Weiterhin stellt sich die Frage, ob der Integrationsprozess notwendigerweise so konzipiert ist bzw. immer schon so konzipiert war, oder ob es auch Zeiten gab, in denen die andere Möglichkeit, der Ausbau nationalstaatlicher Interventionsmöglichkeiten zur Stärkung eines interventionistischen Staates, gewählt wurde.

Um diese Frage $\mathrm{zu}$ beantworten, wird eine historische Herangehensweise gewählt und der gesamte Prozess der europäischen Integration in 
die Untersuchung einbezogen. Auf diese Weise kann nicht nur der These der intentionalen Neoliberalisierung der Nationalstaaten durch die europäischen Vorgaben nachgegangen werden, sondern auch der Frage, ob es hierzu Alternativen gab und somit möglicherweise gibt. Die dritte Forschungsfrage dieser Arbeit lautet damit: Hat es bei der Beeinflussung von Handlungsfähigkeit sowie dem zugrunde liegenden Staatsverständnis einen Wandel gegeben, wenn ja, wie sieht dieser aus?

\subsection{Zielsetzung und Aufbau der Arbeit}

Das Ziel der Arbeit ist, wie an den drei soeben entwickelten Forschungsfragen deutlich wird, eine systematische, analytische Untersuchung, auf welche Weise die nationalstaatliche Handlungsfähigkeit im Prozess der europäischen Integration durch europäische Vorgaben beeinflusst werden sollte und welches Staatsverständnis dem jeweils zugrunde lag. In diese Untersuchung wird der Zeitraum ab den Römischen Verträgen von 1957 einbezogen, um verschiedene Formen der Beeinflussung und unterschiedliche Staatsverständnisse untersuchen sowie Wandlungen und Entwicklungen aufzeigen zu können.

Die Arbeit gliedert sich wie folgt: Zu Beginn steht die Definition der zentralen Begriffe Staatsverständnis, staatliche Handlungsfähigkeit, staatliche Interventionsmöglichkeiten sowie die Eingrenzung der zu untersuchenden Politikfelder mit der Begründung, warum die Ausgabenpolitik für die Untersuchung herangezogen wird.

Im nachfolgenden ersten großen Teil der Arbeit wird ein theoretischer Rahmen für die Analyse ausgearbeitet, und somit eine Grundlage geschaffen, auf der die empirischen Ergebnisse eingeordnet werden können. Zu diesem Zweck werden im ersten Abschnitt idealtypische Staatsverständnisse entwickelt. Hierfür werden die drei für diesen Zeitraum relevanten Wirtschaftstheorien (Keynes'sche Theorie, Monetarismus, Angebotsökonomie/Neue Klassische Makroökonomie) herangezogen und es wird herausgearbeitet, welche grundsätzlichen Einstellungen gegenüber dem Markt/marktlicher Koordination sowie dem Staat/staatlicher Intervention sich dort finden, welche Aufgaben die Theorien dem Staat in den Bereichen Allokation, Distribution und Stabilisierung zuweisen, wie die Bereiche aufeinander bezogen und gegeneinander gewichtet werden und ob der Staat allgemein eher regelgebunden oder diskretionär handeln soll.

Den Zusammenhängen zwischen den zentralen Begriffen Staatsverständnis, Handlungsfähigkeit und Interventionsmöglichkeiten widmet sich der zweite Abschnitt des Theorieteils: Insbesondere aus der Globa- 
lisierungsforschung werden mögliche Strategien herausgearbeitet, die mit den europäischen Vorgaben in Bezug auf die nationalstaatliche Handlungsfähigkeit verfolgt werden können. Implizite These ist hier, dass je nach Staatsverständnis die Handlungsfähigkeit über einen Ausbau oder eine Einschränkung von Interventionsmöglichkeiten gestärkt wird.

Mit Hilfe dieses theoretischen Rahmens werden im zweiten großen Teil der Arbeit die europäischen Vorgaben für die nationale Ausgabenpolitik analysiert (empirische Auswertung). Dies erfolgt in zwei Schritten: Zuerst wird untersucht, welche Aspekte nationalstaatlicher Ausgabenpolitik (Interventionsmöglichkeiten) durch die Vorgaben eingeschränkt/ausgebaut werden sollten. Zu diesem Zweck werden folgende Aspekte untersucht: In welchen Bereichen wurden ausgabenpolitische Vorgaben gemacht, welche Begründungen gab es für das gemeinsame Vorgehen, welche Ziele und Instrumente (für die nationalstaatliche Ebene sowie für die europäische Form der Zusammenarbeit) wurden genannt und wie verbindlich waren die Vorgaben gestaltet? Im zweiten Schritt wird untersucht, welche Staatsverständnisse den Vorgaben zugrunde lagen. Das hierfür notwendige intersubjektiv nachvollziehbare und regelgeleitete Vorgehen wird durch die Anwendung der Methode der qualitativen Inhaltsanalyse gewährleistet. Diese beruht auf den drei idealtypischen Staatsverständnissen. Auf dieser Grundlage wird untersucht, um welche der im theoretischen Rahmen herausgearbeiteten Strategien es sich jeweils handelte.

Um die Entwicklungen besser herausarbeiten zu können, erfolgt die Untersuchung in Phasen. Die Phaseneinteilung beruht auf folgenden Überlegungen: Der Beginn der Untersuchung ist durch die Gründung der Europäischen Wirtschaftsgemeinschaft im Jahr 1957 bestimmt. 2004 wird als Ende gewählt, da in diesem Jahr der europäische Verfassungsvertrag durch die Staats- und Regierungschefs unterzeichnet wurde. Obwohl dieser nicht in Kraft getreten ist, sondern leicht abgewandelt und unter neuem Namen bis 2009 ratifiziert werden soll, kann er als bisherig letzter Meilenstein in der Geschichte der europäischen Integration angesehen werden. Da ein Wandel in der Beeinflussung von Handlungsfähigkeit und dem zugrunde liegenden Staatsverständnis in den 1970er/ 1980er Jahren vermutet wird, sind die beiden mittleren Phasen kürzer gewählt als die erste und die letzte. Die erste Phase endet 1973, im Jahr der ersten Ölkrise, sie umfasst damit das sogenannte >goldene Nachkriegszeitalter`. Die zweite und die dritte Phase werden im Jahr 1982 geteilt, im Jahr des Regierungswechsels im größten europäischen Mitgliedstaat Deutschland. Die letzte Phase beginnt 1990, mit der ersten Stufe der Wirtschafts- und Währungsunion und dem ersten Jahr nach der 
Öffnung des Eisernen Vorhangs. ${ }^{5}$ Auf diese Weise ergibt sich folgende Phaseneinteilung: Phase I: 1957-1973, Phase II: 1974-1982, Phase III: 1983-1989, Phase IV: 1990-2004. Ob diese Phaseneinteilung die Entwicklungen zureichend abbildet, wird am Ende noch einmal diskutiert, sie ist bewusst nicht ausführlich theoretisch fundiert, um auch für überraschende Entwicklungen offen zu bleiben. $\mathrm{Zu}$ Beginn jeder Phasenuntersuchung werden das wirtschaftliche und politische Umfeld sowie der Stand der europäischen Integration und der Globalisierung dargestellt.

Im dritten Teil der Arbeit erfolgt die Ergebnisauswertung unter der Fragestellung, ob es einen Wandel im beabsichtigten Einfluss der europäischen Vorgaben, d.h. in der Strategie sowie im Staatsverständnis (Veränderung der Aufgaben in und Verschiebungen zwischen den drei Bereichen Allokation, Distribution und Stabilisierung) gegeben hat: Wie war die Entwicklung in den einzelnen Politikbereichen? Handelt es sich um eine lineare Entwicklung, gab es Brüche oder widersprüchliche Entwicklungen? War die ursprüngliche Phaseneinteilung sinnvoll? Kann man den Phasen bestimmte Idealtypen von Staatsverständnissen zuordnen? Abschließend wird der Wandel aus einer zweifach veränderten Perspektive betrachtet: Zum einen wird auf eine allgemeine Systematisierung von Wandlungsprozessen zurückgegriffen, zum anderen wird der Fokus auf die europäischen Vorgaben selbst, ihre Formen und Verfahren, gelegt.

5 Der Wegfall der Systemkonkurrenz hat vermutlich große Auswirkungen auf die Wirtschaftspolitik im Westen. Da die Ereignisse jedoch erst Ende 1989 stattfanden, ist es unwahrscheinlich, dass sich ihre Folgen vor 1990 in den Vorgaben wiederfinden. 



\section{EingRenzUngen UND DEFINITIONEN}

\subsection{Definition von Staatsverständnis, staatlicher Handlungsfähigkeit und staatlichen Interventionsmöglichkeiten}

Im Folgenden sollen die drei zentralen Begriffe dieser Arbeit, Staatsverständnis, staatliche Handlungsfähigkeit und staatliche Interventionsmöglichkeiten, genauer definiert werden. Alle drei beziehen sich auf die nationale Ebene, es soll nicht untersucht werden, ob die Europäische Union als Staat bezeichnet werden kann. Grundlegend wird `Staat $\iota-$ da es in der Arbeit darum geht, ob auf marktliche Koordination vertraut wird oder ob der Staat wirtschaftspolitisch intervenieren muss und soll - sehr viel eingeschränkter gefasst als beispielsweise in der Politikwissenschaft: Es geht immer nur um den Staat als wirtschaftspolitischen Akteur, d.h. das Verhältnis von Staat und Markt, nicht um Demokratie, Rechtsstaatlichkeit oder ähnliches.

Das Staatsverständnis wird normativ bestimmt, es wird also danach gefragt, was der Staat tun soll, welche wirtschaftspolitische Rolle ihm zugeschrieben wird; man könnte also präziser von einem >ökonomischen Staatsverständnis` sprechen. Relevant sind hier drei - miteinander zusammenhängende - Ebenen: Erstens die generelle Einstellung gegenüber dem Staat bzw. staatlicher Steuerung im Gegensatz zum Markt bzw. marktlicher Koordination: Wird staatliches Handeln als notwendig angesehen oder abgelehnt? Wird der Markt als inhärent stabil oder instabil und daher interventionsbedürftig beurteilt? Zweitens sind die zentralen Ziele der Wirtschaftspolitik wie z.B. Vollbeschäftigung, Preisstabilität, Konjunkturstabilisierung oder Wachstum und ihre Gewichtung zueinander angesprochen. Schließlich gehören drittens die eingesetzten 
wirtschaftspolitischen Instrumente zum Staatsverständnis. Grundlegend kann man zwischen einem interventionistischen und einem zurückhaltenden Staatsverständnis unterscheiden: Bei ersterem wird der Staat positiv gesehen und sein Intervenieren ist in vielen Fällen erforderlich und erwünscht. Bei einem zurückhaltenden Staatsverständnis ist dieses Bild eher negativ, weshalb nur wenige staatliche Interventionen als sinnvoll bzw. notwendig angesehen werden und die Lösung wirtschaftlicher Probleme dem (inhärent stabilen) Markt überlassen wird.

Die Begriffe Interventionsmöglichkeiten und Handlungsfähigkeit beziehen sich nur auf die dritte Ebene, die Instrumente. Mit Interventionsmöglichkeiten sind, wie das Wort schon sagt, die Möglichkeiten des Staates, in die Wirtschaft einzugreifen, gemeint. Bei der Handlungsfähigkeit geht es darum, ob die real vorhandenen Interventionsmöglichkeiten mit den normativ, d.h. vom Staatsverständnis her erwünschten Interventionsmöglichkeiten übereinstimmen (vgl. Abb. 1). Wenn dies der Fall ist, kann man von einer starken Handlungsfähigkeit sprechen (vgl. Abb. 2). Eine Stärkung von Handlungsfähigkeit liegt somit in einer Erhöhung der Kongruenz. Dies kann sowohl über eine Ausweitung wie über eine Einschränkung von Interventionsmöglichkeiten erfolgen. Ein zurückhaltender Staat wird in seiner Handlungsfähigkeit gestärkt, indem real vorhandene, aber normativ unerwünschte Interventionsmöglichkeiten eingeschränkt werden (Stärkung seiner Legitimität) (vgl. Abb. 3). Bei einem interventionistischen Staat ist es umgekehrt, hier geht es darum, real nicht vorhandene, aber normativ erwünschte Interventionsmöglichkeiten zu schaffen (vgl. Abb. 4). Eine dauerhafte Einschränkung oder Ausweitung von Interventionsmöglichkeiten könnte auch zu einem Wandel des Staatsverständnisses führen. 
Abb. 1: Zusammenhang zwischen Staatsverständnis, staatlichen Interventionsmöglichkeiten und staatlicher Handlungsfähigkeit (Eigene Darstellung)

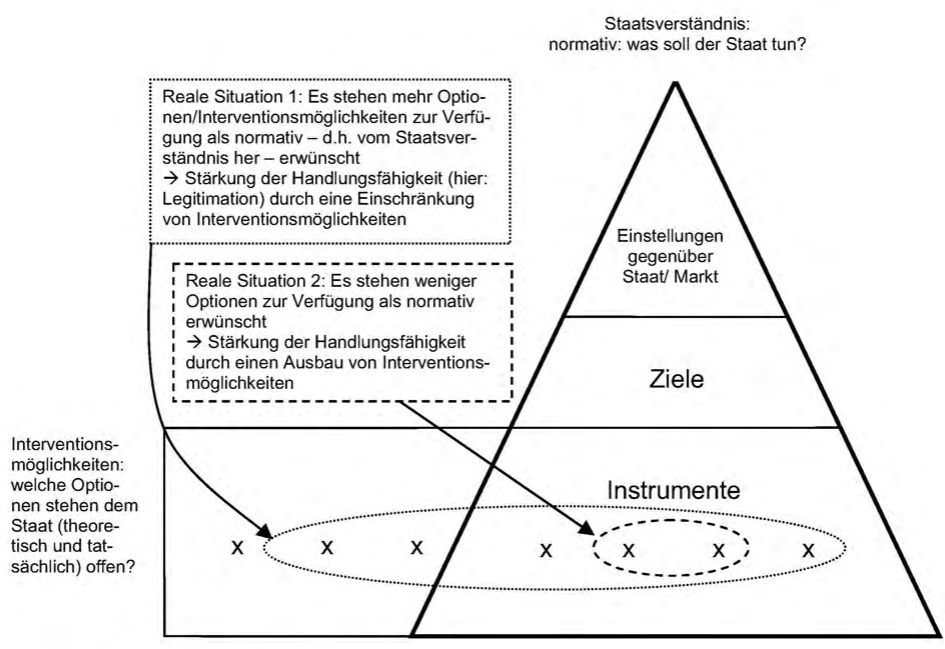

Abb. 2: Starke Handlungsfähigkeit (Eigene Darstellung)

Staatsverständnis:

normativ: was soll der Staat tun?

Interventionsmöglichkeiten: welche Optio-

nen stehen dem Staat (theoretisch und tat-

sächlich) offen?

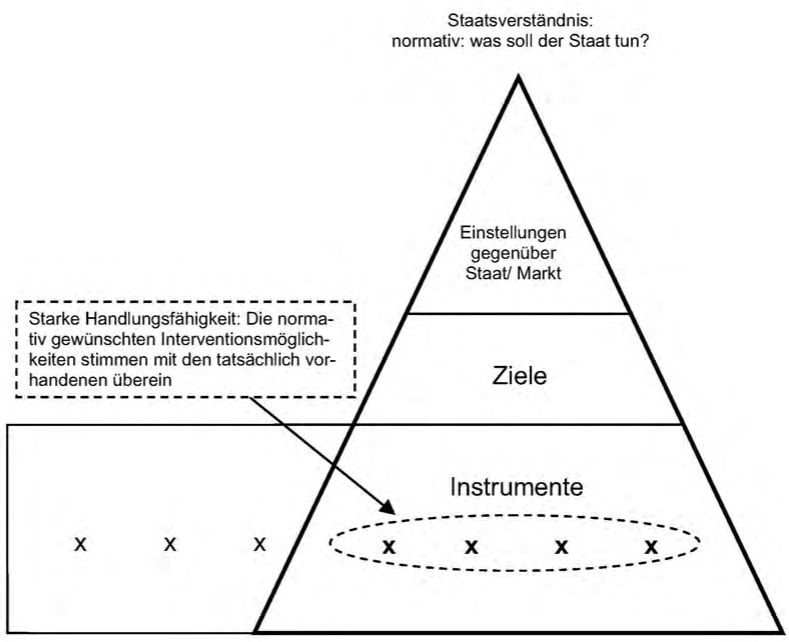


Abb. 3: Stärkung der Handlungsfähigkeit bei einem zurückhaltenden Staatsverständnis (Eigene Darstellung)

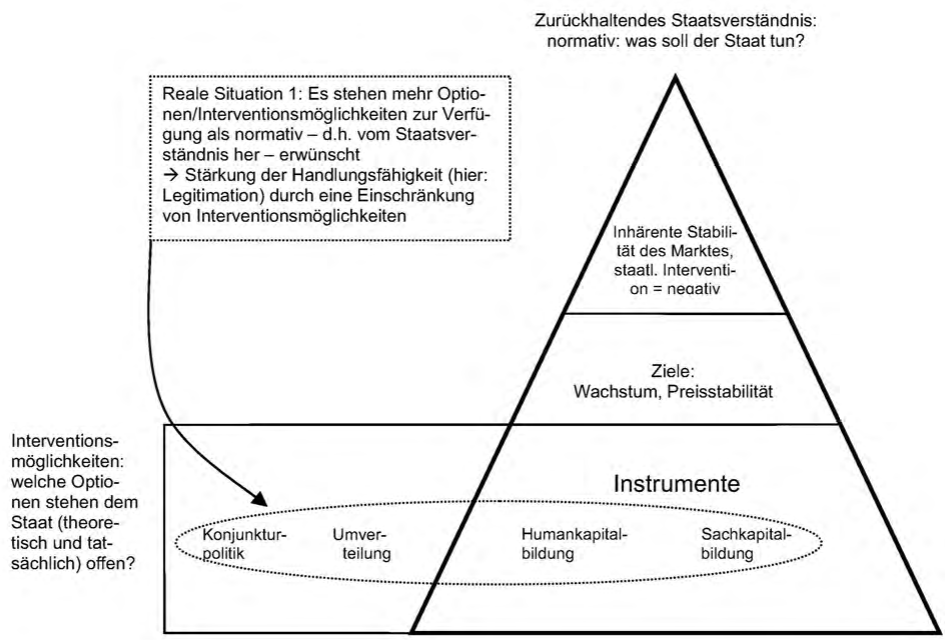

Abb. 4: Stärkung der Handlungsfähigkeit bei einem interventionistischen Staatsverständnis (Eigene Darstellung)

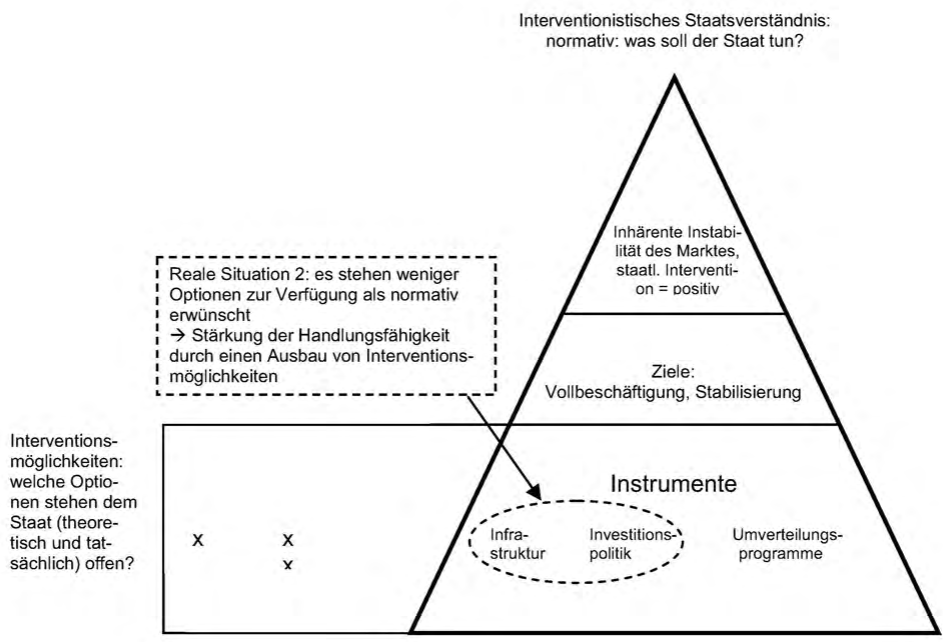




\subsection{Eingrenzung der zu untersuchenden Politikfelder}

Wie soeben dargelegt, werden die drei zentralen Begriffe dieser Arbeit Staatsverständnis, Handlungsfähigkeit und Interventionsmöglichkeiten immer in Bezug auf die Rolle des Staates in der Wirtschaft definiert. Würde man die europäischen Vorgaben für die gesamte Wirtschaftspolitik einbeziehen, müsste aufgrund der Menge an Dokumenten der Untersuchungszeitraum begrenzt werden. Da für diese Arbeit jedoch absichtlich ein langer Zeitraum gewählt wurde, um unterschiedliche Formen der Beeinflussung und verschiedene Staatsverständnisse analysieren zu können, werden im Folgenden die zu untersuchenden Politikfelder eingegrenzt.

Der Staat kann seine wirtschaftspolitischen Aufgaben mit Hilfe einer Vielzahl von Instrumenten wahrnehmen, besonders wichtig sind Gesetze (Ordnungspolitik) und Geld (Finanzpolitik). Die beabsichtigte Beeinflussung der nationalstaatlichen Interventionsmöglichkeiten bzw. ihrer Handlungsfähigkeit sowie der Wandel im Staatsverständnis sollen in dieser Arbeit am Beispiel der Finanzpolitik, genauer gesagt der Ausgabenpolitik, dargestellt werden. ${ }^{6}$ Die Ausgabenpolitik eignet sich aus folgenden Gründen besonders gut für diese Untersuchung: Zum einen umfasst sie alle hierfür wichtigen Aspekte: Mit der Variation der Ausgaben, des Budgetsaldos sowie der Struktur des Staatshaushalts kann der Staat in allen drei Bereichen klassischer staatlicher Intervention - Allokation, Distribution, Stabilisierung - Einfluss auf die Wirtschaft nehmen. Dabei kann er sowohl diskretionär wie regelgebunden vorgehen. Zweitens spielt die Ausgabenpolitik in alle möglichen Politikfelder hinein, in denen öffentliche Gelder von Bedeutung sind: Sozialpolitik, Agrarpolitik, Bildungspolitik etc. Die Staatsausgaben können somit als materieller Spiegel der Staatstätigkeit angesehen werden. Schließlich wird durch die Beschäftigung mit der Ausgabenpolitik insofern eine Forschungslücke geschlossen, als dass die vorhandenen Studien mit wenigen Ausnahmen aus den 1990er Jahren stammen und vor allem um Fragen von Finanzpolitik in der Währungsunion, insbesondere den Stabilitäts- und Wachstumspakt kreisen (vgl. z.B. Eijffinger/de Haan 2000; Ohr/Schmidt 2004; Schelkle 2005).

Im Rahmen dieser Arbeit lässt sich nicht die gesamte Ausgabenpolitik untersuchen, unter anderem, weil es von der europäischen Ebene nicht für alle Bereiche (auswertbare) Vorgaben gibt. Um die Politikfel-

6 Was die (intendierte) europäische Beeinflussung der Einnahmeseite angeht kann auf Uhl 2008 verwiesen werden. 
der festzulegen, die für die Analyse herangezogen werden, ist daher zuerst eine Übersicht über die bestehenden ausgabenpolitischen Vorgaben erforderlich. $\mathrm{Zu}$ diesem Zweck werden die europäischen Vertragstexte ausgewertet, da sie die Bereiche festlegen, in denen die Gemeinschaft ihren Mitgliedstaaten Vorgaben machen darf. Vorangestellt wird eine kurze Übersicht, welche Ziele der Staat mit Hilfe der Ausgabenpolitik grundsätzlich verfolgen kann.

\section{Überblick über die Ziele staatlicher Ausgabenpolitik}

Bei der Darstellung des Einflusses, den der Staat mit Hilfe der Ausgabenpolitik auf die Wirtschaft nehmen kann, folge ich Musgrave et al. (1994: 5f), die die Funktionen der öffentlichen Haushalte in drei Gruppen unterteilen: Allokation, Distribution und Stabilisierung. ${ }^{7}$

\section{Das Allokationsziel}

Unter Allokation versteht man die effiziente Verteilung der Produktionsfaktoren und Güter auf die Produzenten bzw. Konsumenten. In einer Marktwirtschaft erfolgt dies hauptsächlich über den Preismechanismus. Staatliches Eingreifen ist zum einen notwendig, um diesen Mechanismus und damit die Funktionsfähigkeit des Marktes aufrechtzuerhalten, indem Wettbewerbsregeln aufgestellt und durchgesetzt werden. Ausgabenpolitisch greift der Staat in die Allokation ein, indem er öffentliche Güter bereitstellt, externe Effekte internalisiert oder die marktliche Allokation über Subventionen beeinflusst.

Öffentliche Güter unterscheiden sich in zwei Eigenschaften von privaten: Von ihrer Nutzung kann niemand ausgeschlossen werden, weshalb die Wirtschaftssubjekte (individuell rational) ihre Präferenzen für diese Güter nicht offen legen, in der Hoffnung, dass andere dies tun und sie diese Güter dann kostenlos mit nutzen können (vgl. Heise 2005: 41). Da öffentliche Güter - zweite Eigenschaft - im Konsum nicht rivalisierend sind, ist es weder möglich noch sinnvoll Personen von ihrer Nutzung auszuschließen. Diese Eigenschaften haben zur Folge, dass öffentliche Güter nicht über den Markt bereitgestellt werden: Wenn die Konsumenten ihre Präferenzen verschleiern und die Grenzkosten der Nutzung gleich null sind, ist auch der Nachfragepreis null. Der Angebots-

7 Die Bezugnahme auf Musgrave et al. führt nicht dazu, dass bereits ein bestimmtes Staatsverständnis - ein Staat, der potentiell in diesen drei Bereichen interveniert - festgelegt wird. Vielmehr ermöglicht dieses breite Verständnis, später auch enger gefasste Staatsverständnisse einordnen zu können. 
preis ist aufgrund der Produktionskosten aber immer positiv, so dass Angebot und Nachfrage nicht über den Markt ausgeglichen werden können (vgl. Blankart 2006: 60f). In diesem Fall versagt die marktliche Allokation und der Staat stellt, wenn es gesellschaftlich gewünscht ist, die Güter zur Verfügung. Dabei muss er sie nicht selbst produzieren, sondern nur finanzieren, d.h. ohne unmittelbare Gegenleistung bereitstellen (vgl. Musgrave et al. 1994: 9). Die Aufteilung der Steuerlast und das Ausmaß, in dem die öffentlichen Güter bereitgestellt werden, sind eigene Gebiete der Finanzwissenschaft, auf die in dieser Arbeit nicht weiter eingegangen wird (vgl. bspw. Musgrave et al. 1994: 109ff; Blankart 2006: $77 \mathrm{ff}$ und 193ff).

Reine öffentliche Güter, welche die beiden oben genannten Eigenschaften uneingeschränkt aufweisen, sind selten. In vielen Fällen ist ein Ausschluss von der Nutzung möglich, wenn auch teuer, technisch aufwendig oder gesellschaftlich nicht gewünscht (z.B. Bildung), in anderen Fällen wird der Konsum - zumeist ab einer bestimmten Nutzerzahl - rivalisierend (bei Straßen, Umweltgütern etc.). Diese Güter werden $>$ Mischgüter` genannt. Weiterhin gibt es sogenannte >meritorische Güter, bei denen beide Eigenschaften (wenn überhaupt) nur sehr eingeschränkt auftreten, z.B. bestimmte Gesundheitsleistungen (vgl. Musgrave et al. 1994: 89f). Auch diese werden jedoch in vielen Ländern vom Staat bereitgestellt bzw. - sofern sie, wie Umweltgüter, bereits vorhanden sind - geschützt. $^{8}$ Hierfür sind mehrere Gründe zu nennen (vgl. Ahrns/Feser 1997: 15; Bajohr 2003: 27f): Zum einen weist die Bereitstellung dieser Güter externe Effekte auf, die wirtschaftlich oder gesellschaftlich erwünscht sind. So fördert der Bau von Straßen die ErschlieBung abgelegener Regionen, die gesamtwirtschaftliche Produktion wird durch ein gutes Bildungswesen erhöht etc. Zweitens sind die Präferenzen der Individuen teilweise verzerrt, was sich unter anderem darin ausdrückt, dass Gegenwartskonsum höher geschätzt wird als Zukunftskonsum oder Güter in bestimmten Situationen als nicht wichtig eingestuft werden (Lernmittelfreiheit bei Kinderlosen). In diesen Fällen greift der Staat präferenzkorrigierend ein. Schließlich spielen vor allem bei den meritorischen Gütern auch gesellschaftliche Präferenzen oder Gerechtigkeitserwägungen eine Rolle, so soll z.B. Gesundheit in den meisten europäischen Gesellschaften nicht vom Einkommen abhängen. Mit der Bereitstellung dieser Güter werden oft eher distributive als allokative Ziele

8 Der Schutz von Umweltgütern kann finanzpolitisch bspw. über Subventionen (für ökologische Landwirtschaft etc.) oder Steuern (auf CO2Ausstoß o.ä.) geregelt werden. Darüber hinaus sind ordnungspolitische Maßnahmen von Bedeutung, auf die hier jedoch nicht weiter eingegangen wird (vgl. hierzu z.B. Blankart 2006: 547ff). 
verfolgt. Es ist in der Finanzwissenschaft jedoch umstritten, ob der Staat diese nicht reinen öffentlichen Güter bereitstellen soll (vgl. Blankart 2006: 77ff).

Der Begriff 〉öffentliche Güter` wird manchmal sehr breit definiert, so dass auch Konjunkturstabilisierung, soziale Sicherheit etc. darunter fallen (vgl. Heise 2005: 41). Um Verwirrungen zu vermeiden, wird in dieser Arbeit die enge (traditionelle) Definition verwendet, da öffentliche Güter sonst sowohl ein Überbegriff für die drei Bereiche Allokation, Distribution und Stabilisierung als auch Teil der ersten beiden Bereiche wären.

Von externen Effekten (vgl. hierzu Brümmerhoff 2001: 73ff) spricht man, wenn die wirtschaftliche Tätigkeit von Unternehmen oder Einzelpersonen zu Kosten oder Nutzen bei anderen Wirtschaftssubjekten führt, die außerhalb des Marktes stehen. Diese Effekte können sowohl positiv wie negativ sein, wirken aber bei dem produzierten Gut weder preiserhöhend noch preismindernd, somit ist die effiziente Allokation gestört. Beispiele sind die Lärmbelästigung durch Flughäfen oder Impfungen, welche die Ausbreitung von Krankheiten in der Bevölkerung verringern: Weder erhöht die Lärmbelastung den Preis des Fliegens, noch vermindert sich der Preis einer Impfung durch seine positiven gesellschaftlichen Folgen. Mögliche ausgabenpolitische Instrumente zur Internalisierung externer Effekte sind Beihilfen für >Produzenten` von positiven externen Effekten, z.B. Forschungsförderung.

Damit sind bereits die Beihilfen/Subventionen ${ }^{9}$ angesprochen. Es handelt sich hierbei um direkte Geldzahlungen, Steuervergünstigungen oder ähnliches (vgl. Färber 1993: 31). Neben der Internalisierung positiver externer Effekte können die Staaten mit ihrer Hilfe versuchen, Unternehmen zu bestimmten Verhaltensweisen $\mathrm{zu}$ animieren, »die dazu führen sollen, die marktwirtschaftlichen Allokationsergebnisse [...] nach politischen Zielen zu korrigieren« (Hansmeyer 1977: 963). Hierbei kann es sich beispielsweise um die soziale Abfederung des Strukturwandels oder um Umweltschutz handeln.

\section{Das Distributionsziel}

Eine effiziente Allokation birgt keine Garantie dafür, dass die Verteilung von Einkommen über den Markt (die Primärverteilung) von der Gesellschaft als gerecht empfunden wird. Wie eine gerechte Verteilung aussieht, kann objektiv nicht bestimmt werden. In der Finanzwissenschaft

9 Beides wird in der Wirtschaftswissenschaft - im Gegensatz zum juristischen Sprachgebrauch - synonym benutzt (vgl. Stockhausen 2002: 28). Ich folge in dieser Arbeit der Wirtschaftswissenschaft. 
wurde Gerechtigkeit daher lange als exogener Begriff angesehen, der von der Philosophie oder anderen Wissenschaften definiert werden sollte. Mittlerweile wird versucht, Gerechtigkeitsvorstellungen auch endogen herzuleiten. Auf beide Ansätze wird hier nicht weiter eingegangen (vgl. dazu bspw. Blankart 2006: 89ff). Es bleibt jedoch zu sagen, dass das Verteilungsproblem aufgrund der unterschiedlichen Gerechtigkeitsvorstellungen eine der wichtigsten Kontroversen bei der Bestimmung der Finanzpolitik darstellt (vgl. Musgrave et al. 1994: 10).

Bei der Korrektur der Marktergebnisse unter sozialen Gesichtspunkten verfolgt der Staat mehrere Ziele (vgl. Bajohr 2003: 89): Er greift ein, um die Einkommen vertikal zu nivellieren, um sie zu sichern und schließlich, um einen Ausgleich für besondere Belastungen zu bieten (Beispiel: Kindergeld). Das hinter diesen dreien liegende Gesamtziel ist die Sicherung des sozialen Friedens und damit die Aufrechterhaltung bzw. Stabilisierung des Systems (vgl. Ahrns/Feser 1997: 22). Die Instrumente, die dem Staat dafür zur Verfügung stehen, sind überwiegend finanzpolitischer Natur. Am wichtigsten sind das Steuer- und Transfersystem: Über eine progressive Einkommenssteuer sowie Steuern auf Erbschaften und Vermögen werden die Bezieher hoher Einkommen und großer Vermögen stärker belastet. Die Sozialversicherungen sichern im Falle von Arbeitslosigkeit, Rente oder Krankheit ein gewisses Einkommen. Schließlich können auch öffentliche Güter mit distributiver Funktion eingesetzt werden, vor allem wenn sie besonders den ärmeren Teilen der Gesellschaft nutzen, wie z.B. der soziale Wohnungsbau (vgl. Musgrave et al. 1994: 12). Umverteilung kann aber nicht nur zwischen Personen(gruppen), sondern auch zwischen Regionen erfolgen. Damit fallen auch Bereiche wie die Regionalpolitik, Länderfinanzausgleiche etc. unter das Distributionsziel der Ausgabenpolitik.

\section{Das Stabilisierungsziel}

Einer der grundlegenden Streitpunkte der Wirtschaftswissenschaft ist, ob marktliche Allokation und Distribution, eventuell ergänzt durch staatliche Eingriffe, zu einem Zustand wirtschaftlicher Stabilität führen und (weitere) staatliche Eingriffe überflüssig machen. Die eine Position, die im Wesentlichen auf der neoklassischen Theorie beruht, geht von einer inhärenten Stabilität des Systems aus: Das Güterangebot wird von der Angebotsseite bzw. dem Arbeitsmarkt her bestimmt, dem Say'schen Gesetz folgend gibt es keine Nachfrageprobleme, Schwankungen werden vom System eigenständig und schnell ausgeglichen (vgl. Heine/Herr 2003: 518). Bezüglich des Arbeitsmarktes gilt das Konzept der natürlichen Rate der Unterbeschäftigung: Die in dieser Situation bestehende 
Arbeitslosigkeit ist freiwillig, von strukturellen Faktoren hervorgerufen oder Sucharbeitslosigkeit (vgl. Friedman 1976: 144). Stabilisierende Eingriffe des Staates - mit Hilfe der Ausgabenpolitik oder anderen Instrumenten - sind demnach unnötig und teilweise sogar schädlich.

Die auf Keynes beruhende Gegenposition gibt die grundlegende Annahme auf, die Märkte würden sich selbst überlassen eine Situation der Vollbeschäftigung erreichen. Sie geht vielmehr davon aus, dass sich nicht - wie im Say'schen Gesetz postuliert - jedes Angebot seine Nachfrage schafft und somit die Nachfrage nicht beachtet werden muss. Im Gegenteil, die Nachfrage ist hier zentral: Die Unternehmen produzieren nur so viel, wie sie absetzen können und stellen entsprechend auch nur die dafür benötigte Menge an Arbeitskräften ein. Wenn in einer solchen Situation noch Arbeitslosigkeit besteht, kann diese nicht über Lohnsenkungen gemindert werden, da dies die Nachfrage und damit Beschäftigung noch weiter verringern würde. Diese Situation nennt man Unterbeschäftigungsgleichgewicht, da es keine Marktkräfte gibt, welche die Wirtschaft aus dieser Situation befreien könnten. Stattdessen muss der Staat eingreifen und die Nachfrage erhöhen, über direkte Staatsausgaben oder eine Änderung der Verteilung. Die Ausgabenpolitik spielt somit im Bereich der lang- wie auch der kurzfristigen Stabilisierung eine wichtige Rolle (vgl. ausführlicher zu beiden Positionen Kapitel 3.1).

\section{Ausgabenpolitische Vorgaben in den Europäischen Verträgen}

Nachdem die drei Zielbereiche der Ausgabenpolitik dargelegt worden sind, geht es nun darum, in welchen Bereichen die europäische Ebene ausgabenpolitische Vorgaben gemacht hat bzw. macht. Ziel dieses Schrittes ist, die Bandbreite der europäischen Vorgaben für die nationale Ausgabenpolitik aufzuzeigen, um auf dieser Grundlage eine Auswahl der genauer zu untersuchenden Politikfelder zu treffen. Für diesen Überblick wird nur das Primärrecht herangezogen, auf dem das Sekundärrecht aufbaut: Der Vertrag zur Gründung der Europäischen Wirtschaftsgemeinschaft (EWGV), die Einheitliche Europäische Akte (EEA), der Vertrag zur Gründung der Europäischen Gemeinschaft in der Fassung von Maastricht (EGV-M), ${ }^{10}$ in der Fassung von Amsterdam (EGV-A) und von Nizza (EGV-N) sowie der Vertrag über die Europäische Union (EUV) in der Fassung von Nizza. Schließlich wird auch der - nicht rati-

10 In Maastricht wurde auch der EU-Vertrag verabschiedet. Da ich diesen nur in der Fassung von Nizza heranziehe, ist im Folgenden, wenn vom Vertrag von Maastricht gesprochen wird, immer der EG-Vertrag gemeint. 
fizierte - Vertrag über eine Verfassung für Europa (VerfV) ${ }^{11}$ untersucht. ${ }^{12}$

$\mathrm{Zu}$ Beginn soll bereits mit Blick auf die Fragestellungen der Arbeit eine gewisse Eingrenzung anhand von zwei Kriterien vorgenommen werden: Die zu untersuchenden europäischen Vorgaben müssen sich 1. auf die Ausgaben der Mitgliedstaaten beziehen und 2. Rückschlüsse auf die intendierte Beeinflussung der Interventionsmöglichkeiten und das nationale Staatsverständnis zulassen. Dem ersten Kriterium folgend fallen alle Politikfelder heraus, die rein aus EU-Mitteln ${ }^{13}$ finanziert werden,

11 Dieser wurde von den Staats- und Regierungschefs am 29.10.2004 unterzeichnet und bereits von einigen Ländern ratifiziert, in Frankreich und den Niederlanden wurde die Ratifizierung per Volksabstimmung abgelehnt. Daraufhin wurde nach einer langen Phase der Reflexion im Juni 2007 eine Regierungskonferenz einberufen, um den vorliegenden Entwurf noch einmal zu überarbeiten. Das Ergebnis - der sog. Reformvertrag - enthält im Vergleich zum Verfassungsvertrag nur Änderungen in für diese Arbeit nicht relevanten Bereichen wie den Abstimmungsverfahren oder Geltungsbereich der Grundrechtecharta.

12 Untersucht wird in dieser Arbeit die europäische Integration im Rahmen der 1957 gegründeten Europäischen (Wirtschafts-)Gemeinschaft. Dementsprechend werden nur die diesbezüglichen Verträge (EWGV, EEA, EGV, EUV) und das hierauf beruhende Sekundärrecht einbezogen. Neben diesem Hauptstrang der Integration gibt es zwei weitere für bestimmte Wirtschaftsbereiche: Die Europäische Atomgemeinschaft (EAG) und die Europäische Gemeinschaft für Kohle und Stahl (EGKS). Sie werden in dieser Arbeit nicht untersucht, da es sich bei beiden um eine spezifische, europäische Verwaltung bestimmter Sektoren handelt. Grunwald (2007, o.S.) spricht daher auch von »sektorielle[n] Verwaltungsverträge[n]«, die Tätigkeiten umfassen, die »im Vergleich zu denen des EG-Vertrags außerordentlich begrenzt und [...] zudem [in] Gebieten [angesiedelt sind], in denen der Gesetzgeber in besonderer Weise auf wissenschaftlich-technischen Sachverstand angewiesen ist."

Hinzu kommt, dass diese beiden Stränge der Integration auch auf Grundlage der im Folgenden (Kap. 2.2) entwickelten Kriterien aus der Untersuchung herausfallen würden: Die intendierte Beeinflussung der nationalen Ausgabenpolitik ist in beiden Fällen sehr gering. Die Tätigkeiten werden hauptsächlich europäisch finanziert (vgl. z.B. Art. 54ff EGKSV; Art. 6 und $46 \mathrm{EAGV}$ ), Empfehlungen für nationale (Investitions-)Ausgaben dürfen nur in Form von >Hinweisen< erfolgen (vgl. Art. 40 EAGV; Art. 46 EGKSV). Der einzige Bereich, der in die Arbeit einbezogen werden könnte, wären die Beihilfenvorgaben im Rahmen der EGKS. Diese sind jedoch überwiegend sehr speziell, auf einzelne Unternehmen oder Kohlearten bezogen, so dass sich hieraus keine allgemeinen Aussagen zur Beeinflussung von Handlungsfähigkeit oder über ein ökonomisches Staatsverständnis ableiten lassen - womit sich der Kreis zur o.g. grundlegenden Begründung wieder schließt.

13 Zwar speist sich der EU-Haushalt aus mitgliedstaatlichen Mitteln, bei seiner Verhandlung dominieren jedoch Fragen von Nettozahlern, Ausnahmeregelungen etc., was keine Rückschlüsse auf ein Staatsverständnis zulässt. 
was insbesondere die Landwirtschaftspolitik betrifft. ${ }^{14}$ Weiterhin werden auch die Politikfelder, bei denen nur ein Teil aus dem EU-Haushalt finanziert wird, nicht in die Untersuchung einbezogen. Es handelt sich hierbei um die regionale Strukturpolitik, ${ }^{15}$ den Europäischen Sozialfonds, ${ }^{16}$ die gemeinsame Forschungspolitik ${ }^{17}$ sowie die Vorgaben für die Transeuropäischen Netze (TEN). ${ }^{18}$ In diesen Feldern werden keine Vorgaben für die Mitgliedstaaten gemacht, sondern versucht, über die Vergabe europäischer Mittel (z.B. aus den Strukturfonds) Anreize für nationale Ausgaben zu schaffen, indem die EU-Mittel nur dann vergeben werden, wenn die Mitgliedstaaten eine sogenannte Kofinanzierung aufbringen. Mit diesen Anreizen soll nicht primär Einfluss auf die staatliche Handlungsfähigkeit genommen werden, vielmehr werden gesamteuropäische Ziele (z.B. Angleichung der Lebensbedingungen, Förderung der Mobilität von Arbeitskräften, Stärkung der wissenschaftlichen und technologischen Basis der europäischen Industrie) verfolgt. Schon dies spricht gegen eine Einbeziehung in die Arbeit. Da es überdies um direkte Geldflüsse an die Mitgliedstaaten geht, kann man davon ausgehen, dass es in diesem Bereich in besonderem Maße zu Package-Deals kommt, so ist z.B. nach Moravesik (1997: 234) die Strukturpolitik als reine Kompensationsleistung geplant worden. Dies macht eine Interpretation dieser Anreizmaßnahmen äußerst schwierig. Insgesamt ist es daher sehr fraglich, ob bei der Analyse dieser Anreizmaßnahmen Aussagen über den beabsichtigen Einfluss auf die Interventionsmöglichkeiten bzw. das Staatsverständnis getroffen werden könnten (2. Kriterium), weshalb sie für die Arbeit nicht weiter berücksichtigt werden. Ebenfalls auf Grundlage des zweiten Kriteriums werden jene Vorgaben nicht einbezogen, bei denen es sich um nicht weiter spezifizierte Anreiz- und Förder-

14 Bei der Landwirtschaft ist keine Kofinanzierung vorgesehen, die Ausgaben werden vollständig aus dem EU-Haushalt finanziert (vgl. Weidenfeld/Wessels 2002: 249).

15 Vgl. z.B. Art. 130a-e EEA/EGV-M; Art. 158ff EGV-A/N; Art. III-220ff VerfV.

16 Vgl. z.B. Art. 125ff EWGV/EEA/EGV-M; Art. 146ff EGV-A/N; Art. III219 VerfV.

17 Vorgaben, welche sich im Rahmen der Koordinierung der allgemeinen Wirtschaftspolitik (s.u.) mit einem gemeinsamen Vorgehen im Rahmen der Forschungspolitik beschäftigen, werden einbezogen.

18 Für die TEN ist neben der Kofinanzierung bzw. sonstigen finanziellen Anreizen durch Gemeinschaftsausgaben auch ein Leitlinienverfahren vertraglich festgelegt (vgl. Art. 129c EGV-M; Art. 155 EGV-A/N; Art. III-247 VerfV), die Leitlinien beinhalten jedoch nur relativ vage die Ziele, Prioritäten und Grundzüge gemeinsamer Projekte (vgl. bspw. 1692/96/EG). 
maßnahmen handelt, wie z.B. in den Bereichen Gesundheitswesen und Industrie. $^{19}$

Nach dieser allgemeinen Eingrenzung werden im Folgenden die verbliebenen vertraglichen Vorgaben für die nationale Ausgabenpolitik dargestellt. Zur besseren Übersichtlichkeit wird nicht der Struktur der Verträge gefolgt, vielmehr werden die Vorgaben direkt den im vorhergehenden Abschnitt erläuterten Bereichen Allokation, Distribution und Stabilisierung zugeordnet.

\section{Allokationspolitische Vorgaben in den Verträgen}

Da die Allokation vor allem über den Markt, d.h. den Preismechanismus, erfolgen soll, zielen viele ausgabenpolitischen Vorgaben darauf $a b$, den Wettbewerb im Gemeinsamen Markt bzw. Binnenmarkt zu fördern. Seit dem EWGV sind staatliche Beihilfen, die den Wettbewerb verfälschen und den Handel zwischen den Mitgliedstaaten verzerren, verboten (vgl. Art. 92ff EWGV/EEA/EGV-M; Art. 87ff EGV-A/N; Art. III-167ff VerfV). Es wurden und werden jedoch auch eine Reihe von Ausnahmeregeln festgelegt, z.B. zur Erreichung gemeinsamer Ziele (vgl. Art. 92 EWGV/EEA/EGV-M; Art. 87 EGV-A/N; Art. III-167 VerfV) sowie im Rahmen der gemeinsamen Verkehrspolitik (Art. 77 EWGV/EEA/EGVM; Art. 73 EGV-A/N; Art. III-238 VerfV). Die Kontrolle des Beihilfenverbots liegt in den Händen der Europäischen Kommission, sie entscheidet, ob die nationalen Beihilfen vertragskonform sind, wobei der Rat hier ein Veto einlegen kann (vgl. Art. 93 EWGV/ EEA/EGV-M; Art. 88 EGV-A/N; Art. III-168 VerfV). Beihilfen werden überdies im Bereich der Gemeinsamen Handelspolitik angesprochen, dabei geht es jedoch mehr um die Harmonisierung als um den Abbau von Ausfuhrbeihilfen, um auf diese Weise gleiche Wettbewerbsbedingungen innerhalb

19 Im Bereich Gesundheitswesen geht es um Fördermaßnahmen, die den Schutz und die Verbesserung der menschlichen Gesundheit sowie die Bekämpfung grenzüberschreitender schwerer Krankheiten zum Ziel haben. Ausdrücklich wird darauf hingewiesen, dass die Verantwortung der Mitgliedstaaten für die Organisation des Gesundheitswesens und die medizinische Versorgung in vollem Umfang gewahrt bleibt (vgl. Art. 129 EGVM; Art. 152 EGV-A/N; Art. III-278 VerfV). Ähnlich unklar bleibt die Ausgestaltung der Maßnahmen im Bereich Industrie. Hier geht es um die Schaffung der Voraussetzungen für die Wettbewerbsfähigkeit der Gemeinschaft, z.B. die Förderung eines für die Initiative und Weiterentwicklung der Unternehmen günstigen Umfelds sowie einer besseren Nutzung des industriellen Potentials. Dies soll durch eine Koordination zwischen den Staaten und eine Unterstützung nationaler Maßnahmen gewährleistet werden (vgl. Art. 130 EGV-M; Art. 157 EGV-A/N; Art. 279 VerfV). 
der Gemeinschaft zu gewährleisten (vgl. Art. 112 EWGV/EEA/EGV-M; Art. 132 EGV-A/N; Art. III-315 VerfV).

Die Staaten sollen die marktliche Allokation fördern, aber auch bei unbefriedigenden Ergebnissen derselben eingreifen: In Bezug auf öffentliche Güter gibt es die Aussage, dass Dienste von allgemeinem wirtschaftlichen Interesse von den Wettbewerbsregeln (z.B. vom Beihilfenverbot) ausgenommen werden können, wenn ansonsten ihre Aufgabenerfüllung verhindert würde (vgl. Art. 90 EWGV/EEA/EGV-M; Art. 86 EGV-A/N; Art. III-166 VerfV). Überdies sollen - seit dem Vertrag von Amsterdam - Mitgliedstaaten und Gemeinschaft die Grundsätze und Bedingungen für das Funktionieren der Dienste so gestalten, dass sie ihren Aufgaben nachkommen können (vgl. Art. 16 EGV-A/N), womit - seit dem Verfassungsvertrag präzisiert - insbesondere die finanziellen und wirtschaftlichen Bedingungen angesprochen sind (vgl. Art. III-122 VerfV). Weiterhin gibt es Vorgaben für das öffentliche Gut >Sicherheit und Verteidigung : Im EUV (Art. 17) findet sich die Klausel, dass die Mitgliedstaaten die schrittweise Festlegung einer gemeinsamen Verteidigungspolitik durch eine rüstungspolitische Zusammenarbeit unterstützen. Der Verfassungsvertrag präzisiert dies, indem die Gründung einer Europäischen Verteidigungsagentur festgelegt wird, welche die Rüstungsausgaben der Mitgliedstaaten beeinflussen soll (vgl. I-41 und III311 VerfV).

\section{Distributionspolitische Vorgaben in den Verträgen}

In den Verträgen finden sich nur wenige Vorgaben für die staatliche Beeinflussung der personellen Verteilung. Eine direkte Korrektur der Einkommensverteilung wird europäisch nicht geregelt. Das Kapitel zu Sozialpolitik - welches durch den Vertrag von Amsterdam eingeführt wur$\mathrm{de}^{20}$ - enthält die Möglichkeit, in verschiedenen Bereichen wie z.B. der sozialen Sicherheit der Arbeitnehmer Mindeststandards zu setzen. Dies könnte zur Folge haben, dass die Mitgliedstaaten ihre Ausgaben in diesen Bereichen erhöhen müssen (vgl. Art. 136 EGV-A/N; Art. III-210 VerfV). Erst seit dem Verfassungsvertrag ist ein Koordinierungsverfahren im Bereich Sozialpolitik bzw. soziale Sicherung vorgesehen, in

20 In der EEA (Art. 118a) gab es bereits die Möglichkeit, soziale Mindeststandards festzulegen, jedoch nur im Arbeits- und Gesundheitsschutz. Dem EGV-M wurde ein Sozialprotokoll angehängt, das aufgrund des britischen Widerstands nur für die anderen elf Mitgliedstaaten galt. 
dessen Rahmen Leitlinien für die mitgliedstaatlichen Sozialausgaben gemacht werden können (Art. III-213 VerfV). ${ }^{21}$

\section{Stabilisierungspolitische Vorgaben in den Verträgen}

Im EWGV sowie der EEA gab es einen eigenen Artikel zur Koordinierung der Konjunkturpolitik, die von den Mitgliedstaaten als Angelegenheit von gemeinsamem Interesse angesehen werden sollte. Der Rat konnte über »die der Lage entsprechenden Maßnahmen entscheiden« (Art. 103, Abs. 2 EWGV/EEA) und diese sogar mit Hilfe von Richtlinien durchsetzen (vgl. ebenda). Dieser Artikel wurde jedoch nicht in den Vertrag von Maastricht übernommen. Stattdessen wurden im EGV-M die Konvergenzkriterien für die WWU eingeführt, darunter das Fiskalkriterium »eine[r] auf Dauer tragbare[n] Finanzlage der öffentlichen Hand, ersichtlich aus einer öffentlichen Haushaltslage ohne übermäßiges Defizit« (Art. 109j EGV-M; Art. 121 EGV-A/N, Art. III-198 VerfV). Die Kriterien von $3 \%$ des BIP für die Neuverschuldung sowie $60 \%$ für die Gesamtverschuldung werden überdies in einem separaten Artikel festgehalten, ergänzt um ein Sanktionsverfahren für das Defizitkriterium (vgl. Art. 104c EGV-M; Art. 104 EGV-A/N; Art. III-184 VerfV). Hierbei handelt es sich um eine der detailliertesten ausgabenpolitischen Bestimmungen. Im Verfassungsvertrag wird die Koordination der Haushaltsdisziplin noch einmal verschärft (vgl. Art. III-184). In einer Erklärung zu diesem Artikel bekräftigen die Mitgliedstaaten, dass die Steigerung des Wachstumspotentials sowie die Erreichung einer soliden Haushaltslage die beiden fundamentalen Ziele ihrer Wirtschafts- und Finanzpolitik sind. Neben der Einhaltung des Stabilitäts- und Wachstumspakts wird hierfür die Notwendigkeit, in konjunkturell guten Zeiten Überschüsse zu erzielen, besonders hervorgehoben (vgl. Erklärung zu Art. III-184 VerfV). Überdies wird für die Mitglieder der Eurozone eine zusätzliche Koordination - mit einem expliziten Verweis auf die Haushaltsdisziplin - eingeführt (vgl. Art. III-194 VerfV)

\section{Allgemeine Vorgaben für die mitgliedstaatliche Wirtschaftspolitik}

Neben den ausgabenpolitischen Vorgaben, die sich den drei Bereichen Allokation, Distribution und Stabilisierung zuordnen lassen, finden sich in den Verträgen allgemeine Vorgaben für die mitgliedstaatliche Wirt-

21 In Artikel 140 EGV-A/N war auch vorgesehen, dass die Kommission die Mitgliedstaaten bei der Koordination ihrer Sozialpolitik unterstützt, allerdings nur durch Untersuchungen, Stellungnahmen und Berichte. 
schaftspolitik, die auch die Ausgabenpolitik umfassen. Laut EWGV und EEA sollen die Mitgliedstaaten bei ihrer Wirtschaftspolitik folgende Ziele verfolgen: Wahrung eines hohen Beschäftigungsstands und eines stabilen Preisniveaus sowie Sicherung des Gleichgewichts der Zahlungsbilanz und des Vertrauens in die Währung (vgl. Art. 104 EWGV/EEA). Der EGV ersetzt diese Zielstellungen durch die Grundsätze "stabile Preise, gesunde öffentliche Finanzen und monetäre Rahmenbedingungen sowie eine dauerhaft finanzierbare Zahlungsbilanz« (Art. 3a EGV-M; Art. 4 EGV-A/N; Art. III-177 VerfV).

Die Mitgliedstaaten sollen jedoch nicht nur gemeinsame Ziele verfolgen, sondern sich dabei auch abstimmen: Die Koordination der nationalen Wirtschaftspolitik taucht in allen Verträgen auf, ein Koordinationsverfahren wird allerdings erst seit Maastricht vertraglich festgelegt (vgl. Art. 105 EWGV/EEA; Art. 103 EGV-M; Art. 99 EGV-A/N; Art. III-179 VerfV). Auch hier hat es eine Verschiebung gegeben: Im EWGV sowie der EEA wird mit der Koordinierung das Ziel einer "schrittweise[n] Annäherung der Wirtschaftspolitik der Mitgliedstaaten« (Art. 2 EWGV/EEA) verfolgt, es wird von einer »für die Weiterentwicklung der Gemeinschaft erforderlichen Konvergenz der Wirtschafts- und Währungspolitiken« (Art. 102a EEA) gesprochen. Im EGV ist nur mehr die Rede von der »engeren Koordinierung der Wirtschaftspolitik und einer dauerhaften Konvergenz der Wirtschaftsleistungen« (Art. 103 EGV-M; Art. 99 EGV-A/N; Art. III-179 VerfV). Der Schwerpunkt liegt nun auf der Konvergenz der Ergebnisse nationaler Wirtschaftspolitik und der wirtschaftlichen Leistung, nicht mehr auf der Annäherung der Mittel zu ihrer Erreichung.

Eine Koordination der mitgliedstaatlichen Politik ist seit dem Vertrag von Amsterdam auch im Bereich der Beschäftigungspolitik vorgesehen (vgl. Art. 125-130 EGV-A/N; Art. III-203-208 VerfV), zu diesem Zweck werden sogenannte beschäftigungspolitische Leitlinien erstellt (vgl. Art. 128 EGV-A/N; Art. III-206 VerfV). Grundsätzlich untersteht auch die Beschäftigungspolitik dem Grundsatz der gesunden öffentlichen Finanzen, da die beschäftigungspolitischen Leitlinien mit den Grundzügen der Wirtschaftspolitik in Einklang stehen müssen (vgl. Art. 126 EGV-A/N; Art. III-206 VerfV).

\section{Zusammenfassung: Untersuchungsgegenstand}

Zusammengefaßt werden folgende Politikfelder in die Untersuchung einbezogen: Mit Blick auf die Allokation sind dies die Beihilfenpolitik sowie die öffentlichen Güter mit allokativer Funktion (in den Verträgen explizit angesprochen wird die Daseinsvorsorge sowie Sicherheit und 
Verteidigung). Da für die Internalisierung externer Effekte nur Bezug auf die Einnahmeseite genommen wird (Möglichkeit von Umweltsteuern, vgl. z.B. Art. 175, Abs. 2 EGV-N), ist dieser Bereich für die Arbeit nicht relevant.

Vorgaben für die nationalen Sozialausgaben sowie öffentliche Güter mit distributiver Funktion finden sich hauptsächlich im Sekundärrecht: die im Vertrag angesprochenen Leitlinien zur Koordinierung der Sozialpolitik (und evtl. der Beschäftigungs- und Wirtschaftspolitik).

Für den Bereich Stabilisierung wird neben den bereits dargestellten vertraglichen Bestimmungen untersucht, welche Vorgaben sich aus dem konjunkturpolitischen Artikel des EWGV und der EEA sowie den Leitlinien im Bereich der allgemeinen Wirtschaftspolitik ergeben haben. Letztere können auch Empfehlungen für die Bereiche Allokation und Distribution umfassen. 

In dieser Arbeit werden die europäischen Vorgaben zur nationalen Ausgabenpolitik daraufhin analysiert, auf welche Weise die nationalstaatliche Handlungsfähigkeit durch sie beeinflusst werden sollte: Hatte das gemeinsame Vorgehen eine Einschränkung oder einen Ausbau von Interventionsmöglichkeiten zum Ziel? Die gewählte Strategie ist, wie in Kapitel 2.1 dargelegt, abhängig vom vorherrschenden Staatsverständnis: Ein zurückhaltender Staat, der nicht in die Wirtschaft eingreifen soll, wird durch eine Einschränkung von Interventionsmöglichkeiten in seiner Handlungsfähigkeit gestärkt, ein interventionistischer Staat durch einen Ausbau dieser Möglichkeiten. Für die Untersuchung der Vorgaben ist es somit notwendig, die möglichen Beziehungen zwischen Staatsverständnis, Interventionsmöglichkeiten und Handlungsfähigkeit genauer zu klären. Dafür soll in einem ersten Schritt ein Raster entwickelt werden, mit dessen Hilfe untersucht werden kann, welches Staatsverständnis den Vorgaben zugrunde liegt (3.1). In einem zweiten Schritt werden mögliche Strategien zur Beeinflussung von Handlungsfähigkeit, basierend auf diesen unterschiedlichen Staatsverständnissen, abgeleitet (3.2).

\subsection{Entwicklung idealtypischer Staatsverständnisse}

In dieser Arbeit wird - wie bereits gesagt - eine recht eingeschränkte Definition von Staatsverständnis verwendet, ein >ökonomisches Staatsverständnis $\measuredangle$. In dieses fließen die normativen Vorstellungen über die Rolle von Staat und Markt ein sowie darüber, welche ökonomischen Probleme bzw. Ziele als zentral angesehen werden und ob der Staat re- 
gelgebunden oder diskretionär in die Wirtschaft eingreifen soll. Zentral sind die ausgabenpolitischen Aufgaben des Staates in den klassischen Bereichen Allokation, Distribution und Stabilisierung. Da diese nicht getrennt voneinander existieren, sondern sich gegenseitig beeinflussen (vgl. Musgrave 1969: 24ff, Brümmerhoff 2001: 8), ist auch die Verknüpfung und relative Gewichtung dieser drei Felder mit- bzw. zueinander relevant. Um die in den Vorgaben enthaltenen Staatsverständnisse systematisch herauszufiltern und Entwicklungen bzw. Brüche erkennen zu können, ist es notwendig, die Staatsverständnisse einordnen zu können. Eine solche Einordnung ist mit Hilfe einer Folie bzw. eines Rasters möglich, welche(s) in diesem Kapitel erarbeitet werden soll. Hierfür werden drei idealtypische Staatsverständnisse aus Wirtschaftstheorien abgeleitet. Wirtschaftstheorien bieten sich an, da sie konsistente Staatsverständnisse im oben genannten Sinn enthalten. Die Auswahl der Wirtschaftstheorien, die in dieser Arbeit herangezogen werden, erfolgte anhand von zwei Kriterien: Zum einen sollen sich die daraus ableitbaren Staatsverständnisse in den europäischen Vorgaben finden lassen. Dies setzt insofern eine Begrenzung, als dass nur Wirtschaftstheorien in Frage kommen, die im Untersuchungszeitraum eine gewisse wirtschaftspolitische und wirtschaftswissenschaftliche Relevanz hatten. ${ }^{22}$ Zum zweiten sollen die idealtypischen Staatsverständnisse klar voneinander abgrenzbar sein. Das schließt Überschneidungen nicht völlig aus, die gemeinsame Schnittmenge sollte jedoch nicht so groß sein, dass eine klare $\mathrm{Zu}$ -

22 Die wirtschaftswissenschaftliche Relevanz ist insofern von Bedeutung, als dass eine Verbreitung an den Universitäten dazu geführt hat, dass die dort ausgebildeten Politiker und ihre Berater von ihnen beeinflusst werden konnten. Die Relevanz der drei für diese Arbeit ausgewählten Theorien wird unter anderem in den folgenden Zitaten aus wichtigen Übersichtsbüchern zu Wirtschaftstheorien deutlich: »The Keynesian Revolution is one of the most remarkable episodes in the entire history of economic thought; never before had the economics profession been won over so rapidly and so massively to a new theory, nor has it since. Within the space of about a decade, 1936-46, the vast majority of economist throughout the Western world were converted to the Keynesian way of thinking « (Blaug 1999: 642). »Obwohl sich in der Nachkriegszeit zunächst die keynesianische Konzeption des globalgesteuerten Kapitalismus in der Wirtschaftswissenschaft und der Wirtschaftspolitik der westlichen Industrienationen fast überall durchgesetzt hatte, hat mit Beginn der siebziger Jahre die Konzeption des sich selbst steuernden Kapitalismus [...] erneut viele Anhänger gefunden. [...] Sie konnte sich [...] auch deswegen Gehör verschaffen, weil mit dem Monetarismus eine makroökonomische Theorie als Alternative zum Keynesianismus zur Verfügung stand, deren Mittelpunkt die Erklärung der Inflation bildet « (Kromphardt 2004: 205). »The contributions made by leading new classicists [...] dominated macroeconomic discussion throughout the 1970s« (Snowdon et al. 2002: 215). 
ordnung verhindert wird. Aufgrund dieser beiden Kriterien wurden die folgenden drei Wirtschaftstheorien ausgewählt: die Keynes'sche Theorie (interventionistisches Staatsverständnis), der Monetarismus sowie die Angebotsökonomie verbunden mit der Neuen Klassischen Makroökonomie (beides liberale Staatsverständnisse, wobei der Monetarismus dem Staat die geringste Rolle zuschreibt). Zu Beginn des Kapitels steht eine kurze Gegenüberstellung von liberalen und interventionistischen Staatsverständnissen. Danach folgt die Ableitung der drei idealtypischen Staatsverständnisse in chronologischer Reihenfolge, d.h. beginnend mit der Keynes'schen Theorie über den Monetarismus zur Angebotsökonomie/Neuen Klassischen Makroökonomie.

\section{Gegenüberstellung: Liberale und interventionistische Staatsverständnisse}

In Bezug auf das oben definierte Staatsverständnis kann man grundlegend von zwei großen, sich gegenüber stehenden Positionen sprechen: Die liberale Position, die einen zurückhaltenden Staat bevorzugt, und die interventionistische, welche dem Staat eine aktive Rolle in der Wirtschaftspolitik zuschreibt. $^{23}$

Liberale Theorien haben ihren Ursprung in der durch die Aufklärung beeinflussten englischen und schottischen Moralphilosophie des 18 . Jahrhunderts mit Vertretern wie Locke, Hume und Smith (vgl. Nowotny 1999: 10). In ihrem Zentrum steht das vernunftbegabte Individuum, welches rational seinen individuellen Nutzen maximiert und damit über die unsichtbare Hand von Adam Smith (1996: 371) - allen dient (vgl. Bohnet 1989: 3). Wichtigstes Ziel ist es, die (negative) Freiheit des Individuums zu schützen, sowohl seine politische als auch seine wirtschaftliche. Politische Freiheit kann im liberalen Weltbild nur dann realisiert werden, wenn auch die wirtschaftliche garantiert ist, insofern wird die freie Marktwirtschaft mit vollkommenem Wettbewerb angestrebt. Der Markt bzw. die Wirtschaft stabilisiert sich nach liberaler Vorstellung selbst, die Koordinierung erfolgt über den Preismechanismus, über-

23 »Beim Liberalismus und Interventionismus handelt es sich sowohl um geistesgeschichtliche Grundpositionen als auch um wirtschaftspolitische $\mathrm{Pa}$ radigmen und theoretische Ansätze zum Verhältnis von Markt und Wirtschaft, wobei sie gleichzeitig eine allgemeine ökonomische Theorie der Wirtschaftspolitik bzw. wirtschaftspolitischen Konzeption beinhalten. Die Theorie der Wirtschaftspolitik geht nicht wie die allgemeine ökonomische Theorie von konkreten ökonomischen Gegebenheiten aus, sondern von erwünschten ökonomischen Zuständen und fragt nach den Instrumenten, durch deren Einsatz sie herbeigeführt werden können« (Ambrosius 1996: 367). 
dies wird von der Gültigkeit des Say'schen Theorems ausgegangen (vgl. Bohnet 1989: 4f).

Die Rolle des Staates wird von den liberalen Strömungen unterschiedlich gesehen, grundlegend hat er nur eine kleine Rolle: Da die Wirtschaft sich selbst stabilisiert und staatliche Stabilisierungspolitik demzufolge als unnötig wie auch unmöglich angesehen wird (vgl. Felderer/Homburg 2003: 159), muss der Staat nur einen Rahmen, eine Wettbewerbsordnung, schaffen, um monopolistische Tendenzen zu verhindern. Zusätzlich wird manchmal gefordert, der Staat solle bestimmte öffentliche Güter, insbesondere mit allokativer Funktion, bereitstellen. Sozialpolitische Eingriffe beschränken die Freiheit der Individuen (vgl. Mill 1924: 15) ${ }^{24}$ und werden als paternalistisch abgelehnt. Da jedes Individuum nach der Locke'schen Staatsphilosophie »ein natürliches (also vorstaatliches) Recht auf seine Talente und Fähigkeiten« (Rosen/Windisch 1997: 12) bzw. die Früchte derselben hat, sollte Umverteilung auf Notlagen beschränkt bleiben (vgl. ebenda: 11). Die Staatsaufgaben sind demnach auf den allokativen Bereich beschränkt, weitergehende Staatseingriffe, vor allem prozesspolitischer Art, werden als schädlich bewertet, in erster Linie weil sie destabilisierend wirken, das Wachstum behindern etc. (vgl. Ambrosius 1996: 367; Felderer/Homburg 2003: 159). Somit bleibt für den Staat vor allem, die Freiheit der Individuen nach innen, d.h. Rechtsstaatlichkeit, insbesondere Schutz von Privateigentum und Vertragseinhaltung, und nach außen (Verteidigung) zu sichern (vgl. Tanzi 1997: 9).

Im Gegensatz zum Liberalismus steht hinter dem Interventionismus keine geschlossene Gesellschaftskonzeption. Bohnet (1989: 14) definiert Interventionismus sehr breit als Sammelbegriff für Denkrichtungen, die von einer Gestaltbarkeit der wirtschaftlichen und gesellschaftlichen Entwicklung ausgehen. Grundlegend ist die Annahme, dass es keinen Mechanismus gibt, der den individuellen und gesellschaftlichen Nutzen automatisch in Übereinstimmung bringt, infolgedessen kann bzw. muss der gesamtgesellschaftliche Nutzen teilweise über Staatseingriffe herbeigeführt werden (vgl. Nowotny 1999: 21). Diese Eingriffe werden zweckrational bewertet: Der Staat macht das, was der Markt nicht kann, durchaus auch prozesspolitisch (vgl. Bohnet 1989: 16). Im Gegensatz zum Liberalismus wird nicht von einer Selbstheilungsfähigkeit des

$24 \gg$ That principle is, that the sole end for which mankind may be warranted, individually or collectively, in interfering with the liberty of action of any of their members, is selfprotection. That the sole purpose for which power can be rightfully exercised over any member of a civilized community, against his will, is to prevent harm to others. His own good, either physical or moral, is not a sufficient warrant« (Mill 1924: 15). 
Marktes ausgegangen, Stabilisierung wird damit zu einer der wichtigsten Aufgaben des Staates (vgl. Felderer/Homburg 2003: 159).

Weitere Aufgaben hat der Staat im distributiven Bereich. Dies kann darauf zurückgeführt werden, dass er in der interventionistischen Sicht nicht nur die negative Freiheit der - durchaus auch sozialen - Individuen schützen soll, sondern auch die positive. Es geht demnach nicht nur um die Abwesenheit von Zwang, sondern auch um die Möglichkeit, ein der Würde des Menschen entsprechendes Dasein zu führen (vgl. Rosen/Windisch 1997: 12). Distributive Politik wird weiterhin als produktivitäts- und wachstumssteigernd angesehen, z.B. über die Erleichterung des Strukturwandels, die Sicherung des sozialen Friedens (vgl. Nowotny 1999: 27) sowie über Transferleistungen, die als automatische Stabilisatoren wirken können (vgl. Tanzi 1997: 10). Obgleich der Interventionismus eine deutlich höhere Eingriffsintensität befürwortet als der Liberalismus, zielt er nicht auf eine Überwindung des kapitalistischen Systems: Das Privateigentum an Produktionsmitteln wird nicht in Frage gestellt und staatliche Eingriffe in private Verfügungsrechte bleiben die Ausnahme (vgl. Mansfeld 1980, Sp. 554).

\section{Das Staatsverständnis in der Keynes'schen Theorie}

\section{Überblick}

Im Zuge der Weltwirtschaftskrise war die neoklassische Annahme der inhärenten Stabilität des Marktes nur mehr schwer mit der Realität in Übereinstimmung zu bringen. Trotz deutlich sinkender Löhne ging die Arbeitslosigkeit nicht zurück. Insbesondere vor diesem Hintergrund entwickelte Keynes seine Theorie. ${ }^{25}$ Er stellte die Behauptung auf, die Neoklassik sei nur für den Spezialfall der Vollbeschäftigung gültig und entwickelte eine >Allgemeine Theorie ‘ für die anderen, seiner Ansicht nach weitaus realistischeren Fälle (vgl. Keynes 1936: 3). Dabei gibt er einige der Hauptannahmen der Neoklassik auf: Zentral ist die Ablehnung des Say'schen Gesetzes, nach dem sich jedes Angebot seine Nachfrage schafft. Auf diese Weise rückt die Nachfrage in den Mittelpunkt, und zwar die effektive, d.h. am Markt geäußerte. Weiterhin entwickelt Keynes eine einkommensabhängige Konsumfunktion, bei der Sparen sich als Restgröße definiert. Sparen ist somit nicht vom Zins, sondern vom Einkommen abhängig. Investitionen werden dagegen weiterhin vom Zins, in stärkerem Maße jedoch von der Grenzleistungsfähigkeit des Ka-

25 Für dieses Kapitel wurde vor allem auf den >alten Keynes`, d.h. die General Theory und andere in diesem Zeitraum entstandene Schriften, zurückgegriffen. 
pitals und damit von den unsicheren Erwartungen über zukünftige Erträge bestimmt.

Auf diese Weise gibt Keynes den Zinsmechanismus auf, der in der neoklassischen Theorie für einen ständigen Ausgleich von Sparen und Investieren gesorgt hatte. Der Ausgleich läuft bei ihm über das Einkommen: Durch ein Ansteigen (Sinken) der Investitionen steigt (sinkt) das Einkommen, wodurch auch die Ersparnis steigt (sinkt). Dieser Prozess setzt sich fort, bis ein neues Gleichgewicht erreicht ist. Dieses ist jedoch nicht unbedingt identisch mit einer Situation der Vollbeschäftigung - hiermit ist das sogenannte >Unterbeschäftigungsgleichgewicht` gemeint. Dieser Theorie folgend kann sich über den Arbeitsmarkt kein Vollbeschäftigungsgleichgewicht einstellen, da die Arbeitsnachfrage über den Gütermarkt bestimmt wird: Die Unternehmer produzieren nur so viel, wie sie auch absetzen können, was wiederum von der effektiven Nachfrage abhängig ist. ${ }^{26}$ Der Arbeitsmarkt steht also hierarchisch unter (d.h. er ist abhängig von) dem Gütermarkt, welcher wiederum unter dem Finanzmarkt steht, auf dem Liquiditätsangebot und -nachfrage in Übereinstimmung gebracht werden müssen (vgl. Hödl 1988: 445).

Auch die Quantitätstheorie des Geldes wird von Keynes aufgegeben. Veränderungen auf dem Geldmarkt haben, so seine Annahme, auch realwirtschaftliche Auswirkungen: Eine Erhöhung der Geldmenge führt bspw. zu einer Zinssenkung, welche die Investitionen und damit das Einkommen anregt. ${ }^{27}$

Weiterhin führt Keynes (1936: 97ff) den sogenannten Multiplikatoreffekt ein. Demzufolge können selbst kleine Impulse große wirtschaftliche Auswirkungen haben: Eine Erhöhung (Senkung) der Nachfrage führt zu einem steigenden (sinkenden) Angebot, welches mit steigender (sinkender) Beschäftigung einhergeht, die wiederum steigende (sinkende) Nachfrage mit sich bringt etc. Die Höhe des Multiplikators ist (bei gegebener Technik) abhängig von der Höhe der marginalen Konsumquote $^{28}$ : Ist diese hoch, wird ein großer Teil des zusätzlichen Einkommens nachfragewirksam, bei einer hohen marginalen Sparquote wird

26 Zur Frage der Auswirkungen von Nominallohnsenkungen vgl. Keynes 1936, 19. Kapitel: 217ff. Die Diskussion, ob eine Rigidität der Nominallöhne erforderlich ist, um im Keynes'schen Modell zu Vollbeschäftigung zu kommen, greife ich nicht auf, vgl. hierzu Hagemann 1988: 183ff; Blaug 1999: 669; Snowdon et al. 2002: 107ff.

$27 \mathrm{Da}$ in dieser Arbeit die Finanz- und nicht die Geldpolitik behandelt wird, lasse ich diesen Aspekt hier weitgehend außen vor, vgl. dazu bspw. Snowdon et al. 2002: 66 .

28 In der deutschen Übersetzung von Keynes wird anstelle von marginaler Konsumquote vom Hang zum Verbrauch gesprochen, ich bleibe bei der mittlerweile üblichen Bezeichnung. 
hingegen mehr gespart, und der Multiplikator ist entsprechend kleiner. Der Multiplikatoreffekt führt aber auch dazu, Schwankungen, denen das System ausgesetzt ist, zu vergrößern. Die Schwankungsanfälligkeit begründet Keynes damit, dass die Grenzleistungsfähigkeit des Kapitals, welche die Investitionen bestimmt, von den stark fluktuierenden Erwartungen abhängt (vgl. ebenda: 124ff). Das System ist jedoch nicht nur schwankungsanfällig, ihm wohnt auch eine Tendenz zur Unterbeschäftigung inne, da die Investitionen vor allem in den entwickelten kapitalistischen Systemen aufgrund von Sättigungserscheinungen hinter der Vollbeschäftigungsersparnis zurückbleiben. ${ }^{29}$

\section{Staatsaufgaben}

Obwohl Keynes dem Staat eine bedeutende Rolle in der Wirtschaft zuschrieb, gibt es von ihm keinen zusammenhängenden Text zu den Staatsaufgaben und auch nur wenig Sekundärliteratur zu diesem Thema. Für die folgende Übersicht über die Staatsaufgaben in den drei Interventionsbereichen Allokation, Distribution und Stabilisierung wird hauptsächlich auf Originaltexte von Keynes zurückgegriffen. Was der Staat ${ }^{30}$ tun soll, ist laut Keynes nicht auf der Grundlage abstrakter Theorien entscheidbar, grundlegend wichtig sei es, die Annahme aufzugeben, jede Staatseinmischung sei schädlich und zwecklos (vgl. Keynes 1926: 31). Da die sunsichtbare Hand abgelehnt wird, muss an ihre Stelle ein anderer Mechanismus treten, um Eigeninteressen und Gesamtinteressen in Übereinstimmung zu bringen. Dies können Keynes Ansicht nach nicht in erster Linie die Unternehmer sein, die nur über den Markt mit anderen Wirtschaftssubjekten verbunden sind, es muss vielmehr eine öffentliche Instanz sein (vgl. Mattfeldt 1985: 31). Keynes plädiert für einen Übergang

29 Dies wird damit begründet, dass aufgrund des hohen Kapitalbestandes die Grenzleistungsfähigkeit des Kapitals recht gering ist und aufgrund des hohen Einkommensniveaus die marginale Konsumquote ebenfalls gering ist (vgl. Keynes 1936: 91; Pribram 1992: 941).

30 Nach Skidelsky (1989: 144ff) meint Keynes mit >Staat< etwas anderes als moderne Ökonomen und Sozialwissenschaftler: Charakteristikum des Staats war bei ihm nicht der Mechanismus oder die Funktion, sondern das Motiv: die Verfolgung des Gemeininteresses. Das bedeutet, dass er Politiker, die ihre eigenen Interessen verfolgen, nicht, große Unternehmen oder halb-autonome Institutionen wie Universitäten, Zentralbanken etc., die mehr das öffentliche als das private (Profit-)Interesse verfolgen, jedoch sehr wohl als Staat definiert. Da Keynes jedoch bei seinen jeweiligen wirtschaftspolitischen Vorschlägen nicht weiter auf die Akteure eingeht, bleibe ich beim Begriff >Staat<. Diese Definition ist jedoch z.B. wichtig um zu verstehen, warum Keynes sich nicht mit Staatsversagen auseinandersetzt. 
'sout of the nineteenth century laissez-faire state into an era of liberal socialism, by which I mean a system where we can act as an organised community for common purposes and to promote social and economic justice, whilst respecting and protecting the individual - his freedom of choice, his faith, his mind and its expression, his enterprise and his property« (CW XXI: 500).

Die Notwendigkeit des Übergangs begründet er folgendermaßen: »I bring in the state; I abandon laissez-faire, - not enthusiastically, not from contempt of that good old doctrine, but because, whether we like it or not, the conditions for its success have disappeared « (CW XIX: 228).

"Auf wirtschaftlichem Gebiet bedeutet dies vor allem anderen, daß wir eine neue Politik und neue Geräte finden müssen, um die wirtschaftlichen Kräfte so anzufassen und zu überwachen, daß sie mit der zeitgenössischen Vorstellung von dem, was im Interesse der allgemeinen Gerechtigkeit und des gesellschaftlichen Gleichgewichts recht und billig ist, nicht unerträglich zusammenstossen« (Keynes 1925: 254).

Allerdings spricht er sich explizit dagegen aus, dass der Staat sich in alle wirtschaftlichen Belange einmischt:

$»$ Die wichtigsten Agenda des Staates betreffen nicht die Tätigkeiten, die bereits von Privatpersonen geleistet werden, sondern jene Funktionen, die über den Wirkungskreis des Individuums hinausgehen, jene Entscheidungen, die niemand trifft, wenn der Staat sie nicht trifft. Nicht das ist wichtig für den Staat, daß er die gleichen Dinge etwas besser oder etwas schlechter ausführt, die heute bereits von Einzelpersonen getan werden, sondern daß er die Dinge tut, die heute überhaupt nicht getan werden« (Keynes 1926: 35).

Somit grenzt Keynes sich auch von der Planwirtschaft und dem Sozialismus immer wieder ab (vgl. bspw. ders. 1936: 319). Er tritt für eine gemäßigte Planung ein und widerspricht Hayek in der Annahme, auch dies würde >in die Knechtschaft « führen: »Moderate planning will be safe if those carrying it out are tightly orientated in their own minds and hearts to the moral issue« (CW XXVII: 387).

\section{Allokation}

Die allokativen Aufgaben des Staates werden bei Keynes kaum thematisiert. Dies lässt sich damit erklären, dass die wirtschaftlichen Hauptprobleme für ihn auf dem Finanzmarkt liegen, wo Liquiditätsangebot und nachfrage in Übereinstimmung gebracht werden müssen. Allokative Probleme auf dem Gütermarkt sind somit sekundär und werden nicht ge- 
sondert betrachtet. Nur an wenigen Stellen findet man Verweise auf mögliche allokative Eingriffe: In >Das Ende des Laissez-Faire s spricht Keynes sich gegen Monopole und Trusts aus, welche »die Gleichheit beim freien Vertragsabschluss aufheben« (ders. 1926: 25). In der Allgemeinen Theorie stellt er dar, dass es wichtig ist, das Umfeld zu bestimmen, in dem die wirtschaftlichen Kräfte frei walten können, bezieht sich jedoch ziemlich klar nicht nur auf Ordnungspolitik (vgl. Keynes 1936: 320). Ähnlich kann man den Ausspruch deuten, auch die moderne klassische Theorie habe bestimmte Bereiche aufgezeigt, »in denen es notwendig sein mag, das freie Spiel der wirtschaftlichen Kräfte zu zügeln oder zu leiten« (ebenda).

Ein weiterer wichtiger Aspekt, der die Vernachlässigung der Wettbewerbspolitik erklären kann, liegt in Keynes positiver Einstellung gegenüber großen Unternehmen begründet. Er geht davon aus, dass sich Aktiengesellschaften ab einer bestimmten Größe von selbst sozialisieren, da der breit gestreute Aktienbesitz die Manager von der Verfolgung kurzfristiger Profitinteressen entbindet und diese mehr Wert auf das Ansehen der Institution und gesamtwirtschaftliche Stabilität legen (vgl. Keynes 1926: 32f). Diese Hoffnung spricht dagegen, dass Keynes ein Verfechter strikter Wettbewerbspolitik war.

Zum Thema Subventionen äußert Keynes sich sehr wenig. Er spricht sich gegen Exportsubventionen aus, da diese das weltwirtschaftliche Gleichgewicht gefährden können, indem reiche Länder sich diese eher leisten können als arme (vgl. CW XXVI: 268 und 325). ${ }^{31}$ Subventionen aus politischen, sozialen und industriellen Gründen lässt er jedoch ausdrücklich zu (vgl. CW XXV: 189), vor allem was die Förderung junger Industriezweige (>infant industries ) angeht (vgl. CW XXVI: 249 und 252). Die Subventionen müssen sich allerdings auf die Produktion für den heimischen Markt beziehen (vgl. CW XXVI: 325). Weiterhin kann man Keynes Ausführungen zur konjunkturstabilisierenden Wirkung von auf öffentliches Risiko hin getätigten Investitionen und gemeinnützigen Unternehmen (s.u., Stabilisierung) so auslegen, dass er Subventionen in diesen Fällen nicht ablehnend gegenüber steht (vgl. ders. 1936: 138).

Auch öffentliche Güter werden bei Keynes vor allem unter dem Gesichtspunkt der Stabilisierung betrachtet. Dafür eignen sich zwar prinzipiell alle Arten öffentlicher Investitionen, wie auch das berühmte Beispiel der mit Geld gefüllten Flaschen, die verbuddelt und danach wieder ausgegraben werden, zeigt (vgl. Keynes 1936: 110). Keynes zieht jedoch

31 Das Problem sah Keynes vor allem mit Blick auf die USA, die in der Lage seien, all ihre Produkte über Subventionen wettbewerbsfähig zu machen (vgl. CW XXVI: 318). Anstelle von Subventionen setzt er sich für Importbeschränkungen ein (vgl. CW XXVII: 444f; CW XXVI: 268). 
sinnvolle Investitionen vor und sah die Notwendigkeit staatlicher Infrastrukturinvestitionen, unter anderem bei Straßen, Elektrizität (vgl. CW XIX: 222) und Eisenbahnstrecken (vgl. Keynes 1936: 111). Der Produktion von Rüstungsgütern - welche ebenfalls zu den öffentlichen Gütern zählen - stand er kritisch gegenüber: »If we can cure unemployment for the wasted purposes of armament we can cure it for the productive purposes of peace« (CW XXI: 532).

\section{Distribution}

Keynes weist immer wieder auf die möglichen problematischen Effekte einer Umverteilung von den Lohnbeziehern zu den Rentiers bzw. reicheren Schichten hin: Nach der >grundlegenden psychologischen Regel ist in der letztgenannten Gruppe die marginale Konsumquote geringer, weshalb eine Umverteilung zu ihren Gunsten die effektive Nachfrage gesamtwirtschaftlich senkt (vgl. bspw. Keynes 1936: 221). Im letzten Kapitel der Allgemeinen Theorie nimmt Keynes sich explizit dem zentralen neoklassischen Argument für starke Ungleichheit - diese sei nötig, damit die Kapitalbesitzer viel sparen und somit das Wachstum anregen an und entgegnet, dass »bis zu dem Punkt, an dem Vollbeschäftigung vorherrscht, das Wachstum des Kapitals sich keineswegs auf einen niedrigen Hang zum Verbrauch stützt, sondern im Gegenteil, von ihm zurückgehalten wird « (ebenda: 314). »Unbedingt günstig für das Wachstum von Kapital« (ebenda) sei daher eine Umverteilung des Einkommens, welche die marginale Konsumquote erhöht, d.h. die Ungleichheit zwischen den verschiedenen Schichten vermindert.

Die Bedeutung der Umverteilung nimmt mit steigendem Gesamtwohlstand einer Volkswirtschaft zu, da die >grundlegende psychologische Regel auch bei längerfristigen Einkommensänderungen gilt und die reicheren Bevölkerungsschichten ihre Sättigungsgrenzen erreichen (vgl. Nolte/Schaaff 1994: 301). In diesem Fall ist eine Umverteilung zu denjenigen, die ihre absoluten (physischen Grund-)Bedürfnisse ${ }^{32}$ noch nicht befriedigt haben, notwendiges Mittel für die Aufrechterhaltung von Vollbeschäftigung und wirtschaftlichem Wachstum (vgl. ebenda: $304)^{33}$ bzw. »to provide the purchasing power for the enormous potential output of modern productive technique« (CW XXI: 36).

32 Keynes (1930: 267) unterscheidet zwischen absoluten (physische Grundbedürfnisse) und relativen Bedürfnissen (Verlangen nach Überlegenheit).

33 An anderer Stelle schreibt Keynes: »[W]hat sort of means could be adopted to keep an entrepreneur economy in a neutral condition: [...] Income might be redistributed so as to fall, increasingly or decreasingly, into the hands of individuals more likely to expend it« (CW XXIX: 95). 
Aufgabe des Staates ist es somit, Ungleichheit zu mindern, um die marginale Konsumquote zu vergrößern (vgl. Keynes 1936: 318), z.B. über eine hohe progressive Einkommenssteuer, Erbschaftssteuern (vgl. ebenda: 315f) oder eine Kapitalsteuer (vgl. CW IX: 407). Weiterhin kann der Konsum durch soziale Transferleistungen wie die Arbeitslosenversicherung stabilisiert werden, was Keynes (1936: 84) ebenfalls als sinnvoll ansieht. Umverteilung soll jedoch nicht zu einer Gleichverteilung führen. Keynes bezeichnet zwar die »willkürliche und unbillige Verteilung von Reichtum und Einkommen« als eine der beiden herausragenden Schwächen der heutigen Gesellschaft, hält jedoch einen gewissen Grad an Ungleichheit aus zwei Gründen für notwendig: Zum einen sei für viele Tätigkeiten der Gelderwerb immer noch ein wichtiger Anreiz, zum anderen könnten bestimmte menschliche Triebe so >ungefährlich ausgelebt werden (vgl. ebenda: $314 \mathrm{f}){ }^{34}$

Was öffentliche Güter mit distributiver Funktion angeht, so nennt er Wohnungsbau (vgl. Keynes 1936: 111) sowie den »freigiebigen Gebrauch öffentlicher Einkünfte für >soziale Reform`, das heißt für Versicherung gegen Krankheit, Arbeitslosigkeit und Alter, für Erziehung, Behausung und öffentliche Gesundheit« als sinnvolle Ziele (vgl. Keynes 1925: 247).

Im Gegensatz zur Allokation schreibt Keynes also der Distribution über Steuern, Sozialtransfers und öffentliche Güter - eine wichtige Rolle zu. Primäres Ziel ist jedoch nicht die Schaffung sozialer Gerechtigkeit, sondern die Förderung von Stabilität und Wachstum (vgl. Nolte/Schaaff 1994: 303).

\section{Stabilisierung}

Stabilisierung steht in der Keynes'schen Theorie im Mittelpunkt der wirtschaftspolitischen Aufgaben des Staates. Wie bereits beschrieben besteht der zentrale Widerspruch zur Neoklassik in der Annahme, dass die Wirtschaft sich nicht selbst stabilisieren kann und überdies eine chronische Tendenz zur Unterbeschäftigung innehat. Daher muss der Staat stabilisierend eingreifen.

Dies ist zum einen mit Hilfe der Geldpolitik möglich. Über eine Ausweitung der Geldmenge können die Zinsen gesenkt und somit Investitionen angeregt werden. Allerdings reicht dies nach Keynes Ansicht

34 Langfristig hielt Keynes (1930: 270) folgendes für möglich: »Die Liebe zum Geld als Besitz [...] wird als das anerkannt werden, was es ist: ein ziemlich widerliches Leiden, eine jener halbverbrecherischen, halbkrankhaften Neigungen, die man mit Schaudern an die Fachleute für geistige Erkrankungen verweist.« 
nicht aus (vgl. ders. 1936: 138). ${ }^{35}$ Der Staat muss auch auf anderem Wege versuchen, die Investitionen auf einem Vollbeschäftigungsniveau zu stabilisieren (vgl. Keynes 1936: 319). Wie dies genau aussehen soll, stellt er allerdings nicht explizit dar. ${ }^{36}$ Wichtig ist ihm, dass die Investitionen »nicht ohne Gefahr in privaten Händen gelassen werden« können (Keynes 1936: 271), nicht nur aufgrund der Tendenz des Systems zu Unterbeschäftigung, sondern auch, um starke Schwankungen, die bei laissez-faire unvermeidlich sind, zu verhindern (vgl. ebenda). Das am wenigsten interventionistische Instrument sind Investitionsmeldestellen, welche die Unsicherheit, die sich negativ auf die privaten Investitionsentscheidungen auswirken können, reduzieren sollen (vgl. Keynes 1926: 36). An anderer Stelle spricht Keynes sich für die Einrichtung eines nationalen Investitionsamts aus, das überwachen soll, ob die Investitionen im Verhältnis zu den vorhandenen nationalen Ressourcen ausreichend sind, um einen hohen Beschäftigungsgrad zu sichern (vgl. CW XXI: 137). ${ }^{37}$

Hauptsächlich werden jedoch finanzpolitische Maßnahmen genannt, von denen sich einige eher auf die kurze Frist, d.h. die Überwindung von

$35 »$ Ich bin selbst einigermaßen zweifelnd geworden über den Erfolg einer lediglich geldlichen Politik, die darauf abzielt, den Zinsfuß zu beeinflussen. Ich bin darauf gefaßt, daß der Staat, der die Grenzleistungsfähigkeit der Kapitalgüter auf lange Sicht und auf der Grundlage des allgemeinen sozialen Wohls berechnen kann, eine immer wachsende Verantwortung für die unmittelbare Organisation der Investitionen übernehmen wird. Denn es ist wahrscheinlich, daß die Schwankungen in der Marktbewertung der Grenzleistungsfähigkeit verschiedener Arten von Kapital, nach den oben beschriebenen Grundsätzen berechnet, zu groß sein werden, als daß sie durch irgendwelche Änderungen im Zinsfuß ausgeglichen werden könnten« (Keynes 1936: 138). Ein weiteres Argument gegen die Geld- bzw. Zinspolitik ist, dass die Investitionsnachfrage typischerweise recht unelastisch ist. Geringe Zinsänderungen führen also nicht zu einer großen Änderung bei den Investitionen (vgl. ebenda: 209f). Weiterhin sei das Vertrauen der Investoren wichtiger als die Zinsrate (vgl. ebenda: 125). Überdies muss die Zinsrate, die Vollbeschäftigung sichert, evtl. so klein sein, dass sie für die Rentiers inakzeptabel wird (vgl. ebenda: 261), wobei Keynes längerfristig vom »sanften Tod der Rentiers « ausgeht, wenn der Kapitalbestand in einer Volkswirtschaft sehr hoch und die Knappheitsrente entsprechend gering ist (vgl. ebenda: $317 \mathrm{f}$ ). Die Liquiditätsfalle, auf die v.a. im von Hicks und anderen entwickelten IS-LM-Modell viel Wert gelegt wird, um zeitweilige Unbrauchbarkeiten der Geldpolitik aufgrund einer völlig elastischen Liquiditätspräferenz zu erklären, benennt Keynes zwar, sagt aber auch, dass diese in der Realität noch nicht aufgetreten sei (vgl. ebenda: 173).

36 Snowdon et al. (2002: 64) bemerken, dass die Allgemeine Theorie keine explizite Analyse der Effekte einer Ausgabenvariation, stimuliert entweder direkt durch Staatsausgaben oder indirekt durch Steueränderungen, enthält.

37 Mehr wird zum Investitionsamt leider nicht ausgeführt. 
Krisen, andere auf eine langfristige, dauerhafte Stabilisierung des Systems (Krisenvermeidung) beziehen. Letzterem Aspekt widmet Keynes - im Gegensatz zu den Keynesianern - mehr Raum, sein Hauptanliegen ist die Vermeidung von Krisen, nicht ihre Bekämpfung (vgl. Nielen 2000: 245). Zur kurzfristigen Überwindung von Krisen schlägt Keynes (1929: 187ff) eine diskretionäre Politik vor, insbesondere öffentliche Investitionen sowie öffentliche Beschäftigungsprogramme (vgl. Keynes 1936: 108). Diese sind in Krisen besonders wirksam, weil in diesen Situationen die marginale Konsumquote recht hoch ist und der Multiplikator entsprechend groß (vgl. ebenda). Auch die automatische, konjunkturbedingte Veränderungen von Sozialversicherungsbeiträgen hält er für ein sinnvolles Instrument (vgl. CW XXVII: 324). Indirekter Einfluss kann über Steuerreformen, bessere Abschreibungsmöglichkeiten oder andere Verbesserungen der Gewinnerwartungen genommen werden (vgl. Fees/Tibitanzl 1997: 39), hier sieht Keynes jedoch das Problem, dass diese in parlamentarischen Demokratien nur schwer schnell genug zum Einsatz kommen können (vgl. Mattfeldt 1985: 58). Daher schlägt er weiterhin vor, dass eine Art Behörde gegründet wird, die detaillierte Pläne für sinnvolle Investitionen in den Bereichen Eisenbahn, Wasser-, Gasund Elektrizitätsversorgung, Baugewerbe, Städtebau etc. vorlegt, damit diese innerhalb von wenigen Monaten umgesetzt und Krisen somit schnell bekämpft werden können (vgl. CW XXI: 394).

Zur Vermeidung von Krisen bzw. Konjunkturschwankungen, d.h. zur langfristigen, dauerhaften Stabilisierung, finden sich eine ganze Reihe von unterschiedlich weitgehenden Vorschlägen. Grundlegend geht es darum, die Lücke zwischen Vollbeschäftigungsersparnis und privater Investitionstätigkeit, die sogenannte Investitionslücke, zu schließen (vgl. Heise 2001: 10). Die Steigerung der effektiven Nachfrage über die Erhöhung des privaten Konsums wurde bereits bei der Distributionspolitik erwähnt. Konjunkturstabilisierend wirken nach Keynes Ansicht auch gemeinnützige Unternehmen, die eine sichere Investitionsgrundlage haben, da ein bedeutender Teil ihrer Erträge durch Monopolrechte gewährleistet wird, sowie öffentliche Investitionen bzw. Investitionen, die auf öffentliches Risiko hin getätigt werden, weil bei ihnen die Ertragserwartungen weniger wichtig sind als die sozialen Vorteile (vgl. Keynes 1936: 138). In einer Situation, in der die privaten Investitionen aufgrund von verschlechterten Erwartungen zurückgehen, tragen die eben genannten Instrumente zur Stabilisierung der Nachfrage bei (vgl. Keynes 1936: 138). Im 24. Kapitel der Allgemeinen Theorie empfiehlt Keynes eine »ziemlich umfassende[n] Verstaatlichung der Investitionen « (Keynes 1936: 319), was allerdings auch Zwischenlösungen wie die Zusammenarbeit von Staat und Privaten mit einschließen soll. Nach Blaug ist mit Ver- 
staatlichung (im englischen Original: >socialisation $`$ ) gemeint, dass der Staat die Investitionen über einen permanenten Anstieg des Einkommensanteils, den die Regierung ausgibt, stabilisiert (vgl. Blaug 1999: 649). Es geht also nicht darum, weite Teile der Industrie auf diese Weise zu verstaatlichen oder staatlich zu lenken (vgl. CW XXVII: 324). ${ }^{38}$

Zur Finanzierung der kurz- wie langfristig stabilisierenden öffentlichen Investitionen spricht Keynes sich auch für Verschuldung (deficit spending) aus und weist darauf hin, dass man die Staatsführung nicht mit dem Anschein >vorsichtiger Geldleute < betreiben kann (vgl. ders. 1936: 109 und 111). Überdies hält er eine Politik des Haushaltsausgleichs und der Beschäftigungserhöhung nicht für einen Widerspruch: Durch eine steigende Beschäftigung steigt das Nationaleinkommen und auf diese Weise kann der Haushalt ausgeglichen werden (vgl. CW XXVII: 368). Mögliche negative Auswirkungen öffentlicher Investitionsprogramme lässt Keynes nicht außer acht: Die Gefahren von Crowding-Out und Inflation schwächt er in ihrer Bedeutung ab: Investitionsprogramme kommen dann zur Anwendung, wenn die Kapazitäten nicht ausgelastet sind, so dass mit Mengen- und nicht mit Preisreaktionen gerechnet werden kann (vgl. Keynes 1929: 187ff). Crowding-Out ist in der Keynes'schen Theorie auch daher kein großes Problem, weil die Investitionen sich über den Multiplikatoreffekt die notwendige Ersparnis schaffen. Kommt es dennoch zu einem Zinsanstieg durch die vermehrte Kreditnachfrage auf dem Finanzmarkt, kann dem mit einer Ausweitung der Geldmenge begegnet werden (vgl. Keynes 1936: 102). Überdies könnte ein Teil auch durch die Erlöse einer expansiven Politik (steigende Steuereinnahmen, sinkende Arbeitslosenunterstützung etc.) finanziert werden, was die Kreditnachfrage wieder reduzieren würde (vgl. CW XXVII: 319f; Keynes 1929: 190).

Ein Problem könnte allerdings sein, dass sich »bei der oft vorherrschenden verworrenen Psychologie« (Keynes 1936: 102) eventuell negative Auswirkungen auf das Vertrauen ergeben, die wiederum zu einer steigenden Vorliebe für Liquidität oder einer sinkenden Grenzleistungsfähigkeit des Kapitals führen können, beides schwächt die privaten Investitionen (vgl. ebenda).$^{39}$ Überdies ergibt sich die Schwierigkeit, dass bei offenen Volkswirtschaften ein Teil des durch die öffentlichen Investitionen ausgelösten Multiplikatoreffekts ins Ausland abwandert - allerdings

38 Eine weitere Möglichkeit, die Investitionstätigkeit und damit die Konjunktur zu stabilisieren, ist die Einführung einer beträchtlichen Umsatzsteuer auf Börsengeschäfte »um die Vorherrschaft der Spekulation über die Unternehmungslust [...] abzuschwächen« (Keynes 1936: 135).

39 Heine/Herr (2003: 560) sprechen in diesem Fall von >Erwartungs-Crowding-Out<. 
partizipiert man ebenfalls an Nachfragesteigerungen, die im Ausland ausgelöst werden (vgl. Keynes 1936: 102). Keynes erkannte bereits das Potential supranationalen Vorgehens: $»[$ E $]$ s ist die gleichzeitige Verfolgung dieser Politik gemeinsam durch alle Länder, die wirtschaftliche Gesundheit und Stärke international wiederherstellen kann, ob wir sie am Niveau der inländischen Beschäftigung oder an der Menge des internationalen Handels messen« (ebenda: 295).

Auf diese Weise werde auch der Frieden gesichert, da die Länder nicht mehr versuchen, Waren und insbesondere Arbeitslosigkeit zu exportieren, sondern ihre Binnenwirtschaft zu stärken. Somit könne der internationale Handel ein »williger und ungehinderter Austausch von Gütern und Dienstleistungen in Zuständen des gegenseitigen Vorteils sein « (Keynes 1936: 323). Keynes sprach sich in diesem Zusammenhang auch für die Schaffung eines europäischen Binnenmarktes aus, welcher zu einer Minderung ökonomischer Probleme und zu einer gleichmäßigen ökonomischen Entwicklung beitragen kann (vgl. Mattfeldt 1985: 68).

Bei der langfristigen Stabilisierung hat Keynes allerdings nicht nur Phasen im Blick, bei denen eine Investitionslücke vorliegt, d.h. die Nachfrage zu gering ist, sondern auch den umgekehrten Fall. Dies sah er für die Phase nach dem 2. Weltkrieg voraus, in dieser Zeit würden die geplanten Investitionen die Vollbeschäftigungsersparnis übertreffen (vgl. CW XXVII: 320). In dieser Situation müsse der Staat ebenfalls eingreifen und die Nachfrage nach Investitions- und Konsumgütern, beschränken, um auf diese Weise inflationären Tendenzen und einer dadurch bedingten Umverteilung der Einkommen durch Profitinflation (was die Ersparnis wiederum erhöhen würde) vorzubeugen (vgl. Heise 1993: 711). Mögliche Instrumente sind Rationierung und Investitionskontrollen (vgl. CWXXVII: 321).

\section{Fazit}

Insgesamt kann man sagen, dass Keynes sowohl die Allokations- als auch die Distributionspolitik als Stabilisierungselemente begreift: Subventionen und öffentliche Güter zur Stärkung der Investitionsnachfrage und eine Umverteilung des Einkommens sowie soziale Transferleistungen zur Stärkung des Konsums sollen dazu beitragen, ein Nachfrageniveau $\mathrm{zu}$ erreichen, welches wiederum Vollbeschäftigung ermöglicht. Der wichtigste wirtschaftspolitische Bereich ist jedoch die aktive Stabilisierungspolitik über öffentliche Investitionen oder finanzielle Anreize 
für private Investitionen. ${ }^{40}$ Die Stabilisierung soll durchaus diskretionär erfolgen, wobei diskretionär nicht bedeutet, dass die Politik »willkürlich betrieben werden soll, sondern dass ein wirtschaftspolitisches Ziel [...] entsprechend der spezifischen historischen Situation mit spezifischen wirtschaftspolitischen Impulsen anvisiert werden muss« (Heine/Herr 2003: 522). Die Aufgabe der Nachfragestabilisierung kommt dem Staat deshalb zu, weil die Wirtschaft sie nicht von sich heraus garantieren kann und in entwickelten Volkswirtschaften das Investieren die Tendenz hat, hinter der Vollbeschäftigungsersparnis zurückzubleiben. Nach Keynes Schätzungen ist es notwendig, zwei Drittel bis drei Viertel der Investitionen staatlich zu übernehmen oder zu beeinflussen, um die wirtschaftliche Entwicklung langfristig stabil zu halten. ${ }^{41}$ Dies entspricht seiner Schätzung nach 7,5-20\% des Nettonationaleinkommens (vgl. CW XXVII: 322f).

Für die konkrete Struktur des Staatshaushaltes, die Einfluss auf alle drei Interventionsbereiche hat, entwickelt Keynes folgendes Modell (vgl. CW XXVII: 320ff sowie 405ff; Heise 1993: 715f): Er unterscheidet zwischen einem laufenden und einem Investitionsbudget. Das laufende Budget (current budget) enthält alle nicht-investiven Ausgaben (Sachund Personalausgaben, Sozialversicherungsausgaben etc.) und dient hauptsächlich allokativen und distributiven Zwecken. Das laufende Budget sollte im konjunkturellen Durchschnitt über Steuern ausgeglichen sein. Das Investitionsbudget (capital budget) enthält die Investitionsausgaben des Staates und dient der langfristigen Stabilisierung, seine Höhe ist abhängig von der Größe der Investitionslücke sowie dem politischen Wunsch, diese zu schließen. Finanziert werden kann es zumindest teilwiese über Kredite, vor allem aber über den Selbstfinanzierungseffekt.

In der konkreten Politik sind insbesondere die Aspekte der gerade dargestellten Theorie wirkungsmächtig geworden, die Keynes Nachfolger hervorgehoben haben: das IS-LM-Modell, entwickelt vor allem von Hicks (1937) sowie die Globalsteuerung (vgl. Kromphardt 2004: 186ff). Der wohl wichtigste Unterschied ist, dass sie sich in erster Linie auf die kurze Frist und eine `Feinsteuerung ^ der Wirtschaft konzentrieren, wäh-

40 Damit spricht sich Keynes für die interventionistischste Form der Stabilisierung aus, eine Erhöhung des privaten Konsums wäre weniger interventionistisch (vgl. Peacock 1993: 62).

41 »If two-thirds or three quarters of total investment is carried out or can be influenced by public or semi-public bodies, a long-term programme of a stable character should be capable of reducing the potential range of fluctuations to much narrower limits than formerly, when a smaller volume of investment was under public control and when even this part tended to follow, rather than to correct, fluctuations of investment in strictly private sector of the economy« (CW XXVII: 322). 
rend Keynes eher auf Krisenprävention gesetzt hat. »The problem of the long-run demand for investment, on which Keynes differed from Marshall, gave way to concern over fluctuations in demand for investment in the course of the business cycle« (Sweezy 1986: 48 ). Überdies vernachlässigen diese Nachfolger den Aspekt der Einkommensumverteilung zur Stabilisierung des Systems. Ihre zentralen wirtschaftspolitischen Empfehlungen lagen somit darin, den Konjunkturschwankungen diskretionär entgegenzuwirken, indem die Nachfrage in Abschwüngen über eine expansive Finanzpolitik und sinkende Zinsen erhöht und in Boomphasen über eine gegenteilige Politik vermindert wird.

\section{Das Staatsverständnis in der monetaristischen Theorie}

\section{Überblick}

Der Monetarismus, der oft als Gegenrevolution zum Keynesianismus dargestellt wird, gewann seine politische Bedeutung in einer Zeit, in der die Inflation zu einem zentralen Problem wurde (vgl. Johnson 1971: 8). Sein wichtigster Vertreter ist Milton Friedman, auf den ich mich im Folgenden hauptsächlich beziehen werde. ${ }^{42}$ Der Monetarismus kann als Fortentwicklung der neoklassischen Theorie bezeichnet werden. ${ }^{43}$ Grundlegend ist die Annahme der inhärenten Stabilität des marktwirtschaftlichen Systems. Schwankungen werden von (exogenen) Schocks herbeigeführt (vgl. Heine/Herr 2003: 518), aber eigenständig und schnell ausgeglichen (vgl. Mayer 1978: 25). Die Koordinationsprobleme (v.a. von Sparen und Investieren bzw. Liquiditätsangebot und -nachfrage), die bei Keynes zentral sind, sowie das Problem des sich daraus ergebenden effektiven Nachfragemangels werden - anknüpfend an das Say'sche Theorem - verneint (vgl. Heine/Herr 2003: 518). Das Güterangebot wird von der Angebotsseite bzw. dem Arbeitsmarkt her bestimmt. Veränderungen im Output werden somit langfristig von realen Faktoren wie Unternehmungslust, Struktur von Industrie und Staat, Investitionspotentia-

42 Samuelson (1971: 8) sagte einmal, Friedman könne über sich selbst sagen »Monetarism, that's me.« Der Bezug auf Friedman ist auch wichtig, um zu einem einheitlichen Staatsverständnis zu kommen, denn $»[t]$ here are almost as many versions of monetarism as there are monetarists « (Allsopp 1989: 197). Ob der Monetarismus als eigenständige >Theorie< bezeichnet werden kann, ist umstritten, Snowdon et al. 2002 widmen ihm ein ganzes Kapitel, während Felderer/Homburg (2003: 231) ihn mit dem Satz »Der Monetarismus ist die Bezeichnung für eine bunte Ansammlung von theoretischen Visionen und Modellen « abhandeln.

43 Heine/Herr 2003 sprechen von »monetärer neoklassischer Makroökonomie $\ll$. 
len, Technik etc. hervorgerufen (vgl. Friedman/Heller 1969: 47; Friedman 1970: 24).

Eine weiteres wesentliches Element des Monetarismus ist die Wiedereinführung und Neubegründung der Quantitätstheorie, die besagt, dass Geld keinen Einfluss auf die reale Seite der Ökonomie hat. ${ }^{44}$ Friedman bezieht sich für die Neubegründung der Theorie auf die alte Fisher'sche Quantitätsgleichung $\left(\mathrm{M} * \mathrm{v}=\mathrm{Y}^{\mathrm{r}} * \mathrm{P}\right.$, Geldmenge * Umlaufgeschwindigkeit $=$ realer Output $*$ Preisniveau), konzeptioniert diese jedoch als Theorie der Geldnachfrage, die bei ihm stabil ist. Damit ist auch die Umlaufgeschwindigkeit stabil (vgl. Snowdon et al. 2002: 140). $\mathrm{Da}$ das reale Angebot von den Angebotsbedingungen (s.o.) bestimmt wird, hat die exogene Geldmenge nur mehr Einfluss auf das Preisniveau, bestimmt lediglich das nominale Einkommen. Weil die aggregierte nominale Nachfrage hauptsächlich von der - stabilen - Geldnachfrage und dem Geldangebot abhängig ist (vgl. Mayer 1978: 23), ergibt sich für die Sicherstellung der nominalen makroökonomischen Stabilität die Notwendigkeit einer festen Geldmengenwachstumsregel (vgl. Snowdon et al. 2002: 163).

Bezüglich des Arbeitsmarktes stellt Friedman (1968) das Konzept der natürlichen Rate der Unterbeschäftigung auf. Bei dieser Rate ist der Arbeitsmarkt geräumt und es gibt einen Vollbeschäftigungsreallohn (vgl. Blaug 1999: 679). Die in dieser Situation bestehende Arbeitslosigkeit ist freiwillig oder Sucharbeitslosigkeit, sie ist überdies verursacht von strukturellen Faktoren, Arbeitsmarktunvollkommenheiten, Sozialtransfers etc., nicht jedoch von fehlender effektiver Nachfrage. ${ }^{45}$ Die Ursachen der Arbeitslosigkeit werden also (im Gegensatz zu Keynes) auf dem Arbeitsmarkt gesucht und können auch nur dort, d.h. über eine erhöhte Flexibilität, verbesserte Informationen etc. beseitigt werden (vgl. Friedman 1976: 146). Der Versuch, die Arbeitslosigkeit mit Hilfe makroökonomischer Politik unter die natürliche Rate zu senken, kann nach diesem Konzept nur kurzfristig erfolgreich sein: Eine Erhöhung der Geldmenge $^{46}$ führt zuerst zu einer steigenden Nachfrage nach Gütern ${ }^{47}$

44 Da dieser Punkt für die Finanzpolitik nicht entscheidend ist, wird er hier nur sehr verkürzt behandelt, für eine ausführlichere Darstellung vgl. bspw. Friedman 1976: 154; Kromphardt 2004: 225.

45 Definition nach Friedman (1976: 144): »Das >natürliche Unterbeschäftigungsniveau< ist mit anderen Worten jenes, das sich aus dem Walrasianischen Gleichgewichtssystem ergeben würde, vorausgesetzt, die aktuellen Strukturcharakteristika der Arbeits- und Gütermärkte sind eingebaut, und zwar einschließlich Marktunvollkommenheiten, Zufallsvariabilität von Angebot und Nachfrage, Kosten der Informationsbeschaffung über freie Stellen und Arbeitsreserven, Mobilitätskosten.«

46 Zur Unwirksamkeit der Fiskalpolitik s.u. den Abschnitt 〉Stabilisierung〈. 
und somit auch nach Arbeitskräften. Neue Arbeitskräfte können aber nur zu höheren Nominallöhnen eingestellt werden, wozu die Arbeitgeber bereit sind, da sie zuvor antizipiert haben, dass auch das Preisniveau aufgrund der höheren Güternachfrage gestiegen ist, die Reallöhne also konstant bleiben. Die Arbeitnehmer hingegen unterliegen einer Geldillusion und gehen von höheren Reallöhnen aus. Sobald sie jedoch das gestiegene Preisniveau ebenfalls bemerken, führen sie ihr Arbeitsangebot auf das alte Niveau zurück, die Arbeitslosigkeit liegt wieder bei der natürlichen Rate, nur das Preisniveau ist gestiegen. ${ }^{48}$ Die Wirkungen der Geldpolitik könnten einzig dann längerfristig aufrecht erhalten werden, wenn die Geldmenge immer weiter ausgedehnt wird, d.h. auf Kosten einer immer stärker steigenden Inflation (vgl. Friedman 1976: 147).

Dieser Ansatz wird dem bis dahin vorherrschende Konzept der Phillipskurve entgegen gesetzt, nach dem ein Trade-off zwischen Arbeitslosigkeit und Inflation besteht, der es der Politik ermöglicht, einen Punkt auf der Kurve zu wählen, d.h. eine Entscheidung zwischen Inflation und Arbeitslosigkeit zu treffen (vgl. Snowdon et al. 2002: 195). ${ }^{49}$ Dies ist aber nur möglich, wenn die Kurve stabil und geneigt ist. Nach Friedmans >expectations-augmented phillips-curve` (ebenda: 153) gibt es jedoch für jede Inflationserwartung eine eigene - kurzfristig geneigte Phillipskurve, und in einer Situation mit der natürlichen Rate der Arbeitslosigkeit bzw. langfristig ist die Kurve vertikal, die erwarteten Inflationsänderungen entsprechen den tatsächlichen, es gibt keine realen Auswirkungen einer Geldmengenausweitung (vgl. Blaug 1999: 680).

47 Der Transmissionsmechanismus ist jedoch ein anderer als bei Keynes, der davon ausgeht, dass eine Erhöhung der Geldmenge zu einer Zinssenkung und damit einer steigenden Investitionsnachfrage führt. Bei den Monetaristen führt eine Erhöhung der Geldmenge zu einer Umstrukturierung des Portfolios, das nicht nur Bargeld und Wertpapiere, sondern auch andere Vermögensformen sowie Realaktiva enthält. Somit steigt auch die Konsumnachfrage, der Zins muss sich jedoch nicht verändern (vgl. Kalmbach 1973: 27f).

48 Für eine ausführlichere Darstellung vgl. bspw. Friedman 1976: 146f; Heine/Herr 2003: 288ff.

49 Einige Autoren stellen die Philipskurve als Teil der keynesianischen - d.h. als Weiterentwicklung der Keynes'schen - Theorie dar (vgl. Mayer 1978: 45), andere meinen, dass dieser Zusammenhang nicht dem keynesianischen Denken entspricht (vgl. Heine/Herr 2003: 278). 


\section{Staatsaufgaben}

Literatur, die sich explizit mit dem monetaristischen Staatsverständnis auseinandersetzt, gibt es kaum. Dies ist damit zu erklären, dass Monetaristen dem Staat keine bedeutende Rolle zuweisen. Aus den Annahmen der inhärenten Stabilität des marktwirtschaftlichen Systems, der Unwirksamkeit der Geldpolitik bei der Beeinflussung realer Größen und der natürlichen Rate der Unterbeschäftigung lässt sich leicht ableiten, dass staatliche Interventionen als nicht notwendig angesehen werden. Vielmehr werden sie als schädlich eingestuft: Neben der oben dargestellten inflationären Wirkung einer makroökonomischen Bekämpfung der Arbeitslosigkeit ist hier noch die Annahme der Wirkungsverzögerung insbesondere bei diskretionären wirtschaftspolitischen Maßnahmen zu nennen, in deren Folge staatliche Interventionen oft prozyklisch wirken. Dies ist eine Form des Staatsversagens, ein Aspekt, auf den der Monetarismus ein besonderes Gewicht legt. Überdies wird staatliches Handeln oft als Befriedigung der Wünsche mächtiger Interessengruppen angesehen (vgl. Ziegler 1998: 199).

Zentrale Politikempfehlung ist somit, der Staat solle nicht >stören<, keine kurzfristigen Erwartungsirrtümer (auch wenn diese - ebenso kurzfristig - reale Effekte haben) erzeugen, sondern eine stetige, regelgebundene Politik verfolgen. Wichtig ist hierbei die Glaubwürdigkeit zur Erwartungsstabilisierung, was am besten über eine Selbstbindung der Politik sichergestellt wird (vgl. Heine/Herr 2003: 519). Bekanntestes Beispiel ist die Geldpolitik, die über eine stetige Geldmengenregel das Preisniveau sichern soll (vgl. Friedman 1976: 154). Eine aktive Politik wird nur auf der Angebotsseite als sinnvoll erachtet bzw. zur Sicherstellung eines Rahmens, in dem die Marktkräfte sich ungehindert entfalten können (vgl. Kromphardt 2004: 226).

Friedman (2002: 49) tritt neben den genannten Gründen auch aus einem wichtigen nicht-ökonomischen Grund für eine Beschneidung staatlicher Tätigkeiten ein: Er geht davon aus, dass der Staat die größte Bedrohung für die - bei ihm zentrale - Freiheit der Individuen ist. Somit ist eine seiner wichtigsten Fragen: »Wie können wir verhindern, dass die Regierung, die wir geschaffen haben, ein Monster wie `Frankenstein wird, das schließlich die Freiheit vernichtet, zu deren Schutz wir die Regierung doch überhaupt erst eingesetzt haben?« (ebenda: 24). 


\section{Allokation}

Monetaristen beschäftigen sich nicht sehr intensiv mit Details der Allokation, da die Annahme der inhärenten Stabilität des privaten Sektors wenig Anlass hierzu bietet (vgl. Mayer 1978: 26).$^{50}$ Diese Stabilität ist jedoch nur dann gegeben, wenn vollkommener Wettbewerb herrscht, somit hat der Staat die Aufgabe, diesen zu gewährleisten. Bezüglich der Sicherstellung des Wettbewerbs auf dem Gütermarkt tritt Friedman bei technischen Monopolen - bei denen es sich häufig um öffentliche Daseinsvorsorge (Elektrizität, Transport etc.) handelt - für maßvolle private Monopole anstelle von staatlichen oder öffentlicher Monopolkontrolle ein (vgl. Friedman 2002: 53). Er begründet dies mit den schlechten Erfahrungen, die man mit den beiden letztgenannten Möglichkeiten gemacht hat (vgl. ebenda: 52f) sowie damit, dass Staatsmonopole oft auch weiter bestehen, wenn die technischen Möglichkeiten für eine Auflösung gegeben wären. Überdies sind technische Monopole seiner Meinung nach seltener als angenommen (vgl. ebenda: 152). Ein Staatsmonopol ist nur bei unentbehrlichen Gütern oder Dienstleistungen zu akzeptieren (vgl. ebenda: 53). In Bezug auf öffentliche Güter mit allokativer Funktion plädiert Friedman dafür, diese Aufgabe wo immer möglich d.h. dort, wo eine direkte, >preismäßige < Finanzierung realisierbar ist an Private zu übertragen. So soll der Staat beispielsweise vielbefahrene Zufahrtstraßen unterhalten, Autobahnen mit der Möglichkeit von Mautsystemen sollen hingegen von Privaten betrieben werden (vgl. Nowotny 1999: 15). Auch wenn Friedman sich zu Subventionen nicht explizit äuBert, ${ }^{51}$ kann man doch aus seiner Annahme der Überlegenheit marktwirtschaftlicher Steuerung schließen, dass er diese ablehnt, weil sie die marktliche Koordination verzerren.

Was den Arbeitsmarkt angeht, so schreibt Friedman dem Staat durchaus eine Rolle zu:

»Um Mißverständnisse zu vermeiden, lassen Sie mich betonen, daß ich mit dem Gebrauch des Terminus >natürliches` Unterbeschäftigungsniveau nicht etwa nahe legen möchte, daß es unwandelbar und unveränderlich sei. Im Gegenteil sind viele der dieses Niveau bestimmenden Marktcharakteristika Menschenwerk und Ergebnis der Wirtschaftspolitik« (Friedman 1976: 146).

50 Überdies wird davon ausgegangen, dass einzelne Sektoren keinen Einfluss auf das Preisniveau haben (dieses wird von der Geldmenge bestimmt) (vgl. ebenda S. 25).

51 Ich habe zumindest keine Aussage dazu von ihm gefunden. 
Bei der zur Senkung der natürlichen Rate der Unterbeschäftigung notwendigen Angebotspolitik zur Verbesserung der Struktur und Funktionsweise von Arbeitsmarkt und Industrie werden auch finanzpolitische Maßnahmen angesprochen, z.B. Privatisierungen zur Erhöhung der Flexibilität der Güter- und Dienstleistungsmärkte (vgl. Snowdon et al. 2002: 164).

\section{Distribution}

Im Bereich Distribution argumentiert Friedman (2002: 232) sowohl ökonomisch als auch ethisch und empirisch. So leitet er aus der liberalen Einstellung ab, dass gleiche Rechte und Möglichkeiten wichtig sind, gleiche Resultate und materielle Gleichheit jedoch nur ein Nebenprodukt der freiheitlichen Gesellschaft, nicht ihre Hauptberechtigung sein können. Empirischen Ergebnissen zufolge sind kapitalistische Systeme gleicher als andere und weisen überdies eine hohe soziale Mobilität auf (vgl. Friedman/Friedman 1983: 164ff). Friedman (2002: 193f) bezeichnet Ungleichheit als Ergebnis zweier ethischer Prinzipien der freien Marktwirtschaft: 〉Jedem nach seiner Leistung` und `Gleichbehandlung`. Ungleichheit spiegelt somit unterschiedliche Tätigkeits- und Risikopräferenzen der Individuen wieder. Die Marktkräfte sorgen dafür, dass alle Produktionsfaktoren mit dem Äquivalent ihres Grenzertrags entlohnt werden (eine Form der Gleichheit), insofern ist Umverteilung nicht notwendig. Sie ist im Gegenteil sogar schädlich, denn sie verzerrt den Markt - nur eine Bezahlung im Verhältnis zur Leistung ermöglicht den freiwilligen Tausch und damit die marktförmige Allokation. Überdies verhindert Umverteilung die Setzung von Anreizen und die Lenkung durch Ungleichheit. Friedman tritt daher für die Kürzung von Sozialtransfers und die Reduzierung von Grenzsteuersätzen zur Erhöhung des Arbeitsanreizes ein (vgl. Snowdon et al. 2002: 163).

Ein weiteres Argument gegen Umverteilung bzw. den Sozialstaat ist Paternalismus. Dieser hat eine Einschränkung der persönlichen Freiheit zur Folge, was Friedman am Beispiel der staatlichen Rentenversicherung darstellt: Diese schränke die Freiheit ein, das Geld für andere Zwecke als die Altersvorsorge auszugeben und sich bewusst für einen niedrigen Lebensstandard im Alter zu entscheiden. Seiner Ansicht nach ist staatliches Eingreifen hier nur gerechtfertigt, wenn ein großer Teil der Menschen sich für diese Möglichkeit entscheide und die Gesellschaft im Alter für diese Menschen aufkommen müsse. Paternalistisches Eingreifen des Staates ist ansonsten nur bei geistig Behinderten und Kindern tragbar (vgl. Friedman 2002: 222), für diese beiden Gruppen 
nicht voll Verantwortlicher soll der Staat Sorge tragen (vgl. ebenda: 57f).

Hinsichtlich öffentlicher Güter mit distributiver Funktion spricht Friedman sich ebenfalls gegen eine staatliche Bereitstellung aus. Wenn diese Güter einen beträchtlichen positiven Nutzen haben, soll der Staat ihre Bereitstellung jedoch fördern. Als Beispiel nennt er die Elementarbildung, die dazu dient, die Demokratie aufrecht zu erhalten (vgl. Friedman 2002: 109). Seine Forderung ist nun aber kein öffentliches Bildungswesen, sondern die Ausgabe von Bildungsgutscheinen, der Staat soll nur die Einhaltung bestimmter Minima garantieren (vgl. ebenda: 113). Gegen die staatliche Bereitstellung öffentlicher Güter sprechen auch deren häufige kontraproduktive Effekte, so führte der öffentliche Wohnungsbau entgegen der eigentlichen Zielsetzungen zu einer Abnahme von Sozialwohnungen und einer Zunahme der Jugendkriminalität (vgl. Friedman/Friedman 1983: 124ff). Grundlegend vertritt Friedman (2002: 211f) das Prinzip, jegliche soziale Unterstützung solle in Form von Geld erfolgen, damit nicht der Staat paternalistisch, sondern die Leistungsempfänger eigenständig entscheiden können, was sie benötigen. Zur Bekämpfung von Ungleichheit schlägt Friedman die Beseitigung von Marktunvollkommenheiten (Monopolprivilegien etc.) sowie eine Ausweitung der pädagogischen Möglichkeiten vor (vgl. ebenda: 209). Eine staatliche soziale Sicherung, die über die Armutsbekämpfung hinaus geht, lehnt er ab. Was letzteres angeht wäre zwar prinzipiell eine private Wohltätigkeit wünschenswerter, da diese jedoch aufgrund des freerider Problems ${ }^{52}$ unwahrscheinlich ist, muss der Staat eingreifen. Als sinnvollstes Instrument wird eine negative Einkommensteuer genannt, da diese den Marktmechanismus nicht stört (vgl. Nowotny 1999: 16).

\section{Stabilisierung}

In diesem Bereich staatlicher Intervention treten die Unterschiede zwischen Keynes und den Monetaristen besonders deutlich hervor. Von der Annahme ausgehend, dass die Wirtschaft sich selbst stabilisiert, sind staatliche Interventionen mit diesem Ziel nicht notwendig. Greift der Staat dennoch ein, hat dies entweder keine oder negative, d.h. destabilisierende Wirkungen. Dies wird auf verschiedenste Weise begründet. Für die Geldpolitik wurde bereits oben die Unwirksamkeit bezüglich der Beeinflussung realer Größen und die daraus folgende Forderung nach einer

52 Jeder profitiert auch davon, wenn andere das Armutsproblem finanziell lindern (vgl. Friedman 2002: 227). 
regelgebundenen Politik dargestellt. Im Folgenden soll es um die (Un-)Möglichkeiten finanzpolitischer Stabilisierung gehen.

Die bekannteste Begründung für die Unwirksamkeit finanzpolitischer Stabilisierung ist das sogenannte >Crowding-Out<: Der Versuch, die effektive Nachfrage durch eine Ausweitung staatlicher Ausgaben zu erhöhen, führt - so die Monetaristen - zu einer Abnahme der privaten Ausgaben. Dies ist über mehrere Wege möglich. Zum einen ist das ZinsCrowding-Out zu nennen (vgl. Heine/Herr 2003: 566): Wenn der Staat seine zusätzlichen Ausgaben über den Kapitalmarkt finanziert, ${ }^{53}$ verdrängt er die private Kreditaufnahme. Die zusätzliche Nachfrage verschiebt die Kapitalnachfragefunktion, nicht jedoch die Kapitalangebotsfunktion (da das gleichgewichtige Produktionsvolumen und damit auch das Volkseinkommen durch die Realökonomie gegeben sind). Dies führt zu steigenden Zinsen, welche das Sparvolumen ansteigen lassen und die private Investitionsnachfrage senken. Beides verringert die private Nachfrage (vgl. Heise 2005: 103). Das Ausmaß ist jeweils abhängig von der Zinselastizität der Spar- und Investitionsfunktion. Der Zins ändert sich nur dann nicht, wenn die Investitionsnachfrage völlig zinsunelastisch ist (vgl. Friedman 2002: 105) oder eine Indifferenz der Privaten bezüglich der Frage, ob sie Geld oder Wertpapiere halten, vorliegt (vgl. Friedman 2002: 105). Das Problem, welches bei diesen Ausnahmen bestehen bleibt, ist, dass die Gläubiger weniger konsumieren können (vgl. Friedman 1970: 19). Eine weitere Möglichkeit ist das Preis-CrowdingOut (vgl. Heine/Herr 2003: 566ff): Durch die zusätzliche Güternachfrage $^{54}$ steigen nicht die Angebotsmengen (diese werden nicht von der Nachfrageseite her determiniert), sondern die Preise. Dies führt zu einem rückläufigen privaten Konsum. Schließlich kann es zu einem direkten Crowding-Out kommen, wenn der Staat Dinge übernimmt, für die vorher privat bezahlt wurde (vgl. Friedman 2002: 104) oder wenn er seine Ausgaben über Steuern finanziert und die private Nachfrage im Umfang der gezahlten Steuern zurückgeht (vgl. Friedman/Heller 1969: 53). Das Ausmaß des Crowding-Out ist von vielen Faktoren abhängig. In der extremsten Form wird die staatliche Politik vollständig kompensiert.

Kommt es jedoch zu einer Beeinflussung der Wirtschaft, hat dies nur geringe und negative Folgen. Der bei Keynes so wichtige Multiplikator-

53 Eine weitere Möglichkeit der Kreditfinanzierung ist die Finanzierung über die Zentralbank, d.h. das Drucken von Geld. In diesem Fall handelt es sich jedoch um Geld-, nicht Finanzpolitik (vgl. Friedman 1979: 85).

54 Bei der zusätzlichen Nachfrage kann es sich auch um zusätzliche private Nachfrage handeln, welche über den Realkasseneffekt zustande gekommen ist, dies ändert jedoch nichts daran, dass diese Nachfragesteigerung auf ein gegebenes Güterangebot trifft und somit nur die Preise erhöht (vg1. Heine/Herr 2003: 567). 
effekt wird von den Monetaristen als vernachlässigbar angesehen. Die schwache Reaktion wird mit der von Friedman neu eingeführten These des >permanent income $<$ begründet. Demnach machen die Individuen ihre Ausgabenentscheidungen nicht von ihrem laufenden, sondern von ihrem Einkommen über den Lebensverlauf, dem permanenten Einkommen, abhängig (vgl. Kromphardt 2004: 223). Ein kurzfristiger Anstieg der privaten Einkommen, z.B. durch eine Erhöhung der Sozialtransfers, führt daher nicht oder zumindest in sehr viel geringerem Umfang dazu, dass die Individuen mehr ausgeben, die zusätzliche Nachfrage versickert (vgl. Ziegler 1998: 195f). Nach empirischen Berechnungen hält Friedman (2002: 107) einen Multiplikator von eins für wahrscheinlich.

Wenn die Stabilisierungspolitik Auswirkungen hätte, wäre der Versuch einer diskretionären Feinsteuerung der Wirtschaft kontraproduktiv bzw. schädlich. ") Feinsteuerung〈 ist ein geradezu herausfordernder Begriff in unserem Elektronenzeitalter, aber er hat wenig Bezug zu dem, was wir in der Praxis vermögen - und ist, sollte ich noch hinzufügen, ein durchaus vielgestaltiges Übel« (Friedman 1976: 138). Eine diskretionäre Konjunkturpolitik wäre nur möglich, wenn die staatlichen Maßnahmen sofern sie überhaupt wirken - keinerlei Wirkungsverzögerungen aufwiesen. Dies ist jedoch nicht der Fall, im Gegenteil, Friedman identifiziert gleich drei >lags $:$ zwischen der Handlungsnotwendigkeit und ihrer Erkenntnis, zwischen Erkenntnis und Handlung und schließlich zwischen der Handlung und ihrer Wirkung (vgl. Friedman 1948: 255f). Aufgrund von Informationsproblemen, dem politischen Prozess etc. sind diese lags kaum zu verringern. Die Maßnahmen wirken daher nicht antizyklisch, sondern meist prozyklisch (vgl. Ziegler 1998: 195): Sie führen der ursprünglichen Störung eine weitere Störung hinzu und verstärken damit die wirtschaftlichen Schwankungen, anstatt ihnen entgegen zu wirken (vgl. Friedman 2002: 102). Überdies verunsichert eine diskretionäre Politik die Privaten und beeinflusst damit vor allem ihre Investitionstätigkeit negativ (vgl. Kalmbach 1981: 14). Zusammenfassend sagt Friedman:

»The goal of an extremely high degree of economic stability is certainly a splendid one. Our ability to attain it, however, is limited; we can surely avoid extreme fluctuations; we do not know enough to avoid minor fluctuations; the attempt to do more than we can will itself be a disturbance that may increase rather than reduce instability« (Friedman/Heller 1969: 48).

Friedman spricht sich daher auch in der Finanzpolitik gegen ein diskretionäres Vorgehen und für eine Regelbindung aus. Die finanzpolitische Regel - als Äquivalent zur geldpolitischen - wird damit begründet, dass 
der Staatshaushalt so groß ist, dass er die Wirtschaft zwangsläufig beeinflusst. Daher sollen die Staatsausgaben stabilisiert werden, um nicht mit erratischen Schwankungen die Wirtschaft zu destabilisieren (vgl. Friedman 2002: 100). Friedman tritt dafür ein, Ausgabenprogramme ausschließlich nach den Wünschen der Bevölkerung zu planen, d.h. danach, was die Individuen gemeinsam und nicht privat machen wollen. Kurzfristige Stabilisierungserwägungen sollen keine Rolle spielen (vgl. ebenda: 102). Dies trägt auch zu einer - gewünschten - Verstetigung des gesamten Staatshaushalts bei, da ein rezessionsbedingtes Ansteigen der Staatsausgaben in Boomphasen selten zurückgenommen wird (vgl. bspw. Fees/Tibitanzl 1997). Die Finanzpolitik soll somit entsprechend der langfristig gewünschten Staatsquote verstetigt werden (vgl. Nowotny 1999: 16). Grundsätzlich soll der Staatshaushalt so gering gehalten werden wie möglich, hier spielt auch wieder Friedmans zentrale Überlegung, die menschliche Freiheit, hinein (vgl. Friedman 1979: 101).

\section{Fazit}

Die Rolle des Staates ist bei den Monetaristen sehr gering, mit der dreifachen Begründung, staatliches Eingreifen sei nicht notwendig, nicht zielführend und schädlich. Dies ist nicht nur in der Stabilisierungspolitik der Fall, auch was die Distribution und Allokation angeht werden Staatseingriffe eher negativ beurteilt. So bleibt für die staatliche Finanzpolitik nur die Aufgabe, öffentliche Güter mit allokativer Funktion und positiven externen Effekten zu fördern (aber möglichst nicht selbst anzubieten) sowie die Armut zu bekämpfen. Die Finanzpolitik soll insgesamt stetig und regelgebunden sein (vgl. Kromphardt 2004: 225), möglichst über eine Selbstbindung der Politik (vgl. Heine/Herr 2003: 519). Sie ist wichtig für die Bestimmung des Einkommensanteils, der von der Regierung ausgegeben wird und die Festlegung, wer die Last dieser Ausgaben trägt (vgl. Friedman 1970: 24). Die Höhe des Staatsanteils sowie die Ausgaben sollen allein von den Wünschen der Individuen geleitet sein.

Grundlegend treten Monetaristen für eine Verringerung der staatlichen Interventionen ein, da sie den Staat als Ursache vieler (wirtschaftlicher) Probleme ansehen und immer wieder die Abwägung des Nutzens staatlicher Eingriffe gegen die Einschränkung der persönlichen Freiheit erfolgen muss:

»Aber solange wir lediglich die Verschwendung und Bürokratie dafür [für die steigenden Staatsausgaben, A.K.] verantwortlich machen, aber weiterhin an die Allmächtigkeit, das Wohlwollen und die Segnungen der Regierung glauben, wird die Entwicklung in Richtung auf eine noch größer werdende Regie- 
rung anhalten. Dieser Trend wird so lange nicht aufhören, bis wir erkennen, daß die Regierung das Problem ist, und nicht die Lösung; daß es für die allgemeine Wohlfahrt notwendig ist, daß die Bundesregierung von ihrer Rolle als >Großer Bruder befreit wird und zu ihrer historischen Rolle als Bewahrer des Friedens und als Schiedsrichter zurückkehrt« (Friedman 1979: 101).

Kurz gesagt: »Was wir dringend für eine stabile und wachsende Wirtschaft brauchen, ist eine reduzierte, nicht eine vermehrte Einmischung der Regierung« (Friedman 2002: 61).

\section{Das Staatsverständnis in der Angebotsökonomie/Neuen Klassischen Makroökonomie}

\section{Überblick}

In der Nachfolge des Monetarismus kamen in den 1970ern zwei Wirtschaftstheorien auf: die Neue Klassische Makroökonomie (NKM) sowie die Angebotsökonomie. Diese beiden werden hier zu einem Staatsverständnis zusammengefasst, da die NKM als makroökonomische Fundierung der Angebotsökonomie - welche eher wirtschaftspolitisch als wirtschaftstheoretisch sowie stärker mikroökonomisch ausgerichtet ist - angesehen werden kann. ${ }^{55} \mathrm{Zu}$ Beginn werden die Prämissen dieser beiden Theorien dargestellt. ${ }^{56}$

Grundlegend für die NKM ist die Annahme rationaler Erwartungen, ${ }^{57}$ eine Weiterentwicklung der im Monetarismus verwendeten adaptiven Erwartungen. In der schwachen Version dieser Annahme wird den Wirtschaftssubjekten unterstellt, dass sie die vorhandenen Informationen über die Einflussgrößen der Variablen, deren Verlauf sie prognostizieren wollen, effizient nutzen. Dies bedeutet, dass nur bis zu dem Punkt zusätzliche Informationen gesucht und verwertet werden, an dem der Grenznutzen aus den neuen Informationen den Grenzkosten der Informationssuche entspricht. Bei der starken Version wird zusätzlich unter-

55 Andere (bspw. Flassbeck 1982: 79) sprechen davon, dass der Monetarismus die makroökonomische Grundlage der Angebotsökonomie ist, da ersterer in der Arbeit jedoch aus den Arbeiten Friedmans abgeleitet wurde, der Staatseingriffe vehement ablehnt, ist es zur Entwicklung der Idealtypen sinnvoller, die NKM als Grundlage zu wählen, da der Staat bei der Angebotsökonomie wieder eine größere Rolle zugeschrieben bekommt.

56 Weder die NKM noch die Angebotsökonomie können auf einen Hauptvertreter zurückgeführt werden, in diesem Kapitel werde ich mich daher vor allem auf Literatur mit Übersichtscharakter beziehen.

57 Dies geht zurück auf Muth (1961: 315), seine Definition lautet: »expectations since they are informed predictions of future events are essentially the same as the predictions of the relevant economic theory." 
stellt, dass die Wirtschaftssubjekte das relevante ökonomische Modell, d.h. dessen Struktur, die Parameter etc. kennen. Infolgedessen decken sich die subjektiven Erwartungen mit den wahren oder objektiven, mathematisch bedingten Erwartungen (vgl. Snowdon et al. 2002: 190). Diese Version ist in die Modelle der NKM eingegangen, als das wahre Modell wird das neuklassische angenommen (vgl. ebenda). Es wird allerdings nicht behauptet, die Wirtschaftssubjekte könnten die Zukunft perfekt voraussagen (`perfect foresight $\iota$ ). Vielmehr geht es darum, dass Erwartungsirrtümer nur dann auftauchen, wenn die Wirtschaftssubjekte überrascht werden (z.B. von zeitinkonsistenter Wirtschaftspolitik) und dass die Fehler nicht systematisch sind, d.h. die Erwartungsirrtümer einen Durchschnittswert von Null haben.

Angebot und Nachfrage werden durch vollkommen flexible Preise jederzeit und sofort zum Ausgleich gebracht, was zu einer beständigen Markträumung führt. Hierin drückt sich die Annahme der inhärenten Stabilität des marktwirtschaftlichen Systems aus, welche kennzeichnend für die auf der Neoklassik aufbauenden Theorien ist. In der NKM sind die Märkte - im Unterschied zum Monetarismus - aber nicht nur lang-, sondern auch kurzfristig ständig geräumt. Das Gleichgewicht wird bei Störungen immer unmittelbar wieder hergestellt, die Preise reagieren ohne Verzögerung, die Wirtschaft befindet sich nie in einem Ungleichgewichtszustand. Da die rationalen Erwartungen nicht wie die adaptiven graduell angeglichen werden, gibt es keine Anpassungszeiten, sondern Sprünge von einem Gleichgewichtszustand in den nächsten (vgl. Felderer/Homburg 2003: 241). Auch Konjunkturschwankungen werden als Gleichgewichtsphänomene bzw. Prozesse von Gleichgewichtszuständen betrachtet (vgl. Heine/Herr 2003: 297). Der Arbeitsmarkt ist wie die anderen Märkte immer im Gleichgewicht, da völlige Lohnflexibilität unterstellt wird. Jede Form vorhandener Arbeitslosigkeit wird als freiwillig angesehen, als freie Entscheidung zwischen Arbeit und Freizeit (vgl. Söllner 1999: 224).

Eine weitere wichtige Prämisse ist die im vorhergehenden Kapitel bereits beschriebene Quantitätstheorie des Geldes. Zu Abweichungen des Outputs und der Beschäftigung von ihrem natürlichen (Gleichgewichts-)Niveau kommt es aufgrund der oben genannten Annahmen nicht in der kurzen Frist, sondern nur durch Erwartungsirrtümer bzw. nicht antizipierte Politik. Daraus folgt die Angebotskurve, die >Lucas surprise supply function (vgl. Heine/Herr 2003: 297ff). Ein Anstieg der relativen Preise führt annahmegemäß zu einer Erhöhung des Angebots sowohl von Gütern als auch von Arbeit. Da die Wirtschaftssubjekte nicht in der Lage sind, Preisänderungen korrekt in einen Anstieg des allgemeinen und des relativen Preises aufzuteilen (Dekompositionsproblem), 
schwanken Output und Beschäftigung kurzfristig um ihre natürlichen Werte. In Abwesenheit von Erwartungsirrtümern sowie langfristig ist die Angebotskurve vertikal, d.h. auch die um (adaptive) Erwartungen erweiterte Phillipskurve wird aufgegeben (vgl. Ziegler 1998: 206). Die Rolle des Staates wird somit noch weiter eingeschränkt, einzig mikroökonomisch wird ihm noch eine Rolle zuerkannt: in der Stärkung der Anreize für Unternehmen und Haushalte, ihr Angebot zu erhöhen (vgl. Snowdon et al. 2002: 214).

An dieser Stelle setzt die Angebotsökonomie an. Sie stellt - wie der Name schon sagt - die Angebotsseite in das Zentrum der Betrachtung, wobei sie vor allem auf dem Say'schen Gesetz und der Schumpeter'schen Analyse des innovativen Unternehmers beruht. Mit dem Say'schen Gesetz argumentieren die Angebotstheoretiker - in Übereinstimmung mit der oben dargestellten Annahme der beständigen Markträumung - dass sich von der Nachfrageseite her keine (dauerhaften ${ }^{58}$ ) Probleme ergeben, der Expansion des Angebots somit von hier keine Grenzen gesetzt sind (vgl. Flassbeck 1982: 80ff). Die bestehenden Probleme sind infolgedessen auf der Angebotsseite zu suchen: Marktkräfte müssen entfesselt und Anreize gesetzt werden. Dies bedeutet nicht, dass die Angebotsökonomie von Ungleichgewichten ausgeht, sie konzentriert sich vielmehr auf die Beeinflussung des Wachstums, nicht der Konjunktur (vgl. Sievert 1982: 55).

Mit Schumpeter (1926) argumentieren die Angebotsökonomen, dass die Unternehmer die eigentlichen Motoren der Wirtschaft sind und nicht nur - wie bei Keynes - passiv die Nachfrage befriedigen (vgl. Kromphardt 2004: 226). Vielmehr schaffen sie durch vielfältige Innovationen neue Angebote, welche wiederum latente Bedürfnisse wecken, die Sättigungserscheinungen auf alten Märkten kompensieren und damit langfristig für Wirtschaftswachstum sorgen (vgl. Pätzold 1998: 381). Wichtiger Anreiz für die Unternehmer sind die sogenannten Pioniergewinne: Mit einer Innovation kann so lange ein zusätzlicher Gewinn erzielt werden, wie diese Innovation von der Konkurrenz noch nicht kopiert bzw. imitiert wird, der >dynamische Unternehmer s somit eine (temporäre) Monopolstellung innehat. Durch die Möglichkeit der Konkurrenz nachzuziehen, entsteht dann wiederum der Anreiz, nicht beim Erreichten stehen zu bleiben, sondern weiter innovativ zu sein. Die Entwicklung kapitalistischer Wirtschaftssysteme wird aus dieser Sichtweise durch erfolgreiche Innovationen vorangetrieben (vgl. Kromphardt 2004: 227), in den Worten Schumpeters (1943: 13) einem >Prozeß der schöpferischen Zerstö-

58 Nach Sievert (1982: 45) bestreiten Angebotsökonomen nicht die Existenz eines Nachfragemangels, allerdings dessen latente Präsenz bzw. die prinzipielle Instabilität des marktwirtschaftlichen Systems. 
rungく. Insgesamt gehen die Angebotsökonomen davon aus, dass den Faktoren, die das potentielle Angebot bestimmen, mehr Aufmerksamkeit gewidmet werden muss: Kapitalakkumulation, technischer Fortschritt, Verbesserungen der Qualität der Beschäftigten, Freiheit von regulierenden Eingriffen und Vergrößerung der persönlichen Anreize (vgl. Feldstein 1986: 26).

\section{Staatsaufgaben}

Wie schon im Monetarismus wird dem Staat, von der Annahme der inhärenten Stabilität des marktwirtschaftlichen Systems ausgehend, keine bedeutende Rolle zugeschrieben. Eine kurzfristige, diskretionäre Beeinflussung der Konjunktur wird hier noch vehementer abgelehnt, da diese unter den getroffenen Annahmen - v.a. von rationalen Erwartungen vollkommen wirkungslos ist. Stattdessen liegt das Augenmerk auf der Förderung des Wachstums. Perspektive ist somit nicht in erster Linie die kurze, sondern die mittlere bis lange Frist (vgl. Sievert 1982: 48). ${ }^{59}$ Und auf diese bezogen kann der Staat dann auch eingreifen, erhält eine deutlich stärkere Rolle als im Monetarismus: Die Angebotsseite kann vom Staat beeinflusst werden, indem dieser zum einen den Wettbewerb schützt und fördert, um die Marktkräfte zu stärken, zum anderen Anreize setzt, welche die Leistungsbereitschaft erhöhen. Diese offensive Marktpolitik wird auf der Grundlage einer verstetigten Geld- und Finanzpolitik (um keine destabilisierenden Impulse zu geben) durchgeführt, es geht demnach vor allem um mikroökonomisch ausgerichtete Politik (vgl. Pätzold 1998: 377). Mit der Förderung der Angebotsseite werden die Voraussetzungen für Innovationen, eine höhere Produktivität und eine bessere Rentabilität von Investitionen geschaffen - den Voraussetzungen für mehr Wachstum, Beschäftigung und Wettbewerbsfähigkeit.

\section{Allokation}

Im Bereich der Allokation wird dem Staat ein breites Aufgabenfeld zugeschrieben. Wettbewerb ist sowohl eine unabdingbare Voraussetzung für die inhärente Stabilität des marktwirtschaftlichen Systems und die beständige Markträumung als auch zentral für den Prozess der schöpferischen Zerstörung. ${ }^{60}$ Daher muss er sowohl geschützt wie gefördert

59 Die Angebotspolitik kann allerdings auch kurzfristig schon positive Auswirkungen haben, indem sie über eine Verbesserung der Erwartungen die Investitionsbereitschaft erhöht (vgl. Sievert 1982: 48).

60 Ausführlicher zur Bedeutung und Funktion des Wettbewerbs vgl. Pätzold 1998: $397 \mathrm{ff}$. 
werden. Der Schutz des Wettbewerbs erfolgt über - hier nicht weiter zu beschreibende - Ordnungspolitik (Kartellverbot, Fusionskontrolle etc.). Bei der Förderung des Wettbewerbs besteht die staatliche Aufgabe zum einen darin, sich >aktiv` zurückzuziehen: Bürokratie soll abgebaut, Regelungen vereinfacht und reduziert, Strukturreformen durchgeführt werden. Im Mittelpunkt steht das Ziel, Investitionen als wichtiges Element im Prozess der schöpferischen Zerstörung zu erleichtern, indem z.B. die Genehmigungsverfahren vereinfacht und institutionelle Investitionshemmnisse abgebaut werden (vgl. Kromphardt 2004: 232). Weiterhin sollen auf diese Weise die Märkte flexibilisiert und insbesondere die Mobilität der Arbeitskräfte gefördert werden (vgl. Schatz 1988: 197).

Zur >Entfesselung der gefesselten Marktkräfteく gehört es weiterhin, neue Märkte für den Wettbewerb zu öffnen. Hierbei handelt es sich vor allem um Märkte für Güter und Dienstleistungen, die bisher (überwiegend) in staatlicher Hand waren, insbesondere netzgebundene Dienstleistungen, öffentliche Unternehmen etc. Diese sollen so weit wie möglich privatisiert werden, um auch in diesen Bereichen die innovativen, Schumpeter'schen Unternehmer zum Zuge kommen zu lassen (vgl. Kromphardt 2004: 229). Subventionen werden abgelehnt, da sie die Anreiz- und Lenkungsfunktionen des Marktes ausschalten und durch den Erhalt nicht wettbewerbsfähiger Unternehmen den Strukturwandel bzw. den Prozess der schöpferischen Zerstörung behindern. Somit führen Subventionen zu einer Verlangsamung des Wachstums, durch derartige Maßnahmen gehen insgesamt mehr Arbeitsplätze verloren als geschützt werden (vgl. Fees/Tibitanzl 1997: 144). Schließlich fördert auch der Freihandel den Wettbewerb und ist daher zu intensivieren (vgl. Sievert 1982: 41). Deregulierung, Privatisierung und Intensivierung des Freihandels können unter dem Stichwort >offensive Marktpolitikı zusammengefasst werden (vgl. Pätzold 1998: 397).

Eine weitere allokationspolitische Aufgabe des Staates besteht in der Bereitstellung öffentlicher Güter mit allokativer Funktion, ebenfalls mit dem Ziel, das Wachstum zu fördern (vgl. Pätzold 1998: 234). Dazu zählen vor allem solche Güter, die als Grundlage für die wirtschaftliche Entwicklung angesehen werden können, insbesondere Infrastruktur sowie Forschung und Entwicklung. Letztere sollen - mit Ausnahme der Grundlagenforschung - jedoch hauptsächlich indirekt gefördert werden, d.h. über eine Unterstützung der Eigenkapitalbildung bzw. eine geringere Gewinnbesteuerung, da der Staat nicht wissen kann, in welchen Bereichen die Forschung lohnend ist (vgl. Kaufer 1982: 200f). Auch im Bereich Bildung soll der Staat tätig bleiben bzw. seine Tätigkeit ausbauen, um den Unternehmen qualifizierte Arbeitskräfte zur Verfügung zu stellen (vgl. Sievert 1982: 41). Diese Tätigkeiten zielen ebenfalls auf ei- 
ne Verbesserung der Angebotsseite der Wirtschaft, neben dem Wachstumsziel spielt hier auch die internationale Wettbewerbsfähigkeit eine wichtige Rolle.

\section{Distribution}

Unverfälschte Allokation sorgt - so die Annahme - für eine gerechte Verteilung, weshalb eine staatliche Sekundärdistribution als nicht notwendig erachtet wird. Der Staat kann jedoch über Bildung und Qualifizierung die Primärverteilung beeinflussen, indem er die Chancen der Menschen auf dem Arbeitsmarkt verbessert (vgl. Fees/Tibitanzl 1997: 142). Eine über die Herstellung von Chancengleichheit hinausgehende staatliche Umverteilung wird als schädlich bezeichnet, da sie Anreize verringert oder sogar Fehlanreize hervorruft (vgl. Kromphardt 2004: 229). So wird beispielsweise der Anreiz eine Arbeit aufzunehmen durch $\mathrm{zu}$ hohe Sozialtransfers verringert. Anreizprobleme entstehen nicht nur auf der Leistungs-, sondern auch der Finanzierungsseite: Hohe Sozialabgaben mindern den Arbeitsanreiz bereits Beschäftigter (vgl. ebenda: 233), Unternehmer werden durch zu hohe Steuern und Abgaben daran gehindert, innovativ zu sein, da ihre Pioniergewinne auf diese Weise dezimiert werden (vgl. Pätzold 1998: 381).

In diesem Zusammenhang ist auch die sogenannte Laffer-Kurve zu nennen. Sie drückt aus, dass die Steuersätze nicht zu hoch sein dürfen, weil $\mathrm{ab}$ einem bestimmten Punkt die Zahlungswiderstände zunehmen und die Fehlanreize so hoch werden, dass negative Wachstumseffekte und eine Flucht in die Schattenwirtschaft die Folge sind, wodurch im Endeffekt auch das Gesamtaufkommen an Steuern und Leistungen zurückgeht. So wird begründet, dass Steuersenkungen eine Erhöhung des Steueraufkommens zur Folge haben können (vgl. Pätzold 1998: 382). Diese Argumentation ist auch auf Sozialabgaben übertragbar, weshalb sie über eine stärkere Betonung des Äquivalenzprinzips im Verhältnis zum Solidarprinzip in den Sozialversicherungen sowie eine Verstärkung der privaten Vorsorge gesenkt werden sollen (vgl. Milbradt 1982: 132), um auf diese Weise die Fehlanreize für Arbeit, Sparen und Investieren zu beseitigen und das Wachstum zu fördern (vgl. Pätzold 1998: 383). Somit ist die einzige distributive Aufgabe des Staates die Verbesserung der Lage der Ärmsten. Als Instrument werden hier die - den Marktmechanismus am wenigsten verfälschenden - direkten Transferleistungen empfohlen, öffentliche Güter mit distributiver Funktion werden abgelehnt (vgl. Milbradt 1982: 129f). 


\section{Stabilisierung}

Grundsätzlich ist staatliche Stabilisierungspolitik unter der Annahme einer inhärent stabilen Wirtschaft unnötig. Mit der Aufnahme der rationalen Erwartungshypothese zeigt die Stabilisierungspolitik auch in der kurzen Frist keine Wirkung. Die Wirtschaftssubjekte sehen die staatliche Politik voraus und reagieren entsprechend. Die einzige Möglichkeit, die dem Staat zur Beeinflussung der realen Größen verbleibt, ist die Erzeugung von Erwartungsirrtümern über die Geldpolitik. In diesem Fall kann es dazu kommen, dass die Wirtschaftssubjekte einen Anstieg des allgemeinen Preisniveaus mit einem Anstieg der Nachfrage speziell nach ihrem Produkt verwechseln und daraufhin ihr Angebot ausdehnen (vgl. Felderer/Homburg 2003: 251). Dies merken sie aber nach kurzer Zeit, der Output geht zurück und die Angebotskurve kehrt wieder in ihre Ausgangslage zurück (vgl. Heine/Herr 2003: 297). ${ }^{61}$ Die Reaktion erfolgt im Gegensatz zum Monetarismus - im gleichen Augenblick wie die Erkenntnis, d.h. es gibt keine Anpassungszeiten, die ausgenutzt werden könnten. Auch eine Politik, die langfristig auf Überraschungseffekte angelegt ist, ist zum Scheitern verurteilt, denn bei rationalen Erwartungen beziehen die Wirtschaftssubjekte in ihre Planung mit ein, dass die Politik sie schon öfters getäuscht hat und versuchen, möglichen Überraschungen vorzubeugen, was negative Effekte auf die Wirtschaftsentwicklung haben kann (vgl. Snowdon et al. 2002: 208ff). Da ein stabiles Preisniveau die Voraussetzung für ein funktionsfähiges Marktsystem ist (keine Beeinträchtigung der Lenkungs- bzw. Allokationsfunktion der Preise), fordert die NKM eine regelgebundene und zeitkonsistente, potentialorientierte Geldpolitik, durchgeführt von einer unabhängigen Zentralbank (vgl. Pätzold 1998: 385). ${ }^{62}$

Was die Stabilisierungsmöglichkeiten der Finanzpolitik angeht, so stehen auch hier der kurzfristigen, diskretionären Beeinflussung der Wirtschaft die rationalen Erwartungen der Wirtschaftssubjekte entgegen.

61 Zusammenfassend kann man sagen, dass die Preiselastizität des aggregierten Güterangebotes im Verlauf der Zeit sukzessive abnimmt, sich dem Wert Null nähert. Wenn man nun noch in Betracht zieht, dass der Durchschnittswert der Erwartungsirrtümer Null ist, kann man allgemein von einer preisunelastischen Angebotskurve sprechen, die Geldpolitik hat keinerlei Einfluss auf Output und Beschäftigung. Eine antizipierte Geldpolitik ist super-neutral (vgl. Snowdon et al. 2002: 197ff).

62 Die Unabhängigkeit der Zentralbank wird damit begründet, dass eine diskretionäre Politik immer den Anreiz hat, zeitinkonsistent zu sein, um ein besseres Ergebnis zu erzielen. Da die Privaten dies mit einbeziehen, wird die Erreichung eines Optimums verhindert. Durch die Unabhängigkeit und Regelgebundenheit von Zentralbanken soll diese Situation verbessert werden (vgl. Snowdon et al. 2002: 208ff). 
Versucht der Staat beispielsweise, über eine kreditfinanzierte Erhöhung der Ausgaben die Arbeitslosigkeit zu senken, so antizipieren die Wirtschaftssubjekte eine zukünftige Steuererhöhung und führen ihre Nachfrage in genau dem Umfang der staatlichen Nachfrageausweitung zurück, um für die erwarteten Steuererhöhungen zu sparen, es kommt nicht zu einer Erhöhung der gesamtwirtschaftlichen Nachfrage (vgl. Stiglitz 1989: 728). Dies wird auch als Ricardo-Barro-Äquivalenztheorem bezeichnet (vgl. Söllner 1999: 224). ${ }^{63}$ Eine andere Möglichkeit der Erwartungskompensation (bzw. des Erwartungs-Crowding-Out) ist, dass als Reaktion auf die staatliche Politik von einem Preisanstieg ausgegangen wird und die Preise daher sofort heraufgesetzt werden - die staatliche Politik also wiederum auch kurzfristig keine realen Wirkungen hat (vgl. Kromphardt 2004: 224f). Somit soll auch die Finanzpolitik nicht versuchen, die Konjunktur über diskretionäre Maßnahmen zu stabilisieren. Eine Kompensation der nicht von ihr ausgelösten Schocks ist mit Hilfe staatlicher Stabilisierungspolitik ebenfalls nicht möglich, da sie nicht mehr Informationen und damit auch keine bessere Prognosefähigkeit hat als die anderen Marktteilnehmer (vgl. Felderer/Homburg 2003: 254). Einzig die positive Wirkung der automatischen Stabilisatoren wird anerkannt, diese sollen nicht konterkariert werden. Anstelle einer kurzfristigen Politik wird eine Ausrichtung der Finanzpolitik an der Wachstumsrate des Produktionspotentials, d.h. dem langfristigen Trend der wirtschaftlichen Entwicklung, als sinnvoll angesehen (vgl. Pätzold 1998: 232). Diese ist konjunkturneutral, d.h. weder expansiv noch kontraktiv, und dient der Verstetigung der Erwartungen (vgl. ebenda: 233).

Laut der NKM ist diskretionäre Politik einer regelgebundenen grundsätzlich unterlegen. Dies nicht nur in der - oben angesprochenen Hinsicht, dass eine regelgebundene Politik die effizienten Marktgleichgewichte nicht durch Täuschungen stören kann, während diskretionäre Möglichkeiten immer den Anreiz zeitinkonsistenter Wirtschaftspolitik beinhalten (vgl. Snowdon et al. 2002: 206ff). Es gilt auch, wenn diskretionäre Politik wohlfahrtserhöhend wirken könnte, d.h. nicht grundsätzlich ineffizient ist. Dies basiert auf dem Wechselspiel zwischen Politikund Erwartungsänderungen: Eine bestimmte wirtschaftspolitische Maßnahme kann immer nur in Bezug auf die gegebenen Erwartungen optimal sein. Da diese sich jedoch als Reaktion auf den Plan ändern, muss

$63 »[D]$ ie Art der Finanzierung des Staathaushaltes [ist] irrelevant [...]: unter bestimmten (allerdings sehr restriktiven) Bedingungen würde es für rationale Wirtschaftssubjekte keinen Unterschied machen, ob sie sofort durch Steuern oder später durch (höhere) Steuern zur Finanzierung von Zins und Tilgung für eine früher erfolgte Schuldenaufnahme belastet werden« (Söllner 1999: 224). 
der Plan dies mit einbeziehen - stabile Erwartungen (und somit optimale Maßnahmen) kann es jedoch nur bei einer stabilen, d.h. regelgebundenen Politik geben (vgl. Söllner 1999: 228f).

»[P]olicymakers should follow rules rather than have discretion. The reason that they should not have discretion is not that they are stupid or evil but, rather, that discretion implies selecting the decision which is best, given the current situation. Such behaviour either results in consistent but suboptimal planning or in economic instability.« (Kydland/Prescott 1977: 487)

Daher wird empfohlen, einfache und leicht verständliche Regeln zu wählen (damit ein Abweichen schnell erkannt werden kann) und einen institutionellen Rahmen zu schaffen, der die Änderung der Regeln schwer und zeitaufwändig macht (vgl. ebenda). (Diskretionäre) staatliche Stabilisierungspolitik ist nach diesen Theorien also sowohl unnötig als auch schädlich. Der Fokus liegt auf der langfristigen Verstetigung der Geld- und Fiskalpolitik, kurzfristige Prozesspolitik wird abgelehnt. Daher spricht man teilweise auch nicht von Stabilisierungs-, sondern Stabilitätspolitik (vgl. Ambrosius 1996: 367).

\section{Fazit}

Insgesamt soll die Wirtschaftspolitik den hier dargestellten Theorien folgend regelgebunden verstetigt und die Wachstumskräfte durch eine Förderung der Marktkräfte und Leistungsanreize gestärkt werden. Diskretionäre Politik wirkt nicht nur destabilisierend, sondern kann langfristige Investitionsentscheidungen erschweren und auf diese Weise auch das Wachstum bremsen, im Gegenzug ist eine Stabilisierung der Erwartungen die Grundlage für eine gute wirtschaftliche Entwicklung (vgl. Pätzold 1998: 376).

Hatten bei Keynes noch alle drei staatlichen Interventionsbereiche im Zeichen der Stabilisierung gestanden, so wird nun alles auf die Allokation ausgerichtet. Distributive Maßnahmen dürfen die marktliche A1lokation nicht verzerren und keine Fehlanreize setzen, Stabilisierungspolitik soll keine Erwartungsirrtümer erzeugen. Eine gut funktionierende wettbewerbliche Allokation verbunden mit einer Zurückhaltung des Staates in den anderen beiden Bereichen ersetzt auch eine staatliche Distributions- noch Stabilisierungspolitik: Instabilitäten entstehen annahmegemäß nur durch eine mangelnde Funktionsfähigkeit des Wettbewerbs oder staatliche Eingriffe, was auf diese Weise vermieden wird (vgl. Pätzold 1998: 259). Die Förderung des Wettbewerbs im Rahmen der Allokationspolitik fördert die Anpassungsfähigkeit der Wirtschaft und redu- 
ziert auf diese Weise konjunkturelle Schwankungen. Angebotspolitik stärkt die wirtschaftliche Dynamik, verringert die Volatilität von Output und Beschäftigung und macht so Ungleichgewichte unwahrscheinlicher (vgl. SVR 1981: Ziff. 301). Folglich könnte die Allokationspolitik als einzig sinnvolle - Stabilisierungspolitik bezeichnet werden.

Entsprechend soll der Staat neben der mikroökonomischen Deregulierung der Märkte auf der makroökonomischen Ebene eine stetige, regelgebundene Politik verfolgen und die Staatsanteile reduzieren, um die Belastung für Haushalte und Unternehmen zu verringern und ihre Erwartungen zu stabilisieren (vgl. Schatz 1988: 206). In diesem Sinne soll auch der Staatshaushalt verkleinert werden und insgesamt nur so groß sein, wie allokationspolitisch erwünscht, ${ }^{64}$ Stabilisierungsaspekte sollen außer acht bleiben. Die Ausrichtung am Produktionspotential besagt dann, dass die über diesen sogenannten Basishaushalt ermittelten Staatsausgaben-, Steuer- und Defizitquoten mit der gleichen Rate wachsen sollen wie das Produktionspotential (vgl. Pätzold 1998: 252f). Der Haushalt soll insgesamt konjunkturneutral sein, aber wachstumsfördernd ausgerichtet (vgl. ebenda: 391). Letzteres beinhaltet eine Umschichtung von konsumtiven (v.a. Sozialtransfers und Subventionen) zu investiven Ausgaben, der Staat soll insbesondere seine Ausgaben im Bereich Bildung und Infrastruktur steigern. Eine Verringerung des Budgetdefizits wird empfohlen, weil die staatliche Kreditaufnahme die Kapitalmärkte belastet (Crowding-Out) und die Wirtschaftssubjekte verunsichert (vgl. Kromphardt 2004: 229): »Staatsdefizite absorbieren einen großen Teil der privaten Kapitalbildung und führen dazu, daß die Zinsen, Preise und Wechselkurse für privates Wachstum ungünstiger sind, als sie es sein müßten« (SVR 1981: Ziff. 299). Hierbei geht es insbesondere um den Rückbau des strukturellen Defizits durch Ausgabenkürzungen (vgl. Milbradt 1982: 135f). Insgesamt soll der Staatssektor zugunsten der privaten Wirtschaft und privaten Initiative zurückgebaut werden, sowohl was den Haushalt als auch was die sonstigen Eingriffe in die Wirtschaft angeht, um auf diese Weise den Spielraum für Private zu erhöhen.

64 Hierbei geht es v.a. um die Frage, welche öffentlichen Güter der Staat bereitstellen soll (vgl. Pätzold 1998: 250). 


\section{Synopse der drei idealtypischen Staatsverständnisse}

Als Abschluss dieses ersten Theorieteils sollen die drei entwickelten idealtypischen Staatsverständnisse kurz vergleichend betrachtet werden. Dies erfolgt zum einen anhand der grundsätzlichen Einstellungen gegenüber dem Staat bzw. Markt, zum anderen mit Blick auf die Aufgaben, die dem Staat in den drei Bereichen Allokation, Distribution und Stabilisierung zugeschrieben werden.

Was die grundlegenden Einstellungen angeht, so lassen sich zwei der Theorien den eingangs beschriebenen liberalen Staatsverständnissen zuordnen: Der Monetarismus sowie die NKM/Angebotsökonomie betrachten den Markt als inhärent stabil und weisen dem Staat entsprechend eine geringe Rolle zu. Staatliche Interventionen werden zusätzlich abgelehnt, weil die beiden Theorien davon ausgehen, dass diese wirkungslos oder, z.B. aufgrund von lags, schädlich sind. Der Monetarismus geht noch einen Schritt weiter, der staatliche Rückzug aus der Wirtschaft wird - über die wirtschaftstheoretische Fundierung hinaus - auch ethisch, mit der Freiheit der Individuen, begründet und damit zu einem eigenständigen Ziel. Das Keynes'sche Staatsverständnis ist hingegen eindeutig bei den interventionistischen Vorstellungen einzuordnen, der Markt wird als inhärent instabil und schwankungsanfällig angesehen, mit einer Tendenz zu Unterbeschäftigung, weshalb dem Staat eine bedeutende Rolle zukommt.

Beim vergleichenden Blick auf die Staatsaufgaben, welche die Theorien in den drei Interventionsbereichen nennen, zeigt sich folgendes Bild: Im Bereich Allokation werden Beihilfen nur in der Keynes'schen Theorie geduldet, sofern sie aus politischen, sozialen und industriellen Erwägungen gewährt werden, nicht für die Förderung von Exporten. Die beiden anderen Theorien lehnen Subventionen ab, da sie den Wettbewerb verzerren und die Flexibilität hemmen, die NKM/Angebotsökonomie führt überdies die Behinderung des Strukturwandels bzw. des Prozesses der schöpferischen Zerstörung sowie die Belastung des Staatshaushalts als Ablehnungsgründe an. Öffentliche Güter mit allokativer Funktion werden bei Keynes zur Stabilisierung der Nachfrage empfohlen, der NKM/Angebotsökonomie folgend sind sie eine wichtige Grundlage für die (privat-)wirtschaftliche Entwicklung, nur zu diesem Zweck wird eine staatliche Bereitstellung gewünscht. Im Monetarismus sollen sie hingegen nur dann vom Staat finanziert (und möglichst privat produziert) werden, wenn sie unentbehrlich sind.

Im Bereich Distribution steht Keynes den Sozialausgaben sowie den öffentlichen Gütern mit distributiver Funktion positiv gegenüber, da sie den Konsum bzw. die Investitionen stabilisieren. Monetaristen und 
NKM/Angebotsökonomen haben eine andere Position, sie wollen die Sozialausgaben senken, erstere generell, letztere durch einen Umbau der Sozialversicherungssysteme, der die Anreize für Beschäftigung erhöht. Öffentliche Güter mit distributiver Funktion werden jeweils abgelehnt, wobei die NKM/Angebotsökonomie strikter ist und nur Geldleistungen für sinnvoll hält, während der Monetarismus bei ausgeprägten positiven externen Effekten eine staatliche Finanzierung dieser Güter befürwortet.

Was die Stabilisierungsaufgaben des Staates angeht, spricht Keynes sich für eine (durchaus diskretionäre) Stabilisierung sowohl in der kurzen wie in der langen Frist aus. Die anderen beiden Theorien setzen indes auf eine regelgeleitete Stabilisierung durch eine verstetigte Finanzpolitik, aufgrund der negativen Auswirkungen einer diskretionären Politik sowie - bei der NKM/Angebotsökonomie - wegen der grundsätzlichen Überlegenheit einer regelgeleiteten gegenüber einer diskretionären Politik. Das Instrument der automatischen Stabilisatoren wird nur von der monetaristischen Theorie abgelehnt, die NKM/Angebotsökonomie unterstützt ihren Einsatz bedingt, d.h. nur dann, wenn das Ziel des Haushaltsausgleichs nicht gefährdet wird. Der Keynes'schen Theorie folgend fällt auch diese Bedingung, automatische Stabilisatoren werden uneingeschränkt begrüßt.

Zusammenfassend kann man festhalten, dass die Theorien sich in ihrer grundsätzlichen Einstellung gegenüber Staat und Markt unterscheiden: Die Monetaristen stehen dem Staat am kritischsten gegenüber und sehen den Markt sehr positiv, die Keynes'sche Theorie stellt das andere Extrem dar. Dementsprechend setzen sie hinsichtlich der Staatsaufgaben unterschiedliche Schwerpunkte: Bei Keynes steht die Stabilisierung im Zentrum, für die auch die Distribution und Allokation eingesetzt werden sollen, bei den anderen Wirtschaftstheorien geht es hauptsächlich um Allokation, in die Distribution und Stabilisierung soll der Staat sich eher nicht einmischen.

\subsection{Entwicklung möglicher Strategien zur Beeinflussung von Handlungsfähigkeit}

Vor dem Hintergrund der gerade entwickelten idealtypischen Staatsverständnisse wird nun die erste Forschungsfrage theoretisch unterfüttert: Auf welche Weise sollte mit den europäischen Vorgaben Einfluss auf die nationalstaatliche Handlungsfähigkeit genommen werden, durch einen Ausbau oder eine Einschränkung von Interventionsmöglichkeiten? Wie bereits in Kapitel 2.1 angesprochen gehe ich davon aus, dass die Wahl zwischen den beiden Alternativen davon abhängt, welches Staatsver- 
ständnis den Vorgaben zugrunde liegt, was im Folgenden genauer erläutert werden soll. Ziel dieses Kapitels ist es demnach, auf verschiedenen Staatsverständnissen basierende Strategien zur Beeinflussung von Handlungsfähigkeit herauszuarbeiten. Auf dieser Grundlage kann im Empirieteil untersucht werden, welche dieser Strategien zu welchem Zeitpunkt mit den europäischen Vorgaben verfolgt wurde.

\section{Hinführung}

Obgleich die Strategien sich auf die europäischen Vorgaben beziehen sollen, bietet sich für ihre Entwicklung in erster Linie ein Rückgriff auf die Globalisierungsforschung an: Erstens beschäftigt sich diese stärker als die Forschung zur europäischen Integration damit, wie die wirtschaftspolitischen Interventionsmöglichkeiten der Nationalstaaten durch supranationale Prozesse beeinflusst werden. Damit ist die Beziehung zwischen Interventionsmöglichkeiten, Handlungsfähigkeit und Staatsverständnis ein zentrales Thema, zu dem es verschiedene Positionen gibt - aus denen wiederum unterschiedliche Strategien ableitbar sind. Zum zweiten handelt es sich bei der Globalisierung um ähnliche Prozesse, wie sie auch (bzw. sogar in besonderem Maße) innerhalb der EU anzutreffen sind. Dies gilt v.a. für die Einschränkung von Interventionsmöglichkeiten durch eine zunehmende wirtschaftliche Verflechtung und ihre mögliche Wiedergewinnung durch eine supranationale politische $\mathrm{Zu}$ sammenarbeit. Beide Prozesse - in der Globalisierungsforschung gefasst unter `ökonomische` und >politische`Globalisierung - spielen für die Strategien zur Beeinflussung staatlicher Handlungsfähigkeit eine wesentliche Rolle. Deshalb, aber auch weil sie nicht immer ganz eindeutig definiert sind, werden sie vor der Ableitung der Strategien kurz erläutert.

\section{Einleitende Begriffsbestimmungen: Ökonomische und politische Globalisierung}

Unter ökonomische Globalisierung wird die zunehmende Verflechtung nationaler Märkte verstanden. Die daraus resultierende Mobilität von Waren, Dienstleistungen, Kapital, Arbeitskräften etc. führt zu einer »zunehmende[n] Ausdehnung und Intensität ökonomischer Austauschbeziehungen« (Bernauer 2000: 28). In der Forschung überwiegt die Ansicht, dass die ökonomische Globalisierung zu einer Einschränkung nationalstaatlicher Interventionsmöglichkeiten führt. Die Bezeichnung ökonomische Globalisierung darf nicht darüber hinwegtäuschen, dass ihre Ursachen neben Faktoren wie der technologischen Entwicklung und der damit einhergehenden Senkung von Informations- und Transaktions- 
kosten (vgl. Heise 2005: 312) auch im politischen Bereich zu finden sind: Die Politik schafft - über den Abbau von tarifären und nicht-tarifären Handelshemmnissen - die Vorbedingungen für die zunehmende wirtschaftliche Verflechtung, beispielsweise durch Abkommen wie GATS oder TRIPS. Weiterhin setzt sie wichtige Rahmenbedingungen, um die Globalisierung abzusichern, ein Beispiel hierfür ist das Schiedsgericht der Welthandelsorganisation.

Der wirtschaftlich am stärksten verflochtene Handelsraum der Welt ist die EU (vgl. Risse 1999: 4; Hirst/Thompson 2002: 256), da hier »traditionelle nationalstaatliche Hindernisse für grenzüberschreitende wirtschaftliche Aktivitäten am stärksten abgebaut wurden und somit die wirtschaftliche Verflechtung mit den europäischen Partnerstaaten verhältnismäßig weit vorangeschritten ist« (Scherrer 2000: 51). Zusätzlich ist die Verflechtung gut abgesichert, was z.B. an der vertraglichen Festlegung der Binnenmarktfreiheiten deutlich wird. Daher sprechen einige Autoren davon, dass die EU für ihre Mitgliedstaaten der wichtigste Teil der Globalisierung ist (vgl. z.B. Schulte 2001: 23).

Unter dem Begriff politische Globalisierung werden diejenigen politischen Kooperationen auf supranationaler Ebene verstanden, welche darüber hinausgehen, die ökonomische Globalisierung zu ermöglichen oder abzusichern. Eine solche Zusammenarbeit kann in unterschiedlichen Bereichen (z.B. Umwelt und Kultur) stattfinden, die Arbeit beschränkt sich entsprechend der Forschungsfragen auf die Wirtschaftspolitik. In diesem Sinne kann politische Globalisierung zum einen unabhängig von der ökonomischen in supranationalen Kooperationen zur Lösung grenzüberschreitender Probleme oder zur Erreichung gemeinsamer Ziele bestehen. Zum anderen ist sie auch als Reaktion auf die wirtschaftliche Verflechtung denkbar: Sie kann darauf abzielen, diese voranzutreiben oder als Region in der globalisierten Welt zu bestehen, z.B. durch gemeinsame Infrastrukturprojekte zur Erhöhung der Wettbewerbsfähigkeit. Ebenso kann politische Globalisierung das Ziel haben, der ökonomischen etwas entgegen zu setzen, z.B. Maßnahmen, um die in Folge der wirtschaftlichen Verflechtung verlorenen Interventionsmöglichkeiten wieder zu erlangen. Letzteres kann auch dann der Fall sein, wenn die Interventionsmöglichkeiten faktisch nicht bzw. nicht im wahrgenommenen Maße eingeschränkt wurden, wenn es sich bei den einschränkenden Faktoren um >soziale Konstruktionen rung ). Dies ist damit zu erklären, dass $»$ it is the ideas that actors hold about the context in which they find themselves rather than the context itself which informs the way in which actors behave« (Hay/Rosamond 
2002: $148^{65}$ ). Im Gegensatz zur ökonomischen kann die politische Globalisierung die Interventionsmöglichkeiten der Nationalstaaten somit nicht nur einschränken, sondern auch ausbauen.

Wie die ökonomische ist auch die politische Globalisierung in bestimmten Weltregionen weiter vorangeschritten, dies ist insbesondere wieder für die EU der Fall. Dabei reicht sie von einer weichen Koordination in Form von Absprachen oder unverbindlichen Leitlinien bis hin zu einer Übertragung von Kompetenzen an supranationale Organe.

\section{Einleitende Bemerkungen zu den drei Strategien}

Zur Ableitung der Strategien wird im Folgenden jener Bereich der Globalisierungsforschung herangezogen, der sich hauptsächlich mit den Auswirkungen der zunehmenden wirtschaftlichen Verflechtung auf die nationalen Interventionsmöglichkeiten beschäftigt. ${ }^{66}$ Dies ist insofern relevant, als dass hier Aussagen dazu gemacht werden, wie diese Verflechtung - die ja in der EU besonders weit vorangeschritten ist - sich auf die drei Interventionsbereiche Allokation, Distribution und Stabilisierung bzw. auf die Politikfelder Beihilfen, öffentliche Güter, Sozialpolitik und Stabilisierung auswirkt und wie die Auswirkungen dieser Verflechtungen bewertet werden. Hierzu gibt es verschiedene Positionen, aus denen sich wiederum unterschiedliche Strategien ableiten lassen. Drei Positionen bieten sich besonders an: Kurz gesagt gehen >Globalisierungskritiker davon aus, dass die Globalisierung die (national-)staatlichen Interventionsmöglichkeiten einschränkt und damit die Handlungsfähigkeit der Staaten schwächt. Im Gegensatz dazu führt bei den >Globalisierungsbefürwortern` die Einschränkung der Interventionsmöglichkeiten zu einer Stärkung von Handlungsfähigkeit. Letzteres wird auch von einer dritten Position, den >Revisionisten`, so gesehen, sie argumentieren allerdings zusätzlich, dass die Staaten dies bewusst genutzt und Globali-

$65 » \mathrm{Zu}$ einem großen Teil handelt es sich [...] bei der >Globalisierung ökonomischen Bereich um einen Mythos, allerdings einen sehr wirkungsmächtigen. Obwohl der neoliberale Globalisierungsdiskurs nur sehr wenige und überdies widersprüchliche Korrelate in der Praxis hat, scheint er dennoch fast das Definitionsmonopol für die Behandlung weltweiter wie auch nationaler Wirtschaftsprobleme erreicht zu haben« (Risse 1999: 5).

66 Es wird nur der Teil der Forschung einbezogen, bei dem es um die für die Arbeit relevanten Gebiete geht: Ausgabenpolitik und die drei Bereiche Allokation, Distribution und Stabilisierung. Dies bedeutet u.a. einen weitgehenden Verzicht auf den Aspekt der deregulierenden Auswirkungen der Globalisierung. Auch die Frage wirtschaftspolitischer Konvergenz durch Globalisierung ist für diese Arbeit nicht relevant. 
sierung zur Lösung ihrer internen Probleme >gemacht « hätten. ${ }^{67}$ Alle Positionen $^{68}$ stimmen demnach darin überein, dass staatliche Interventionsmöglichkeiten durch eine zunehmende wirtschaftliche Verflechtung eingeschränkt werden. Der Hauptdissens liegt darin, ob diese Einschränkung die Handlungsfähigkeit stärkt oder schwächt - was mit ihren jeweils unterschiedlichen Staatsverständnissen zu erklären ist. Überdies wird die Rolle der Staaten im Globalisierungsprozess verschieden eingeschätzt. Dies wird im Folgenden genauer, vor allem mit Blick auf die drei Interventionsbereiche, herausgearbeitet, um auf dieser Grundlage abzuleiten, welches Staatsverständnis mit welcher Strategie zur Stärkung von Handlungsfähigkeit einhergeht. Die Argumente der drei Positionen werden dabei nur kurz skizziert und nicht diskutiert. ${ }^{69}$

Da die mit den europäischen Vorgaben verfolgbaren Strategien nicht nur als Reaktion oder in Bezug auf die ökonomische Globalisierung gesehen werden sollen, werden die aus der Globalisierungsforschung abgeleiteten Strategien im letzten Schritt zum einen abstrahiert bzw. verallgemeinert, um so auch auf Situationen anwendbar zu sein, in denen die Einschränkungen der Interventionsmöglichkeiten von anderen Faktoren als der wirtschaftlichen Verflechtung verursacht werden, z.B. der demographischen Entwicklung oder der Konjunkturlage. Zum anderen wer-

67 Einheitliche Bezeichnungen für die Positionen gibt es in der Forschung nicht. Dies ist problematisch, weil durch die Wahl bestimmter Begriffe immer auch Assoziationen geweckt werden. Die Arbeit folgt mit der Wahl der Bezeichnungen Genschel (2003), der allerdings die ersten beiden Positionen unter dem Begriff Globalisierungstheoretiker zusammenfasst. Jede Position umfasst nur das, was in diesem Kapitel zu ihnen ausgeführt wird, so ist mit >Globalisierungskritikern « z.B. nicht die globalisierungskritische Bewegung als ganzes gemeint - was aufgrund der Heterogenität der Bewegung auch gar nicht möglich wäre.

68 Weitere bekannte Positionen wurden nicht einbezogen, da sie für die Entwicklung von Strategien nicht geeignet sind: Die Vorgaben waren immer darauf ausgerichtet, Interventionsmöglichkeiten zu beeinflussen, insofern macht es keinen Sinn, die sog. >skeptische Position< (vgl. Hirst/Thompson 1996, Garrett 1998) einzubeziehen, die argumentiert, dass nationalstaatliche Interventionsmöglichkeiten durch die Globalisierung nicht beeinflusst werden. Vertreter der >Kompensationsthese (vgl. bspw. Rodrik 1996) gehen davon aus, dass mit zunehmender Offenheit von Volkswirtschaften auch die Staatsausgaben anwachsen, um die gestiegenen Unsicherheiten bzw. Ungleichheiten zu kompensieren. Hinter dieser Position steckt jedoch kein Staatsverständnis, anhand dessen der Globalisierungsprozess (und damit das Verhältnis von Interventionsmöglichkeiten und Handlungsfähigkeit) bewertet wird, hieraus lässt sich daher ebenfalls keine Strategie ableiten.

69 Für eine ausführlichere Darstellung bzw. Kritik vgl. bspw. Held et al. 1999; De Vries 2001; Genschel 2003; für die Wohlfahrtsdimension/Sozialausgaben Kumpmann 2005. 
den sie ergänzt um Strategien, die unabhängig von einer vorhergehenden Einschränkung von Interventionsmöglichkeiten darauf gerichtet sind, über eine supranationale Kooperation Interventionsmöglichkeiten einzuschränken oder auszubauen. Hierfür wird zum Teil auch auf die Globalisierungsforschung ergänzende Literatur zurückgegriffen. Dementsprechend werden die jeweiligen Strategien im Folgenden mit einem allgemeineren, sich nicht ausdrücklich auf >Globalisierung ‘ beziehenden Titel als kritische, affirmative und revisionistische Strategie bezeichnet.

\section{Die kritische Strategie}

Die Globalisierungskritiker sehen die ökonomische Globalisierung ${ }^{70}$ als ein Phänomen, das die Interventionsmöglichkeiten der Nationalstaaten verringert und damit ihre Handlungsfähigkeit schwächt: »Die Transnationalisierung der Industrie- und Dienstleistungszweige und die aus ihr folgenden politischen Probleme schränken die Möglichkeit der liberaldemokratisch konstituierten Nationalstaaten ein, eigenbestimmt zu handeln« (Narr/Schubert 1994: 13). Die grundlegende These ist ein negativ bewerteter $>$ Rückzug des Nationalstaates ${ }{ }^{71}$, da dieser in Folge der wirtschaftlichen Verflechtung bestimmte Aufgaben nicht mehr wahrnehmen kann, was eine Schwächung seiner Handlungsfähigkeit bedeutet. Hinsichtlich der in dieser Arbeit zu untersuchenden Politikfelder konzentriert sich die Forschung vor allem auf die distributiven Aufgaben des Staates (vgl. ausführlich Tanzi 2002). So stellt Schulte (2001: 23) fest, dass als Folge der Internationalisierung »der Nationalstaat als bislang dominantes Aktionsfeld der Sozialpolitik sowohl de iure als auch vor allem de facto an Einfluss verliert.« Die Ursachen hierfür werden auf der Einnahmen- wie der Ausgabenseite des Sozialstaates gesehen: Durch die vermehrten (echten oder unechten) Exit-Optionen für mobile Produktionsfaktoren und den dadurch ausgelösten Steuerwettbewerb erodiere die Finanzierungsbasis (vgl. Heise 2005: 307). ${ }^{72}$ Einen Beitrag hierzu leiste, insbesondere bei beitragsfinanzierten Sozialsystemen, auch die steigende Arbeitslosigkeit, für die einige Globalisierungskritiker die Globalisierung - zumindest im Bereich der gering Qualifizierten - (mit)verant-

70 Im Folgenden ist - wenn nicht explizit >politische Globalisierung< geschrieben steht - mit >Globalisierung $<$ immer die ökonomische gemeint.

71 So die deutsche Übersetzung des Buches von Strange (1996): »The retreat of the state«.

72 »Globalization and tax competition are likely to reduce the scope for redistributive policies, especially promoted through progressive taxation « (Tanzi 1997: 24). Für eine ausführliche Darstellung der Diskussion um Globalisierung und Steuerwettbewerb vgl. Genschel 2000. 
wortlich machen (vgl. Narr/Schubert 1994: $75 f f) .{ }^{73}$ Da Sozialpolitik im Standortwettbewerb umdefiniert werde, gerate auch die Ausgabenseite unter Druck. Streeck (2004, o.S.) beschreibt dies folgendermaßen:

»Sozialpolitik, die vorher aus dem Wettbewerb herausgenommen war bzw. dazu diente, dessen Resultate teilweise rückgängig zu machen, wird im Wettbewerbsstaat zum >Standortfaktor<: sie dient nicht mehr der Korrektur, sondern der Akkommodierung von Märkten - weniger der >sozialen Gerechtigkeit`als der Aktivierung und Qualifizierung flexibel einsetzbaren Humankapitals.«

Auch die Richtung der Reformen, besonders die Umstellung der Rentenversicherungen von Umlagefinanzierung auf Kapitaldeckung, wird mit der Globalisierung erklärt: Dies liege - so Huffschmid (2003: 34) - im unmittelbaren Interesse der immer mächtiger werdenden Finanzinvestoren, denen auf diese Weise »Milliardenbeträge zur Verfügung stehen, mit denen sie auf den internationalen Finanzmärkten operieren können [...].« Zusammengefasst führen Globalisierung und Standortwettbewerb, so unter anderem Sinn (1995: 246), dazu, dass die Sicherstellung eines solidarischen Sozialsystems gefährdet wird und die Staaten weniger öffentliche Güter mit distributiver Funktion bereitstellen. ${ }^{74}$

Auch die Stabilisierungsaufgaben der Nationalstaaten werden - folgt man dieser Position - durch die Globalisierung erschwert. So würden der Keynes'schen diskretionären Konjunkturpolitik von zwei Seiten her Grenzen gesetzt: Eine staatlich induzierte Erhöhung der Nachfrage könne nicht mehr auf das Inland begrenzt werden, da sie auch durch Importe gedeckt werden kann. Dies setze die Wirkungsmächtigkeit dieser Politik herab (vgl. Altvater/Mahnkopf 1996: 403). Überdies würde die Defizitfinanzierung schwieriger, weil die Kapitalmarktintegration das Sanktionspotential der Kapitalbesitzer stärke und die Staaten somit bei hohen Budgetdefiziten mit Risikoaufschlägen zu rechnen hätten (vgl. Held et al. 1999: 440; Bernauer 2000: 65).

$73 »$ Mit dem Wettbewerb zwischen Jurisdiktionen werden aber auch weitreichende Befürchtungen verbunden: [...] Der Wettbewerb führe zu Arbeitslosigkeit, die vor allem gering qualifizierte Arbeitskräfte betrifft« (Theurl 1999: 34).

74 » $\mathrm{Zu}$ vermuten ist aber, daß man von einem ungeschützten Wettbewerb der Fiskalsysteme auf die Dauer eine Optimierung der Sozialpolitik nicht erwarten kann « (Sinn 1995: 246). Bzgl. der Bereitstellung öffentlicher Güter argumentiert Sinn (ebenda: 248) folgendermaßen: Öffentliche Güter werden nicht über den Markt erstellt, weil der private Wettbewerb in diesem Fall nicht funktioniert, aus dem gleichen Grund sei auch nicht zu erwarten, dass sie bei einem Wettbewerb der Staaten weiterhin erbracht würden. 
Bei den allokativen Aufgaben wird der Übergang zum >Wettbewerbsstaat` (Hirsch 1995) bzw. >schumpeterianischen Leistungsstaatく (Jessop 2003: 43ff) festgestellt, aber nicht begrüßt: »Die Verschärfung der internationalen Konkurrenz im Zuge der Weltmarktintegration erhöht die Bedeutung der Infrastrukturausstattung und der öffentlichen Dienstleistungen für die Attraktivität der Länder als Investitionsstandorte« (Goldberg 2000: 180). Der Staat solle demnach zunehmend nur mehr öffentliche Güter bereitstellen, die die Wettbewerbsfähigkeit erhöhen, genannt werden unter anderem Bildung und Forschung (vgl. Narr/Schubert 1994: 15). In diesem Bereich blieben dem Staat demnach Aufgaben erhalten.

Zusammenfassend kann man sagen, dass die Globalisierungskritiker von einem interventionistischen - den im vorhergehenden Kapitel erarbeiteten Idealtypen folgend: Keynes'schen - Staatsverständnis ausgehen, dessen Interventionsmöglichkeiten und damit Handlungsfähigkeit durch die Globalisierung eingeschränkt werden. Dies trifft vor allem auf die Bereiche der Stabilisierung und Distribution zu, die bei diesem Staatsverständnis zentral sind. Die Strategie, die in diesem Falle verfolgt würde, wäre zum einen der Versuch, die in Folge der wirtschaftlichen Verflechtung (oder anderer Faktoren) eingeschränkten Interventionsmöglichkeiten durch ein gemeinsames Vorgehen wieder auszuweiten und auf diese Weise die staatliche Handlungsfähigkeit zu stärken. ${ }^{75}$ So kann eine Abstimmung der Konjunkturpolitik in Krisensituationen die >Sickereffekte` einer staatlich induzierten Nachfrageerhöhung minimieren und die Effizienz der auf diese Weise erreichten Stabilisierung erhöhen (vgl. Etxezarreta et al. 2003: 46ff). Ein weiteres Beispiel sind Mindeststandards oder gemeinsam festgelegte Korridore für Sozialleistungen, um die Sozialausgaben zumindest zum Teil aus dem Standortwettbewerb herauszunehmen (vgl. Busch 1998). Eine supranationale Koordinierung kann bei einem Keynes'schen Staatsverständnis aber auch unabhängig von vorhergehenden Einschränkungen einen Ausbau von Interventionsmöglichkeiten zum Ziel haben, indem sie die wirtschaftliche Verflechtung positiv nutzt oder (relativ) unbeeinflusst davon gemeinsame Ziele zu erreichen sucht. Beispiele wären hier die Bereitstellung bestimmter öffentlicher Güter wie strategische Forschung oder transnationale Infrastruktur auf der europäischen Ebene (vgl. Collignon 2003: 137), die Nutzung des größeren Multiplikatoreffekts bei einer gemeinsamen Bekämpfung von Wirtschaftskrisen oder koordinierte Armutsbekämpfungsprogramme (vgl. Wehlau 2006: 70).

75 Eine mögliche Strategie zur Wiedergewinnung der Interventionsmöglichkeiten könnte auch nationaler Protektionismus sein, dies wird jedoch kaum ein Ziel europäischer Vorgaben sein. 


\section{Die affirmative Strategie}

Die Globalisierungsbefürworter folgen den -kritikern in der grundlegenden Annahme, die wirtschaftliche Verflechtung verringere staatliche Interventionsmöglichkeiten. Der wesentliche Unterschied zwischen beiden Positionen besteht darin, dass die beschränkten Interventionsmöglichkeiten hier zu einer Stärkung staatlicher Handlungsfähigkeit führen, nicht zu einer Schwächung. »[S]owohl zunehmender Handel mit Gütern und Dienstleistungen als auch schnelle Reaktionsmöglichkeiten der Kapitalanleger sorgen dafür, daß sich der Anpassungsdruck aufgrund sich schneller ändernder weltwirtschaftlicher Strukturen in den Industrieländern erhöht« (Freytag et al. 1998: 32). Dieser Druck führt nach Caspers (1999: 13) dazu, dass die Wirtschaftspolitik in mancherlei Hinsicht diszipliniert wird, was aber keine Einschränkung staatlicher Handlungsfähigkeit zur Folge hat. Eingeschränkt würden durch die Globalisierung nur die Interventionsmöglichkeiten: Gewisse Politikoptionen bzw. Instrumente stünden nicht mehr zur Verfügung. Dies führe dazu, dass der Staat bestimmte Aufgaben nicht mehr, andere hingegen besser wahrnehmen könne: »Der Zwang zu mehr Rationalität in der Wirtschaftspolitik bedeutet mehr Zwang zu sachgerechtem Handeln, in den Worten des Kapitals mehr Ordnungspolitik, Regelbindung der Wirtschaftspolitik und mehr Angebotspolitik« (Donges/Freytag 2001: 271). Ähnlich argumentiert Donges (1998: 6): In Bezug auf die internen wirtschaftlichen und sozialen Probleme wird die Politik durch die Globalisierung »zu sachgerechtem Handeln [gezwungen], sprich zur konsequenten Ursachentherapie, [Globalisierung] verbaut ihr den vermeintlich einfacheren Weg des Kurierens am Symptom. « Auch hier kommt wieder zur Sprache, dass die Handlungsfähigkeit der Nationalstaaten nicht als geschwächt angesehen wird - im Gegenteil, das Sichtbarmachen der Probleme könne bestimmte Maßnahmen sogar erleichtern,

»wenn es anders nicht gelingt, sklerotische Verkrustungen in der Wirtschaft und in der Gesellschaft aufzulösen und die Politik zu stimulieren, gebotene Strukturreformen einzuleiten und konsequent durchzuführen und damit das Ihrige zu tun, um die Wirtschaft wieder auf einen angemessenen Wachstumspfad bei nachhaltig verbesserten Beschäftigungsmöglichkeiten zu bringen« (Donges/Freytag 1998: 5f).

Im Vergleich der beiden Positionen unterscheiden sich Globalisierungskritiker und -befürworter in einem weiteren wichtigen Punkt: Letztere sehen die Staatstätigkeit als zu hoch an, weshalb sie es begrüßen, wenn durch den Standortwettbewerb »staatliche Leistungen [...] auf das Maß 
zurückgeschrumpft [werden], das für die Aufrechterhaltung einer funktionstüchtigen Marktwirtschaft notwendig ist« (Donges et al. 2003: 110). Die erforderlichen Anpassungen würden im Bereich der Allokation den zu begrüßenden Abbau von Subventionen und im distributiven Bereich die Senkung von Sozialausgaben forcieren (vgl. Caspers 1999: 28) und damit staatliche Handlungsfähigkeit stärken. Letzteres ist auch damit zu erklären, dass die Systeme der sozialen Sicherheit als nicht tragfähig angesehen werden. »Eine wichtige Implikation des Standortwettbewerbs ist also, daß der Verteilungsspielraum der Regierungen, die Möglichkeit zur Redistribution und zur Finanzierung der sozialen Sicherung, eingeschränkt wird« (Siebert 1998: 59).

Hinsichtlich der stabilisierenden Aufgaben des Staates stellen die Globalisierungsbefürworter zwar - mit der gleichen Argumentation wie die -kritiker, der kontrollierenden Funktion der Kapitalmärkte - eine Begrenzung der Interventionsmöglichkeiten fest, werten dies jedoch wiederum nicht negativ (vgl. Siebert 1998: 44f). Diese Entwicklung lässt sich »durchaus dahingehend interpretieren, dass der Nationalstaat weniger Spielraum für Wirtschaftspolitik bekommt, die wenig wirksam und jedenfalls nicht nachhaltig ist« (Donges et al. 2003: 117). Hier spielt auch das Argument des wettbewerblichen Entdeckungsverfahrens hinein: Konjunkturpolitik - soweit sie denn noch möglich ist - soll sich in einem intensiveren Wettbewerb messen, auf der stetigen Suche nach dem effizientesten und stabilsten System (vgl. ebenda: 110).

Die Globalisierung führe jedoch nicht nur zu einem Abbau von Staatstätigkeit, sondern auch zu neuen Aufgaben, vor allem bei der attraktiven Gestaltung des Standorts: »[G]lobalisierter Wettbewerb ist zunehmend auch Wettbewerb der Wirtschaftspolitik um gute Angebotsbedingungen der Wirtschaft« (Donges 2002: 19). Zentrale Aufgaben schreiben die Globalisierungsbefürworter den Staaten im allokativen Bereich zu, in der Sach- und Humankapitalbildung (vgl. Caspers 1999: 14), sowie in der Schaffung günstiger Rahmenbedingungen für Investition und Innovation (vgl. Siebert 1998: 57). Von einer Gefährdung der Finanzierung öffentlicher Güter durch die wirtschaftliche Vernetzung gehen sie nicht aus (vgl. Donges et al. 2003: 110).

Zusammenfassend vertreten die Globalisierungsbefürworter ein liberales, entsprechend der Idealtypen ein monetaristisches oder angebotsökonomisches/NKM, Staatsverständnis: Ordnungs- statt Prozesspolitik, Angebots- statt Nachfragepolitik und regelgebundene statt diskretionäre Politik (vgl. Donges/Freytag 1998: 6). Der Schwerpunkt liegt im Bereich Allokation, distributive und stabilisierende Aufgaben soll (und dem Staatsverständnis folgend: muss) der Staat möglichst nicht bzw. nur begrenzt wahrnehmen. Insofern sehen die Vertreter dieser Position die 
Einschränkung von Interventionsmöglichkeiten durch die Globalisierung insbesondere im Bereich Distribution und Stabilisierung positiv: Dies stärke die Handlungsfähigkeit, weil die Staaten sich auf ihre Kernaufgaben konzentrieren müssen und können. Dem entsprechend bestünde die strategische Reaktion auf eine Einschränkung von Interventionsmöglichkeiten (durch die wirtschaftliche Verflechtung oder andere Ursachen) in einem wohlwollenden Abwarten, da sich auf diese Weise das erwünschte Staatsverständnis quasi von alleine durchsetzt. Eine supranationale Kooperation zum Ausbau von Interventionsmöglichkeiten ist hingegen unwahrscheinlich, denkbar wäre nur ein gemeinsames Vorgehen bei den öffentlichen Gütern mit allokativer Funktion zur attraktiveren Gestaltung des >Standorts Europa .

\section{Die revisionistische Strategie}

Die Revisionisten setzen an dem globalisierungsbefürwortenden Argument an, dass eine Einschränkung staatlicher Interventionsmöglichkeiten zu einer Stärkung von Handlungsfähigkeit führen kann. Sie gehen davon aus, dass die Nationalstaaten sich dies bewusst zu nutze machen, indem sie Globalisierung aktiv planen und vorantreiben. Globalisierung wird bei dieser Position demnach explizit >gemachtı, sie bricht nicht herein. Bezüglich der in dieser Arbeit zu untersuchenden Politikfelder kann man grundsätzlich davon ausgehen, dass »in democracies, the scope of government for fiscal restraint is small due to its responsibility to its electorate, and due to the role of rent-seeking lobbies for supporting political decision-makers as well as for the formulation of economic policy« (Rotte/Zimmermann 1998: 388). Die Globalisierung könne nun als Argument genutzt werden, sich gegenüber den Wählern und Interessengruppen durchzusetzen und unliebsame, nicht-interventionistische Politikentscheidungen zu rechtfertigen (vgl. Vaubel 1986: 48). Man spricht hier auch vom Selbstbindungsmotiv. ${ }^{76}$

Die Folgen einer Selbstbindung über Globalisierung für die nationalstaatlichen Interventionsmöglichkeiten sind die bereits beschriebenen: Die Staaten werden im Standortwettbewerb >gezwungen`, ihre Interven-

76 Neben der hier angesprochenen Public Choice Literatur (u.a. Politische Ökonomie der Reform, vgl. dazu auch Donges/Freytag 2001: 215ff) taucht das Selbstbindungsmotiv auch in der Literatur zu internationalem Recht auf. Dort wird es verwendet, um zu erklären warum Staaten freiwillig Verträge eingehen, die ihre Souveränität beschränken (vgl. bspw. Abbott/Snidal 2000, zur Steigerung von Glaubwürdigkeit durch die Schaffung internationaler Institutionen Hefeker 2003). Dabei geht es allerdings oft darum, dass durch die Verträge andere Staaten, nicht Interessengruppen im Innern der Staaten gebunden werden. 
tionen zurückzunehmen. Hinsichtlich der allokativen und distributiven Aufgaben des Staates lässt sich vor allem bei den Kürzungen der Sozialausgaben das Bild der durch die Globalisierung bzw. den Standortwettbewerb >gebundenen Hände` finden. Dieses Argument könnte auch im Bereich Allokation (Subventionsabbau) eine Rolle spielen. Genschel (2003: 442) nennt überdies Privatisierung als Mittel zur Selbstbindung, was insofern einen Bezug zur Globalisierung hat, als dass Privatisierung durch Globalisierung befördert wird, um vormals staatliche Sektoren für ausländische Anbieter und damit den internationalen Wettbewerb zu öffnen (vgl. Donges et al. 2003: 111). Was die stabilisierende Funktion des Staates angeht, so wird neben der ebenfalls oben dargestellten Wirkungsverminderung im Zuge der wirtschaftlichen Verflechtung auch darauf eingegangen, dass Staaten sich über rechtliche Regelungen oder Institutionen daran hindern, Defizite aufzubauen bzw. zu halten (vgl. Rotte/Zimmermann 1998: 388).

Damit ist ein zweiter Aspekt der Selbstbindung angesprochen: Neben einem Verweis auf die Zwänge der Globalisierung bzw. der wirtschaftlichen Verflechtung kann diese Bindung auch über eine spolitische Globalisierung erfolgen, bei der bestimmte Politikbereiche auf die supranationale Ebene verlagert und somit dem Zugriff der Nationalstaaten - zumindest ein Stück weit - entzogen werden. Hier wird oft die EU als Beispiel genannt: ${ }^{77}$

»By transferring competences to EC/EU regulation, be it the European Commission, be it the Council of Ministers, national governments have thus been able to circumvent serious domestic trouble in negotiating compromises between various interest groups at home which might have had negative consequences for their political ratings « (Rotte/Zimmermann 1998: 390). ${ }^{78}$

Im Rahmen der supranationalen Koordinierung werden rechtlich mehr oder weniger verbindliche Verpflichtungen eingegangen und deren Einhaltung überwacht und sanktioniert (vgl. Abbott/Snidal 2000). Durch den Verweis auf diese Verpflichtungen und die drohenden Sanktionen bei Nichteinhaltung könnten die nationalen Regierungen bestimmte Politiken einfacher durchsetzen. Internationale Abkommen erlauben es somit, die Verantwortung für unliebsame Entscheidungen auf die supra-

77 Andere Beispiele sind monetäre Institutionen wie fixe Wechselkurse und unabhängige Zentralbanken (vgl. Bernhard/Leblang 2002) sowie internationale Organisationen wie der Internationale Währungsfonds, die WTO und die Weltbank (vgl. Hefeker 2003).

78 Wolf (1997: 278) argumentiert, dass die Staaten zu diesem Zweck über supranationale Koordinierung Verantwortlichkeiten verstreuen, Mitwirkungsmöglichkeiten verringern und generelle Vorgaben schaffen. 
nationale Ebene zu schieben, diese als >Sündenbock` zu benutzen (vgl. Vaubel 1986: 45). Auch hierfür eignet sich die EU nach Rotte/Zimmermann (1998: 390) besonders gut, da die Wähler zwar durchaus über die Mitentscheidungsmöglichkeiten ihrer Regierung in der EU informiert sind, das Projekt der europäischen Integration jedoch so hoch stellen, dass sie bestimmte ökonomische Kosten eher durch europäische denn nationale Regelungen zu tragen bereit sind. Besondere Beachtung als Selbstbindungsmechanismus erfahren die Konvergenzkriterien von Maastricht bzw. der Stabilitäts- und Wachstumspakt: »[T]he Maastricht Treaty provides a unique international commitment that enables governments to follow restrictive fiscal policies by attributing their negative side-effects to Europe, and to implement austerity measures despite rising unemployment or a decline in growth « (ebenda: 385). Zusammenfassend kann man sagen, dass die EU sich als Legitimationsinstanz anzubieten scheint: Interne Probleme werden argumentativ und regulativ verlagert und kommen normativ (in Form von Vorgaben) zurück.

Die revisionistische Position wird oft in einer abgeschwächten Form vertreten: Die meisten ihrer Vertreter sehen weitere positive Effekte der ökonomischen Globalisierung (vgl. Genschel 2003: 442f) bzw. der europäischen Integration, überdies wird teilweise davon ausgegangen, dass die Staaten sich der tatsächlichen Selbstbindung bei Abschluss der supranationalen Regelungen nicht vollständig bewusst gewesen sind, sie dann aber doch gerne akzeptierten (vgl. Rotte/Zimmermann 1998: 386). Hefeker (2003: 6) weist zusätzlich darauf hin, dass im Inland grundsätzlich Reformbereitschaft bestehen muss, damit die Selbstbindungsstrategie funktioniert. Dennoch wird deutlich, dass die Revisionisten ein zurückhaltendes Staatsverständnis vertreten, einen Staat bevorzugen, der sich auf den als positiv bewerteten Standortwettbewerb einlässt, was entsprechende Aufgaben im Bereich Allokation mit sich bringt. Dieses Staatsverständnis wird durch die Selbstbindung gestützt. Im Unterschied zu den Globalisierungsbefürwortern wird hier die aktive, gestaltende Rolle der Nationalstaaten hervorgehoben. Die aus dieser Position ableitbare Strategie läge darin, die wirtschaftlichen Verflechtungsprozesse bewusst hervorzurufen bzw. zu unterstützen sowie durch ein gemeinsames Vorgehen, z.B. in Form von Vorgaben, die Interventionsmöglichkeiten im Bereich Distribution und Stabilisierung (sowie im Bereich Allokation bei den Beihilfen) weiter einzuschränken. Eine Ausweitung von Interventionsmöglichkeiten ist - wie bei den Globalisierungsbefürwortern nur bei der gemeinsamen Bereitstellung öffentlicher Güter mit allokativer Funktion zu erwarten, um im weltweiten Standortwettbewerb besser bestehen zu können. 


\section{Fazit}

Die drei dargestellten Positionen bewerten eine Einschränkung von Interventionsmöglichkeiten mit Blick auf die staatliche Handlungsfähigkeit unterschiedlich. Dies liegt in ihren jeweiligen Staatsverständnissen begründet: Globalisierungsbefürworter und Revisionisten bewerten die Einschränkung von Interventionsmöglichkeiten positiv, weil hierdurch die Handlungsfähigkeit eines Staates in ihrem Sinne (zurückhaltender Staat, der wenn überhaupt nur regelgebunden und überwiegend mit allokativem Ziel in die Wirtschaft eingreift) gestärkt wird. Globalisierungskritiker haben ein anderes Staatsverständnis (der Staat greift v.a. im Bereich Distribution und Stabilisierung aktiv und diskretionär in die Wirtschaft ein) und sehen die Auswirkungen verminderter Interventionsmöglichkeiten auf die Handlungsfähigkeit dementsprechend als problematisch an. Daraus folgend würden die Positionen unterschiedliche Strategien vorschlagen, die mit Hilfe der europäischen Vorgaben als Reaktion auf eine Einschränkung von Interventionsmöglichkeiten wie auch unabhängig davon verfolgt werden können. Zum Abschluss werden die drei entwickelten Strategien noch einmal explizit formuliert:

Kritische Strategie: Wenn den europäischen Vorgaben ein Keynes'sches Staatsverständnis zugrunde liegt, haben sie das Ziel, nationalstaatliche Handlungsfähigkeit durch eine Wiedergewinnung sowie einen Ausbau von Interventionsmöglichkeiten aktiv (v.a. im Bereich diskretionäre Stabilisierungspolitik und Distribution) zu stärken.

Affirmative Strategie: Wenn den europäischen Vorgaben ein monetaristisches bzw. angebotspolitisches/NKM Staatsverständnis zugrunde liegt, setzen sie einer Einschränkung von Interventionsmöglichkeiten (v.a. im Bereich Distribution und diskretionäre Stabilisierungspolitik) nichts entgegen, um auf diese Weise passiv die nationalstaatliche Handlungsfähigkeit zu stärken. Nur im Bereich öffentlicher Güter mit allokativer Funktion ist eine Ausweitung von Interventionsmöglichkeiten durch supranationale Zusammenarbeit vorstellbar.

Revisionistische Strategie: Wenn den europäischen Vorgaben die Vorstellung eines ein zurückhaltenden Staates, der nur sehr wenig und wenn überhaupt, dann regelgebunden in die Wirtschaft eingreift (monetaristisches oder angebotsökonomisches/NKM Staatsverständnis), zugrunde liegt, so wird mit den Vorgaben das Ziel verfolgt, die Interventionsmöglichkeiten der Mitgliedstaaten aktiv einzuschränken - mit Ausnahme des Bereichs der öffentlichen Güter mit allokativer Funktion, bei dem das gemeinsame Vorgehen eine Ausweitung von Interventionsmöglichkeiten zum Ziel haben kann. 



\section{UNTERSUCHUNG DER INTENDIERTEN BEEINFLUSSUNG VON HANDLUNGSFÄHIGKEIT SOWIE DES STAATSVERSTÄNDNISSES IN DEN VERSCHIEDENEN PHASEN DES INTEGRATIONSPROZESSES}

\subsection{Durchführung und Methoden}

Auf Grundlage des soeben entwickelten theoretischen Rahmens werden in diesem zweiten Teil der Arbeit die europäischen Vorgaben daraufhin untersucht, wie mit ihrer Hilfe Einfluss auf die nationalstaatliche Handlungsfähigkeit genommen werden sollte und welches Staatsverständnis ihnen zugrunde lag. Zur Beantwortung der ersten Frage wird analysiert, ob mit den Vorgaben das Ziel verfolgt wurde, die Interventionsmöglichkeiten einzuschränken oder auszubauen. Dies geschieht in Anlehnung an die Methode der Globalauswertung. Um die Staatsverständnisse aus den Vorgaben herauszufiltern, wird auf die Methode der qualitativen Inhaltsanalyse zurückgegriffen. Beide methodischen Vorgehensweisen werden im Folgenden dargestellt. Zuvor wird das Datenmaterialeingegrenzt und kurz auf die Dokumentenrecherche eingegangen.

\section{Eingrenzung des Datenmaterials}

Aufgrund der inhaltlichen Eingrenzung des Untersuchungsgegenstands (Kapitel 2.2) ist das Datenmaterial bereits auf die europäischen Vorgaben für die nationale Ausgabenpolitik in den Politikfeldern Beihilfen, öffentliche Güter mit allokativer und distributiver Funktion, Sozialausgaben und Stabilisierung beschränkt. Für die Analyse der Vorgaben ist da- 
rüber hinaus auch eine >formale Eingrenzung des Datenmaterials erforderlich. Dies betrifft i) die Frage, die Vorgaben welcher europäischen Akteure einbezogen werden, ii) die Festlegung auf Vorgabentypen und schließlich iii) die Auswahl der zu untersuchende Teile der Vorgaben.

Hinsichtlich der Akteure konzentriert die Arbeit sich auf den Europäischen Rat sowie den Ministerrat. Der Europäische Rat wurde 1974 gegründet und setzt sich aus den Staats- und Regierungschefs der Mitgliedstaaten sowie dem Präsidenten der Kommission zusammen (vgl. Art. 4 EUV). Vor 1974 trafen diese sich als »Konferenz der Staats- bzw. Regierungschefs «. Bei seinen Treffen, die mindestens zwei, in der Regel viermal im Jahr stattfinden, gibt der Europäische Rat »der Union die für ihre Entwicklung erforderlichen Impulse und legt die allgemeinen politischen Zielvorstellungen für diese Entwicklung fest« (Art. 4 EUV). Dies umfasst zum einen Vertragsreformen: Der Europäische Rat ist »the key forum for determining treaty reforms« (Wallace 2000: 20), dort werden nicht nur die Regierungskonferenzen einberufen, sondern auch die strittigsten Punkte diskutiert und entschieden (vgl. Wessels 2006: 208f). Zum anderen bestimmen die Staats- und Regierungschefs - im Konsens - die allgemeinen politischen Leitlinien für die Gemeinschaft, die dann, da sie in dieser Form rechtlich unverbindlich sind, von den anderen europäischen Organen in konkrete Vorgaben umgesetzt werden. Eine zentrale Rolle spielt dabei der auch Ministerrat genannte Rat der Europäischen Gemeinschaft(en) bzw. seit Ende 1993 Rat der Europäischen Union (im Folgenden: Rat), der sich aus den jeweils zuständigen Fachministern zusammensetzt (vgl. Art. 203 EGV; Wallace 2000: 16). Der Rat kann als das mächtigste Organ der Gemeinschaft bezeichnet werden, da er den überwiegenden Teil des europäischen Sekundärrechts ${ }^{79}$ beschließt (vgl. Hayes-Renshaw 2002: 62), in einigen Bereichen gemeinsam mit dem Europäischen Parlament. Obwohl der Rat in einigen Fällen mit qualifizierter oder einfacher Mehrheit abstimmen kann, werden die Entscheidungen in der überwiegenden Mehrheit im Konsens getroffen (vgl. ebenda: 58). Die verabschiedeten Vorgaben sind meist - wenn auch in unterschiedlichen Abstufungen - verbindlich (s.u.).

Die drei anderen zentralen europäischen Akteure, Kommission, Parlament und Gerichtshof bzw. ihre Vorgaben werden nicht in die Untersuchung einbezogen: Die Kommission erstellt zwar die Vorlagen (Empfehlungen und Vorschläge) für die Ratsbeschlüsse, die Entscheidung liegt aber beim Rat. Weiterhin schreibt sie Berichte, die aber keine Vorgaben enthalten. Verbindliche Vorgaben kann die Kommission hinsicht-

79 Das Primärrecht - in erster Linie die Verträge - werden von den einzelnen Mitgliedstaaten in Parlamentsabstimmungen oder Referenden ratifiziert. Das Sekundärrecht baut auf den Verträgen auf. 
lich der hier relevanten Politikfelder nur bei den Beihilfen verabschieden, dabei handelt es sich jedoch nur um die konkreten Einzelfallentscheidungen, den Vollzug der vom Rat festgelegten großen Linien der Beihilfenpolitik (vgl. Art. 88 EGV). Das Europäische Parlament spielt in den für diese Arbeit relevanten Politikfeldern nur eine sehr geringe Rolle, es wird höchstens angehört (z.B. bei der Verabschiedung der beschäftigungspolitischen Leitlinien, vgl. Art. $128^{80}$ ), hat also keine Entscheidungsbefugnis. Der Europäische Gerichtshof schützt das Gemeinschaftsrecht und legt es in strittigen Fällen aus, erlässt jedoch eigenständig keine Vorgaben, weshalb auch er nicht einbezogen wird.

Insgesamt kann man mit Oliver Treib (2002: 5) schließen, dass » trotz der Agenda-Setting-Macht der Europäischen Kommission, trotz des gestiegenen Einflusses des Europäischen Parlaments und trotz der signifikanten Rolle von Interessengruppen in einigen Politikbereichen der >critical bottleneck innerhalb des Entscheidungssystems nach wie vor die Notwendigkeit der Einigung zwischen den Mitgliedstaaten im Ministerrat ist.« Ähnlich argumentiert Hayes-Renshaw (2002: 62f), sie bezeichnet den Rat als »the Union's key decision-making institution. [...] no legislative decisions can be adopted without ministerial agreement. The Council's position in the EU decision-making in particular and the Union in general is therefore central, endowing it with a large degree of influence over other institutions and authorities." Die Beschränkung auf die Akteure Europäischer Rat und Rat ist auch deshalb sinnvoll, weil beide sich aus Vertretern der Mitgliedstaaten zusammensetzen. Insofern kann man bei der folgenden Untersuchung von der Absicht der Mitgliedstaaten bezüglich der Beeinflussung von Interventionsmöglichkeiten bzw. von ihrem Staatsverständnis sprechen - bzw. zumindest von der Absicht und dem Staatsverständnis, auf die bzw. das die Mitgliedstaaten sich einigen konnten.

Die akteursspezifische Eingrenzung hat auch Einfluss auf die Vorgabentypen. Folgende bleiben für die Untersuchung: Die Europäischen Verträge, die Schlussfolgerungen des Europäischen Rates (bzw. der Konferenz der Staats- bzw. Regierungschefs), die Richtlinien, Verordnungen und Entschließungen des Rates, sowie die von ihm verabschiedeten wirtschafts-, beschäftigungs- und sozialpolitischen Leitlinien und Aktionsprogramme. Die Verträge, Richtlinien und Verordnungen sind rechtlich verbindlich. Verordnungen gelten in allen Teilen unmittelbar in

80 Ebenfalls angehört wird es bei der Festlegung von Durchführungsverordnungen im Beihilfenbereich (vgl. Art. 89 EGV), über die wirtschaftspolitischen Leitlinien wird es nur unterrichtet (vgl. Art. 99 EGV), gleiches ist im Verfassungsvertrag für die sozialpolitischen Leitlinien festgelegt (vgl. III-213 VerfV). 
jedem Mitgliedstaat, während Richtlinien hinsichtlich des Ziels verbindlich sind, die Umsetzung in nationales Recht wird jedoch den jeweiligen Staaten überlassen. Entscheidungen sind ebenfalls verbindlich (vgl. Art. 249 EGV). Über die Einhaltung der Verträge, Richtlinien und Verordnungen wachen die Kommission und der Europäische Gerichtshof, letzterer kann bei einer Nichtumsetzung bzw. -einhaltung im Rahmen eines Vertragsverletzungsverfahrens ${ }^{81}$ Sanktionen bis hin zu Geldbußen verhängen (vgl. Art. 226ff EGV). Die jährlichen Leitlinien im Bereich Wirtschafts- und Beschäftigungspolitik (Empfehlungen des Rates) sind insofern verbindlich, als dass sie seit dem Vertrag von Maastricht bzw. Amsterdam vertragsbasiert sind (vgl. Art. 99 bzw. Art. 128 EGV) und eine Nichtumsetzung eine - bei den wirtschaftspolitischen Leitlinien öffentliche - Empfehlung des Rates nach sich ziehen kann. Die sozialpolitischen Leitlinien, die Aktionsprogramme sowie die Schlussfolgerungen des Europäischen Rates (bzw. der Konferenz der Staats- bzw. Regierungschefs), die die Staats- und Regierungschefs bei ihren Treffen verabschiedet, sind nicht verbindlich, bei Nichteinhaltung drohen nur Sanktionen in Form von >Naming und Shaming chen Verbindlichkeit werden alle genannten Vorgabentypen - unter Berücksichtigung dieser Unterschiedlichkeit - in die Analyse einbezogen. Dies ist sinnvoll, da die Detailliertheit meist mit der Verbindlichkeit abnimmt, eine Konzentration auf die Verträge und bindenden Vorgaben würde demnach weniger Rückschlüsse zulassen. Überdies sind im Untersuchungszeitraum nur sehr wenige Richtlinien und Verordnungen verabschiedet worden, so dass Aussagen auf dieser Basis nicht möglich wären.

Für die Analyse wird schließlich nur der Teil der Vorgaben herangezogen, der sich auf alle Länder bezieht, d.h. die - insbesondere bei den wirtschaftspolitischen Leitlinien vorkommenden - Länderleitlinien werden nicht untersucht. Diese Leitlinien sind auf die spezifische Situation in den einzelnen Mitgliedstaaten ausgerichtet und würden auf diese Weise Verzerrungen in die Untersuchung tragen. Das gleiche gilt für die Sanktionsverfahren im Rahmen des Stabilitäts- und Wachstumspakts, diese sind überdies nicht sehr aussagekräftig, da sie nur die Entwicklung der Haushaltssituation der betroffenen Länder schildern und zu weiteren Sparanstrengungen aufrufen, ohne dies über die allgemeine Begründung für den SWP hinaus zu begründen.

81 Ein Vertragsverletzungsverfahren kann von der Kommission eingeleitet werden, wenn Mitgliedstaaten gegen das gemeinschaftliche Primär- oder Sekundärrecht verstoßen. Die Klage vor dem EuGH ist dabei die letzte von drei Stufen. 
Insgesamt können damit letztlich - d.h. nach Durchsicht einer deutlich höheren Zahl, um die tatsächlich auswertbaren Dokumente herauszufiltern - 243 Vorgaben in die Analyse einbezogen werden. Diese haben eine Länge von einer bis weit über hundert Seiten, so dass Gesamtmaterial im Umfang von über 2000 Seiten ausgewertet werden kann.

Im Rahmen der Dokumentenrecherche wurden zum einen Stichwortsuchen in den elektronischen Datenbanken des Amts für amtliche Veröffentlichungen der Europäischen Gemeinschaften - EUR-LEX (eur-lex. europa.eu/) sowie CELEX (mittlerweile mit EUR-LEX zusammengeschlossen) - durchgeführt. Diese beiden Datenbanken sind jedoch gerade für die älteren Dokumente recht unvollständig. Ergänzend wurden daher die »Gesamtberichte über die Tätigkeit der Europäischen Gemeinschaften/Europäischen Union« sowie die »Bulletins der Europäischen Wirtschaftsgemeinschaft/Europäischen Gemeinschaften/Europäischen Union«, die von der Europäischen Kommission jährlich (Gesamtbericht) bzw. zehnmal im Jahr (Bulletin) herausgegeben werden und unter anderem kurze Beschreibungen der Ratstreffen sowie anderer wichtiger Ereignisse enthalten, nach Hinweisen auf relevante Dokumente durchsucht. Diese konnten dann - mit Hilfe der zusätzlichen Hinweise - entweder in den elektronischen Datenbanken gefunden werden, oder mussten direkt aus den Amtsblättern der Europäischen Gemeinschaften/Europäischen Union (Reihen L und C) oder anderen amtlichen Veröffentlichungen entnommen werden. Hilfreich und notwendig waren in diesem Zusammenhang Recherchen im Archiv der Europäischen Kommission in Brüssel, im Historischen Archiv der Europäischen Union in Florenz sowie im Europäischen Dokumentationszentrum des European University Institute, das sich ebenfalls in Florenz befindet.

\section{Durchführung der Untersuchung der intendierten Beeinflussung von Handlungsfähigkeit}

Bei der ersten Forschungsfrage wird untersucht, ob mit Hilfe der europäischen Vorgaben die Interventionsmöglichkeiten der Mitgliedstaaten eingeschränkt oder ausgeweitet werden sollten. Es geht dabei - wie bereits dargelegt - nicht um die tatsächlichen Auswirkungen der Vorgaben, sondern die hinter ihnen stehenden Intentionen, den beabsichtigen Einfluss.

Die nach den oben genannten Kriterien ausgewählten Vorgaben werden in Anlehnung an die Methode der Globalauswertung (vgl. Legewie 1994) analysiert. Diese ermöglicht es, »eine größere Anzahl von Textdokumenten zu sichten, nach inhaltlichen Gesichtspunkten zu erschließen« (Legewie 1994: 177) und dabei sowohl den Inhalt wie die 
Absicht der Autoren zu erfassen (ebenda). Die Auswertung erfolgt in vier Schritten: Zuerst wird das Material gesichtet. Dies entspricht der in Kapitel 2.2 sowie 4.1 dargestellten Eingrenzung. Dann werden - zweitens - Fragestellungen festgelegt, anhand derer das Material durchgearbeitet werden kann. Die Frage nach der intendierten Beeinflussung nationaler Interventionsmöglichkeiten/Handlungsfähigkeit wird zu diesem Zweck aufgeteilt in folgende Unterfragen:

- In welchen Bereichen wurden finanzpolitische Vorgaben gemacht?

- Welche Begründungen gab es für das gemeinsame Vorgehen?

- Welche Ziele und Instrumente wurden genannt?

Da für eine sinnvolle Untersuchung des beabsichtigten Einflusses der Vorgaben auf die nationalstaatlichen Interventionsmöglichkeiten nicht nur Inhalt und Begründung, sondern auch die Form des gemeinsamen Vorgehens relevant ist, werden auch die angesprochenen Verfahren einbezogen. Die Dokumente werden in einem dritten Schritt anhand dieser Fraugestellungen analysiert. Für die Ergebnisdarstellung (Schritt vier) werden die Vorgaben in jeder Phase bestimmten, sich aus der jeweilig vorliegenden Situation ergebenden Bereichen, z.B. Aufbau des Gemeinsamen Marktes, Wirtschafts- und Währungsunion, Sozialpolitik etc., zugeordnet. Durch diese Aufteilung entsteht ein anschaulicheres Bild der Vorgaben als durch eine Beschreibung anhand der drei Dimensionen A1lokation, Distribution und Stabilisierung, die jedoch für die Zusammenfassung der Ergebnisse genutzt wird.

\section{Methodisches Vorgehen bei der Analyse der den Vorgaben zugrunde liegenden Staatsverständnisse}

\section{Allgemeiner Überblick über die Methode}

Zur Beantwortung der Frage, welche Staatsverständnisse den europäischen Vorgaben zugrunde lagen (2. Forschungsfrage), wird die Methode der qualitativen Inhaltsanalyse angewandt. ${ }^{82}$ Qualitative Inhaltsanalyse kann definiert werden als »eine empirische Methode zur systematischen, intersubjektiv nachvollziehbaren Beschreibung inhaltlicher und formaler Merkmale von Mitteilungen« (Früh 1998: 24). Besonders wichtig ist der Aspekt der Intersubjektivität. Damit ist gemeint, dass das Vorgehen und die Ergebnisse der Untersuchung von anderen nachvoll-

82 Viele Anregungen für dieses Kapital habe ich durch Prof. Margit Schreier und die von ihr geleitete Forschungswerkstatt »Inhaltsanalyse« des Forums Qualitative Sozialforschung (24.-25.6.2004, Berlin) erhalten, bei der das methodische Vorgehen dieser Arbeit exemplarisch diskutiert wurde. 
zogen werden können (vgl. Rustemeyer 1992: 13). Voraussetzung hierfür ist eine systematische Vorgehensweise (vgl. Mayring 2007: 12). Diese wird dadurch erreicht, dass » [e]in Ausschnitt aus der sozialen Realität [...] nach definierten Regeln gemessen [wird], und diese Regeln [...] vom Forscher vorab im Untersuchungsinstrument festgelegt werden [müssen] (Rössler 2005: 19). Durch diese Art des Vorgehens wird vermieden, sich bei der Textanalyse zu sehr von subjektiven Voreinstellungen leiten zu lassen und dadurch möglicherweise einige Textstellen stärker zu gewichten als andere. Dies würde zu einem verzerrten Verständnis der Bedeutung bzw. der Aussagen eines Textes führen (vgl. Rustemeyer 1992: 12). Ein regelgeleitetes und systematisches Vorgehen ist bei der Frage nach den Staatsverständnissen besonders deshalb wichtig, weil diese nicht eindeutig aus den Vorgaben hervorgehen und gleichzeitig die subjektiven Vorvermutungen recht stark sein können. Daher muss eine intersubjektiv nachvollziehbare Interpretation des Inhalts der Vorgaben geleistet werden. Die dementsprechend höhere Interpretationsleistung erfordert dementsprechend eine elaboriertere Methode als die Untersuchung der intendierten Beeinflussung von Handlungsfähigkeit.

Qualitative Inhaltsanalyse kann verschiedene Formen annehmen. Mayring, einer der Entwickler und wichtigsten Vertreter dieser Methode, unterscheidet drei Grundprinzipien der Textinterpretation, die einer Inhaltsanalyse zugrunde liegen können: Zusammenfassung, Explikation und Strukturierung (vgl. Mayring 2007: 59ff). Bei der Zusammenfassung geht es darum, mit Hilfe von sogenannten >Makrooperatoren « wie Generalisierung, Bündelung und Auslassung die Texte auf ihre wichtigsten Aussagen zu konzentrieren. Die Explikation verfolgt das Ziel, unklare Abschnitte weiter auszudeuten, indem zusätzliches Material wie Lexika, Nachschlagewerke, weitere Stellen aus dem zu untersuchenden Text o.ä. hinzugezogen werden. Bei der Strukturierung sollen bestimmte Aspekte - Thema, Autor, Rezipient, Situation - aus dem Material gefiltert bzw. die Struktur der Texte mittels bestimmter Kriterien herausgearbeitet werden. Für diese Arbeit ist das dritte Grundprinzip von Bedeutung, aus dem Material sollen bestimmte - thematische - Aspekte (Staatsverständnisse) herausgefiltert werden. Hierfür bietet sich die von Rustemeyer (1992) vorgeschlagene Vorgehensweise, auch `komplexe Inhaltsanalyse genannt, an.

Das Prinzip des strukturierenden inhaltsanalytischen Vorgehens besteht darin, das Material durch eine systematische Informationsentnahme auszuwerten. $\mathrm{Zu}$ diesem Zweck werden bestimmte Textteile intersubjektiv bestimmten Bedeutungsaspekten zugeordnet. Anders formuliert: Die für die Fragestellung relevanten Inhalte werden mit Hilfe eines vorher konstruierten Analyserasters gefunden, indem die Textstellen (Analyse- 
einheiten) in das Raster eingeordnet werden (vgl. Gläser/Laudel 1999: 4). Diese Zuordnung von Analyseeinheiten zu Kategorien ist der entscheidende Interpretationsakt (vgl. Mayring 2005: 11).

Im Zentrum des inhaltsanalytischen Vorgehens steht somit die Bildung von Kategorien bzw. (in ihrer Gesamtheit) des Kategoriensystems. Kategorien können definiert werden als >deskriptive Analyseraster (Reinhoffer 2005: 125), formale und inhaltliche Kriterien, die an das Untersuchungsmaterial angelegt werden (vgl. Rössler 2005: 19). Sie können entweder deduktiv, d.h. aus Theorien und anderem Vorwissen, oder induktiv direkt aus dem zu analysierenden Material gewonnen werden. Für die vorliegende Arbeit bietet sich eine deduktive Vorgehensweise an: Die Kategorien werden aus den idealtypischen Staatsverständnissen abgeleitet. Dabei ist es wichtig, für jedes idealtypische Staatsverständnis möglichst viele Kategorien zu bilden, um offen zu sein für >nicht-reineく Verständnisse. Auf diese Weise können auch für Verschiebungen zwischen den Staatsverständnissen bzw. Entwicklungen besser dargestellt werden. Für ein vollständiges inhaltsanalytisches Kategoriensystem ist eine sogenannte Kategorienexplikation erforderlich (vgl. Rustemeyer 1992: 92): Die Kategorien werden nicht nur benannt, sondern auch beobachtungssprachlich definiert, um sie im Text leichter auffinden zu können (vgl. ebenda: 63). Bei den europäischen Vorgaben bedeutet dies die Benutzung ökonomischer sowie juristischer Ausdrücke. Zusätzlich können die Kategorien mit einem Ankerbeispiel, d.h. einer prägnanten und eindeutigen Textstelle aus dem zu analysierenden Material, sowie (wo notwendig) Abgrenzungsregeln versehen werden, um die Nachvollziehbarkeit der Zuordnung zu gewährleisten (vgl. ebenda: 93). Auf diese Weise entsteht ein hierarchisches Kategoriensystem (vgl. Kuckartz 1999: 200), bestehend aus einigen Ober- und mehreren Unterkategorien, welche klar und nachvollziehbar definiert sind.

Für die Bildung des Kategoriensystems formuliert die inhaltsanalytische Literatur folgende Gütekriterien (vgl. Rustemeyer 1992: 104ff ${ }^{83}$ )

Eindeutigkeit: Die Kategorien sollten eindeutig sein, um eine intersubjektive Zuordnung zu ermöglichen. Die Eindeutigkeit wird insbesondere durch die drei Schritte der Kategorienexplikation (deduktive Ableitung, textbezogene Verbalisierung, Ankerbeispiel und Abgrenzungsregeln) erreicht.

Exklusion bzw. Disjunktheit: Die Kategorien sollten sich gegenseitig ausschließen, sofern sie sich auch theoretisch ausschließen. Ist letzteres

83 Kuckartz (1999: 87) geht ähnlich vor, er nennt: theoretische Ableitung, eindeutige Definition, Unabhängigkeit voneinander, Eindimensionalität der Messung, Ausschließlichkeit und Vollständigkeit im Hinblick auf die Forschungsfrage. 
nicht der Fall, kann eine Analyseeinheit auch mehreren Kategorien zugeordnet werden.

Erschöpfung/Vollständigkeit der Kategorisierung: Jede Analyseeinheit muss einer Kategorie zuordenbar sein. Es kann eine Kategorie $>$ Restgröße< gewählt werden, in die nicht-zuordenbare Analyseeinheiten fallen, die Anzahl letzterer sollte jedoch begrenzt sein.

Saturiertheit: Jeder Kategorie sollte mindestens eine Analyseeinheit zugeordnet werden können. Ausnahmen sind bei stark theoriegeleiteter Forschung möglich, vor allem wenn es um das Aufzeigen von Entwicklungen geht.

Im Prozess des Codierens werden die Analyseeinheiten (Textstellen) den Kategorien zugeordnet. Das Ergebnis ist dann weiter auswertbar, auch mit quantitativen Verfahren. Für die vorliegende Fragestellung bietet sich eine Frequenzanalyse an (vgl. Rustemeyer 1992: 126ff; Mayring 2007: 13f). Hiermit kann deutlich gemacht werden, wie stark einzelne Kategorien besetzt sind, d.h. wie viele Analyseeinheiten den jeweiligen Kategorien zugeordnet werden konnten.

Zusammengefasst sieht das Verfahren folgende Schritte vor. Ich orientiere mich hierbei vor allem an Rustemeyer (1992), ergänzend an Mayring (2007).

- Praktische Vorbereitungen

Auswahl des zu analysierenden Materials (Auswahleinheit), formale Charakterisierung (in welcher Form liegt es vor)

Analyse der Entstehungssituation

Festlegung der Analyseeinheit (formal oder inhaltlich)

- Theoretische Vorüberlegungen

Richtung der Analyse (Rückschlüsse auf Thema, Autor, Rezipient oder Situation)

Festlegung der Bedeutungsaspekte (theoriegeleitete Hypothesen oder Fragestellungen)

- Vorbereitung der intersubjektiven Zuordnung

Kategorienexplikation (deduktiv oder induktiv, Verbalisierung, Ankerbeispiel, Abgrenzungsregeln)

Test der Kategorien an einem Teil des Materials, induktive Ausdifferenzierung

- Intersubjektive Zuordnung/Prozess des Codierens Zuordnung von Analyseeinheiten zu Kategorien

- Auswertung

Statistische Aufarbeitung, Zusammenfassung der Kategorisierungsdaten 


\section{Darstellung der Vorgehensweise}

Die eben allgemein beschriebenen Schritte der Inhaltsanalyse sollen nun konkret für die empirische Untersuchung der Staatsverständnisse, wie sie in dieser Arbeit vorgenommen wird, dargestellt werden.

\section{Praktische Vorbereitungen}

Hinsichtlich der Auswahleinheit kann auf die inhaltliche Eingrenzung des Untersuchungsgegenstands (vgl. Kapitel 2.2) sowie die Eingrenzung des Datenmaterials (Kapitel 4.1) verwiesen werden. Kurz gesagt handelt es sich bei dem zu analysierenden Material um alle Vorgaben des Europäischen Rates sowie des Rates für die mitgliedstaatliche Ausgabenpolitik in den Bereichen Subventionen, öffentliche Güter, Sozialausgaben und Konjunkturpolitik für den Zeitraum 1957-2004. Es wird eine Vollerhebung durchgeführt. Für die inhaltsanalytische Auswertung muss die vorgenommene Eingrenzung weiter spezifiziert werden: Es werden nur die Vorgaben ausgewertet, in denen sich klare Aussagen zum Staatsverständnis finden lassen, Dokumente, in denen lediglich allgemeine Ziele wie Wachstum und Beschäftigung auftauchen, werden demzufolge außen vor gelassen, da man hieraus kein Staatsverständnis ableiten kann. Formalisiert bedeutet dies: Es werden nur Vorgaben einbezogen, in denen sich mindestens zwei Analyseeinheiten finden, die sich aussagekräftigen (unterschiedlichen) Kategorien zuordnen lassen. ${ }^{84}$ Dies ist insbesondere bei den recht allgemein gehaltenen Europäischen Verträgen nicht der Fall, auch die Schlussfolgerungen des Europäischen Rates sind manchmal - was die thematisch passenden Stellen angeht - sehr kurz und allgemein gehalten. Wenn in den Vorgaben Bezug auf Zielsetzungen genommen wird, die auf anderen Treffen beschlossen wurden, werden diese nicht codiert. ${ }^{85}$ Daraus ergibt sich die Anzahl von 130 Dokumenten, die in die Inhaltsanalyse einbezogen werden können. Zur formalen Charakterisierung des Materials: Die Vorgaben liegen in Kopie oder in elektronischer Form vor.

Die Entstehungssituation wird jeweils zu Beginn der Untersuchungsphasen dargelegt, daher kann hier darauf verzichtet werden.

Die Analyseeinheit wird inhaltlich bestimmt, indem in einem ersten Durchgang die relevanten Stellen markiert und in einem zweiten Durch-

84 Beispiel: Eine Vorgabe, die nur das Ziel Wachstum nennt, aber keine Strategie zur Erreichung, wird nicht in die Frequenzanalyse einbezogen.

85 Beispiel: Wenn in einem Dokument steht: »Beim Europäischen Rat in Lissabon wurde eine Wachstumsinitiative beschlossen«, codiere ich dies nicht, ich codiere nur, wenn in dem Dokument steht »folgende Maßnahmen zur Steigerung des Wachstums werden empfohlen.« 
gang codiert werden. ${ }^{86}$ Eine formale Eingrenzung (Artikel, Absätze oder Leitlinien) wäre nicht sinnvoll, da viele der zu untersuchenden Dokumente aufgrund ihrer thematischen Bandbreite nur in Teilen für die Arbeit relevant sind, überdies werden in einigen formal abgrenzbaren Einheiten (z.B. in einer Leitlinie) mehrere Themen angesprochen, die entsprechend mehrfach codiert werden können und sollen.

\section{Theoretische Vorüberlegungen}

Mit Hilfe der Inhaltsanalyse sollen, wie oben bereits gesagt, Rückschlüsse auf den thematischen Aspekt Staatsverständnis gezogen werden. Die Hauptfragestellung lautet dabei: Welches Staatsverständnis liegt den jeweiligen Vorgaben zugrunde? Dies kann in drei große Unterfragen - mit jeweils weiteren Unterpunkten - aufgeschlüsselt werden:

\section{a. Einstellungen:}

- Wird der Staat/staatliches Eingreifen in die Wirtschaft positiv oder negativ bewertet?

- Wird der Markt/marktliche Koordination positiv oder negativ bewertet?

- Soll der Staatshaushalt vergrößert, verringert oder umgeschichtet werden?

- Wird dem Unternehmertum eine wichtige Rolle für die wirtschaftliche Entwicklung zugeschrieben?

b. Bedeutung sowie Wege zur Erreichung/Lösung folgender Ziele/Probleme:

- Beschäftigung/Arbeitslosigkeit

- Preisstabilität/Inflation

- Haushaltsausgleich/Haushaltsdefizit

- Konjunkturstabilisierung/Konjunkturkrisen

- Wachstum/Wachstumsschwäche

c. Aufgaben des Staates in den Bereichen Allokation, Distribution und Stabilisierung

- Allokation: Subventionen und öffentliche Güter mit allokativer Funktion

- Distribution: Sozialausgaben und öffentliche Güter mit distributiver Funktion

- Stabilisierung: Stabilisierung allgemein und automatische Stabilisatoren

86 Vorschlag von Prof. Schreier in der Forschungswerkstatt »Inhaltsanalyse«. 


\section{Vorbereitung der intersubjektiven Zuordnung}

Die Kategorienexplikation erfolgt deduktiv: Aus den idealtypischen Staatsverständnissen werden Antworten auf die oben entwickelten Fragen abgeleitet. Auf diese Weise entsteht das vollständige Kategoriensystem, welches aus über 70 Ober- und Unterkategorien besteht (s. Anhang I). Die Beschreibung der einzelnen Kategorien im Kategoriensystem erfolgt recht kurz, da hierfür auf das Theoriekapitel zurückgegriffen werden kann, wenn notwendig werden Abgrenzungsregeln formuliert. Das Kategoriensystem wird an einem Teil des Materials getestet und teilweise ergänzt oder anders formuliert, damit die Kategorien leichter auffindbar und eindeutiger zuordenbar sind. Die Kategorienexplikation ist mit Hilfe dieser Schritte präzise genug, auf Ankerbeispiele kann daher verzichtet werden.

\section{Intersubjektive Zuordnung/Prozess des Codierens}

In diesem Schritt werden die vorher festgelegten Analyseeinheiten den Kategorien aus dem Kategoriensystem zugeordnet. Dieser Schritt soll - um die Intersubjektivität der Zuordnung zu gewährleisten - möglichst von mehreren Codierern vorgenommen werden. Dies ist im Rahmen einer Dissertation jedoch nicht möglich, da die zeitliche Belastung für die weiteren Codierer nicht zumutbar wäre. Daher wähle ich das für Dissertationen übliche Vorgehen, das Material selbst doppelt zu codieren und zwar in zwei zeitlich auseinander liegenden Durchgängen. ${ }^{87}$

\section{Auswertung}

In diesem letzten Schritt werden die Ergebnisse des Codierens mittels einer Frequenzanalyse ausgewertet. Bei der Frequenzanalyse wird für jede Kategorie dargestellt, wie viele Analyseeinheiten ihr zugeordnet werden können. Ich stelle allerdings nicht die absolute Häufigkeit der Analyseeinheiten pro Kategorie dar, sondern zähle für jede Kategorie nur eine Analyseeinheit pro Dokument. Auf diese Weise wird dargestellt, in wie vielen Dokumenten sich Analyseeinheiten finden, die der jeweiligen Kategorie zugeordnet werden können. ${ }^{88}$ Eine Frequenzanalyse, die auf absoluten Häufigkeiten beruht, d.h. alle Kategorienzuordnungen zählt, würde zu einem verzerrten Bild führen, da die verschiedenen Dokumententypen (Richtlinie, Leitlinien etc.) von ihrer Länge, ihrer thematischen Bandbreite und ihren Schwerpunkten her sehr unterschiedlich

87 Vorschlag von Prof. Schreier in der Forschungswerkstatt »Inhaltsanalyse«.

88 Beispiel: Als Ergebnis lässt sich sagen, dass in fünf von zehn Vorgaben die Bekämpfung der Arbeitslosigkeit durch Angebotspolitik genannt wird, ob dieses Ziel in den jeweiligen Dokumenten ein- oder mehrmals genannt wird, wird nicht berücksichtigt. 
sind. Wo es von der Anzahl der Dokumente her möglich ist, wird die Frequenzanalyse für die jeweiligen Dokumententypen getrennt aufgeführt. Die Beschreibung der Ergebnisse erfolgt im Text, eine tabellarische Darstellung findet sich in Anhang II.

\section{Gütekriterien}

Zum Abschluss soll noch kurz auf die Gütekriterien der Inhaltsanalyse eingegangen werden. Die quantitative Forschung nennt drei zentrale Gütekriterien, welche für die qualitative modifiziert herangezogen werden können: ${ }^{89}$ Objektivität, Reliabilität und Validität. Nach Bortz und Döring (2002) spielen die Kriterien Objektivität und Reliabilität eine eher untergeordnete Rolle.

Da Objektivität nie ganz erreichbar ist, wird das Kriterium der Nachvollziehbarkeit bzw. Intersubjektivität gewählt (vgl. Knapp 2005: 23). Dieses wird durch das bisher geschilderte systematische Vorgehen gewährleistet (vgl. Rustemeyer 1992: 140).

Unter Reliabilität versteht man nach Mayring (2007: 109) die Zuverlässigkeit, Stabilität und Genauigkeit der Messung sowie die Konstanz der Messbedingungen. Dies soll gewährleisten, dass unterschiedliche Forscher zu verschiedenen Zeitpunkten zu dem selben Ergebnis kommen (vgl. Knapp 2005: 21). Reliabilität ist bei der qualitativen Inhaltsanalyse dann gegeben, wenn die Analyseeinheiten verlässlich denselben Kategorien zugewiesen werden. Dies wird vor allem durch eine gute Kategorienexplikation erreicht. Die Reliabilität lässt sich messen, indem das Material mehrfach codiert wird, entweder von verschiedenen Codierern oder wenn dies - wie im vorliegenden Fall - nicht möglich ist, durch dieselbe Codiererin nach einem gewissen zeitlichen Abstand. Zur Messung der Inter- bzw. Intra-Coder-Übereinstimmung können verschiedene Koeffizienten gebildet werden (vgl. Stemmler 2001), dies unterbleibt jedoch in dieser Arbeit.

Validität fragt nach der Gültigkeit der Ergebnisse, d.h. danach, ob das gemessen wurde, was gemessen werden sollte, bei der Inhaltsanalyse speziell ob Kategorien und Material zusammenpassen (vgl. Mayring 2007: 109). Bei der Abbildung der im Text vorhandenen Bedeutungsinhalte/Dimensionen (nicht jedoch bei Rückschlüssen auf den Autor oder Leser, was in dieser Arbeit jedoch nicht relevant ist) ist dieses Kriterium nach Rustemeyer (1992: 140) durch das Verfahren gegeben. Die Validität wird über weiche Indikatoren erreicht, der Text muss interpretiert

89 Zur Kritik an den quantitativen Kriterien und zur Erarbeitung eigenständiger Kriterien für die qualitative Inhaltsanalyse vgl. Mayring 2007: 208ff. 
werden, um die Kategorienzuordnung zu ermöglichen, auf diese Weise wird sichergestellt, dass die Textbedeutung erfasst wird.

Das Problem der Repräsentativität der Stichprobe stellt sich bei dieser Arbeit nicht, da eine Vollerhebung erfolgt.

\subsection{Phase I (1957-1973)}

\section{Umfeldbeschreibung}

Die erste Untersuchungsphase beginnt mit der Unterzeichnung der Römischen Verträge und damit der Gründung der Europäischen Wirtschaftsgemeinschaft im Jahr 1957. Sie endet 1973, dem Jahr der ersten Erweiterung der Gemeinschaft sowie der ersten Ölkrise und damit dem Ende der nahezu (wirtschafts-)krisenfreien Nachkriegsjahre. 1957 schlossen sich Frankreich, Deutschland, Italien und die drei Beneluxstaaten zur Europäischen Wirtschaftsgemeinschaft zusammen. In Artikel 2 des Gründungsvertrags (EWGV) legten sie als Ziele die Schaffung eines Gemeinsamen Marktes sowie die Annäherung der mitgliedstaatlichen Wirtschaftspolitik fest. In den ersten Jahren der Integration waren jedoch nur Fortschritte in Bezug auf das erste Ziel feststellbar, die Zollunion wurde bereits 1968, und damit zwei Jahre früher als geplant, vollendet. Auf dem Gebiet der wirtschaftspolitischen Koordinierung geschah hingegen in der Anfangszeit recht wenig. Ein wesentlicher Grund hierfür lag in der unterschiedlichen Ausrichtungen der mitgliedstaatlichen Wirtschaftspolitik, vor allem Deutschland wich unter der konservativen Adenauer- bzw. Erhard-Regierung vom interventionistischen Kurs der anderen Länder, insbesondere Frankreichs, ab. Dies änderte sich erst 1966 mit dem Eintritt der SPD in die Regierung und verfestigte sich durch den Übergang zur sozialliberalen Koalition 1969 (vgl. Gros 2002: 102). Damit war der Weg für eine gemeinschaftliche Koordinierung frei, was an der deutlich steigenden Anzahl der Vorgaben seit Mitte der 1960er Jahre festgemacht werden kann.

In der gleichen Zeit erlebte der Integrationsprozess unter dem Stichwort \Politik des leeren Stuhls` seine erste Krise: Ab dem Jahr 1966 wären laut EWGV in bestimmten Sachgebieten Ratsentscheidungen mit qualifizierter Mehrheit möglich geworden. Um dies zu verhindern, blieb Frankreich vom 1. Juli 1965 an den Sitzungen der EWG-Gremien fern, bis mit dem Luxemburger Kompromiss im Januar 1966 jedem Land bei gemeinschaftlichen Entscheidungen, die seine vitalen Interessen betreffen, ein Veto eingeräumt wurde (vgl. Weidenfeld 2006: 21). Ein weiteres wichtiges Ereignis im Integrationsprozess war die in den Fusionsver- 
trägen festgelegte Verschmelzung von EGKS, Euratom und EWG, durch die 1967 die Europäische Gemeinschaft gegründet wurde. Dies schlug sich jedoch nur in einer Zusammenlegung der Entscheidungsorgane, nicht in konkreten Politikänderungen nieder. Nach der Vollendung der Zollunion beschlossen die Staats- und Regierungschefs im Jahr 1969 die Einführung einer Wirtschafts- und Währungsunion innerhalb der nächsten zehn Jahre (vgl. Konferenz der Staats- bzw. Regierungschefs 1969: Ziff. 2 und 8). Integrationspolitisch ist schließlich die erste Erweiterungsrunde von Bedeutung: 1973 traten - nachdem der Widerspruch De Gaulles gegen den britischen Beitritt von seinem Nachfolger Pompidou nicht aufrechterhalten wurde (vgl. Ménudier 2002: 133) - Großbritannien, Irland und Dänemark bei (vgl. Weidenfeld 2006: 22). Dies hatte eine stärkere Heterogenisierung der wirtschaftspolitischen Ansichten und Entwicklungsstände der Gemeinschaft zur Folge. Dänemark und Großbritannien waren überdies erklärte Gegner weiterer Supranationalisierung (vgl. Ziltener 1999: 118).

Was die wirtschaftliche Situation angeht, so war die gesamte erste Phase geprägt von sehr hohen Wachstumsraten (durchschnittlich 5,3\%, vgl. 71/107/EWG: 8) sowie geringer Arbeitslosigkeit, in einigen Ländern und Sektoren herrschte sogar Arbeitskräftemangel. Die Arbeitslosenquote lag im gesamten Zeitraum nur knapp über $2 \%$ (vgl. Europäische Kommission 1993: 200). Leichte Wachstumsabschwächungen gab es 1961/62, 1966/67 sowie zu Beginn der 1970er Jahre (vgl. Europäische Kommission 1993: 207). Zu einem Problem entwickelte sich in dieser Phase die Inflation: Hatte sie in den 1960ern zwischen 2,6\% in Luxemburg und 4,2\% in den Niederlanden gelegen (vgl. 71/107/EWG: 15), so stieg sie zum Ende der Untersuchungsphase deutlich an und lag 1973 bei durchschnittlich 8,3\% (zwischen $6 \%$ in Luxemburg und 12,1 $\%$ in Italien) (vgl. 76/916/EWG: 18). Die erste tiefe Rezession der Nachkriegszeit wurde von der Ölkrise 1973 ausgelöst. Diese Krise traf die Gemeinschaft in einer Zeit zunehmender internationaler Instabilität, die mit der Aufkündigung der Goldkonvertibilität des US-Dollars durch Nixon 1971 und damit dem Ende von Bretton-Woods begonnen hatte (vgl. Ziltener 1999: 121). Die Auswirkungen dieser Krise zeigten sich hauptsächlich in der zweiten Untersuchungsphase. 


\section{Intendierter Einfluss der europäischen Vorgaben auf die Interventionsmöglichkeiten der Mitgliedstaaten und ihre Handlungsfähigkeit}

Im Vertrag zur Gründung der Europäischen Wirtschaftsgemeinschaft hatten die sechs Gründungsstaaten bereits hohe Ansprüche an eine $\mathrm{Zu}$ sammenarbeit auf dem Gebiet der Wirtschaftspolitik festgeschrieben: Laut Artikel 6 koordinieren die Mitgliedstaaten ihre Wirtschaftspolitik, soweit dies der Erreichung der Vertragsziele dient. Nach Artikel 104 sollte jeder Mitgliedstaat eine Wirtschaftspolitik betreiben, die »unter Wahrung eines hohen Beschäftigungsstands und eines stabilen Preisniveaus das Gleichgewicht seiner Gesamtzahlungsbilanz [...] sicher[t] und das Vertrauen in seine Währung aufrecht[erhält].« Die Koordination sollte unter anderem durch eine Zusammenarbeit zwischen den zuständigen Verwaltungsstellen und den Zentralbanken erfolgen (Art. 105), für die Koordinierung auf dem Gebiet der Konjunkturpolitik wurden speziellere Verfahren festgelegt (s.u.). Die angestrebte enge Zusammenarbeit in Fragen der Beschäftigungs- und Sozialpolitik umfasste eine Angleichung der Rechts- und Verwaltungsvorschriften (vgl. Art. 117 EW$\mathrm{GV}$ ) sowie Untersuchungen und Beratungen (vgl. Art. $118 \mathrm{EWGV}$ ).

Für die Untersuchung des beabsichtigten Einflusses der vertraglich und außervertraglich festgelegten europäischen Vorgaben werden diese fünf Bereichen zugeordnet: Dem Aufbau des Gemeinsamen Marktes, der Koordinierung der kurzfristigen Wirtschaftspolitik, der Vorbereitung der Wirtschafts- und Währungsunion, dem gemeinsamen Vorgehen bei der mittelfristigen Wirtschaftspolitik sowie der Koordinierung der Beschäftigungspolitik.

\section{Aufbau des Gemeinsamen Marktes}

Das erste Hauptziel des Integrationsprozesses war die Schaffung eines Gemeinsamen Marktes. Dieses in Art. 2 des EWG-Vertrags festgelegte Ziel sollte innerhalb von 12 Jahren erreicht werden (vgl. Art. 8 EWGV), was auf den Treffen der Staats- und Regierungschefs wiederholt betont wurde. So sprachen diese sich 1961 in Paris für die Errichtung eines einheitlichen Marktes durch die Abschaffung jeglicher Schutzmaßnahmen auf dem Gebiet der Zölle und eine Angleichung der Volkswirtschaften durch eine engere Zusammenarbeit aus (vgl. Konferenz der Staats- bzw. Regierungschefs 1961a: 13) und beschlossen im Juli des gleichen Jahres, »in regelmäßigen Zeitabständen Zusammenkünfte zu dem Zweck abzuhalten, ihre Ansichten zu vergleichen, ihre Politik miteinander ab- 
zustimmen und zu gemeinsamen Auffassungen zu gelangen « (Konferenz der Staats- bzw. Regierungschefs 1961b: 40).

Direkt ausgabenrelevant waren in diesem Zusammenhang vor allem die Vorschriften für die nationale Beihilfenpolitik. Beihilfen waren laut Art. 92 EWGV verboten, sofern sie den Wettbewerb zwischen den Mitgliedstaaten verzerren und den Handel beeinträchtigen. Der Vertrag schrieb fest, dass die Mitgliedstaaten Subventionen nur nach einer Prüfung durch die Kommission vergeben durften (vgl. Art. 93 EWGV). Das Beihilfenverbot wurde in den Anfangsjahren der Integration jedoch nicht weiter ausgebaut und auch in den Vorgaben für die nationalstaatliche Wirtschaftspolitik nur selten - und wenn insbesondere im Zusammenhang mit Ausgabenkürzungen zur Nachfragedämpfung (vgl. z.B. 72/C 133/12: 13; 73/C 116/22: 22) - wieder aufgegriffen. Weitaus häufiger verabschiedete der Rat Ausnahmeregelungen vom Beihilfenverbot. Sehr detailliert erfolgte dies für die Verkehrsunternehmen, um auf dieser Weise Wettbewerbsverzerrungen zwischen den verschiedenen Verkehrsträgern zu vermeiden, aber gleichzeitig staatliche Ausgleichszahlungen für die Belastungen zu ermöglichen, die sich aus öffentlichen Dienstpflichten (Betriebs-, Beförderung- und Tarifpflicht) ergaben (vgl. hierzu 65/271/EWG; VO 1191/69; VO 1107/70, es handelte sich um Präzisierungen von Art. $77 \mathrm{EWGV}$ ). Des Weiteren wurden Beihilfen für den Schiffbau genehmigt, die »dazu bestimmt sind, die auf dem internationalen Schiffbaumarkt festgestellten Wettbewerbsverzerrungen auszugleichen « (69/262/ EWG, Art. 1; ebenso 72/273/EWG: 28). Dies wurde damit begründet, dass der Schutz des Schiffbaus in der Gemeinschaft von gemeinsamem Interesse sei und die notwendigen Beihilfen zur Aufrechterhaltung der Wettbewerbsfähigkeit den innergemeinschaftlichen Handel nicht verfälschen durften (vgl. 69/262/EWG: 25). Bei einer Reduzierung der internationalen Verzerrungen sollten die Beihilfen jedoch auch hier verringert werden (vgl. 72/273/EWG: 28). Die Beihilfenregelungen im Rahmen der Strukturpolitik werden bei der mittelfristigen Wirtschaftspolitik behandelt.

Neben den Beihilfenbestimmungen ist bei der Schaffung des Gemeinsamen Marktes nur noch die Abstimmung der Verkehrsinfrastrukturinvestitionen ausgabenrelevant: Die Mitgliedstaaten sollten der Kommission ihre Vorhaben von gemeinsamem Interesse melden (vgl. 66/ 161/EWG, Art. 1), um durch diese Abstimmung eine Verschwendung von Ressourcen zu vermeiden (vgl. 67/264/EWG: 1545). 


\section{Koordinierung der kurzfristigen Wirtschaftspolitik}

Unter kurzfristiger Wirtschaftspolitik wurde insbesondere eine Koordinierung der Konjunkturpolitik verstanden, wie sie in Art. 103 EWGV festgelegt war. Gemäß diesem Artikel betrachten die Mitgliedstaaten ihre Konjunkturpolitik als eine Angelegenheit von gemeinsamem Interesse (vgl. Art. 103, Abs. 1): Sie setzen sich gegenseitig »über die unter den jeweiligen Umständen zu ergreifenden Maßnahmen ins Benehmen« (ebenda, Abs. 1), dem Rat wurde überdies die Möglichkeit eingeräumt, mit qualifizierter Mehrheit Maßnahmen in Form rechtlich bindender Richtlinien $\mathrm{zu}$ verabschieden, was einer sehr weitgehenden Befugnis entsprach (vgl. ebenda, Abs. 3).

Die Notwendigkeit des gemeinsamen Vorgehens wurde jedoch nicht nur mit dem Vertrag, sondern vor allem mit der zunehmenden wirtschaftlichen Verflechtung begründet. Deren Folgen für die mitgliedstaatliche Wirtschaftspolitik sollte auf unterschiedliche Weise begegnet werden: Zum einen führte die Vernetzung nach Meinung des Rates dazu, dass die Politik eines Mitgliedstaates nicht mehr auf das eigene Territorium begrenzt bliebe, so dass bei nationalen Maßnahmen jeweils auch die anderen Staaten mit bedacht werden mussten (vgl. 71/371/EWG: 17). Um unerwünschte grenzüberschreitende Effekte zu verhindern, wurde vor allem auf das Instrument der Konsultationen gesetzt. Bereits seit 1960 mussten die Mitgliedstaaten die Kommission »über die großen Linien ihrer Vorhaben [unterrichten], die geeignet sein könnten, die Konjunkturlage in den Mitgliedstaaten der Gemeinschaft zu beeinflussen« (60/C 31/764, Art. 2). 1969 wurde das Instrument der Konsultationen verstärkt: Die »Entscheidung des Rates über die Koordinierung der kurzfristigen Wirtschaftspolitik der Mitgliedstaaten« legte fest, dass bei allen wichtigen Entscheidungen oder Maßnahmen eines Mitgliedstaates auf dem Gebiet der kurzfristigen Wirtschaftspolitik, die erhebliche Auswirkungen auf andere Mitgliedstaaten haben könnten (oder eine Abweichung von den gemeinsamen Leitlinien darstellten), vorherige Konsultationen durchgeführt werden müssen (vgl. 69/227/EWG, Art. 1). Eine Konsultation konnte von jedem Mitgliedstaat sowie vom Rat beantragt werden, sie fand in verschiedenen Ausschüssen oder im Rat selbst statt, bei Dringlichkeit nur in einem Ausschuss (vgl. Rat 1970: 88). Die Mitgliedstaaten durften die geplanten Maßnahmen erst nach der Konsultation durchführen. Diese Bestimmung gaben der nationalstaatlichen Wirtschaftspolitik zwar keine bestimmte Richtung vor, die gegenseitige Information und Billigung von Maßnahmen ermöglichte jedoch eine gewisse Annäherung. Ebenso wird deutlich, dass die Mitgliedstaaten von 
einer sehr engen Verflechtung und damit gegenseitigen Beeinflussung ausgingen.

Des Weiteren führte die wirtschaftliche Verflechtung nach Ansicht der Mitgliedstaaten zu einer Einschränkung ihrer Interventionsmöglichkeiten: »Ein korrigierendes Eingreifen ist um so schwieriger geworden, als die Errichtung des Gemeinsamen Marktes die in den verschiedenen Ländern benutzten Steuerungsinstrumente zum Teil ihrer Wirkung beraubt hat« (71/107/EWG: 9). Gemeinsam mit der dritten wahrgenommenen Folge der Verflechtung - einer höheren Effektivität gemeinsamen Vorgehens - lag hierin die Begründung für eine aktive Koordinierung der nationalen Wirtschaftspolitik. Sie umfasste in diesen Fällen nicht nur Konsultationen, sondern auch die Festlegung gemeinsamer Ziele und Vorgehensweisen. Bereits 1959 sprach der Rat sich dafür aus, gemeinsame Richtlinien für die Haushaltspolitik festzulegen, bei denen besonders die konjunkturgerechte Gestaltung der Finanzpolitik beachtet werden sollte (vgl. Rat 1959: 40). Präzisere Empfehlungen folgten in den Jahren 1964-68, vor allem jedoch im Rahmen der Vorbereitung der Wirtschafts- und Währungsunion zu Beginn der 1970er Jahre.

Die beiden Hauptziele der kurzfristigen Koordinierung waren die Bekämpfung der Inflation und die Sicherstellung eines raschen und gleichgewichtigen Wachstums (vgl. 68/147/EWG: 6). Die Inflation entwickelte sich zu Beginn der 1970er Jahre zu einem zentralen Problem, auf das gemeinsam reagiert wurde, da »[a]ngesichts der starken wirtschaftlichen Interdependenz der Mitgliedstaaten [...] der Inflationsbekämpfung nur dann ein nachhaltiger Erfolg beschieden sein [wird], wenn alle Mitgliedstaaten gleichzeitig und mit der notwendigen Energie dieses Ziel verfolgen« (73/C 107/01: 8). Darüber hinaus wurde die Inflation als schädlich für die gemeinschaftliche Wettbewerbsfähigkeit sowie das Beschäftigungsniveau angesehen (vgl. 73/C 116/22: 22). Die Vorgaben empfahlen in erster Linie, die Nachfrage zu reduzieren: Neben einer Verringerung der privaten Nachfrage durch Einkommenspolitik oder Steuererhöhungen wurde auch eine Dämpfung der öffentlichen Ausgaben angesprochen. Da die kollektiven Bedürfnisse noch nicht befriedigt waren und überdies neue hinzukamen (vgl. 72/C 133/01: 6), waren die Empfehlungen hier recht vorsichtig, sie beschränkten sich auf die staatlichen Verwaltungsausgaben (vgl. 67/264/EWG: 1560), Beihilfen (vgl. 72/C 133/12: 13) sowie - mit Einschränkungen formuliert Konsumausgaben (vgl. 73/C 107/01: 9); öffentliche Mittel für Schulen, Krankenhäuser oder Sozialwohnungen (vgl. 64/246/EWG: 1030) sowie Infrastruktur (vgl. 71/371/EWG: 18) sollten nicht gekürzt werden. Es ging auch nicht darum, die öffentlichen Ausgaben insgesamt zu reduzieren, vielmehr sollte ihr Anstieg stabilisiert werden, als Richtwerte wur- 
den ein Ausgabenpfad von unter 5 \% (vgl. 64/246/EWG: 1029) bzw. möglichst unter dem des nominalen BIP genannt (vgl. 72/C 133/01: 7). Überdies forderten die Vorgaben, die Ausgaben zeitlich und örtlich zu staffeln (vgl. 64/246/EWG: 1029; 72/C 133/12: 13) und den Nettofinanzierungssaldo zu verbessern (vgl. 73/C 107/01: 9). Auf die Empfehlungen für Angebotsseite wird bei der Koordinierung der mittelfristigen Wirtschaftspolitik und der Beschäftigungspolitik eingegangen.

Mit dem zweiten Hauptziel der kurzfristigen Koordinierung, der Konjunkturstabilisierung, sollte ein gleichmäßiges Wachstum sichergestellt werden. Zu diesem Zweck wurde hauptsächlich diskretionäre Politik empfohlen: Nachfrageerhöhungen im konjunkturellen Abschwung, Nachfragedämpfungen im Aufschwung (vgl. 68/147/EWG: 6). Beides machte es notwendig, die Möglichkeiten einer schnellen haushaltspolitischen Reaktion auf konjunkturelle Veränderungen zu schaffen (vgl. 66/736/EWG: 4060): Den Mitgliedstaaten wurde empfohlen, Eventualhaushalte aufzustellen, Konjunkturausgleichsrücklagen zu bilden (vgl. 71/107/EWG: 32) und »jederzeit genügend große und gut vorbereitete Prognosen für zusätzliche öffentliche Investitionsprogramme (১Schubladenprogramme $[\ldots]$ ) mit entsprechenden Finanzierungsmodalitäten bereitzuhalten und nach deren Durchführung unverzüglich neue Programme vorzubereiten« (67/452/EWG: 7; ähnlich 71/371/EWG: 22). Die »konzertierte Aktion zur Stützung der Expansion der Globalnachfrage« (68/147/EWG: 6) sollte auch verhindern, dass die schwache Binnenkonjunktur eines Mitgliedstaates sich negativ auf die anderen Mitgliedstaaten auswirkt (67/452/EWG: 7). So wurde z.B. 1968 eine Richtlinie erlassen, nach der die französische Krise durch eine - verbindlich vorgeschriebene - gemeinschaftliche Expansionspolitik gemildert und auf diese Weise auch ein Übergreifen auf andere Länder verhindert werden sollte (vgl. 68/310/EWG: 13).

\section{Koordinierung der Politik im Rahmen der Wirtschafts- und Währungsunion}

Aus Anlass des Eintritts in die Endstufe des Gemeinsamen Marktes beschlossen die Staats- und Regierungschefs bei ihrer Zusammenkunft in Den Haag im Jahr 1969, eine Wirtschafts- und Währungsunion zu errichten (vgl. Konferenz der Staats- bzw. Regierungschefs 1969: Ziff. 2 bzw. 8). Zur Umsetzung dieser Beschlüsse wurde von einem eigens dafür eingesetzten Ausschuss ein Stufenplan erarbeitet (vgl. 70/192/EWG). Bereits in der ersten Ratsentscheidung zu den Zwischenberichten des sogenannten Werner-Ausschusses stellte der Rat fest: »Die Wirtschaftsund Währungsunion bedeutet, daß die wichtigsten wirtschaftspolitischen 
Entscheidungen auf Gemeinschaftsebene getroffen [...] und daß infolgedessen die erforderlichen Befugnisse von nationaler Ebene auf die Ebene der Gemeinschaft übertragen werden« (70/C 136/19: 19). 1971 wurde die Schaffung der WWU binnen der nächsten zehn Jahre für realistisch gehalten und festgelegt, dass »die Schaffung der Währungsunion [...] sich insbesondere auf parallele Fortschritte in der Konvergenz und später der Vereinheitlichung der Wirtschaftspolitik stützen [müsse]« (71/C 28/01: 3).

Auf dem Weg zur Wirtschafts- und Währungsunion wurde die kurzfristige Koordinierung der mitgliedstaatlichen Wirtschaftspolitik somit weiter ausgebaut: Zum einen wurden die Konsultationen verstärkt: Eine Gruppe aus Vertretern der Mitgliedstaaten wurde eingerichtet, die sich ständig über die kurzfristige Wirtschaftspolitik der Mitgliedstaaten austauschen sollte (vgl. 72/C 38/03: 3). Zum anderen sah man eine stärkere Abstimmung der Haushaltspolitik vor. Die 1964 eingeführte Gegenüberstellung der mitgliedstaatlichen Haushaltspläne durch den Haushaltsausschuss (vgl. 64/299/EWG) sollte durch eine Angleichung der Zeitpläne für die einzelstaatlichen Haushaltsverfahren verbessert werden (vgl. 71/C 28/01: 3). Zusätzlich gingen die Mitgliedstaaten in diesem Bereich jedoch weit über Konsultationen hinaus, indem sie sich in der »Entschließung über die stufenweise Verwirklichung der Wirtschafts- und Währungsunion« darauf einigten, dass »die Margen [...], innerhalb derer die Eckwerte der öffentlichen Gesamthaushalte liegen müssen, insbesondere die Änderung ihres Volumens, die Größe sowie die Finanzierungsund Verwendungsart der Salden « (71/C 28/01: 2) auf Gemeinschaftsebene festgelegt werden. Weiterhin sollte das konjunkturpolitische Instrumentarium »den neuen Aufgaben [angepasst werden], die sich für eine engere Koordinierung der Wirtschaftspolitik im Rahmen der stufenweisen Errichtung einer Wirtschafts- und Währungsunion stellen« (71/ 371/EWG: 21), worunter vorrangig eine elastischere Gestaltung der Instrumente der Konjunktur- und Haushaltspolitik verstanden wurde (vgl. ebenda: 22).

Schließlich sollten auch die Grundzüge der allgemeinen Wirtschaftspolitik auf Gemeinschaftsebene festgelegt und die wirtschaftspolitischen Instrumente schrittweise angeglichen werden (vgl. 71/C 28/01: 3). Den ersten Punkt präzisierte die »Entscheidung über die Verstärkung der Koordinierung der kurzfristigen Wirtschaftspolitik« (71/141/EWG). Sie schrieb dem Rat eine zentrale Rolle bei der Koordinierung der Wirtschaftspolitik zu, die er durch drei Zusammenkünfte pro Jahr wahrnehmen sollte. Die erste sogenannte »Prüfung der wirtschaftlichen Lage« diente der Bilanz der Wirtschaftspolitik des Vorjahres sowie ihrer Anpassung an die Erfordernisse der wirtschaftlichen Entwicklung (vgl. 
ebenda, Art. 2), in der zweiten wurde die Wirtschaftspolitik des laufenden Jahres überprüft und »quantitative Orientierungsdaten für die Entwürfe der öffentlichen Gesamthaushalte des folgenden Jahres festgelegt« (ebenda, Art. 3). Im Rahmen der dritten Prüfung wurde schließlich ein »Jahresbericht über die Wirtschaftslage der Gemeinschaft« verabschiedet, der auch Leitlinien für die mitgliedstaatliche Wirtschaftspolitik enthielt (vgl. ebenda, Art. 4). Der Jahresbericht musste den nationalen Parlamenten zur Kenntnis gebracht werden, damit er bei der Haushaltsdebatte berücksichtigt werden konnte (vgl. ebenda, Art. 5). Sanktionen bei Verstößen gegen die in diesem Rahmen gegebenen Empfehlungen waren nicht vorgesehen.

\section{Koordinierung der mittelfristigen Wirtschaftspolitik}

Störende gegenseitige Beeinflussungen sollten nicht nur im Bereich der kurzfristigen Wirtschaftspolitik, sondern auch mittelfristig verhindert werden, um das Ziel des Gemeinsamen Marktes sowie der Wirtschaftsund Währungsunion nicht zu gefährden. Hauptinstrument hierfür waren die »Programme für die mittelfristige Wirtschaftspolitik«, in denen die großen Linien der von den Mitgliedstaaten und der Gemeinschaft zu verfolgenden Wirtschaftspolitik für einen Zeitraum von fünf Jahren niedergelegt wurden. Das entsprechende Verfahren verabschiedete der Rat 1964 (vgl. 64/247/EWG): Auf Grundlage eines Vorentwurfs des eigens dafür eingerichteten »Ausschusses für mittelfristige Wirtschaftspolitik« legt die Kommission einen Programmentwurf vor, den der Rat nach Stellungnahmen des Europäischen Parlaments und des Wirtschafts- und Sozialausschusses verabschiedet. Die Übereinstimmung der mitgliedstaatlichen Politik mit den Leitlinien wird vom Ausschuss geprüft. In die erste Phase fallen die ersten drei Programme für die mittelfristige Wirtschaftspolitik (1967, 1969, 1971), wobei das 2. Programm das erste nur aktualisierte sowie um die Aspekte Struktur- und Regionalpolitik ergänzte.

Eine Abstimmung der mittelfristigen Wirtschaftspolitik der Mitgliedstaaten hielt man aus verschiedenen Gründen für erforderlich. Grundsätzlich ging es darum, mit Hilfe der Programme eine ausgewogene Entwicklung der Gemeinschaft zu fördern, die »nur das Ergebnis eines engstens abgestimmten gemeinsamen Vorgehens sein [kann] « (71/ 107/EWG: 22). Die Entwicklung der nationalen Volkswirtschaften, die von unterschiedlichen Niveaus ausging und sich in ungleichem Tempo vollzog, sollte ohne Rückgriffe auf protektionistische Maßnahmen oder Wechselkursänderungen auskommen (vgl. 71/107/EWG: 12). Letzteres gewann im Rahmen der Vorbereitungen zur WWU eine besondere Be- 
deutung. Mit Hilfe der mittelfristigen Vorausschau sollten überdies Ungleichgewichte aufgelöst bzw. verhindert werden, welche durch die zunehmende Verflechtung die anderen Mitgliedstaaten und damit die ausgewogene Entwicklung behindern könnten (vgl. 67/264/EWG: 1522). Weitere Gründe für das gemeinsame Vorgehen fanden sich bei den ausführlicher behandelten Politikfeldern (s.u.). Neben Leitlinien für die mitgliedstaatliche Wirtschaftspolitik enthielten die Programme auch mittelfristige Projektionen für Wachstum, Beschäftigung, Inflation etc., wobei es sich hierbei nicht um quantifizierte Zielvorgaben, sondern lediglich um Orientierungsdaten handelte (vgl. 67/264/EWG: 1523). Weiterhin wurden im 3. Programm eine Reihe weiterer Instrumente angesprochen, wie die konzertierte Vorbereitung von Entscheidungen, die Ausdehnung der obligatorischen Konsultationen, die Errichtung eines Systems von Warnindikatoren sowie die Festlegung zulässiger Bandbreiten für Konjunkturschwankungen (vgl. 71/107/EWG: 32). Diese wurden jedoch noch nicht weiter ausgeführt.

Bei den in den Programmen angesprochenen Politikfeldern mit ausgabenpolitischer Relevanz handelt es sich um Haushaltspolitik, Strukturpolitik, Forschungs- und Entwicklungspolitik und in geringem Umfang Sozialpolitik.

Die Haushaltspolitik wurde vor allem im 1. Programm ausführlich behandelt. Ein Schwerpunkt lag dabei auf Empfehlungen zur Ausweitung des kollektiven Konsums, da diesem eine wachsende Rolle bei der Entwicklung der Industrieländer zugesprochen wurde (vgl. 67/264/ EWG: 1535). »Das Ausmaß des zu befriedigenden kollektiven Bedarfs, vor allem im Bereich der Verkehrsinfrastruktur, des Unterrichts- und Gesundheitswesens, zwingt die Mitgliedsländer zu außergewöhnlich großen Anstrengungen« (ebenda: 1532). Auch in den Bereichen Kultur, Wissenschaft und Freizeitgestaltung wurde ein starker Rückstand gegenüber industriellen Einrichtungen festgestellt (vgl. ebenda: 1518). Um eine ausgewogene Entwicklung der langfristigen Investitionen zu fördern und die Finanzpolitik zu einem »Angelpunkt der allgemeinen Wirtschaftspolitik« zu machen, wurden die Mitgliedstaaten aufgefordert, mehrjährige Haushaltsprogramme aufzustellen (vgl. ebenda: 1519). Dabei sollte jedoch die Flexibilität der Haushaltspolitik gewahrt bleiben.

Im Gegensatz zur Koordinierung der kurzfristigen Wirtschaftspolitik beschäftigten die Programme für die mittelfristige Wirtschaftspolitik sich auch ausführlich mit der Verbesserung der Angebotsseite, vor allem durch Struktur- und Forschungspolitik. Eine gemeinsame Strukturpolitik sah man als notwendig an, weil der Strukturwandel durch den Gemeinsamen Markt beschleunigt wurde, die Mitgliedstaaten ähnliche Strukturprobleme aufwiesen und es »immer schwieriger [wurde], isoliert auf na- 
tionaler Ebene Lösungen anzustreben, da sich einerseits das nationale Instrumentarium allmählich verringert, und da andererseits die immer noch vorhandenen Instrumente an Durchschlagkraft verloren haben « (69/157/EWG: 32). Letzteres wurde mit der Freizügigkeit der Produktionsfaktoren erklärt, die zu Produktionsverlagerungen, neuen sektoralen Problemen in anderen Mitgliedstaaten sowie einem Aufschaukeln von Beihilfen führen könnten (vgl. ebenda: 33). Eine Zusammenarbeit in diesem Gebiet sollte nicht nur über die mittelfristigen Programme, sondern auch über regelmäßige Konfrontierungen, vorherige Abstimmungen sowie die Festlegung gemeinsamer Kriterien für selektive Fördermaßnahmen erfolgen (vgl. ebenda: 32 und 37ff). Die - ausgabenrelevanten - Empfehlungen für die Mitgliedstaaten gingen dabei in zwei Richtungen: Zum einen sollten die Staaten Sektoren finanziell unterstützen, die sehr negativ vom Strukturwandel betroffen waren. Dabei ging es nicht darum, diese längerfristig zu erhalten, sondern eine sozialverträgliche Anpassung sowie Umstellung zu ermöglichen. Zum anderen sollten zukunftsträchtige Sektoren wie die elektronische Industrie finanziell gefördert werden, die der Gemeinschaft eine Spitzenstellung in der Welt sichern könnten (vgl. ebenda: 44ff).

Die Empfehlungen im Bereich Forschungs- und Entwicklungspolitik gingen in eine ähnliche Richtung, hier wurde vor allem der Wettbewerb mit den USA herausgestellt (vgl. 69/157/EWG: 10). Das gemeinsame Vorgehen wurde damit begründet, dass »die Dimension der einzelnen Mitgliedstaaten nicht mehr ausreicht, um die Ansprüche, die der wissenschaftliche und technische Fortschritt an sie stellt, für sich allein in angemessenem Maße erfüllen zu können« (ebenda: 15). Dies bezog sich insbesondere auf die finanziellen Mittel, welche nur mehr gemeinsam aufgebracht werden konnten. Als Formen gemeinsamen Vorgehens wurden eine Abstimmung von nationalen Entscheidungen und Instrumenten sowie die Entwicklung gemeinsamer Kriterien für prioritäre Forschungsgebiete (vgl. 69/157/EWG: 64f) genannt. Die Mitgliedstaaten wurden aufgefordert, den Mitteln für Forschung in den nächsten Jahren Vorrang einzuräumen, was sich in einem steigenden Anteil am Sozialprodukt widerspiegeln sollte. Als Beispiele wurden das Bildungssystem, insbesondere die Universitäten (hierfür wurden recht präzise Leitlinien aufgestellt), staatliche Forschungsaufträge und Forschungsbeihilfen sowie die Schaffung erster Absatzmöglichkeiten genannt (vgl. 69/157/EWG: 63ff).

Schließlich enthielten die Programme in geringem Umfang auch sozialpolitische Maßnahmen. Im 1. Programm fand sich der Hinweis, dass es in den nächsten Jahren Probleme aufgrund der kräftigen Erhöhung der Renten und der steigenden Leistungen der Krankenversicherung geben würde, weshalb »die gesamten finanziellen Probleme der Sozialversi- 
cherungen $[\ldots]$ unter gebührender Berücksichtigung der wirtschaftlichen und sozialen Aspekte eingehend geprüft werden [müssen]« (67/264/ EWG: 1563). Das 2. und 3. Programm beschäftigten sich mit einem Ausbau der Sozialsysteme. Begründet wurde ein gemeinsames Vorgehen damit, dass die Wirtschaftspolitik der Gemeinschaft erst durch ihren Beitrag zur Verbesserung der Lebensbedingungen ihren Sinn erhalte (vgl. 71/107/EWG: 10). Die Mitgliedstaaten wurden aufgefordert, vermehrt öffentliche Leistungen, insbesondere im Erziehungs- und Gesundheitswesen sowie Wohnungsbau bereitzustellen und den sozialen Schutz an die "gesellschaftspolitischen Erfordernisse der Gegenwart« (71/107/ EWG: 10) anzupassen. Das Ziel einer gerechteren Einkommens- und Vermögensverteilung (vgl. ebenda) wurde im 2. Programm bei der Einkommenspolitik behandelt, die nicht nur die Löhne, sondern auch die staatlichen Transferleistungen umfasste (vgl. 69/157/EWG: 93). Den Mitgliedstaaten wurde empfohlen, diese Leistungen entsprechend der Löhne (und beides möglichst gemäß der wirtschaftlichen Lage) zu erhöhen. Zu diesem Zweck - und um eine gleichmäßige Steigerung der Einkommen in allen Ländern zu gewährleisten - sollten Orientierungsdaten entwickelt werden, die unter anderem die Produktivitätsentwicklung widerspiegeln (vgl. ebenda: 89). Aufgrund der Vielschichtigkeiten und Komplexität des Themas wurden jedoch keine eigenen Leitlinien für die Sozialausgaben formuliert, auch wenn dies für notwendig gehalten wurde (vgl. ebenda: 98). Auch im 3. Programm fand sich der Hinweis, dass es noch nicht möglich sei, alle Mittel zur Erreichung der sozialpolitischen Ziele festzulegen (vgl. 71/107/EWG: 10). Um dieses Problem zu lösen, verabschiedete der Rat im selben Jahr ein Arbeitsprogramm zur Durchführung des sozialpolitischen Art. 118 EWGV. Hierin wurden Bereiche ausgewählt, bei denen sich die dringlichsten Probleme auf Gemeinschaftsebene stellten und Aussicht auf konkrete Ergebnisse bestand. $\mathrm{Zu}$ den möglichen Kooperationsgebieten sollten von der Kommission Studien erarbeitet werden (vgl. 71/C 23/20: 20ff). Weiterhin wurde die Aufstellung eines europäischen Sozialbudgets gefordert, eine vergleichende Übersicht über die Mittel, welche die Mitgliedstaaten im Bereich der Sozialpolitik aufbrachten sowie eine Vorausschau über die künftigen finanziellen Probleme der sozialen Sicherheit (vgl. ebenda: 22). In seiner sozialpolitischen Mitteilung von 1973 empfahl der Rat eine angemessen Abstimmung der Politik der Mitgliedstaaten auf dem Gebiet der sozialen Sicherheit und gemeinsame Maßnahmen zur Bekämpfung von Armut (vgl. Rat 1973: 54). 


\section{Beschäftigungspolitik}

Auch die Beschäftigungspolitik war hauptsächlich mittelfristig ausgerichtet. Im Mittelpunkt stand der Umgang mit der Arbeitskräfteknappheit, Arbeitslosigkeit trat nur temporär auf, hervorgerufen durch den Strukturwandel oder wirtschaftliche Abschwünge. Konjunkturell bedingte Arbeitslosigkeit sollte mit Hilfe der allgemeinen Politik der Konjunkturbelebung abgebaut werden (s.o.). Hinsichtlich der Arbeitskräfteknappheit sowie der durch den Strukturwandel ausgelöste Arbeitslosigkeit wurden insbesondere verstärkte Anstrengungen im Bereich der Berufsausbildung und Umschulung empfohlen. Das gemeinsame Vorgehen - vertraglich abgesichert durch Art. $128 \mathrm{EWGV}^{90}$ - wurde damit begründet, das Arbeitskräftepotential der Gemeinschaft bestmöglich verwenden zu wollen (vgl. 67/264/EWG: 1540) und die Arbeitnehmerfreizügigkeit zu erleichtern (vgl. 63/266/EWG: 1338; 71/C 81/05: 7). Angestrebt wurde eine gemeinsame Berufsausbildungspolitik; ein reger Informationsaustausch sowie die Schaffung einheitlicher Ausbildungsstandards bzw. die Angleichung der Ausbildungsniveaus sollten den Weg dorthin ebnen (vgl. 71/C 81/05: 6). Zu diesem Zweck wurden zwei Dokumente mit Grundzügen bzw. Leitlinien für eine gemeinsame Politik der Berufsausbildung verabschiedet (63/266/EWG und 71/C 81/05). Um die allgemeine Koordinierung der Beschäftigungspolitik zwischen den Mitgliedstaaten und der Gemeinschaft zu erleichtern, wurde 1970 ein »Ständiger Ausschuss für Beschäftigungsfragen« eingerichtet, der den Dialog und die Konsultationen zwischen dem Rat bzw. den Vertretern der Regierungen der Mitgliedstaaten, der Kommission und den Sozialpartnern sicherstellen sollte (vgl. 70/532/EWG, Art. 2).

Die Vorgaben empfahlen vorwiegend, die Kontinuität der Erwerbstätigkeit zu verbessern und die berufliche Mobilität durch eine Verbesserung der Aus- und Umschulungsmöglichkeiten zu erhöhen (vgl. z.B. 71/C 81/05: 9). Einen weiteren Beitrag sollte die Sicherstellung einer angemessenen Einkommenskontinuität für Zeiten der Umschulung leisten (vgl. 71/371/EWG: 21; 71/107/EWG: 36). Auch die europaweite und nationale Mobilität der Arbeitskräfte wurde angesprochen, ersteres um den italienischen Arbeitskräfteüberschuss zur Milderung der Knappheit in den anderen Ländern zu nutzen. Allerdings wurde bei der Mobilität

90 »Auf Vorschlag der Kommission und nach Anhörung des Wirtschaftsund Sozialausschusses stellt der Rat in bezug auf die Berufsausbildung allgemeine Grundsätze zur Durchführung einer gemeinsamen Politik auf, die zu einer harmonischen Entwicklung sowohl der einzelnen Volkswirtschaften als auch des Gemeinsamen Marktes beitragen kann« (Art. 128 EWGV). 
immer auf die sozialen Folgen hingewiesen, weshalb sie nur eingeschränkt empfohlen wurde, stattdessen sollten die Mitgliedstaaten sich bemühen, in den vom Strukturwandel negativ betroffenen Regionen Arbeitsplätze zu schaffen (vgl. 67/264/EWG: 1516). Soziale Ziele spielten auch bei der dritten Lösungsmöglichkeit, der Erhöhung des Arbeitskräftepotentials, eine große Rolle: Dies sollte nicht durch eine Verkürzung der Ausbildungszeit oder eine Erhöhung des Pensionsalters erreicht werden, auch die Steigerung der Erwerbstätigkeit verheirateter Frauen durch einen Ausbau von Kinderbetreuungseinrichtungen wurde nur zaghaft empfohlen (vgl. 67/264/EWG: 1552f). Insgesamt wurde die Überlegung angestellt, dass die Mitgliedstaaten im Beschäftigungsbereich »gleichzeitig präzise Verpflichtungen eingehen [...] um die Befürchtungen jedes einzelnen Landes hinsichtlich der Auswirkungen, die solche Maßnahmen auf seine Wettbewerbsstellung haben könnten, zu zerstreuen« (71/371/EWG: 21).

\section{Schlussfolgerungen}

Zusammenfassend soll nun beantwortet werden, ob die Absicht hinter den europäischen Vorgaben in dieser Phase darin bestand, die mitgliedstaatlichen Interventionsmöglichkeiten zu erweitern oder zu beschränken, um so ihre Handlungsfähigkeit zu stärken.

Hinsichtlich der allokativen Aufgaben der Staaten wurden die Interventionsmöglichkeiten in der Beihilfenpolitik zwar durch den EWGV deutlich eingeschränkt, da die Mitgliedstaaten ohne europäische Erlaubnis keine Subventionen mehr vergeben durften. Das Verbot wurde jedoch in den weiteren Vorgaben gemildert, indem Beihilfen für bestimmte Sektoren (Verkehr, Schiffbau, Sektoren im Strukturwandel, fortschrittliche Sektoren) ausdrücklich erlaubt wurden. Staatliche Interventionen im Bereich öffentliche Güter wurden in dieser Phase sehr nachdrücklich empfohlen und hauptsächlich damit begründet, dass der kollektive Konsum wesentlich zum Wohlstand der Gesellschaft beitrage und die kollektiven Bedürfnisse - traditionelle wie neue - durch die Staaten befriedigt werden sollten. Dies bezog sich sowohl auf öffentliche Güter mit allokativer Funktion (z.B. Infrastruktur, Bildung, Forschung- und Entwicklung) als auch auf Güter mit distributiver Funktion (Gesundheitswesen, Wohnungsbau etc.), da die Empfehlungen sich in den gleichen Dokumententypen befanden, bestand hier auch kein Unterschied in Bezug auf die Verbindlichkeit.

$\mathrm{Zu}$ den Sozialausgaben gab es nicht viele Empfehlungen. Der Verbesserung der Lebensbedingungen wurde eine große Bedeutung zugemessen, ein Ausbau der Sozialleistungen sollte hierzu einen Beitrag lei- 
sten, die Mitgliedstaaten demnach stärker in die Wirtschaft intervenieren. Wegen der Komplexität des Gebiets wurden jedoch keine konkreten Empfehlungen verabschiedet.

Stabilisierung spielte in dieser ersten Phase eine zentrale Rolle: Aufgrund der so wahrgenommenen verminderten Wirkungsmächtigkeit der nationalstaatlichen Instrumente sowie der höheren Effektivität des gemeinsamen Vorgehens sahen die Mitgliedstaaten eine Koordination hier als besonders notwendig an. In den Vorgaben vereinbarten sie, das erforderliche Instrumentarium bereitzustellen, um schnell auf Konjunkturschwankungen reagieren zu können. Abschwünge sollten durch gemeinsame Aktionen zur Erhöhung der Nachfrage gemildert, einer zu starken Expansion durch Nachfragereduzierung - möglichst beim privaten Konsum - entgegen gewirkt werden. Zur Finanzierung der Nachfrageerhöhungen sowie für öffentliche Investitionen waren auch Haushaltsdefizite erlaubt, deren Begrenzung nur empfohlen wurde, um in Boomphasen die Nachfrage zu dämpfen. Die Verbindlichkeit der Stabilisierungsvorgaben schwankte zwischen verbindlichen Richtlinien im Falle der französischen Krise und rechtlich unverbindlichen Empfehlungen, die jedoch aufgrund ihrer teilweise sehr hohen Detailliertheit eine Überprüfung durch die europäischen Organe sowie die Öffentlichkeit ermöglichten.

Die europäischen Vorgaben hatten somit in allen drei Bereichen staatlicher Intervention das Ziel, die nationalen Interventionsmöglichkeiten auszubauen.

\section{Staatsverständnis}

Um herauszufinden, welches Staatsverständnis den europäischen Vorgaben zugrunde liegt, wird im Folgenden eine qualitative Inhaltsanalyse durchgeführt. Vorauszuschicken ist, dass es für diese Phase relativ wenig Dokumente gibt, auf die sich die Inhaltsanalyse und somit die Aussage über das Staatsverständnis beziehen kann. ${ }^{91}$ Dies liegt - wie bereits zu Beginn beschrieben - daran, dass die Mitgliedstaaten in den Anfangsjahren der Integration die Koordination im Bereich der Ausgabenpolitik erst aufbauen mussten. Da es sich insgesamt um 17 Dokumente handelt, sind Rückschlüsse auf das Staatsverständnis jedoch möglich. ${ }^{92}$ Eine

91 Für die Frage nach der Handlungsfähigkeit konnten deutlich mehr Dokumente ausgewertet werden, da einige Dokumente zu Koordinationsverfahren keine für das Staatsverständnis relevanten Stellen aufwiesen.

92 Ausgewertet wurden folgende Dokumente: 63/266/EWG, 64/246/EWG, 65/192/EWG, 66/736/EWG, 67/264/EWG, 67/452/EWG, 68/147/EWG, 69/157/EWG, 71/107/EWG, Rat 1971, 71/371/EWG, 71/C 81/05, 72/C 133/12, 72/C 133/01, 73/C 75/01, 73/C 107/01, 73/C 116/22. 
Aufteilung in verschiedene Dokumententypen hat bei dieser Anzahl allerdings keinen Sinn, weshalb bei den Ergebnissen der Frequenzanalyse besonders beachtet werden muss, dass nicht in jedem Dokument alle in Kapitel 4.1 entwickelten (Ober-)Fragen angesprochen wurden.

Was die (erste) Oberfrage nach den Einstellungen betrifft, so fanden sich in den Dokumenten hierzu kaum Aussagen. Dem Staat wurde eine wichtige Rolle in der Wirtschaftspolitik zugeschrieben, was jedoch anscheinend als selbstverständlich angesehen und nicht extra begründet oder rechtfertigt wurde. So stand beispielsweise im 1. Programm für die mittelfristige Wirtschaftspolitik der Satz: »In den kommenden Jahren wird [...] nach Wegen gesucht werden müssen, um das Instrumentarium der Wirtschaftspolitik zu vergrößern und zu verbessern« (67/264/ EWG: 1539). Dem entspricht auch, dass bezüglich des Staatshaushalts in den meisten Dokumenten nur darauf hingewiesen wurde, dass die Ausgaben in den kommenden Jahren weiter steigen würden, was insbesondere zur Befriedigung des kollektiven Konsums (s.u., öffentliche Güter) für notwendig erachtet wurde. Hinsichtlich der Struktur des Staatshaushalts wurde keine allgemeine Umschichtung von konsumtiven zu produktiven Ausgaben empfohlen. Im Rahmen der kurzfristigen Nachfragedämpfung wurde jedoch recht häufig darauf verwiesen, dass der Staat nicht bei den investiven Ausgaben sparen sollte (10/17) und es »wünschenswert [sei], daß insbesondere in den Ländern mit relativ niedriger Investitionsquote das Schwergewicht der Maßnahmen zur Bremsung der Nachfrage im Bereich der Konsumausgaben liegt« (73/C 107/ 01: 9).

Auch über den Markt fanden sich kaum allgemeine Aussagen, nur in einem Dokument wurde er explizit positiv dargestellt:

»Im Rahmen der globalen Maßnahmen zur Erreichung der großen wirtschaftsund sozialpolitischen Ziele des EWG-Vertrags ist das freie Spiel des Marktes in den Bereichen, in denen ein befriedigender Wettbewerb herrscht, eines der wichtigsten Mittel, um auch die Zielsetzungen der mittelfristigen Wirtschaftspolitik und insbesondere den rationellsten Einsatz der Produktionsfaktoren zu gewährleisten« (67/264/EWG: 1522).

Dem Unternehmertum wurde in keinem der Dokumente eine spezielle Rolle eingeräumt.

Bezüglich der zweiten Frage, Ziele und Probleme, war in dieser ersten, allgemein durch ein sehr rasches Wachstum gekennzeichneten Phase vor allem das Problem der Inflation von Bedeutung. Diese wurde auf eine das Angebot übersteigende Nachfrage (9/17) und zusätzlich auf - auch unabhängig von der Nachfrage - steigende Kosten (7/17) zurückgeführt: »Die Inflation hat immer stärker den Charakter einer Kostenin- 
flation angenommen« (Rat 1971: 15). Als Lösungsstrategie wurde hauptsächlich Nachfragepolitik empfohlen (s.u.).

Die Stabilisierung der Konjunktur spielte ebenfalls eine wichtige Rolle (7/17), auch zu diesem Zweck wurde - und zwar ausschließlich staatliche Nachfragesteuerung empfohlen (7/17): »Wo und solange die Konjunkturlage noch als zu schwach anzusehen ist, sind [...] eine entsprechende Erhöhung der öffentlichen Investitionen und eine Intensivierung der Maßnahmen zur Förderung der Investitionen der Unternehmungen erwünscht«(67/452/EWG: 8). Das Wachstumsziel rückte erst Ende der 1960er Jahre durch die Programme für die mittelfristige Wirtschaftspolitik in den Blick, es wurde in 8 von 17 Dokumenten als Ziel erwähnt, wenn Instrumente genannt wurden, dann angebotspolitische (3/17):

»Während die Konjunkturpolitik hauptsächlich über die Beeinflussung der Nachfrageentwicklung wirkt, hat die mittelfristige Wirtschaftspolitik auch das Angebot zu berücksichtigen. [...] In der Tat durften nach den Projektionen die mittelfristigen Wachstumsperspektiven kaum von der Entwicklung der Gesamtnachfrage her beeinträchtig werden, sondern in erster Linie von dem begrenzten Spielraum zur Erhöhung des Angebots« (67/264/EWG: 1538).

Beschäftigungsprobleme stellten sich hauptsächlich in Form eines Arbeitskräftemangels, dem unter anderem durch eine verstärkte Mobilität der Arbeitnehmer (4/17) sowie gemeinsamen Anstrengungen bei der Berufsausbildung (2/17) entgegen gewirkt werden sollte. So setzte der Rat in seinem »Beschluß über die Aufstellung allgemeiner Grundsätze für die Durchführung einer gemeinsamen Politik der Berufsausbildung« das Ziel der »rechtzeitige[n] Schaffung geeigneter Ausbildungseinrichtungen, damit die in den einzelnen Wirtschaftsbereichen benötigten Arbeitskräfte zur Verfügung stehen« (63/266/EWG: 1339). Wenn das Problem der Arbeitslosigkeit - entweder temporär oder regional - auftauchte, sollte die Politik »nicht nur [darauf ausgerichtet] sein, die Anpassung der Arbeitskräfte an die Strukturänderungen aktiv zu fördern, sondern sie sollte die Arbeitnehmer auch gegen eventuell damit verbundene soziale Nachteile weitgehend schützen« (69/157/EWG: 23). Es wurden also sowohl nachfrage- (4/17) wie angebotspolitische Maßnahmen (6/17) empfohlen.

Bereits in dieser Phase fanden sich recht viele Aussagen zum Haushaltsdefizit (13/17). In konjunkturellen Abschwüngen sollten Defizite »akzeptiert und gegebenenfalls monetär finanziert werden, soweit sie auf konjunkturbedingte Mindereinnahmen und auf Mehrausgaben, die zur Konjunkturstützung notwendig sind, zurückzuführen sein werden« (67/452/EWG: 7). Im Aufschwung wurde eine Minderung der Defizite 
als Mittel zur Verringerung der öffentlichen Nachfrage empfohlen. Dies sollte jedoch nur dann über eine Kürzung öffentlicher Ausgaben erfolgen, wenn hierdurch keine wichtigen Aufgaben des Staates - v.a. im Hinblick auf den notwendigen kollektiven Konsum - behindert würden (10/17). In jenen Fällen war eine Erhöhung der Steuern vorzuziehen, um auf diese Weise den privaten Konsum zu verringern (3/17).

Mit Blick auf die dritte Oberfrage, die Staatsaufgaben in den drei Bereichen Allokation, Distribution und Stabilisierung, muss vorangestellt werden, dass die teilweise geringe Anzahl der Kategorienzuordnungen darauf zurückzuführen ist, dass viele Dokumente nur wenige Interventions- bzw. Aufgabenbereiche behandelten.

Im Bereich der Allokation wurden Subventionen zum einen geduldet $\left(2 / 17^{93}\right)$ : »Unter Vermeidung von Beihilfen mit wettbewerbsverzerrendem Charakter sollten möglichst solche Unternehmen begünstigt werden, die für eine rasche Erreichung der angestrebten Ziele am besten geeignet sind « (69/157/EWG: 33). Zum anderen wurden sie - eher zaghaft - abgelehnt, sowohl zur Verminderung der öffentlichen Nachfrage bzw. des Haushaltsdefizits (4/17) als auch in Fällen, in denen sie den Wettbewerb zu sehr verfälschten (3/17) bzw. den Strukturwandel behinderten (3/17).

Öffentlichen Gütern wurde in dieser Phase eine große Bedeutung zugemessen. So sollte der Staat vor allem Infrastruktur bereitstellen (6/17) und in Forschung und Entwicklung investieren (2/17), um eine gute Grundlage für die europäischen Wirtschaft zu schaffen. Am häufigsten wurden Investitionen in Bildungspolitik empfohlen (11/17), speziell mit dem oben bereits erwähnten Ziel, die Arbeitskräfteknappheit durch einen Ausbau der Berufsqualifizierung zu mindern. Insgesamt wurden öffentliche Güter als »eine wesentliche Voraussetzung für die Stärkung der internationalen Wettbewerbsfähigkeit und für eine Aufrechterhaltung eines raschen Wirtschaftswachstums sowie für die Förderung des sozialen Fortschritts« (67/264/EWG: 1559) betrachtet. Auch die Bereitstellung öffentlicher Güter mit distributiver Funktion wurde als wichtige staatliche Aufgaben angesehen. Genannt wurden sozialer Wohnungsbau (4/17), das Gesundheitswesen (7/17) und Kinderbetreuung (1/17).

$\mathrm{Zu}$ den Sozialausgaben gab es wenige explizite Vorgaben, hier befanden die Staaten sich noch in einer Findungsphase und bekundeten lediglich ihre Absicht, in diesem Bereich zusammen arbeiten zu wollen. In

93 Die geringe Anzahl ergibt sich dadurch, dass bei den Dokumenten, die sich explizit mit Beihilfen in speziellen Sektoren beschäftigen, meist nur eine Kategorienzuordnung - die zur Duldung der Beihilfen - möglich ist und sie daher nicht in die Inhaltsanalyse einbezogen wurden. 
immerhin fünf Dokumenten fand sich die Empfehlung, die Sozialausgaben zu erhöhen.

Den weitaus größten Raum nahmen die Aussagen zu staatlicher Stabilisierungspolitik ein. Hier ging es hauptsächlich um diskretionäre, kurzfristige Interventionen: Der Staat sollte die Nachfrage beeinflussen, um Konjunkturschwankungen auszugleichen (15/17), in dieser Phase insbesondere durch eine Minderung der Nachfrage: »Die Mitgliedstaaten, in denen die Produktionskapazitäten bereits stark ausgelastet sind, wenden ihre Maßnahmen zur Bremsung der steigenden Gesamtnachfrage weiterhin an und bauen sie aus « (73/C 75/01: 1). Aber auch in Schwächephasen wurde Nachfragepolitik empfohlen: »Die für eine Beschleunigung der Wirtschaftstätigkeit notwendigen Impulse müssen vor allem vom Staatshaushalt ausgehen « (71/371/EWG: 20). Teilweise fanden sich auch Aussagen zu langfristiger Stabilisierungspolitik über öffentliche Investitionen (3/17), genau wie die Wachstumsaspekte tauchten sie jedoch hauptsächlich in den Programmen für die mittelfristige Wirtschaftspolitik auf, bei denen es nicht nur um eine direkte Reaktion auf die wirtschaftliche Situation ging: »Die Gesamtnachfrage muß mittelfristig so gesteuert werden, daß ihre Ausweitung den tatsächlichen Entwicklungsmöglichkeiten des Produktionsapparats angepaßt wird« (71/107/EWG: 23).

Zusammenfassend kann man in dieser Phase sehr deutlich ein Keynes'sches Staatsverständnis in den Vorgaben finden: Die bedeutende Rolle des Staates wurde als selbstverständlich erachtet und sollte weiter ausgebaut werden, Interventionen im Bereich Allokation und Distribution wurden fast durchweg begrüßt. Der stärkste Hinweis auf das Keynes'sche Staatsverständnis ist jedoch die Bedeutung, welche man dem Problem der Konjunkturschwankungen einräumte. Diese wurde auf eine zu geringe oder zu hohe Nachfrage zurückgeführt, was eine genuin Keynes'sche Problemanalyse ist. Dem entsprechen auch die vorgebrachten Empfehlungen: Die Möglichkeit, dieses Problem über eine Selbststeuerung des Marktes zu lösen, wurde nicht in Erwägung gezogen, stattdessen fand sich in fast jedem Dokument eine positive Aussage zu diskretionärer Stabilisierungspolitik. Diese bezog sich in diesem Zeitraum des raschen Wirtschaftswachstums, das mit einer sehr hohen Nachfrage einherging, vor allem darauf, die Nachfrage zu bremsen. Dass dies in erster Linie durch eine Minderung des privaten Konsums geschehen sollte, weist wieder auf die positive Wahrnehmung des Staates hin. Dieser sollte seine Ausgaben erhöhen, insbesondere die investiven. Auch dies entspricht der Keynes'schen Denkweise, wenngleich es in der Wiederaufbauphase auch pragmatische Gründe hatte. In konjunkturellen Abschwüngen wurden Haushaltsdefizite geduldet. Die Rolle der Umvertei- 
lung bei der Nachfragestabilisierung, die bei Keynes ebenfalls wichtig ist, wurde nicht angesprochen, was jedoch mit der vorhandenen Übernachfrage in dieser Phase erklärbar ist.

\section{Fazit}

In dieser ersten Phase der europäischen Integration herrschte ein Keynes'sches Staatsverständnis vor. Einem solchen Staatsverständnis folgend soll der Staat häufig und weitgehend in die Wirtschaft eingreifen. Dies wurde in dieser Phase - so die in den Vorgaben herrschende Ansicht - jedoch zunehmend erschwert. Die Mitgliedstaaten gingen grundlegend von einer Einschränkung ihrer Interventionsmöglichkeiten durch die zunehmende wirtschaftliche Verflechtung aus. Diese schränke die bestehenden nationalstaatlichen Instrumente in ihrer Wirksamkeit ein, worauf mit einem gemeinschaftlichen Vorgehen zur Wiedererlangung der Interventionsmöglichkeiten reagiert wurde. Die Koordinierung der Wirtschaftspolitik sollte die Interventionsmöglichkeiten jedoch nicht nur in dem Sinne erweitern, dass dadurch der Status quo wieder hergestellt wurde, sondern auch insofern, als dass die nationalstaatlichen Instrumente und Maßnahmen durch ein gemeinschaftliches Vorgehen effektiver wurden, die Interventionsmöglichkeiten demnach auch im Vergleich zum Status quo ausgeweitet wurden. Dies war nicht nur bei der gemeinsamen Reaktion auf konjunkturelle Krisen der Fall, sondern auch hinsichtlich der Sicherstellung internationaler Wettbewerbsfähigkeit, z.B. durch gemeinsame Anstrengungen im Bereich Forschung und Entwicklung.

Das gemeinsame Vorgehen entspricht der der kritischen Strategie, die aus der globalisierungskritischen Position abgeleitet wurde: Die Handlungsfähigkeit eines interventionistischen Staates wird durch einen Ausbau bzw. eine Wiedererlangung von Interventionsmöglichkeiten gestärkt. Vor diesem Hintergrund wurde im Laufe der Jahre ein recht weitgehendes gemeinsames Vorgehen entwickelt. Dies macht sich besonders deutlich daran fest, dass die Mitgliedstaaten ihre wirtschaftspolitischen Maßnahmen im Rahmen der Konsultationen genehmigen lassen mussten, auf gemeinschaftlicher Ebene quantitative und qualitative Orientierungsdaten für die Haushaltspolitik festlegten und das Ziel der Vergemeinschaftung der Berufsausbildungspolitik verfolgten. 


\subsection{Phase II (1974-1982)}

\section{Umfeldbeschreibung}

Die zweite Untersuchungsphase umfasst die Jahre 1974 bis 1982. Ihr Beginn war geprägt von den Folgen der Ölkrise von 1973, die sich in einer Vervierfachung der Ölpreise äußerte (vgl. Streb 2006: 22). In der dadurch ausgelösten ersten schweren Rezession der Nachkriegszeit nahm 1975 die gesamtwirtschaftliche Produktion in der Gemeinschaft zum ersten Mal seit Kriegsende absolut ab, wenn auch um weniger als $1 \%$. Nach einer kurzen Erholung gingen die Wachstumsraten bereits 1977 wieder zurück, später verstärkt durch die zweite Ölkrise von 1978/79. Erst ganz am Ende der Phase gab es wieder einen leichten Aufschwung (vgl. Europäische Kommission 1993: 207). So endete in jener Phase das >goldene Nachkriegszeitalter : Die Wachstumsraten blieben geringer durchschnittlich 2,5\% im Vergleich zu 4,8\% in der Vorphase -, die Arbeitslosigkeit stieg relativ kontinuierlich von 2,8\% (1974) auf knapp 9 \% (1982), was mehr als einer Verdreifachung entspricht, die Konjunkturzyklen prägten sich aus (vgl. Europäische Kommission 1993: 200 und 207). Ein weiteres großes Problem dieser Phase war die Inflation. Sie lag 1974 im Durchschnitt bei 12,7 \%, sank bis 1978 auf 7,8 \% (vgl. 80/ 1265/EWG: 19), stieg dann jedoch wieder an (vgl. 83/674/EWG: 6). Zwischen den einzelnen Mitgliedstaaten gab es dabei große Unterschiede: Im Jahr mit der höchsten durchschnittlichen Inflation (1981: 12,8 \%) wiesen die Niederlande eine Rate von $6,8 \%$ aus, während Griechenland mit 24,5\% den Spitzenplatz einnahm (vgl. 83/674/EWG: 6).

Die wirtschaftliche Entwicklung wirkte sich auch auf den politischen Bereich bzw. den Fortgang des Integrationsprozesses aus: Das 1969 vereinbarte Vorhaben, eine Währungsunion zu errichten, geriet bereits 1974 in eine schwere Krise, als Frankreich - ohne Absprache mit den anderen Mitgliedstaaten - den Wechselkurs des Franc freigab und somit aus der Währungsschlange ausschied (vgl. Gillingham 2003: 133). Auch andere Länder konnten die Wechselkurse nicht halten und scherten aus. Infolgedessen und auf Initiative von Helmut Schmidt und Valerie Giscard D'Estaing trat an die Stelle der geplanten Währungsunion das Europäische Währungssystem (EWS). Im Verhältnis zur Währungsunion war es deutlich bescheidener, weder wurde eine gemeinsame Geldpolitik angestrebt, noch von der Notwendigkeit einer supranationalen Wirtschaftspolitik gesprochen. Das EWS entsprang auch nicht dem Wunsch nach verstärkter Integration, sondern der Notwendigkeit, nach dem Ende von Bretton Woods und dem anhaltend starken Dollarkurszerfall im Winter 1977/78 die Gemeinschaft vor zu starken Wechselkursschwankungen zu 
schützen (vgl. Ziltener 1999: 133). Zu diesem Zweck wurden im EWS die Wechselkurse der teilnehmenden Länder mit einer gewissen Bandbreite festgeschrieben, wenn der Kurs an die Grenzen der Bandbreiten stieß, waren die zentralen Notenbanken zur Intervention verpflichtet (vgl. Huffschmid 1994: 43).

Neben dem EWS gab in dieser Phase keine großen integrationspolitischen Fortschritte. Die Mitgliedstaaten waren mit den Wirtschaftskrisen beschäftigt, wobei sie eher auf nationale als auf gemeinsame europäische Strategien setzten (vgl. Mazey 1996: 32). Überdies war die Entscheidungsfindung in einer durch die Norderweiterung von 1973 heterogener gewordenen Gemeinschaft (1981 begann mit Griechenland die Süderweiterung) nicht leicht, da das Einstimmigkeitserfordernis des Luxemburger Kompromisses noch immer in Kraft war. Festzuhalten bleibt die Gründung des Europäischen Rates im Jahr 1974, eine Institutionalisierung der bereits vorher stattfindenden Treffen der Staats- und Regierungschefs, die zum Ziel hatten, die Grundlinien der Politik der Gemeinschaft festzulegen. Weiterhin ist die erste direkte Wahl des Europäischen Parlaments vom 7.-10.6.1979 zu nennen, die selbiges deutlich aufwertete (vgl. Weidenfeld 2006: 22). Insgesamt machte zum Ende dieser Phase der Begriff >Eurosklerose〈 die Runde, worunter das Zusammenspiel ökonomischer Stagnation und gesunkener Handlungsfähigkeit intergouvernementaler Gremien verstanden wird (vgl. Ziltener 1999: 127).

Zuletzt der Blick auf die politische Situation in den Mitgliedstaaten: Mit dem Regierungswechsel zu Margaret Thatcher in Großbritannien setzte 1979 ein politischer Wandel hin zu liberal-konservativen Regierungen ein, dem zu Beginn der 1980er Jahre alle Mitgliedsländer folgten (vgl. Gillingham 2003: 136ff). Nur in Frankreich war eine gegenteilige Entwicklung festzustellen: Aus den Wahlen von 1981 ging eine sozialistisch-kommunistische Koalitionsregierung unter Staatspräsident Mitterand hervor, die zumindest in ihren ersten Jahren eine expansive Wirtschaftspolitik und Sozialisierungsprogramme verfolgte (vgl. Ziltener 1999: 137).

\section{Intendierter Einfluss der europäischen Vorgaben auf die Interventionsmöglichkeiten der Mitgliedstaaten und ihre Handlungsfähigkeit}

Zur Untersuchung der Frage, ob mit Hilfe der europäischen Vorgaben die nationalstaatlichen Interventionsmöglichkeiten eingeschränkt oder ausgebaut werden sollten, werden diese vier großen Bereichen zugeordnet: Zum einen erfolgte eine Koordinierung im Hinblick auf die Schaffung einer Wirtschafts- und Währungsunion. Die Wirtschaftskrisen er- 
forderten ein gemeinsames Vorgehen bei der kurzfristigen Wirtschaftspolitik. Die mittelfristige Wirtschaftspolitik wurde unter anderem im Rahmen der Schaffung des Gemeinsamen Marktes koordiniert. Die Überwindung der Arbeitslosigkeit wird zwar sowohl im Rahmen der kurz- wie der mittelfristigen Wirtschaftspolitik angesprochen, da es sich um eines der wichtigsten Probleme dieser Phase handelt und - im Gegensatz zum ebenfalls zentralen Problem der Inflation - viele ausgabenrelevante Maßnahmen empfohlen wurden, wird diesem Problem ein eigener Abschnitt gewidmet.

\section{Koordinierung im Hinblick auf die Wirtschafts-} und Währungsunion

$\mathrm{Zu}$ Beginn der Untersuchungsphase herrschte noch Optimismus bezüglich des 1969 von den Staats- und Regierungschefs ausgegebenen Ziels, eine Wirtschafts- und Währungsunion zu errichten. Eine wichtige Voraussetzung für die gemeinsame Währung wurde in der Konvergenz sowohl der Wirtschaftspolitik als auch der wirtschaftlichen Entwicklung der Mitgliedstaaten gesehen (vgl. 74/120/EWG: 16). Aus diesem Grund straffte der Rat das hierfür bereitstehende Koordinierungsinstrumentarium und fasste es teilweise strenger. Die sogenannte »Konvergenzentscheidung« von 1974 führte die bisherigen Verfahren gebündelt auf, änderte sie jedoch nur wenig: Über Konsultationen sollten nun permanent alle wirtschaftspolitischen Entscheidungen der Mitgliedstaaten vor Verabschiedung auf ihre Vereinbarkeit mit den gemeinschaftlich festgesetzten Zielen und Leitlinien überprüft werden (vgl. 74/120/EWG, Art. 9). Die Treffen des Rates zur Begutachtung und Beratung der wirtschaftlichen Situation wurden von drei auf zwölf erweitert (vgl. ebenda, Art. 1), das Verfahren zur Festlegung und Anpassung der jährlichen wirtschaftspolitischen Leitlinien in Form der Jahresberichte blieb jedoch unverändert (vgl. ebenda., Art. 2-5), gleiches galt für die ebenfalls aufgeführten Programme für die mittelfristige Wirtschaftspolitik. Neu war die Möglichkeit, zur Erreichung der vorgesehenen Ziele Entscheidungen, Richtlinien oder Empfehlungen zu verabschieden (vgl. ebenda, Art. 6). Mit der »Richtlinie über die Stabilität, das Wachstum und die Vollbeschäftigung in der Gemeinschaft« (74/121/ EWG) wählte der Rat noch im gleichen Jahr ein rechtlich verbindliches Instrument für die Koordinierung, die Mitgliedstaaten mussten sie innerhalb von 12 bzw. 24 Monaten umsetzen (vgl. ebenda, Art. 12). Die Richtlinie legte fest, dass die Mitgliedstaaten ihre Wirtschaftspolitik im Einklang mit den gemeinschaftlichen Leitlinien gestalten und bei wichtigen Maßnahmen ausdrücklich auf diese Bezug nehmen sollten (vgl. ebenda, Art. 1-2). Überdies verpflichteten 
die Mitgliedstaaten sich, auch für ein leitlinienkonformes Haushaltsgebaren von nachgelagerten Gebietskörperschaften und der sozialen Sicherheit zu sorgen (vgl. ebenda, Art. 8). Bei von den Leitlinien abweichender oder andere Mitgliedstaaten gefährdender Wirtschaftspolitik konnte die Kommission eine Empfehlung an den betreffenden Staat richten und eine Prüfung im Rat stattfinden (vgl. 74/120/EWG, Art. 11).

Um die verschiedenen Bereiche der Wirtschaftspolitik sinnvoll miteinander zu verbinden, wurden 1974 weiterhin die Ausschüsse für Konjunktur-, Haushalts- und mittelfristige Wirtschaftspolitik im »Ausschuss für Wirtschaftspolitik« zusammengefasst (vgl. 74/122/EWG, Art. 1). Dieser setzte sich aus je vier Mitgliedern der Kommission und jedes Mitgliedstaates zusammen (vgl. ebenda, Art. 3), er sollte die Haushaltspolitik der Mitgliedstaaten prüfen und vergleichen, einen Vorentwurf des Programms für mittelfristige Wirtschaftspolitik vorlegen, die mitgliedstaatliche Politik auf die Übereinstimmung mit den mittelfristigen Vorgaben hin überprüfen und schließlich Gründe für mögliche Abweichungen analysieren (vgl. ebenda, Art. 2).

Obwohl die beschriebenen Instrumente wie vorgesehen angewandt und das Verfahren 1979 durch die Erweiterung um regionalpolitische Aspekte noch einmal explizit anerkannt wurde, machten vor allem die beiden Wirtschaftskrisen die ehrgeizigen Pläne zur Einführung einer gemeinsamen Währung schnell zunichte. Statt der angestrebten Konvergenz wurde eine Divergenz der wirtschaftlichen Entwicklung und Politik in den Mitgliedstaaten festgestellt (vgl. 81/ 1056/EWG: 7). Die Wirtschafts- und Währungsunion verschwand zwar nicht völlig aus den Vorgaben, so bekannte der Europäische Rat 1977, diesem Ziel verbunden zu bleiben (vgl. Europäischer Rat 1977: 26) und durch eine gemeinsame Strategie zur Krisenbekämpfung Fortschritte in diese Richtung machen zu wollen (vgl. Europäischer Rat 1978a: 11). Die WWU tauchte jedoch deutlich seltener und weniger prominent auf. 1979 trat schließlich das EWS an ihre Stelle. Auch in diesem Zusammenhang wurde eine Koordinierung der nationalen Wirtschaftspolitik als sinnvoll angesehen: »Durch eine enge und wirksame Koordinierung der Wirtschafts- und Währungspolitik müßte zunächst eine ausreichende Konvergenz der Wirtschaftsentwicklung erreicht werden. Ohne diese Koordinierung wären die Bemühungen um eine größere Wechselkursstabilität vergeblich« (77/294/EWG: 28). Das System wurde zwar auch ohne eine deutliche Konvergenz eingeführt, die Bemühungen darum jedoch fortgesetzt: »Darüber hinaus vergrößert das Europäische Währungssystem die Notwendigkeit [...], Fortschritte bei der Harmonisierung von Haushaltsund Geldpolitik zu verwirklichen« (79/19/EWG: 18). 
Da die Konvergenz der Politiken und der wirtschaftlichen Entwicklungen über eine Koordinierung sowohl der kurz- wie langfristigen Wirtschaftspolitik erreicht werden sollte, werden die konkreten Inhalte und Empfehlungen dort dargestellt.

\section{Koordinierung der kurzfristigen Wirtschaftspolitik}

Bei der Koordinierung der kurzfristigen Wirtschaftspolitik ging es in dieser Phase hauptsächlich darum, abgestimmt auf die Wirtschaftskrisen zu reagieren. Das gemeinsame Vorgehen wurde in erster Linie mit der zunehmenden wirtschaftlichen Verflechtung begründet. Diese führte nach Ansicht des Rates zum einen dazu, dass sich Störungen in der Wirtschaft eines Mitgliedstaates auch auf die anderen Länder - und über den Multiplikatoreffekt wieder auf das Ursprungsland - auswirken könnten. Dies gelte für die Mitglieder der Gemeinschaft in besonderem Maße, da sie im Verhältnis zu den anderen Industrieländern besonders offen und außenhandelsabhängig seien (vgl. 82/950/EWG: 5). Zum anderen bringe die wirtschaftliche Vernetzung es mit sich, dass ein einzelner Staat nicht mehr in der Lage sei, die Konjunktur zu beleben (77/778/ EWG: 6), weil die zur Überwindung der Krise geschaffene Nachfrage im Ausland versickere, somit in hohem Maße ihrer Wirkung beraubt würde und zusätzlich »der Steuerrückfluß im Anschluß an die Haushaltsmaßnahmen geringer ausfällt und die notwendige Stärkung des Vertrauens von Investoren und Konsumenten eher schwächer ausfällt« (79/ 19/EWG S. 18). Die wirtschaftliche Verflechtung brachte nach Ansicht des Rates jedoch nicht nur Nach-, sondern auch Vorteile, da »die Mitgliedstaaten bei koordiniertem Handeln und in Zusammenarbeit mit den anderen Industrieländern die Multiplikatorwirkung ihrer Maßnahmen verstärken, das Vertrauen der Unternehmen und Verbraucher dauerhaft festigen und auf diese Weise die angestrebten Wachstumsziele verwirklichen [können]« (77/778/EWG: 6). Eine weitere Begründung für das gemeinsame Vorgehen war, dass die Gemeinschaft als ganzes einen stabilisierenden Effekt auf die Weltwirtschaft ausüben könne: »Durch eine wietere Verstärkung ihres Zusammenhalts und durch eine Verbesserung ihres inneren Gleichgewichts wird sie in der Lage sein, wirksam zur internationalen wirtschaftlichen Entwicklung und zur Festigung des Friedens in der Welt beizutragen« (Europäischer Rat 1979a: 9). Dies würde nicht zuletzt ihre internationale Rolle stärken (vgl. Europäischer Rat 1982a: 20).

Bei den Verfahren für das gemeinsame Vorgehen im Rahmen der kurzfristigen Wirtschaftspolitik handelte es sich in erster Linie um die bereits oben beschriebenen. Die wirtschaftspolitischen Leitlinien wurden 
wie vorgesehen einmal jährlich in Form der Jahresberichte verabschiedet - ebenfalls im Sinne des Verfahrens - und immer wieder an die wirtschaftliche Lage angepasst, sowohl bei der Überprüfung im ersten Quartal (hier erfolgte in den Jahren 1974-77 eine Anpassung) als auch unter der Überschrift »Anpassung der Staatshaushalte«, wobei die »quantitative[n] Orientierungsdaten für die Entwürfe der Staatshaushalte« (74/120/ EWG, Art. 3) grundsätzlich nicht veröffentlicht wurden, lediglich in den Jahren 1976-78 die im Rahmen dieser Überprüfung verabschiedeten allgemeinen Leitlinien. Die Schaffung eines schnell einsetzbaren konjunkturpolitischen Instrumentariums sowie die Aufstellung fünfjähriger Programme für Investitionen war den Mitgliedstaaten im Rahmen einer Richtlinie verbindlich auferlegt worden (vgl. 74/121/EWG, Art. 5f). 1979 sollten die Koordinierungsverfahren weiter verstärkt werden, dabei ging es darum, die Konsultationen zu verbessern, die Mitgliedstaaten zu einer sehr viel deutlicheren Verpflichtung zu bringen und ihre Beteiligung an der Koordinierung zu erweitern. In Bezug auf die Haushaltspolitik wollte man die Gleichschaltung der Zeitpläne weiter vorantreiben und die konzeptionelle Basis bei den Haushaltslinien ausweiten. Hierzu sollten von der Kommission konkrete Vorschläge ausgearbeitet werden (vgl. Rat 1979: 81f).

Trotz der umfangreichen Koordinierung nahm die Konvergenz der Mitgliedstaaten nicht zu, sondern ab (s.o.). Die Situation in den einzelnen Staaten unterschied sich, vor allem mit Blick auf Inflation und Zahlungsbilanz, so stark, dass die Vorgaben bei der Krisenbekämpfung kein identisches Vorgehen empfahlen.

»Diese Koordinierung impliziert angesichts der unterschiedlichen konjunkturellen und strukturellen Ausgangslage keine identische Politik für die Mitgliedsländer. Eine Annäherung der grundlegenden wirtschaftspolitischen Ziele ist jedoch unerläßlich, wenn man das gemeinsam Erreichte bewahren und auf dem Wege der europäischen Integration voranschreiten will« (75/C 297/01: 8).

Auch das differenzierte Vorgehen wurde europäisch koordiniert. Die Mitgliedstaaten sollten solidarisch und unterstützend vorgehen, um zu einem für alle zufriedenstellenden Ergebnis zu gelangen. In diesem Sinne fanden sich in den meisten Vorgaben zwei Empfehlungsstränge: Mitgliedstaaten mit einer geringen Inflation und einer ausgeglichenen oder überschüssigen Zahlungsbilanz sollten eine expansive Konjunkturpolitik verfolgen und auf diese Weise ihre Importe aus den Staaten steigern, die eine hohe Inflation und eine defizitäre Zahlungsbilanz hatten. Auf diese Wiese sollte es dieser zweiten Ländergruppe erleichtert werden, eine restriktive Politik mit dem Ziel der Preisstabilität zu verfolgen, die wie- 
derum auch der ersten Ländergruppe zugute kam (vgl. 77/492/EWG: 7). Was die konkreten Empfehlungen angeht, so wurde bei der expansiven Politik - die das Wachstum steigern sollte - hauptsächlich auf eine diskretionäre Nachfrageerhöhung über Haushaltspolitik bzw. deficit spending gesetzt. Die restriktive Politik hingegen, die in erster Linie auf eine Reduzierung der Inflation abzielte, sollte die Nachfrage dämpfen, wobei der Schwerpunkt hier ebenfalls auf der Haushaltspolitik lag: Zum einen wurde empfohlen, die Haushaltsdefizite, vor allem die strukturellen, zu reduzieren, über eine Dämpfung der Ausgaben oder - sofern dies nicht inflationär wirkte - Steuererhöhungen (vgl. 74/374/EWG: 3). Zum anderen sollte die Expansion der Gesamtnachfrage gebremst werden, wenn möglich mit Ausnahme bereits unterbeschäftigter Branchen (vgl. 74/C 149/01: 7). Sobald sie ihre Inflation unter Kontrolle hatten, waren auch die zuerst restriktiv agierenden Länder angehalten, eine expansive Politik zu verfolgen und zwar mit Hilfe bereits im Vorhinein vorbereiteter Investitionsprogramme (vgl. ebenda: 9).

Obwohl fast alle Vorgaben eine diskretionäre Nachfragesteuerung empfahlen, trat im Laufe dieser Periode eine immer stärkere Skepsis gegenüber dieser Vorgehensweise zutage. Bereits 1974 sollte die Konjunkturpolitik in einen längerfristigen Rahmen eingebunden werden: »Eine konjunkturpolitische Aktion zur Integrierung der Entwicklungsprozesse von neun Volkswirtschaften wird nämlich nur dann mit Aussicht auf Erfolg $\mathrm{zu}$ verwirklichen sein, wenn sie auf gemeinsame Ziele für einen längeren Zeitraum ausgerichtet wird« (74/120/EWG: 16). Begründet wurde dies zunächst damit, dass eine globale Ankurbelungspolitik zu einer weiteren Erhöhung der Inflation beitragen könne (vgl. 74/374/EWG: 2). In den Folgejahren versah der Rat die Empfehlungen einer diskretionären Stabilisierungspolitik immer wieder mit Einschränkungen, vor allem für die Länder, die bereits sehr hohe Haushaltsdefizite oder eine hohe Inflation aufwiesen. 1977 wurde die angemessene Anwendung der Konjunkturpolitik folgendermaßen beschrieben:

»[D]ie Wirtschaftstätigkeit wird in der Rezession durch Haushaltsdefizite und den privaten Verbrauch gestützt; in einer späteren Phase muß jedoch der Anteil des privaten und öffentlichen Verbrauchs abnehmen, um Raum für Investitionen zu schaffen; die Haushaltsdefizite müssen je nach Lage der Länder fühlbar zurückgehen oder gar verschwinden. Entsprechende Maßnahmen erfordern allerdings eine Differenzierung, falls die Gesamtnachfrage schwach bleiben sollte« (77/294/EWG: 20).

Die Stimmung wandte sich jedoch immer stärker gegen diese Art der Stabilisierung, insbesondere aufgrund der angespannten Haushaltslage 
vieler Mitgliedstaaten (vgl. 80/1265/EWG: 22). 1981 hielt der Europäische Rat schließlich zum ersten Mal fest, dass eine kurzfristige Stimulierung sich als unwirksam erweisen würde (vgl. Europäischer Rat 1981a: 8). Der Rat begründete dies damit, dass höhere Defizite zu höheren Zinsen führten, welche wiederum das Wachstum schwächten (vgl. 81/1056/ EWG: 6). Diese Crowding-Out-These war schon vorher erwähnt, aber nie als entscheidend angesehen worden, nun wurde in ihrem Sinne allen Mitgliedstaaten eine »gesunde« Haushaltspolitik empfohlen (vgl. Europäischer Rat 1981a: 8), in konjunkturellen Abschwüngen sollten nur noch die automatischen Stabilisatoren wirken (vgl. 82/950/ EWG: 11). Ein »Overkill« bei der Sanierung der Defizite sei jedoch zu vermeiden, da dies über das Sparparadoxon zu weiteren Defiziterhöhungen führen könne (vgl. 81/1056/EWG: 6).

Gleichzeitig mit der wachsenden Skepsis gegenüber der kurzfristigen Stabilisierung erhielt die Inflationsbekämpfung einen immer höheren Stellenwert. Während sie zu Beginn noch gleichrangig mit den anderen wirtschaftspolitischen Zielen wie Wachstum und Beschäftigung war, wurde sie zunehmend als prioritär angesehen, da sie »auf mittlere und lange Sicht eine Voraussetzung für die Lösung der Probleme des Wachstums, der Strukturveränderungen und damit der Beschäftigung [ist]« (Europäischer Rat 1979c: 8).

Die Koordinierung der kurzfristigen Wirtschaftspolitik wurde als mäßig erfolgreich bewertet, der Rat lobte zwar häufig Länder, die sich leitlinienkonform verhalten hatten (vgl. z.B. 76/916/ EWG: 6), bezeichnete die Koordinierung jedoch immer wieder als noch unzureichend: »[R]echtzeitig beschlossene und durchgeführte Gemeinschaftsmaßnahmen [hätten] es wahrscheinlich gestattet, die wirtschaftlichen und sozialen Lasten der Krise für alle zu mildern« (77/ 294/EWG: 10). Die Ursache für den mangelnden Erfolg wurde in den unterschiedlichen Situationen der Mitgliedstaaten gesehen, allerdings zeigte auch die darauf beruhende differenzierte Strategie nicht den rechten Erfolg, die restriktive Politik der Hochinflationsländer wurde nur selten von einer expansiven Politik der preisstabilen Länder aufgefangen (77/778/EWG: 3). Dennoch stellte der Europäische Rat (1981a: 7) im letzten Jahr des Untersuchungszeitraums fest »daß die Gemeinschaft unter den derzeitigen schwierigen Wirtschaftsbedingungen nach wie vor eine wesentliche Einrich-tung und ein unerläßliches Instrument zur Einschränkung der Auswirkungen der Rezession und zur Herbeiführung eines Umschwungs ist.« 


\section{Koordinierung der mittelfristigen Wirtschaftspolitik}

Auch zur Erreichung mittelfristiger Ziele ging man gemeinsam vor. Dies nahm mit der wachsenden Skepsis gegenüber der kurzfristigen Nachfragesteuerung in seiner - zumindest ergänzenden - Bedeutung $\mathrm{zu}$, denn die »klassischen Instrumente der Globalsteuerung allein reichen nicht aus, um diese Probleme zu lösen und den Zusammenhalt der Gemeinschaft zu stärken« (76/646/EWG: 2). Die mittelfristige Wirtschaftspolitik umfasste in erster Linie Struktur- und Investitionspolitik zur Förderung des Gemeinsamen Marktes, aber auch sozialpolitische Maßnahmen. Begründet wurde das gemeinschaftliche Vorgehen nicht nur mit den Vorteilen, die es für die einzelnen Staaten in Bezug auf Wachstum und Wohlstand brachte, sondern auch damit, als europäischer Wirtschaftsraum Wettbewerbsfähigkeit gegenüber den wichtigsten Konkurrenten USA und Japan zu gewinnen. Dabei ging es vor allem um die Vorteile eines großen Gemeinsamen Marktes wie auch um ein Aufholen im Bereich Technologie.

Das gemeinsame Vorgehen bestand zum einen in der Fortführung der Programme für die mittelfristige Wirtschaftspolitik, im Untersuchungszeitraum wurden das 4. und 5. Programm verabschiedet. Das 4. Programm sollte einen wirtschaftspolitischen Aktionsrahmen darstellen, die Mitgliedstaaten wurden angehalten, ihre Maßnahmen systematisch auf ihre Übereinstimmung mit den darin festgelegten Zielen zu untersuchen (vgl. 77/294/EWG: 6). Im Gegensatz zum 3. Programm wurden keine Länderleitlinien mehr aufgestellt, dafür wurden die Orientierungsdaten und Empfehlungen teilweise nach Ländern differenziert. Dies galt insbesondere für die öffentlichen Finanzen, so wurden z.B. der Kreditbedarf und die Art der Finanzierung von Defiziten für einzelne Mitgliedstaaten festgelegt. Überdies hielt der Rat es für notwendig, über quantitative Orientierungsdaten »für die großen Haushaltsblöcke, für jene Arten von Ausgaben, deren Anstieg besonders kräftig oder besonders gering ist, und für die Salden [...] zu verfügen« (77/294/ EWG S. 25). Auch in den Jahresberichten fanden sich Empfehlungen bezüglich der mittelfristigen Wirtschaftspolitik.

Zur Förderung einer gemeinsamen Technologiepolitik wurde 1974 eine Entscheidung (74/C 07/ 02) erlassen, die festlegte, wie die mitgliedstaatliche Politik in diesem Bereich koordiniert sowie Aktionen von gemeinschaftlichem Interesse durchgeführt werden sollten. Man hoffte, durch ein koordiniertes Vorgehen Doppelarbeit und gegenläufige Tendenzen zu verhindern, die Wirksamkeit der einzelstaatlichen Aktionen zu erhöhen und Kosten zu senken (vgl. ebenda, Art. 1). Als Instrumente waren Konsultationen (vgl. ebenda) und die Einrichtung eines Aus- 
schusses vorgesehen, der im Rahmen der Koordinierung unter anderem die Haushaltsposten für Wissenschaft und Technologie der Mitgliedstaaten vergleichen sollte (vgl. ebenda: 4). Auch die jährlichen wirtschaftspolitischen Leitlinien empfahlen den Mitgliedstaaten, Forschung und die Anwendung neuer Technologien zu fördern (vgl. 77/778/EWG: 7).

Weiterhin sollten die Wachstums- und Wettbewerbsfähigkeit über eine Strukturpolitik mit Hilfe von öffentlichen und privaten Investitionen erreicht werden. Zur Förderung produktiver privater Investitionen wurden Subventionen empfohlen, allerdings nur für fortschrittliche Industrien, Erhaltungssubventionen für unproduktive Branchen wurden abgelehnt (vgl. 75/361/EWG: 15; 77/340/EWG: 23). Einen Sonderfall nimmt hier die Schiffbauindustrie ein. Da sie für bedeutende Branchen, darunter einige mit hochentwickelter Technologie, unerlässlich sei, erlaubte der Rat die Gewährung von Erhaltungs- und anderen Subventionen (vgl. z.B. 78/338/EWG: 13). ${ }^{94}$ Ein gemeinsames Vorgehen bei der Beihilfenpolitik wurde allgemein als sinnvoll angesehen, um einen Überbietungswettlauf (vgl. 77/778/EWG: 7), sowie eine Segmentierung der Märkte und nationale Diskriminierungen zu verhindern (vgl. 81/1056/EWG: 10). Hinsichtlich der öffentlichen Investitionen sollte die »Haushaltspolitik [...] stärker als in der Vergangenheit als Instrument der Wachstumspolitik und zur Investitionsförderung eingesetzt werden« (77/492/ EWG: 8). Dazu wurde eine Umstrukturierung der Staatshaushalte hin zu investiven Ausgaben empfohlen (vgl. 80/1265/EWG: 22), wobei auch zwischen den öffentlichen Investitionen eine Prioritätenänderung vorgenommen werden sollte: von den in den letzten 20 Jahren stark geförderten Investitionen in Schulen, Universitäten und Autobahnen hin zu solchen, die - wie FuE, Ausbildung und neue Kommunikationstechnologien - unmittelbar zur wirtschaftlichen Entwicklung beitrugen (vgl. 82/ 950/EWG: 7). Der Ausbau von Infrastruktur und öffentlichen Transportmitteln sollte auch einen positiven Beitrag für den Gemeinsamen Markt leisten (vgl. ebenda). Detaillierte Regelungen gab es für den Bereich der Eisenbahnunternehmen: Ziel war es, dieses Verkehrsmittel und insgesamt den Verkehrsmarkt zu fördern ohne auf diese Weise den Wettbewerb zu verzerren (vgl. 75/327/EWG: 3). Daher wurde angestrebt, die Ausgleichszahlungen für die Transportpflicht $\mathrm{zu}$ harmonisieren (vgl. ebenda, Art. 9) und die finanziellen Beziehungen zwischen Staat und Eisenbahnen möglichst gleich und transparent zu gestalten (vgl. 74/C 111/01: 2).

Den Staaten wurde demnach eine bedeutende Rolle bei der mittelfristigen Wirtschaftspolitik zugeschrieben. Allerdings wurde die Höhe der

94 Die Begründung war die gleiche wie in Phase I dargestellt. 
öffentlichen Ausgaben in einigen Ländern als problematisch angesehen, da dies die Gefahr von Steuererhöhungen und damit Inflationsrisiken in sich berge und dem Markt Ressourcen entzogen würden (vgl. 77/294/ EWG: 24). Andererseits ging der Rat auch davon aus, dass der Bedarf an öffentlichen Gütern weiter ansteigen würde - neben den oben genannten öffentlichen Gütern mit allokativer Funktion auch an öffentlichen Gütern mit distributiver Funktion (die jedoch deutlich seltener empfohlen wurden) wie Gesundheit, soziale Sicherung, Umweltschutz und Stadtsanierung (vgl. 80/1265/EWG: 23). Hier wurde eine Prioritätensetzung und optimale Anpassung der Ausgaben an die »legitimen kollektiven Bedürfnisse« (77/294/EWG: 24) empfohlen.

Diese Empfehlungen leiten bereits über zu den sozialpolitischen Vorgaben, die sich auch auf die Sozialleistungen bezogen. So stellte der Rat im ersten sozialpolitischen Aktionsprogramm von 1974 fest, dass wirtschaftliche Expansion kein Selbstzweck sei, sondern dazu dienen müsse, Lebensqualität und -standard zu verbessern. Daher sprach er sich für die »Einführung einer geeigneten Abstimmung der Politiken der Mitgliedstaaten auf dem Gebiet der sozialen Sicherung, insbesondere im Hinblick auf die Förderung ihrer Annäherung auf dem Wege des Fortschritts« (74/C 13/01: 3) aus. Die sozialen Sicherungssysteme sollten schrittweise ausgeweitet und Verfahren eingeführt werden, welche die Sozialleistungen an den wachsenden Wohlstand anpassten (vgl. ebenda). Im gleichen Jahr setzten die Staats- und Regierungschefs das Ziel, »die Sozialleistungen der einzelnen Mitgliedstaaten im fortschrittlichen Sinn $\mathrm{zu}$ harmonisieren, ohne jedoch die bestehenden Sozialordnungen zu vereinheitlichen« (Konferenz der Staats- bzw. Regierungschefs 1974: 8). Langfristig wurde eine Erhöhung der Umverteilungswirkungen der öffentlichen Ausgaben, vor allem bei den oft degressiv wirkenden Sozialversicherungen angestrebt (vgl. 77/294/EWG: 24). Zum Ende der Phase wurden die - auch aufgrund der immer höheren Arbeitslosigkeit - angestiegenen Sozialausgaben jedoch auch als problematisch angesehen, da sie das Wachstum hemmen könnten (vgl. 82/950/EWG: 8). So sollten die »Haushaltsposten für die soziale Sicherheit [...] daraufhin überprüft werden, ob ihr Wachstum begrenzt, ihre Finanzierung neu überdacht und ihre Wirksamkeit verbessert werden kann« (81/ 1056/EWG: 7) und den Ländern wurde empfohlen, keine langfristigen Ausgabenverpflichtungen, insbesondere in Bezug auf Renten, einzugehen (vgl. 82/950/ EWG: 9).

Obwohl die Koordinierung der mittelfristigen Wirtschaftspolitik in den 1970er Jahren immer stärker in den Mittelpunkt rückte, wurden ihre Erfolge als bescheiden angesehen. Das 3. Programm für die mittelfristige Wirtschaftspolitik wurde als Misserfolg bezeichnet (vgl. 77/294/ 
EWG: 9f), was die Mitgliedstaaten jedoch nicht daran hinderte, ein sehr umfangreiches 4. Programm zu verabschieden. Probleme gab es erst beim 5. Programm aus dem Jahr 1982. Die Mitgliedstaaten konnten sich nur mehr auf zwei Seiten einigen (zum Vergleich: 3.: 55 Seiten, 4.: 28 Seiten), auf denen sie festhielten, dass es unterschiedliche Auffassungen bei den Zielprioritäten und vor allem der Frage, ob eine kurzfristige Stimulierung oder konsequente Stabilisierung notwendig sei, gebe (vgl. 82/ 534/EWG: 11). Daher wurde dieses Programm nur als »eine Art Orientierungsrahmen« verstanden, der keine konkreten Maßnahmen für die Mitgliedstaaten enthielt (vgl. ebenda). Auch der Jahresbericht von 1982 stellte fest, dass die jüngsten Koordinationserfahrungen »nicht gerade ermutigend « (82/950/EWG: 5) seien:

$»$ Ein Zeichen für diese Schwierigkeiten war in den letzten Jahren das allmähliche Abrücken von quantifizierten Zielsetzungen für die einzelnen wirtschaftspolitischen Ziele wie Produktion, Preisstabilisierung, Beschäftigung. Es hat sich gezeigt, daß die wirtschaftspolitischen Steuerungsinstrumente unzureichend waren, um vielfältige Ziele glaubwürdig festzulegen« (ebenda: 9).

Erklärt wurde der Misserfolg damit, dass zwar Einigkeit über die strukturellen Missstände bestehe, aber Uneinigkeit über die Strategien zu ihrer Beseitigung (vgl. ebenda: 5f).

\section{Koordinierung des Kampfes gegen die Arbeitslosigkeit}

Der Anstieg der Arbeitslosigkeit kann in den 1970er Jahren insbesondere auf die Wirtschaftskrisen, aber auch auf den Anstieg der Erwerbsbevölkerung zurückgeführt werden. Letztere wuchs demographisch bedingt um ein Prozent pro Jahr, zusätzlich aus sozialen Gründen, da immer mehr Menschen arbeiten wollten (vgl. 82/950/EWG: 7). In diesem Zusammenhang entwickelte sich vor allem die Jugendarbeitslosigkeit zu einem großen Problem. »Sowohl aus sozialen wie auch wirtschaftlichen und politischen Gründen kann die Gemeinschaft ein Andauern der hohen Arbeitslosigkeit [...] nicht hinnehmen« (77/294/EWG: 4).

Mit einem gemeinschaftlichen bzw. abgestimmten Vorgehen sollte erreicht werden, dass »auf einzelstaatlicher und gemeinschaftlicher Ebene eine Beschäftigungspolitik erreicht wird, mit der die Arbeitslosigkeit wirkungsvoller bekämpft werden kann« (80/C 168/01: 79). Teilweise wurde eine Wiedererlangung der Vollbeschäftigung bis 1980 als Ziel gesetzt (z.B. 77/294/ EWG: 17). Zu diesem Zweck sollte 
»[d]ie Gemeinschaft [...] in die Lage versetzt werden, die Auswirkungen der verschiedenen Gemeinschaftspolitiken auf die Beschäftigung schon in der Konzeptionsphase systematisch zu beurteilen, die Beschäftigungspolitiken auf Gemeinschaftsebene besser zu koordinieren und die Gemeinschaftsmaßnahmen im Bereich der Wirtschaftspolitik und im sozialen und beschäftigungspolitischen Bereich zu harmonisieren« (Europäischer Rat 1980a: 9).

Das gemeinsame Vorgehen erfolgte zum einen im Rahmen der oben beschriebenen Koordinierungsverfahren, zusätzlich sollte es ein »energisches und koordiniertes Gemeinschaftsvorgehen auf dem Arbeitsmarkt« (Konferenz der Staats- bzw. Regierungschefs 1974: 8) geben, um vorrangige Ziele festzulegen und die nationalen Maßnahmen zur Bekämpfung der Arbeitslosigkeit abzustimmen (vgl. ebenda). 1980 wurden zum ersten Mal eigenständige Leitlinien für eine Arbeitsmarktpolitik der Gemeinschaft verabschiedet (80/C 168/01), hierfür war jedoch kein jährlicher Rhythmus vorgesehen.

Die Vorgaben empfahlen eine ganze Reihe von Instrumenten: »Schaffung wirtschaftlich gesunder Arbeitsplätze, Anpassung der Arbeitskräfte an die neuen Gegebenheiten, Erleichterung der Last, die mit der zeitweilig unvermeidlich hohen Arbeitslosigkeit verbunden ist « (80/ 1265/EWG: 20). Die Lösung wurde demnach sowohl auf der Mikro- wie der Makroebene gesucht. Makroökonomisch ging es zum einen um die Bekämpfung der konjunkturellen Arbeitslosigkeit über die beschriebene diskretionäre Nachfragepolitik. Weiterhin wurde empfohlen, durch eine aktive Wirtschafts-, Beschäftigungs- und Investitionspolitik neue Arbeitsplätze zu schaffen (vgl. Europäischer Rat 1978a: 12). Die Mitgliedstaaten sollten die öffentlichen Mittel zugunsten von solchen Ausgaben umschichten, »welche arbeitsschaffende Investitionen direkt oder indirekt und nach Möglichkeit in selektiver Weise anregen « (76/916/EWG: 11). Wie bei der mittelfristigen Wirtschaftspolitik warnte der Rat auch hier davor, Beihilfen für überholte Strukturen zu zahlen (77/340/EWG: 23). Ein gemeinsames Vorgehen sollte vermeiden, »daß sich die nationalen Aktionen bei der sektoralen Orientierung widersprechen und damit zum Teil unwirksam werden« (77/340/EWG: 22). Neben beschäftigungsfördernden öffentlichen Investitionen wurden auch direkte Arbeitsmarkthilfen (81/1056/EWG: 7) sowie Arbeitsbeschaffungsprogramme - sowohl allgemein als auch für gewisse Gruppen (Jugendliche) und in gewissen Sektoren (Energie) - empfohlen, wobei auf den engen haushaltspolitischen Spielraum hingewiesen wurde (80/1265/EWG: 26). Überdies sollte eine Lohnmäßigung einen Beitrag zur Inflationsbekämpfung leisten, indem sie auf diese Weise oder auch direkt die Ertragslage und Investitionsneigung der Unternehmen steigerte (vgl. z.B. 
75/C 297/01: 9). Potential für neue Arbeitsplätze sah der Rat vor allem im Dienstleistungsbereich (vgl. 80/67/EWG: 25).

Bei der - mikroökonomischen - Arbeitsmarktpolitik lag der Schwerpunkt auf dem Bereich Bildung. Auch hier war eine Abstimmung der nationalen Politiken vorgesehen (vgl. 74/C 13/01: 2), die Staaten wurden aufgefordert, die Möglichkeiten der Aus- und Weiterbildung durch erhebliche Investitionen auszubauen (vgl. 74/374/EWG: 2) und die derzeitigen Strukturen den neuen wirtschaftlichen und sozialen Erfordernissen anzupassen (vgl. 80/C 168/01: 80). Um die Weiterbildung attraktiver zu machen, sollten die Staaten in Zeiten der Umschulung angemessene Lohnersatzleistungen zur Verfügung stellen: »Insbesondere soll während der Periode der Umschulung dem Arbeitnehmer ein Einkommensniveau garantiert werden, das nicht zu sehr unter demjenigen in seinem ursprünglichen Beruf liegt« (74/374/EWG: 2). Dies sollte auch die Mobilität der Arbeitskräfte fördern, vor allem in Richtung der Wachstumsbranchen (vgl. 75/ 361/EWG: 15). Weiterhin empfahlen die Vorgaben eine Verkürzung oder zumindest Flexibilisierung der Arbeitszeiten. Ausgabenpolitisch relevant ist die flexiblere Altersgrenze für den Renteneintritt, in einer eigenen Entscheidung legte der Rat fest, dass die Mitgliedstaaten keine prohibitiv hohen Rentenabschläge bei der Frühpensionierung einführen durften (vgl. 82/857/ EWG: 27). Uneingeschränkt wurde jedoch nur Teilzeitarbeit empfohlen (vgl. Europäischer Rat 1978a: 12), ansonsten wurde bei den arbeitszeitpolitischen Empfehlungen immer auch vor höheren Kosten für die Arbeitgeber bzw. - bei der Altersgrenze für die Rente - den Staat gewarnt (vgl. bspw. 80/67/EWG: 25), ebenso sollten negative Auswirkungen auf die Flexibilität der Arbeitsmärkte vermieden werden (vgl. 82/950/EWG: 9). Flexibilisierung wurde ansonsten selten angesprochen, 1977 wurde ein Abbau von Arbeitsmarkthindernissen aller Art, d.h. administrativ, steuerlich, sozialversicherungstechnisch und rechtlich, empfohlen (vgl. 77/ 340/EWG: 23). Schließlich wurde zum Ende der Phase der Gedanke geäußert, eine Absenkung von Sozialbeiträgen könne die Einstellungsanreize für Unternehmer erhöhen (vgl. 81/ 1056/EWG: 11). Insgesamt sollten die »Gemeinschaftsorgane für den koordinierten Einsatz der einzelstaatlichen Instrumente [im Bereich Arbeitsmarktpolitik, A.K.] sorgen und dabei deren Wirkung auf die Beschäftigung berücksichtigen« (77/778/EWG: 7). 


\section{Schlussfolgerungen}

Nach der Darstellung der Vorgaben und Empfehlungen in den vier großen Bereichen wird nun noch einmal zusammenfassend analysiert, ob mit den europäischen Vorgaben das Ziel verfolgt wurde, die nationalstaatlichen Interventionsmöglichkeiten einzuschränken oder auszubauen.

Im Bereich Allokation sollten die Interventionsmöglichkeiten ausgebaut werden: Für die Subventionen wurden viele Ausnahmeregelungen vom vertraglich festgelegten Verbot verabschiedet, sowohl für den Schiffbau als auch zur Förderung produktiver Branchen im Rahmen der Strukturpolitik. Staatliche Interventionen in Bezug auf öffentliche Güter mit allokativer Funktion, insbesondere Forschung und Entwicklung sowie Bildung und Infrastruktur, wurden sehr positiv gesehen: Mit ihrer Hilfe sollten Wachstum und Wettbewerbsfähigkeit angeregt und so auch mehr Beschäftigung geschaffen werden. Bei diesen Vorgaben gab es im Verlauf der 1970er Jahre kaum Änderungen, wobei teilweise auf den eingeschränkten Haushaltsspielraum hingewiesen wurde, weshalb eher eine Umschichtung der Staatsausgaben als ihre Erhöhung empfohlen wurde. Die Verbindlichkeit der Vorgaben reichte von den recht unverbindlichen jährlichen Leitlinien im Rahmen der Jahresberichte - wobei die Mitgliedstaaten durch eine Richtlinie dazu verpflichtet waren, sich an diese zu halten (vgl. 74/121/EWG, Art. 1) - bis hin zu verbindlichen Richtlinien und Verordnungen für den Schiffbau und die Eisenbahnen.

Im Bereich Distribution änderte sich die Absicht hinter den Vorgaben: $\mathrm{Zu}$ Beginn der Phase sollten die nationalstaatlichen Interventionsmöglichkeiten - vor allem über die Jahresberichte - ausgebaut werden: Die Staaten wurden aufgefordert, öffentliche Güter mit distributiver Funktion (Gesundheit, Stadtsanierung etc.) bereitzustellen und die Sozialleistungen dem wachsenden Wohlstand anzupassen. Im Laufe der Zeit nahmen diese Vorgaben jedoch ab und verkehrten sich Anfang der 1980er Jahre teilweise in ihr Gegenteil: Die Staaten sollten sparen und die Sozialleistungen senken, um auf diese Weise die wirtschaftliche Leistung und die Einstellungsbereitschaft der Arbeitgeber zu erhöhen.

Der deutlichste Wandel von einem beabsichtigen Ausbau zu einer Einschränkung von Interventionsmöglichkeiten ist im Bereich Stabilisierung zu erkennen. Im ersten Jahr der Untersuchungsphase verpflichtete der Rat die Mitgliedstaaten per Richtlinie, ein schnell einsetzbares konjunkturpolitisches Instrumentarium aufzubauen. Im Rahmen der differenzierten, solidarischen Strategie wurde in den rechtlich weniger verbindlichen Jahresberichten einigen Staaten eine expansive, interventionistische Stabilisierungspolitik über den Haushalt relativ uneingeschränkt empfohlen. Anderen Staaten - mit hoher Inflation, hohen Haushalts- und 
Zahlungsbilanzdefiziten - sollten hingegen eine restriktive Politik verfolgen. Mit wachsender Skepsis gegenüber der diskretionären Stabilisierungspolitik nahmen auch die Einschränkungen für die erste Staatengruppe zu, Interventionen wurden nur mehr bei gesunder Haushaltslage und am Ende nur noch regelgeleitet (über die automatischen Stabilisatoren) empfohlen.

Für alle drei Bereiche - Allokation, Distribution und Stabilisierung gab es weniger quantifizierte Ziele, was die (öffentliche) Überwachung der Umsetzung erschwerte. Somit wandelte sich in dieser Phase die Absicht hinter den europäischen Vorgaben: In den ersten Jahren sollte das gemeinsame Vorgehen die Interventionsmöglichkeiten der Mitgliedstaaten, die vor allem im Bereich der Stabilisierung durch die wirtschaftliche Verflechtung als eingeschränkt wahrgenommen wurden, wieder ausbauen: »Anders gesagt soll durch ein Vorgehen auf Gemeinschaftsebene der Prozeß umgekehrt werden, der infolge der zunehmenden Einbindung der Wirtschaft der Mitgliedstaaten in die Europäische Gemeinschaft und die Weltwirtschaft die Wirksamkeit einer rein nationalen Wirtschaftspolitik unterhöhlt hat « (79/19/EWG: 17). Zum Ende der Phase gab es immer mehr Vorgaben, welche die mitgliedstaatlichen Interventionsmöglichkeiten einschränken sollten, neben dem Bereich der zu dieser Zeit als unwirksam angesehenen Stabilisierung auch bei den Sozialausgaben.

\section{Staatsverständnis}

Auch für diese zweite Integrationsphase wird eine qualitative Inhaltsanalyse durchgeführt, um daraus Rückschlüsse auf das den Leitlinien zugrunde liegende Staatsverständnis zu ziehen. Da für diesen Zeitraum insgesamt 32 Dokumente analysiert werden konnten, ist eine Unterteilung in zwei Dokumententypen möglich: Die 13 codierten Schlussfolgerungen des Europäischen Rates (bzw. bis 1974: Konferenz der Staats- bzw. Regierungschefs) werden getrennt von den anderen Dokumenten (als ER) ausgewiesen. ${ }^{95}$ Dies ist insofern sinnvoll, als dass die Schlussfolgerungen in dieser Zeit sehr kurz und meist eher allgemein gehalten waren und daher nur wenige Kategorienzuordnungen möglich sind. Bei den restlichen 19 Dokumenten handelt es sich überwiegend um wirtschafts-

95 Es handelt sich hierbei um folgende Dokumente: Konferenz der Staatsbzw. Regierungschefs 1974, Europäischer Rat 1976a, Europäischer Rat 1976b, Europäischer Rat 1978b, Europäischer Rat 1979a, Europäischer Rat 1979b, Europäischer Rat 1979c, Europäischer Rat 1980a, Europäischer Rat 1980b, Europäischer Rat 1981a, Europäischer Rat 1981b, Europäischer Rat 1982a, Europäischer Rat 1982c. 
politische Leitlinien in Form der Jahresberichte mit ihren Anpassungen sowie das 4. und 5. Programm für die mittelfristige Wirtschaftspolitik. ${ }^{96}$

Bezüglich der ersten Frage - Einstellungen - fand sich in den Dokumenten fast nichts. Dem Staat wurde zwar eine bedeutende Rolle eingeräumt, was sich an der Vielzahl der ihm zugeschriebenen Aufgaben ablesen lässt, dies wurde jedoch eher als selbstverständlich hingestellt und nicht weiter begründet. Das gleiche gilt für die Schwächen des Marktes, die bei einer stark interventionistischen Rolle des Staates implizit sind. Das Unternehmertum fand keinerlei Erwähnung. Explizit wurde nur der Staatshaushalt angesprochen und eine Umstrukturierung der Ausgaben empfohlen (7/19; ER: 1/13): »Kürzung der laufenden Ausgaben und höhere Priorität für Ausgaben, die der wirtschaftlichen Entwicklung dienen« (82/950/EWG: 6).

Eines der zentralen Probleme der 1970er Jahre war die Inflation. Als solches tauchte sie in fast jedem Dokument auf (18/19; ER: 13/13), zurückgeführt auf eine zu hohe Nachfrage (4/19; ER: 4/13), vor allem aber zu stark steigende (Rohstoff-)Preise und Löhne (16/19; ER: 4/13). Durch die Ölkrisen entwickelte sich die Arbeitslosigkeit zu einem weiteren drängenden Problem, auf das mit Hilfe von Nachfrage- (10/19; ER: 6/13) wie auch - zum Ende der Phase zunehmend - Angebotspolitik (17/19; ER: 10/13) reagiert werden sollte: Gegen die konjunkturelle Arbeitslosigkeit empfahlen die Vorgaben klassisch Keynes'sche Maßnahmen: »Bei der Zusammensetzung der [...] Haushaltspläne besteht für alle Mitgliedstaaten eine gemeinsame Priorität darin, Raum für notwendige Ausgaben für Beschäftigungsprogramme sowie für die Stimulierung der Investitionen zu finden« (81/1056/EWG: 7). Immer öfter wurde jedoch zusätzlich auf »Strukturprobleme« hingewiesen, die durch angebotspolitische Maßnahmen wie eine Förderung der Mobilität (4/19, ER: 0/13) und Arbeitszeitverkürzungen (5/19, ER: 3/13) gelöst werden müssten. Weiterhin sollten zu einer höheren Preisstabilität und einer höhere Rentabilität führen und so die Unternehmer zu Investitionen anregen (11/19, ER: 1/13). Hier ist eine Mischung aus Keynes (sinkende Löhne senken das Preisniveau) und der Neoklassik (sinkende Löhne führen zu mehr Beschäftigung) zu erkennen.

Als Reaktion auf die konjunkturellen Krisen wurde eine Erhöhung der Nachfrage empfohlen (16/19; ER: 3/13), wobei die öffentliche Nachfrage auch mit Hilfe von Defiziten gesteigert werden durfte (16/19; ER: 1/13). Angebotspolitische Maßnahmen fanden sich deutlich seltener

96 74/374/EWG, 74/C 13/01, 74/C 149/01, 75/361/EWG, 75/C 297/01, 76/440/EWG, 76/646/ EWG, 76/916/EWG, 77/294/EWG, 77/340/EWG, 77/492/EWG, 77/778/ EWG, 79/19/EWG, 80/67/EWG, 80/1265/EWG, 81/1056/EWG, 82/534/EWG, 82/950/EWG, 82/C 186/01. 
(6/19; ER: 3/13). Da die Haushaltsdefizite im Gefolge der Krisen stark anstiegen, empfahlen viele Vorgaben, sie zu begrenzen bzw. die Haushalte zu sanieren (13/19; ER: 1/13), allerdings nicht, wenn dies die Situation verschlimmern könnte. »Die Haushaltspolitik muß [...] ihre antizyklische Funktion beibehalten: Wenn das Wirtschaftswachstum größer als erwartet ist, müssten die Haushaltsdefizite stärker abgebaut werden, ist das Wachstum hingegen geringer, müssten die Haushaltsdefizite höher ausfallen« (80/67/EWG: 24f). In drei Dokumenten wurde die Empfehlung zur Haushaltssanierung mit möglichen Crowding-Out-Effekten begründet.

Zur vorsichtigeren Umgangsweise mit Haushaltsdefiziten trug auch bei, dass immer öfter die Grenzen der kurzfristigen Konjunkturpolitik angesprochen wurden. So stellte der Jahresbericht von 1976 fest: »Zur gleichzeitigen Bekämpfung der Inflation und Arbeitslosigkeit und zur Bewältigung der zahlreichen strukturellen Anpassungen reichen die Instrumente der Globalsteuerung allein nicht mehr aus« (76/916/EWG: 11). Hiermit rückte auch das mittelfristige Wirtschaftswachstum in den Blick. Dieses wurde in den ersten drei Jahren meist nur allgemein als Ziel genannt, erst ab 1977 kamen Strategien zu seiner Erreichung hinzu, sowohl angebots- (7/19; ER: 9/13) als auch nachfragepolitische (6/19; ER: 3/13). In den Leitlinien für 1981 wurde »die richtige[.] strategische[.] Mischung der Angebots- und Nachfragepolitiken« beschrieben:

»Bei kurzfristigen Anpassungen sollte mit mehr Bedacht vorgegangen werden [...], und mehr Schwergewicht sollte auf die Reduzierung der mittelfristigen Inflationserwartungen und die Verbesserung der Angebotsbedingungen in der Wirtschaft gelegt werden. Dies bedeutet wiederum eine stetigere Steuerung der [...] Haushaltsbilanzen [...] und eine [...] Stärkung der Wirtschaftskraft« (80/1265/EWG: 20).

Was die Staatsaufgaben angeht, so lässt sich im Bereich Allokation feststellen, dass dem Beihilfenverbot (obgleich Bestandteil des EWGV, Art. 92) noch kein großes Gewicht beigemessen wurde. Insgesamt behandelten 11 von 19 (ER: 2/13) Vorgaben das Thema, wobei in 9 von 19 (ER: 0/13) Subventionen geduldet oder sogar empfohlen wurden, z.B. um Investitionen $\mathrm{zu}$ fördern und fortschrittliche Technologie zu unterstützen. »Um die Beseitigung überholter Wirtschaftsstrukturen nicht zu verzögern, müssen jedoch Beihilfen, die lediglich der Erhaltung dienen, vermieden werden« (77/340/EWG: 23). Diese Kritik tauchte in drei weiteren Dokumenten auf (ER: 1), in drei Fällen wurden sie abgelehnt, sofern sie die marktliche Koordinierung behindern (ER: 1), in einem Fall aufgrund der Belastung der Staatshaushalte (ER: 0). 
Öffentlichen Gütern wurde in dieser Phase eine große Bedeutung zugemessen: Der Staat sollte Bildung (14/19, ER: 5/13), Infrastruktur (6/19, ER: 1/13) sowie Forschung und Entwicklung (6/19, ER: 0/13) fördern, sowohl zur kurzfristigen Stabilisierung der Wirtschaft als auch, um die langfristigen Wachstumsaussichten zu erhöhen. Bei den öffentlichen Gütern mit distributiver Funktion wurde der Staat - allerdings deutlich seltener - ebenfalls in der Rolle gesehen, den kollektiven Wohlstand zu erhöhen, genannt wurden dreimal Städtebau, zweimal sozialer Wohnungsbau und jeweils einmal soziale Infrastruktur und Gesundheit (ER: jeweils 0).

In den beiden ersten Jahren fand sich in allen fünf verabschiedeten Dokumenten (incl. ER: 6) die Empfehlung, die Sozialausgaben zu erhöhen, 1977 wurde zweimal eine bessere Verteilung angemahnt. Die meisten Empfehlungen bezogen sich auf eine Erhöhung der Arbeitslosenunterstützung, insbesondere in Zeiten von Umschulungen, es gab jedoch auch die allgemeine Empfehlung einer "schrittweise[n] Ausweitung der sozialen Sicherung, insbesondere im Rahmen der Systeme der sozialen Sicherheit, auf die Personengruppen, die durch die bestehenden Systeme nicht oder nur ungenügend gesichert sind« (74/C 13/01: 3). In den Folgejahren verschwand das Thema wieder aus den Vorgaben, erst 1981 und 1982 tauchten die Sozialausgaben wieder auf, allerdings mit ganz anderen Tönen: Anstelle von einer Erhöhung der Sozialausgaben sprachen die Jahresberichte nun von der Problematik steigender Sozialausgaben für die Staatsfinanzen sowie von möglichen Fehlanreizen bezüglich der Arbeitsmotivation.

Stabilisierung wurde als eine der wichtigsten Staatsaufgaben angesehen. In fast allen wirtschaftspolitischen Dokumenten (15/19; ER: 4/13) fand sich die Empfehlung diskretionärer Stabilisierung über eine Steuerung der Nachfrage: »Sollte sich in den nächsten Monaten zeigen, daß die Wirtschaftssubjekte nicht genügend auf die Konjunkturförderungsmaßnahmen ansprechen, dann müssten Mittel gesucht und rasch eingesetzt werden, die deren Wirkung steigern« (75/361/EWG: 14). Zum Ende der Phase gab es jedoch vereinzelt Aussagen zu den Vorteilen regelgebundener Politik, diskretionäre Stabilisierungspolitik wurde sogar für unwirksam erklärt. Stabilisierungspolitik wurde auch aufgrund der hohen Haushaltsdefizite als problematisch angesehen. Dies führte zu der Forderung, dass selbst die automatischen Stabilisatoren, die 1981 zum ersten Mal genannt wurden, nur in den Ländern uneingeschränkt wirken sollten, in denen das Haushaltsgleichgewicht nicht zu stark gestört war (vgl. 82/950/EWG: 13). Was eine längerfristige Stabilisierung à la Keynes angeht, fand sich im Jahresbericht 1977 folgende Aussage: »Die große Gefahr der jetzigen Lage besteht darin, daß die Nachfrage- 
entwicklung sich dauerhaft auf einem Niveau einpendelt, bei dem die Selbstheilungskräfte der Wirtschaft und die Konsum- und Investitionsneigung nicht ausreichen, um ein nachhaltiges Wachstum in Gang zu halten, das sich alleine trägt und das Ansteigen der Arbeitslosigkeit aufhält« (77/778/EWG: 13). Es gab jedoch keine konkreten Empfehlungen, wie die Mitgliedstaaten mit diesem Problem des Keynes'schen Unterbeschäftigungsgleichgewichts umgehen sollten.

Zusammenfassend kann man sagen, dass das Staatsverständnis in dieser Phase offensichtlich im Wandel und daher nicht ganz eindeutig war. Grundlegend war meist eine Keynes'sche Problemanalyse, vor allem bei konjunkturellen Krisen wurde auf eine staatliche Nachfragesteuerung mit Hilfe des Staatshaushalts vertraut, anstatt auf die Selbstheilungskräfte des Marktes zu setzen. Dem entsprechend lag das Schwergewicht der Nachfragesteuerung auf den öffentlichen Investitionen, die zur kurzfristigen Stabilisierung möglichst rasch realisierbar sein sollten. Die Rolle der Umverteilung bei der Nachfragestabilisierung, die bei Keynes ebenfalls wichtig ist, wurde nicht angesprochen.

Im Gegensatz zur ersten Phase empfahl der Rat jedoch - insbesondere zum Ende des Zeitraums - immer öfter angebotspolitische Maßnahmen um die Beschäftigungsprobleme zu lösen und das Wachstums zu steigern. Die unter anderem vorgeschlagenen Strukturreformen und Flexibilisierungen sollten die Marktkräfte fördern und dem Staat (nachdem er die Marktkräfte gestärkt hatte) eine geringere Rolle überlassen. Hinsichtlich des staatlichen Handelns fanden sich erste Aussagen zur Regelgeleitetheit, gegen diskretionäres Verhalten. Begründet wurde dieser Wandel zum einen mit der hohen Inflation, die durch eine Erhöhung der Nachfrage noch weiter zu steigen drohte, sowie mit stark anwachsenen Haushaltsdefiziten, die eine Steuerung über weitere Schuldenaufnahmen erschwerten.

\section{Fazit}

Die untersuchten Jahre können als Phase des beginnenden Umbruchs bezeichnet werden. Zu Beginn stand noch ein eindeutig Keynes'sches Staatsverständnis. Dem entsprechend empfahlen die europäischen Vorgaben den Mitgliedstaaten ein interventionistisches Vorgehen, insbesondere im Bereich der diskretionären Nachfragesteuerung, aber auch zur Bekämpfung der Arbeitslosigkeit sowie der Erlangung von Wachstum, Wohlstand und Wettbewerbsfähigkeit. Durch ein europäisches Vorgehen sollten die nationalstaatlichen Interventionsmöglichkeiten gestärkt werden - zum einen weil aufgrund der wirtschaftlichen Verflechtung nur ein gemeinsames Handeln als möglich angesehen wurde, zum ande- 
ren indem die Koordination die einzelstaatlichen Maßnahmen verstärkte und ihre Effizienz verbesserte. Es ging also um eine Wiedergewinnung von Interventionsmöglichkeiten zur Stärkung eines Keynes'schen Staates, die kritische Strategie. Zu diesem Zweck wurden zahlreiche und teilweise sehr verbindliche Vorgaben verabschiedet.

Im Laufe der Untersuchungsphase wurde dieses diskretionär-interventionistische Vorgehen jedoch immer skeptischer betrachtet und schließlich - wiederum vor allem in Bezug auf die diskretionäre Stabilisierung - als wirkungslos eingestuft. Dies lag nicht (bzw. nur bedingt) daran, dass die Mitgliedstaaten sich häufig nicht an die Vorgaben hielten, insbesondere diejenigen, denen eine expansive Vorgehensweise empfohlen wurde, verfolgten oft ebenfalls eine restriktive Politik. Vielmehr änderte sich die Strategie, zunehmend wurde eine zurückhaltende, regelgebundene Vorgehensweise empfohlen, die Vorgaben ließen erste Absichten erkennen, die Interventionsmöglichkeiten der Mitgliedstaaten einzuschränken. Dazu passend änderte sich auch das Staatsverständnis, wobei sich nur sagen lässt, dass es weniger interventionistisch war; die Konturen sind noch zu unscharf, um es einem neuen Typus zuzuordnen.

\subsection{Phase III (1983-1989)}

\section{Umfeldbeschreibung}

Die dritte Untersuchungsphase umfasst die Jahre 1983 bis 1989. Sie ist hauptsächlich von den Entwicklungen innerhalb der Gemeinschaft geprägt: In den 1970er Jahren war die Integration ins Stocken geraten und es bedurfte zweier Dinge, um die Phase der Stagnation zu überwinden: Zum einen einigte man sich 1984 im Streit um den EU-Haushalt, indem man Großbritannien den sogenannten Britenrabatt gewährte (vgl. Weidenfeld 2006: 28). Wichtiger und weit reichender war das Binnenmarktprojekt, das der europäischen Integration neuen Schwung verlieh, sie jedoch gleichzeitig stark veränderte (vgl. dazu ausführlicher Ziltener 1999). Grundlage war das »Weißbuch Binnenmarkt«, das die Kommission im Auftrag des Europäischen Rates im Jahr 1985 vorlegte (vgl. Europäische Kommission 1985). In diesem waren die notwendigen Schritte zur Errichtung eines »Raum[s] ohne Binnengrenzen, in dem der freie Verkehr von Waren, Personen, Dienstleistungen und Kapital [...] gewährleistet ist « (Art. 8a EEA) aufgelistet. Dabei handelte es sich im Wesentlichen um die Abschaffung bestehender Marktschranken wie Grenzkontrollen, Rechtsvorschriften und Steuerschranken (vgl. Huffschmid 1994: 81). 
Bei den Rechtsvorschriften war man zuvor den Weg der Harmonisierung gegangen, was bei einer seit 1986 (Beitritt Portugals und Spaniens) auf zwölf Mitglieder angewachsenen Gemeinschaft unter Einstimmigkeitserfordernis jedoch immer schwieriger wurde. Diese Methode sollte in Zukunft nur noch für wenige Bereiche wie z.B. Gesundheit und Sicherheit gelten, das Weißbuch enthielt die 280 notwendigen Harmonisierungsschritte (vgl. Huffschmid 1994: 83). Für alle anderen Bereiche wurde das »Prinzip der gegenseitigen Anerkennung« eingeführt, welches der Europäische Gerichtshof durch das Cassis-de-Dijon Urteil etabliert hatte: Waren, die in einem Mitgliedstaat zugelassen waren, durften auch in allen anderen Ländern verkauft werden (vgl. Mazey 1996: 34). Die Harmonisierung der Standards wurde somit nicht mehr politisch vorangetrieben, sondern dem Markt bzw. dem Wettbewerb überlassen. Die Folge dieses »gewünschten Wettbewerbs der Regulationen« (Ziltener 1999: 161) war ein weit reichender Abbau nicht-tarifärer Handelshemmnisse bzw. nationaler Standards (vgl. Mazey 1996: 34).

Das »Projekt '92« - der Binnenmarkt sollte bis Ende 1992 vollendet sein - brachte der Integration einen »europapolitischen Motivationsschub« (Weidenfeld 2006: 30). Der damalige Kommissionspräsident Delors spielte dabei eine besondere Rolle: Er verband die Marktintegration mit institutionellen Reformen, sozialer Regulation und ökonomischer Kohäsion, um so die Widerstände gegen das vorrangig ökonomische Projekt zu mindern (vgl. Mazey 1996: 34). Der neue Integrationsschub erforderte auch eine erste Überarbeitung der Europäischen Verträge. 1985 wurde eine entsprechende Regierungskonferenz eingesetzt, deren Entwurf bereits im Folgejahr unterzeichnet wurde. Die »Einheitliche Europäische Akte« trat dann am 01.07.1987 in Kraft (vgl. Weidenfeld 2006: 29). Die wichtigsten Neuerungen bezogen sich auf das Binnenmarktprojekt: Sowohl das Prinzip der gegenseitigen Anerkennung als auch qualifizierte Mehrheitsentscheidungen für die notwendigen Harmonisierungen wurden im Vertrag festgeschrieben (vgl. Art. 100 EEA). Weiterhin wurde der Europäische Rat formal als EG-Institution aufgenommen (vgl. Streb 2006: 32), das Europäische Parlament durch das Verfahren der Zusammenarbeit gestärkt und die Gemeinschaft bekam unter anderem (erweiterte) Zuständigkeiten in den Bereichen Umwelt-, Sozial- und Regionalpolitik (vgl. Mazey 1996: 34).

Die wirtschaftliche Situation war für den Fortgang der Integration ebenfalls günstig: Nach den Rezessionsjahren der 1970er ging es langsam aber stetig bergauf, die Wachstumsrate stieg von knapp $2 \%$ im Jahr 1983 auf $4 \%$ (1988) und sank nur im letzten Jahr der Untersuchungsphase leicht auf 3 \% ab (vgl. Europäische Kommission 1993: 207). Der Aufschwung wurde diesmal nicht von einer steigenden Inflation beglei- 
tet (vgl. 86/667/EWG: 18), was unter anderem auf die teilweise dramatisch sinkenden Ölpreise - im Jahr 1985 halbierten sie sich (vgl. ebenda) - und geringen Lohnsteigerungen infolge der hohen Arbeitslosigkeit zurückzuführen war. Letztere war das zentrale wirtschaftspolitische Problem dieser Phase, sie lag zu Beginn bei über $10 \%$, sank zwar von 1985 an leicht ab, gelangte bis 1989 jedoch nur knapp unter $9 \%$ (vgl. Europäische Kommission 1993: 200). Trotz der recht guten Wachstumsraten war die Gemeinschaft einem immer stärkeren Wettbewerbsdruck ausgesetzt, auch dies ein wichtiger Grund für das Binnenmarktprojekt, von dem man sich mehr Wettbewerbsfähigkeit gegenüber den Hauptkonkurrenten USA und Japan erhoffte (vgl. Gillingham 2003: 152).

Beim Blick auf die politische Situation in den Mitgliedstaaten ist vor allem der Wandel der wirtschaftspolitischen Orientierung in Frankreich von Bedeutung: 1983 entschied sich die Regierung Mitterand gegen eine Strategie der Abkopplung und ging zu einer Austeritätspolitik über (vgl. Ziltener 1999: 138), die drei Jahre von der mitte-rechts Koalition unter Jacques Chirac fortgeführt wurde (vgl. Gillingham 2003: 195). Was die anderen großen europäischen Länder angeht, so blieben in Deutschland und Großbritannien mit Kohl und Thatcher die konservativen Regierungen an der Macht, während in Italien von 1983 bis 1987 der sozialistische Premier Craxi regierte (vgl. ebenda: 207).

\section{Intendierter Einfluss der europäischen Vorgaben auf die Interventionsmöglichkeiten der Mitgliedstaaten und ihre Handlungsfähigkeit}

Zur Beantwortung der Frage, ob mit Hilfe der europäischen Vorgaben die mitgliedstaatlichen Interventionsmöglichkeiten eingeschränkt oder ausgebaut werden sollten, werden diese drei Bereichen zugeteilt: Erstens beschäftigten sie sich mit dem Binnenmarktprojekt, zweitens wurde gemeinsam gegen die Arbeitslosigkeit vorgegangen, als drittes gab es Vorgaben für die allgemeine Wirtschaftspolitik.

\section{Koordinierung im Rahmen des Binnenmarktprojekts}

Der Binnenmarkt sollte den Wohlstand und die Wettbewerbsfähigkeit der Gemeinschaft steigern. Von der Zusammenführung der nationalen Märkte zu einem großen gemeinsamen Markt versprach man sich unter anderem Kostenersparnisse und Massenproduktionsanreize. Der verstärkte Wettbewerb zwischen den nationalen Unternehmen sollte die Produktivität erhöhen, Innovationen fördern etc. (vgl. 87/609/EWG: 15). In erster Linie ging es bei diesem Projekt um die Abschaffung von Han- 
delshemmnissen aller Art, direkt ausgabenrelevant ist die Empfehlung, die wettbewerbsverzerrenden Beihilfen abzuschaffen: Die »potentiellen Vorteile [des Binnenmarktes, A.K.] werden sich [...] nur dann in der Realität niederschlagen, wenn eine strikte Wettbewerbspolitik betrieben wird, die sicherstellt, daß [...] die positiven Wirkungen eines stärkeren Wettbewerbs nicht durch Staatshilfen und Subventionen vermindert werden« (88/655/ EWG: 18). Das Beihilfenverbot wurde aus dem EWGV unverändert in die Einheitliche Europäische Akte übernommen. Zusätzlich wurden die Mitgliedstaaten in den Vorgaben immer wieder aufgefordert, ihre Subventionen zu verringern (vgl. z.B. 83/674/EWG: 13; 85/105/EWG: 26; 86/667/EWG: 67). Erlaubt wurden Beihilfen nur, wenn dies dem Aufbau des Binnenmarktes diente (s.u.) sowie für bestimmte Sektoren, die innerhalb der Gemeinschaft von besonderer Bedeutung waren, z.B. die Schiffbauindustrie (vgl. z.B. 87/167/ EWG: 55). Auch hier wurden jedoch Höchstgrenzen für die Beihilfen festgelegt, um den Wettbewerb zwischen den Mitgliedstaaten nicht zu verfälschen, sowie mittelfristig eine Senkung angestrebt (vgl. ebenda).

Ein weiteres wichtiges Element bei der Schaffung des Binnenmarktes war der Ausbau bzw. die Vernetzung nationaler Infrastruktur. Die Vorgaben empfahlen den Mitgliedstaaten »umfangreichere Investitionen zur Verbesserung oder Erneuerung der wirtschaftlichen Infrastruktur« (85/105/EWG: 34; ähnlich 86/667/EWG: 56). Die sogenannten Transeuropäischen Netze (transnationale Verkehrs-, Energie- und Telekommunikationswege) wurden aus EU-Mitteln finanziert, sollten aber durch mitgliedstaatliche Investitionen ergänzt werden (vgl. 87/609/EWG: 15). Überdies wurden private Infrastrukturprojekte (vgl. 85/C 165/02: 2) und der kombinierte Verkehr (Straße, Schiene, Binnenschiff) gefördert, indem sie vom Beihilfenverbot ausgenommen waren, beim letztgenannten bis alle Mitgliedsländer den gleichen Stand erreicht hatten (vgl. VO 1100/89: 24).

Der Binnenmarkt sollte die europäische Wettbewerbsfähigkeit auch im Angesicht der technologischen Neuerungen stärken: »Die Gemeinschaft muß jetzt auf die Herausforderung reagieren, die daraus resultiert, daß sie gegenüber den Vereinigten Staaten und Japan bezüglich der industriellen Kapazität bei neuen, rasch expandierenden Technologien allmählich ins Hintertreffen geraten ist« (85/105/EWG: 27). Die technologische Aufholjagd wurde allerdings nicht nur dem Markt überlassen, die Mitgliedstaaten sollten unterstützend eingreifen und ihre Ausgaben für Forschung und Entwicklung erhöhen (vgl. 87/609/EWG: 22) sowie produktive private Investitionen durch Subventionen fördern (vgl. 83/ 674/EWG: 12). Die europäische Ebene spielte insofern eine Rolle, als dass sie die nationalstaatlichen Anstrengungen »ermutigt und koordi- 
niert und einen eigenständigen europäischen Ansatz für Forschung und Technologie entwickelt« (88/655/EWG: 25). In die Einheitliche Europäische Akte wurde ein neuer Titel »Forschung und technologische Entwicklung« aufgenommen, mit dem sich die Gemeinschaft das Ziel setzte, »die wissenschaftlichen und technischen Grundlagen der europäischen Industrie zu stärken und die Entwicklung ihrer internationalen Wettbewerbsfähigkeit zu fördern« (Art. 130, Abs. 1 EEA). Zu diesem Zweck sollten die nationalen Politiken und Programme untereinander koordiniert werden (vgl. Art. 130h EEA).

Der Europäische Rat stellte jedoch gleichzeitig fest, dass die Einführung neuer Technologien - auch als dritte industrielle Revolution bezeichnet - gesellschaftliche Probleme mit sich brachte, auf die gemeinsam reagiert werden musste (vgl. Europäischer Rat 1985c: 8). Hiermit war in erster Linie die berufliche Weiterbildung angesprochen, damit »Arbeitnehmer und Arbeitslose sich auf den technischen Wandel und die sektorielle Umstrukturierung und deren Folgen für Arbeitsplätze und berufliche Qualifikation einstellen und sämtliche von den technischen und industriellen Neuerungen gebotenen Möglichkeiten nutzen können« (89/C 148/01: 2). Dies leitet bereits über zur sogenannten »sozialen Dimension des Binnenmarktes«. Hinter diesem Ausdruck verbirgt sich das häufig genannte Ziel, der Binnenmarkt solle allen zu Gute kommen (vgl. z.B. Europäischer Rat 1988b: 9). Grundlegend ging man davon aus, dass sich dies automatisch ergeben würde, weshalb nur wenige soziale Vorgaben - hauptsächlich in den Bereichen Arbeits- und Gesundheitsschutz - verabschiedet wurden (vgl. Europäischer Rat 1988a: 165). Direkt ausgabenrelevante Vorgaben gab es nur im Bereich der Armutspolitik: Der Rat betrachtete die Bekämpfung der sozialen Ausgrenzung als wesentlichen Bestandteil der sozialen Dimension des Binnenmarktes (vgl. 89/C 277/01: 1) und erklärte das Fortbestehen hoher Armutsraten für unvereinbar mit dem im EWGV sowie der EEA festgelegten Ziel der beschleunigten Hebung der Lebensverhältnisse (vgl. 85/8/EWG: 24). »Die Gemeinschaft kann ihren wirtschaftlichen Zusammenhalt gegenüber der internationalen Konkurrenz nur festigen, wenn sie gleichzeitig ihren $\mathrm{Zu}$ sammenhalt im sozialen Bereich verstärkt. Die Sozialpolitik muß also auf Gemeinschaftsebene ebenso ausgebaut werden wie die Wirtschafts-, Währungs- und Industriepolitik« (84/C 175/01: 1).

Explizit ausgeschlossen wurde eine Harmonisierung der nationalen Sozialsysteme, ebensowenig sollten allerdings Anpassungen der Systeme als »Einsatz im Wettbewerbsspiel zwischen den europäischen Volkswirtschaften [verwendet] werden« (ebenda: 2). Somit wurden zwar die Unterschiede zwischen den Mitgliedstaaten anerkannt, diese »schließen [aber] nicht aus, daß gemeinsame Maßnahmen zur schrittweisen Errich- 
tung eines europäischen Sozialraums getroffen werden« (ebenda: 1). Empfohlen wurden angemessene Sozialleistungen (vgl. Europäischer Rat 1989b, o.S.) sowie Maßnahmen, die den Zugang zu Ausbildung, Beschäftigung, Wohnraum, öffentlichen Dienstleistungen und medizinischer Versorgung ermöglichen (vgl. 89/C 277/01: 1). Das gemeinsame Vorgehen war jedoch recht unverbindlich, vorgesehen waren »Verbreitung und [...] Austausch von Informationen, [...] Koordinierung und Evaluierung der Maßnahmen zur Bekämpfung der Armut sowie [ein] Transfer von innovatorischen Methoden zwischen den Mitgliedstaaten« (85/8/EWG: 24). In der 1989 verabschiedeten »Gemeinschaftscharta der sozialen Grundrechte der Arbeitnehmer« einigten die Mitgliedstaaten sich darauf, dass die Kommission die Fortschritte in jährlichen Berichten überprüft (vgl. Europäischer Rat 1989b, o.S.).

\section{Gemeinsame Bekämpfung der Arbeitslosigkeit}

Obwohl es in dieser Untersuchungsphase keine konjunkturellen Einbrüche gab und auch der demographisch bedingte Anstieg der Erwerbspersonenzahl zum Stillstand kam, blieb die Arbeitslosigkeit auf einem laut Europäischem Rat (1985a: 11) inakzeptabel hohen Niveau. Zurückgeführt wurde dies in erster Linie auf die mangelnde Beschäftigungsintensität des Wachstums, die Vorgaben zielten entsprechend sowohl auf eine Stärkung des Wachstums als auch auf Maßnahmen, die dieses Wachstum in mehr Arbeitsplätze übersetzen sollten. Der erste Punkt wird bei der allgemeinen Wirtschaftspolitik behandelt, im Folgenden geht es nur um die Maßnahmen zur Steigerung der Beschäftigung.

Die Zusammenarbeit im Beschäftigungsbereich basierte auf den Jahresberichten, zusätzlich verabschiedete der Rat in dieser Phase zahlreiche spezielle Entschließungen. Diese betonten, dass die Arbeitsmarktpolitik in erster Linie im Verantwortungsbereich der Mitgliedstaaten liege (vgl. 86/C 340/02: 2), ihre Bemühungen sollten jedoch durch gemeinschaftliche Aktionen flankiert und intensiviert werden (vgl. 85/C 165/ 02: 2). Des Weiteren wurde es als wünschenswert angesehen, dass die Mitgliedstaaten »auf dem Arbeitsmarkt und bei den Lohnkosten weitgehend parallele Maßnahmen treffen« (86/667/EWG: 75). Schließlich sollte ein Erfahrungs- und Informationsaustausch über innovative bzw. Erfolg versprechende Maßnahmen statt finden (vgl. 87/569/EG: 32).

Die Vorgaben enthielten ein ganzes Bündel von Maßnahmen: Die Mitgliedstaaten sollten die Anpassungsfähigkeit bzw. Flexibilität der Arbeitsmärkte erhöhen, allerdings durften dabei »grundlegende Rechte auf dem Gebiet der sozialen Sicherheit, des Schutzes sozialer Errungenschaften und der Arbeitsbedingungen nicht aufs Spiel gesetzt werden« 
(86/C 340/02: 2). Bei der teilweise empfohlenen Verkürzung der Arbeitszeit sollte die Wettbewerbsfähigkeit beachtet werden (vgl. 85/C 02/03: 4). Ausgabenrelevant ist hierbei, dass die Vorruhestandsregelungen zunehmend als finanzielle Belastung der Staatshaushalte angesehen (vgl. 83/674/EWG: 15) und daher nur mehr für Langzeitarbeitslose in Erwägung gezogen wurden (vgl. 85/C 02/03: 4). Auch die finanzielle Belastung der Unternehmen mit Sozialversicherungsbeiträgen wurde problematisiert: »Steigende Sozialversicherungslasten, die zu den Löhnen hinzu kommen, können dazu führen, daß die Unternehmen weniger Arbeitsplätze schaffen« (85/105/EWG: 23).

Ein Schwerpunkt der Vorgaben lag auf der beruflichen Bildung zur Bekämpfung der strukturellen Arbeitslosigkeit. Eine entsprechende Koordination war vertraglich vorgesehen (Art. 128 EEA), sie gewann insbesondere vor dem Hintergrund des oben bereits erwähnten technologischen Wandels an Bedeutung. Die verstärkten Anstrengungen in diesem Bereich zielten auf die »Vermittlung einer breit angelegten Ausbildung, die die Möglichkeit gibt, breitgefächerte Kenntnisse und Fertigkeiten zu erwerben, um durch eine größere berufliche Mobilität den Zugang zum Arbeitsmarkt und eine Beschäftigung auf Dauer zu erleichtern« (83/C 166/01: 2). Das gemeinsame Vorgehen umfasste neben einem ständigen Erfahrungs- und Gedankenaustausch (vgl. ebenda: 3) die Entwicklung eines zusammenhängenden und schrittweisen gemeinsamen Vorgehens im Bereich der Berufsbildung - unter Berücksichtigung der nationalen Unterschiedlichkeiten (vgl. 83/C 193/02: 4).

Neben diesen allgemeinen Empfehlungen zur Bekämpfung der Arbeitslosigkeit verabschiedete der Rat eine Reihe von Vorgaben, die sich auf besonders betroffene Gruppen wie Jugendliche, Langzeitarbeitslose und Frauen bezogen. Auch hier wurden - speziell zugeschnittene - Bildungsmaßnahmen als zentral angesehen (vgl. bspw. 85/C 02/03: 4; 87/C 178/03: 5). Überdies empfahlen einige Vorgaben öffentlich finanzierte Beschäftigungsprogramme, die sich zum Teil über die mit ihrer Hilfe eingesparten Sozialleistungen refinanzieren sollten (vgl. 85/619/ EWG: 40). So bekamen die Mitgliedstaaten den Auftrag, allen Jugendlichen direkt im Anschluss an die schulische Ausbildung die Möglichkeit zu geben, für mindestens ein Jahr an einer Berufsbildungsmaßnahme teilzunehmen (vgl. 87/569/EWG, Art. 1). Die Berufstätigkeit von Frauen wurde gefördert, obwohl hierdurch die Anzahl der Erwerbspersonen und damit das Problem der Arbeitslosigkeit weiter erhöht wurde, allerdings könne auf diese Weise »eine breitere Basis für die Verteilung der Steuer- und Sozialversicherungslast [ge]schaffen [werden]. Angesichts der Überalterung der Bevölkerung in der Gemeinschaft wird dies mittel- und langfristig immer wichtiger« (88/655/EWG: 23). Daher sollten die Mit- 
gliedstaaten Möglichkeiten für die Betreuung von Kindern und anderen pflegebedürftigen Personen bereitstellen (vgl. 88/C 333/01: 2).

\section{Koordinierung der allgemeinen Wirtschaftspolitik}

Die 1980er Jahre waren von einem beständigen, wenn auch - im Vergleich zu den Nachkriegsjahren - relativ langsamen Wachstum geprägt.

»Während die konjunkturellen Anzeichen nach und nach günstiger werden, besteht nach wie vor die wichtige Frage, ob sich die europäische Wirtschaft jetzt auf einem Pfad grundlegender struktureller Verbesserung befindet. Hierbei geht es insbesondere darum, die mittelfristige Investitions- und Beschäftigungsneigung zu steigern und die Leistungsfähigkeit in entscheidenden Wirtschaftszweigen [...] zu erhöhen« (83/674/ EWG: 8).

Das zentrale Ziel des gemeinsamen Vorgehens lag somit darin, den Aufschwung zu stärken, konjunkturpolitische Maßnahmen wurden selten und wenn dann meist im Hinblick auf mögliche außenwirtschaftliche Risiken angesprochen (vgl. bspw. 85/619/ EWG: 14).

Obwohl die mittlere Frist im Zentrum des gemeinsamen Vorgehens stand, erfolgte die Koordination nicht über die Programme für die mittelfristige Wirtschaftspolitik: Nachdem man sich 1982 nur auf ein sehr kurzes und eher Differenzen als Gemeinsamkeiten konstatierendes 5. Programm hatte einigen können, wurden keine weiteren Programme dieser Art mehr aufgelegt. Für die Koordinierung wurden stattdessen die jährlich verabschiedeten Jahresberichte genutzt. Im Vergleich zur Vorphase paßte der Rat sie im Rahmen seiner mehrmals im Jahr stattfindenden Treffen seltener - nur 1983 in geringem Maße - an, ihr Umfang stieg jedoch von durchschnittlich 15 (Phase II) auf bis zu 75 Seiten im Jahr 1986. Was den Detailgrad der festgelegten Ziele angeht, so wurde im Jahresbericht 1984 angemerkt: »Die Kenntnisse über die Auswirkungen wirtschaftspolitischer Schritte sind zu ungewiß, als daß förmliche Preis- und Wachstumsziele festgesetzt werden könnten. Über die Größenordnungen sollte jedoch geredet werden« (85/105/ EWG: 17). In einigen Jahresberichten griff man auf das Instrument der Szenarienbildung zurück, um die Notwendigkeit bestimmter Politiken zu rechtfertigen, dabei wurden zwar quantifizierte Aussagen über Wachstumsraten, Beschäftigungsanstiege etc. gemacht, diese waren jedoch nicht als Zielvorgaben zu verstehen (vgl. bspw. 85/619/EWG: 14ff; 86/667/EWG: 48ff). Eine leichte Änderung bei der Form der Koordination ergab sich durch die Verabschiedung der »Kooperativen Strategie für ein beschäftigungsfreundlicheres Wachstum« im Jahr 1985. Für ihre Umsetzung - im Rah- 
men der Jahresberichte - waren folgenden Schritten vorgesehen: Bis Ende 1985 sollte Einvernehmen über die Zielsetzungen und Initiativen herrschen, die 1986 durchgeführt werden sollten. Auf Grundlage einer Erfolgskontrolle sollte im Jahr 1987 das zweite Maßnahmenbündel folgen etc. (vgl. 85/619/EWG: 48). Zusätzlich waren die Mitgliedstaaten aufgerufen, Kurzberichte über ihre im Rahmen der Strategie getroffenen Maßnahmen vorzulegen (vgl. 86/667/EWG: 10).

Das gemeinsame Vorgehen zur Stärkung eines inflationsfreien, beschäftigungsintensiven Wachstums beruhte auf der unverändert in die EEA übernommenen vertraglichen Verpflichtung zur Koordinierung der nationalen Wirtschaftspolitik (vgl. Art. 105 EEA). Begründet wurde die Notwendigkeit der Koordinierung in erster Linie mit der hohen wirtschaftlichen Verflechtung, die durch die Vollendung des Binnenmarktes sowie die voranschreitende monetäre Integration im Rahmen des Europäischen Währungssystems noch weiter ansteigen würde (vgl. 88/655/ EWG: 29). Die in Folge der Verflechtung schnellere Reaktion der Güter- und Finanzströme setze dem autonomen wirtschaftspolitischen Handeln der Mitgliedstaaten enge Grenzen (vgl. 87/609/ EWG: 17), so dass

»[d]ie einzelnen europäischen Länder [...] kaum hoffen [können], Stabilisierungserfolge in einen dynamischen Aufschwung umzusetzen, wenn sie dabei unkoordiniert vorgehen. Nur ein großer Schritt nach vorne im Rahmen einer konzertierten Aktion der einzelnen Staaten und der Europäischen Gemeinschaft [...] kann einen kräftigen Aufschwung herbeiführen« (83/674/EWG: 19).

Weiterhin wurde die »größere Konvergenz in Richtung auf mehr Stabilität, die für die Fortsetzung des Wachstumsprozesses und für Fortschritte hin zur Wirtschafts- und Währungsunion erforderlich ist" (89/685/ EWG: 14) als Begründung für die Koordinierung angeführt.

Die empfohlenen Maßnahmen wurden - ohne inhaltliche Änderungen - ab 1985 in einem »kohärente[n] wirtschaftspolitische[n] Konzept « (89/685/EWG: 8) der Gemeinschaft zusammengefasst, der oben bereits angesprochenen $»$ Kooperativen Strategie für ein beschäftigungsfreundlicheres Wachstum«. Wie schon bei der Bekämpfung der Arbeitslosigkeit und durch den Titel der Strategie angesprochen, ging es nicht nur darum, das Wachstum, sondern auch dessen Beschäftigungsintensität zu erhöhen. Letzteres wurde bereits dargestellt, im Folgenden wird auf die Empfehlungen zur Wachstumssteigerung eingegangen: Die kooperative Strategie umfasste angebots- wie nachfragepolitische Maßnahmen. Die Angebotsseite sollte unter anderem durch das Binnenmarktprojekt sowie die oben angeführten Maßnahmen zu dessen Erreichung gestärkt werden 
(vgl. 86/665/EWG: 8), den Strukturwandel wollte man durch die Abschaffung von Erhaltungssubventionen (vgl. bspw. 85/105/ EWG: 22) sowie verstärkte Bemühungen bei der Berufsbildung erleichtern (vgl. bspw. 83/C 166/01: 1). Auch die beschriebene Technologiepolitik ist von Bedeutung. Einige Dokumente wiesen weiterhin auf die Notwendigkeit stabiler Rahmenbedingungen hin (vgl. bspw. 86/667/EWG: 25).

Breiten Raum nimmt die Vorgabe ein, zur Verbesserung der Angebotsseite die Lohnanstiege zu mäßigen, um die Rentabilität der Unternehmen zu verbessern und somit erweiternde anstelle von arbeitsplatzsparenden Investitionen anzuregen (vgl. 85/105/EWG: 29). Gleichzeitig wurde jedoch das mit der Lohnmäßigung einhergehende Problem des Nachfragemangels gesehen und angegangen: Die Nachfragestützung wurde dabei explizit als Aufgabe des Staates betrachtet, zumindest bis die zusätzlichen Arbeitsplätze und das Wachstum die Nachfrage ausreichend erhöht hätten (vgl. 85/619/EWG: 22). Zur Stabilisierung der Nachfrage war in erster Linie die Haushaltspolitik gefragt, auch wenn die Mitgliedstaaten hierfür höhere Defizite in Kauf nehmen müssten. Ausgenommen von dieser Strategie waren die Länder, die bereits sehr hohe Schulden hatten. Damit deren notwendig restriktive Politik ihnen selbst wie auch ihren Partnern nicht zu sehr schadete, empfahl der Rat ein koordiniertes Vorgehen: Die Länder, in denen dies möglich war, sollten eine expansive Politik verfolgen, um so das Wachstum auch in den anderen Ländern zu steigern und es letzteren auf diese Weise zu ermöglichen, in absehbarer Zeit ebenfalls eine expansive Politik betreiben zu können (vgl. 87/609/EWG: 18). Das Ziel eines mittelfristig ausgeglichen Haushalts gewann an Bedeutung (vgl. z.B. 88/655/EWG: 15).

Mit den zusätzlichen öffentlichen Mitteln zur Steigerung des Wachstums sollten insbesondere öffentliche Investitionen finanziert werden, um neben der Nachfrage auch das Produktionspotential zu stärken (vgl. 87/609/EWG: 16). In diesem Bereich stellten die Vorgaben einen besorgniserregenden Rückgang fest, der auf die Sparpolitik der vergangenen Jahre zurückgeführt wurde, welche somit explizit auch als Problem gesehen wurde: »Die öffentlichen Investitionen haben unter der Konsolidierung der öffentlichen Haushalte gelitten [...]. Heute besteht ein Nachholbedarf an volkwirtschaftlich rentablen Projekten dieser Art" (86/667/EWG: 9). Empfohlen wurden Investitionen in Infrastruktur, Forschung und Entwicklung sowie Bildung, weiterhin in Bereiche wie Stadterneuerung oder Umweltschutz. Der Anteil der Investitionen am BIP sollte auf ca. $3 \%$ gesteigert werden (vgl. 86/667/EWG: 39), gleichzeitig wurde jedoch ein Rückgang der Staatsausgaben angemahnt, teilweise präzisiert auf eine jährliche Verminderung des Anteils der Ausgaben am BIP um $1 \%$ (vgl. 85/105/EWG: 22). Daher wurde auch eine 
Umstrukturierung der Staatshaushalte empfohlen: Gekürzt werden sollte vor allem bei den laufenden Ausgaben, z.B. den Sozialleistungen (vgl. 83/674/EWG: 12). Bei den sozialen Dienstleistungen wie Gesundheitsund Altersvorsorge wurde eine »wirtschaftliche Handhabung, nicht aber ein Abbau dieser Leistungen« (86/667/EWG: 57) empfohlen, in den wirtschaftspolitischen Leitlinien für 1987 fand sich eine explizite Ablehnung von Privatisierungen in diesem Bereich, da dies die Kosten nicht notwendigerweise reduzieren und somit die Lohnkosten nicht senken würde (vgl. ebenda). Kürzungsbedarf sah man auch bei den von »Fehlern im Funktionieren des Wirtschaftssystems« hervorgerufenen Ausgaben, wie z.B. der Arbeitslosenhilfe, wobei hier auch eine Umwidmung der Mittel z.B. in Beschäftigungsprogramme vorgeschlagen wurde (vgl. ebenda). Der Jahresbericht von 1984 legte grobe Anhaltspunkte für die laufenden wie auch für die Investitionsausgaben von 1987 fest: Der Anteil der laufenden Ausgaben am BIP sollte um vier Prozentpunkte sinken, der Anteil der Investitionsausgaben (incl. der vermögenswirksamen Leistungen) um einen Prozentpunkt zunehmen (vgl. 85/105/EWG: 22).

Die kurzfristige Wirtschaftspolitik wurde mit Blick auf die möglichen Risiken für die Wirtschaftsentwicklung angesprochen: Bei einer Verschlechterung des außenwirtschaftlichen Umfelds sollten zum einen die automatischen Stabilisatoren wirken, sofern die Verschuldung dies zuließ (vgl. 83/674/EWG: 11; Rat 1983: 16). Zum anderen wurden die Mitgliedstaaten aufgefordert, zusätzliche nachfragestützende Maßnahmen durchzuführen, um die Arbeitslosigkeit zu verringern (vgl. 85/619/ EWG: 23). So empfahlen die Vorgaben das Vorziehen öffentlicher Investitionsprogramme, aufgrund der unumgehbaren zeitlichen Verzögerungen sollten die Mitgliedstaaten mit den entsprechenden Vorarbeiten jeweils bereits in guten Zeiten beginnen (vgl. 85/105/EWG: 22). Auch bei diesen Maßnahmen der kurzfristigen Wirtschaftspolitik wurde ein gemeinsames Vorgehen als sinnvoll erachtet: Im Falle einer konjunkturellen Abschwächungen müsste »eine gemeinsame und zeitlich gut aufeinander abgestimmte Anstrengung [es] ermöglichen, die Interdependenzen zwischen den Mitgliedsländern positiv zu nutzen« (87/609/ EWG: 7), da »[e]in solcher Haushaltsimpuls [...] ertragreicher [ist], je mehr Länder sich daran beteiligen könnten« (ebenda: 29). Der entsprechende Artikel zur Koordinierung der Konjunkturpolitik war unverändert in die EEA übernommen worden (Art. 103 EEA).

Wie die obigen Ausführungen zeigen, hängen die drei beschriebenen Bereiche - Binnenmarkt, Beschäftigung und allgemeine Wirtschaftspolitik - eng zusammen: Der Binnenmarkt sollte das wirtschaftliche Potential stärken, während von der Wachstumsstrategie und den beschäftigungsfördernden Maßnahmen eine erleichterte Vollendung des Binnen- 
marktes erhofft wurde, indem sie den hierdurch hervorgerufenen Strukturwandel und seine sozialen Folgen besser abfedern halfen (vgl. 86/ 667/EWG: 8). Hinsichtlich der Bewertung des gemeinsamen Vorgehens wurde im Jahresbericht von 1989 festgestellt: »Die Koordinierung der Wirtschaftspolitik innerhalb der Gemeinschaft war nie leicht. Seit den frühen 80er Jahren sind jedoch auch in diesem Bereich Fortschritte gemacht worden, und die Koordinierung ist wesentlich wirksamer geworden« (89/685/EWG: 14). Betont wurde, dass es für den Erfolg nicht nur auf die Verfahren der Koordinierung ankomme, sondern insbesondere auf den Konsens über die wesentlichen Zielsetzungen bzw. Grundlinien der Wirtschaftspolitik (vgl. 88/655/EWG: 30). Letzteres wurde immer mehr als gegeben gesehen: Für die vergangenen Jahre wurde ein »breite[r] Konsens über die Prioritäten und die Orientierungen der Wirtschaftspolitik in allen ihren Bereichen [sowie] eine verstärkte Konvergenz in den Ergebnissen« (85/619/EWG: 33) festgestellt. Diesen wirtschaftspolitischen Grundkonsens weiter zu stärken war auch eine Aufgabe der Jahresberichte (vgl. ebenda). Was die konkreten Ergebnisse der Koordinierung in den Mitgliedstaaten anging, so wurde eine zunehmende Konvergenz in der makroökonomischen und finanzpolitischen Entwicklung (vgl. 83/674/EWG: 10), der Wirtschafts- und Technologiepolitik sowie der Inflationsraten festgestellt, nicht jedoch bei der Bekämpfung der Arbeitslosigkeit sowie der Angleichung der Lebensbedingungen (vgl. Europäischer Rat 1986b: 8).

\section{Schlussfolgerungen}

Zusammenfassend wird nun dargestellt, wie die europäischen Vorgaben die mitgliedstaatlichen Interventionsmöglichkeiten in den drei Bereichen Allokation, Distribution und Stabilisierung beeinflussen sollten: Bezüglich der Allokation wurde das weiterhin vertraglich festgehaltene Beihilfenverbot im Rahmen des Binnenmarktprojektes immer wichtiger, da nationale Subventionen den Wettbewerb verzerrten und den Strukturwandel behinderten, obgleich beides durch den Gemeinsamen Markt intensiviert werden sollte. Dennoch gab es weiterhin Ausnahmen vom Verbot, die allerdings ebenfalls zur Vollendung des Binnenmarktes und zum Strukturwandel beitragen sollten; vor allem die Vorgaben für Infrastruktur sowie Technologie. Die Mitgliedstaaten wurden angehalten, diese nicht nur durch Subventionen zu fördern, sondern auch eigenständig bereitzustellen, letzteres galt auch für den Bereich Bildung. Öffentliche Güter mit allokativer - wie auch teilweise mit distributiver (Stadterneuerung) - Funktion spielten auch in der Strategie zur Steigerung des Wachstums und damit der Beschäftigung eine große Rolle, die Mitglied- 
staaten wurden demnach in allen drei oben genannten Bereichen (Binnenmarkt, Beschäftigung, allgemein Wirtschaftspolitik) dazu angehalten, ihre Interventionen im Bereich öffentliche Güter auszudehnen.

Wenngleich in den Vorgaben immer wieder die Rede von der sozialen Dimension des Binnenmarktes war, wurden nur wenige distributive Vorgaben zu ihrer Erreichung verabschiedet. Bei den Sozialleistungen wurde - wenn angesprochen - zwar manchmal ihre notwendige Angemessenheit betont, hauptsächlich wurden sie jedoch als Belastung der Unternehmen wie der Staatshaushalte dargestellt, weshalb ihre Kürzung bzw. die Umschichtung der Staatshaushalte zugunsten produktiver Ausgaben empfohlen wurde. Öffentliche Güter mit distributiver Funktion wurden den Mitgliedstaaten ebenfalls sehr selten und wenn, dann nicht nur mit sozialpolitischen Zielen, sondern auch zur Steigerung des Wachstums oder der Erwerbsmöglichkeiten von Frauen nahegelegt. Im distributiven Bereich ging es somit eher um eine Einschränkung von Interventionsmöglichkeiten. Ein Dokument hielt allerdings fest, dass die Sozialleistungen nicht als Instrument im Wettbewerb zwischen den Mitgliedstaaten eingesetzt werden sollten.

Im Bereich Stabilisierung wurde eine Einschränkung der Interventionsmöglichkeiten der Mitgliedstaaten festgestellt und negativ beurteilt, da dem Staat bei der Stabilisierung des Aufschwungs eine wichtige Rolle zukam. So empfahlen die Vorgaben für den Fall von Wirtschaftskrisen unter anderem die Erstellung von Schubladenprogrammen für Investitionen, überdies sollten öffentliche Investitionen die Nachfrage stützen, solange die für das Wachstum ebenfalls notwendigen Lohnmäßigungen diese schwächten. Das koordinierte Vorgehen sollte die Interventionsmöglichkeiten der Mitgliedstaaten zum einen dadurch ausweiten, dass eine gemeinsam durchgeführte expansive Politik zur Konjunkturbelebung ertragreicher schien als ein nationales Vorgehen. Zum anderen sollte eine expansive Politik von Ländern mit geringem Schuldenstand den hoch verschuldeten Ländern ermöglichen, mit der Zeit von ihrer restriktiven Politik abzurücken, ihre Interventionsmöglichkeiten also auszubauen. Allerdings lässt sich auch eine beabsichtige Einschränkung mitgliedstaatlicher Interventionsmöglichkeiten feststellen, da öfters eine regelgeleitete Stabilisierung empfohlen und am Ziel des mittelfristigen Haushaltsausgleichs festgehalten wurde.

Insgesamt wurde die Koordinierung als erfolgreich angesehen, auch wenn ihre Ergebnisse weniger messbar geworden waren: Weder wurden (mit Ausnahme des Beihilfenbereichs) rechtlich verbindliche Richtlinien oder Verordnungen verabschiedet, noch wurden die gemeinsamen Ziele quantifiziert. Eine Ausnahme bildeten einige Vorgaben für die Staatshaushalte und den Umfang der öffentlichen Ausgaben. Der festgestellte 
Konsens über die wirtschaftspolitischen Grundlinien wird in dieser Phase auch daran deutlich, dass sich die Empfehlungen kaum ändern.

\section{Staatsverständnis}

Im Rahmen der Inhaltsanalyse konnten für diese Phase 28 Dokumente ausgewertet werden. Dies ermöglicht eine - aufgrund der Unterschiede in Art und Umfang sinnvolle - Unterteilung der Vorgaben in drei Gruppen: Schlussfolgerungen des Europäischen Rates (ER) ${ }^{97}$, wirtschaftspolitische Vorgaben (WI) ${ }^{98}$ sowie beschäftigungs- und sozialpolitische Vorgaben (BS) ${ }^{99}$. Die wirtschaftspolitischen Leitlinien sind die umfassendsten Dokumente, sowohl von der Länge als auch vom Inhalt her, weshalb bei ihnen die meisten Kategorienzuordnungen möglich sind.

In dieser Phase fand sich eine sehr positive Einstellung gegenüber dem Markt, insbesondere verbunden mit dem zentralen Projekt dieser Jahre, dem Binnenmarkt (ER: 6/9, WI: 5/8, BS: 1/11). Auch das Unternehmertum wurde manchmal positiv erwähnt, seine Förderung entsprechend in einigen Dokumenten empfohlen, jedoch ohne dies länger auszuführen (ER: 1/9, WI: 2/8, BS: 2/11). Den Staat betrachtete man hingegen eher skeptisch (WI: 3/8), so wurde lobend erwähnt, dass

»sich die Regierungen in einigen Mitgliedstaaten [bemühen], die Eingriffe des Staates in ihre Wirtschaften zu verringern [...]; ob es sich nun um eine Deregulierung in verschiedenen Bereichen (Verkehrswesen, Energiewirtschaft), Privatisierungen (oder Reprivatisierungen) verschiedener Tätigkeiten handelt, die zuvor vom öffentlichen Sektor wahrgenommen wurden, oder aber um den erklärten Willen, den Umfang der öffentlichen Interventionen in Form von Subventionen zurückzuschrauben - Ziel ist immer eine vermehrte Effizienz« (86/667/EWG: 67).

Damit einher gingen die Empfehlungen, die Staatshaushalte in Richtung produktiver, marktfördernder Ausgaben umzuschichten (WI: 8/8) und insgesamt zu reduzieren (WI: 3/8).

97 Europäischer Rat 1983c, Europäischer Rat 1984, Europäischer Rat 1985a, Europäischer Rat 1985c, Europäischer Rat 1986a, Europäischer Rat 1986b, Europäischer Rat 1988a, Europäischer Rat 1988b, Europäischer Rat 1989a.

98 83/674/EWG, Rat 1983, 85/105/EWG, 85/619/EWG, 86/667/EWG, 87/609/EWG, 88/655/EWG, 89/685/EWG.

$9983 / \mathrm{C} 166 / 01,83 / \mathrm{C} 193 / 02,84 / \mathrm{C} 29 / 01,84 / \mathrm{C} 184 / 01,84 / \mathrm{C} 175 / 01,85 / \mathrm{C}$ 02/03, 85/C 165/02, 86/C 340/02, 88/C 333/01, 89/C 277/01, Europäischer Rat 1989b. 
Das zentrale Problem dieser Phase war die hohe Arbeitslosigkeit. Eine Lösung wurde vor allem auf der Angebotsseite gesucht, Nachfragepolitik empfahlen nur mehr wenige Dokumente (ER: 1/9, WI: 2/8). Bei den angebotsökonomischen, arbeitsmarktpolitischen Maßnahmen zur Steigerung der Beschäftigungsintensität des Wachstums stand Bildung bzw. Qualifizierung an erster Stelle (ER: 6/9, WI: 7/8, BS: 10/11), wodurch gleichzeitig die Mobilität der Arbeitskräfte erhöht werden sollte. Auch die Steigerung der Flexibilität bzw. Anpassungsfähigkeit der Arbeitsmärkte spielte eine große Rolle (ER: 5/9, WI: 6/8, BS: 5/11). Weiterhin wurden Lohnmäßigungen empfohlen (WI: 7/8). »Da die Lohneinkommen einen derart großen Teil des inländischen Gesamteinkommens ausmachen, wird dies jedoch wahrscheinlich einen gewissen restriktiven Effekt auf die Nachfrage haben« (85/619/EWG: 22), was über eine Erhöhung staatlicher Ausgaben (oder Steuersenkungen) kompensiert werden sollte. Der Nachfragestabilisierung wurden auch die Konsolidierungsbemühungen untergeordnet - sofern die Haushaltsdefizite der Mitgliedstaaten nicht zu groß waren (WI: 7/8).

Die Inflation stabilisierte sich in diesem Zeitraum wieder auf geringem Niveau, weshalb Preisstabilität zwar immer noch als allgemeines Ziel genannt wurde (ER: 2/9, WI: 7/8, BS: 2/11), jedoch meist mit Verweis darauf, dass sie durch eine potentialorientierte Geldpolitik, mäßig steigende Löhne und (Rohstoff-)Preise auf einem befriedigenden Niveau sei (WI: 7/8).

Da die 1980er Jahre von keinen großen wirtschaftlichen Schwankungen gezeichnet waren, fanden sich nicht viele Aussagen zur Konjunkturpolitik: In lediglich drei wirtschaftspolitischen Vorgaben wurde das Thema angesprochen und jeweils nachfragepolitische Maßnahmen empfohlen. Wachstum hingegen sollte vor allem über die Angebotsseite gesteigert werden (ER: 3/9, WI: 7/8, BS: 3/11). Nachfragepolitik wurde nur noch in vier der acht wirtschaftspolitischen Dokumente vorgeschlagen, wobei der Bedeutung der Nachfrage für das Wachstum dadurch Rechnung getragen wurde, dass die durch Lohnmäßigung bedingten Nachfrageausfälle vom Staat kompensiert werden sollten.

Bei den Staatsaufgaben wurde der Abbau staatlicher Beihilfen im Rahmen des Binnenmarktprojekts als sehr wichtig angesehen: »Insbesondere muß in praktisch allen Mitgliedstaaten das System der Subventionen von Grund auf neu durchdacht werden, nicht zuletzt, um die wettbewerbspolitischen Spannungen im Zuge der Vollendung des Binnenmarktes auf ein Mindestmaß zu begrenzen« (88/655/EWG: 28). Neben möglichen Wettbewerbsverzerrungen (WI: 5/8) wurden auch eine Behinderungen des Strukturwandels (WI: 4/8) sowie eine Belastung der Staatshaushalte (WI: 1/8) zur Begründung der Ablehnung genannt. Ge- 
duldet wurden Beihilfen nur an zwei Stellen (WI: 1/8, BS: 1/11) und zwar zur Förderung produktiver Investitionen.

Öffentliche Güter mit allokativer Funktion sollten zum einen die Grundlage der privatwirtschaftlichen Entwicklung verbessern, insbesondere durch eine Qualifizierung im Rahmen der Bekämpfung der Arbeitslosigkeit: »Auf längere Sicht ruhen Europas Hoffnungen auf dem geistigen und technologischen Potential seiner Bevölkerung und insbesondere der jüngeren Generation. Daher muß Investitionen in Humankapital im allgemeinen und Bildung und Berufsbildung im besonderen in sämtlichen Mitgliedsländern ein hoher Rang eingeräumt werden« (88/655/ EWG: 25). Neben Empfehlungen für Bildung (ER: 6/9, WI: 7/8, BS: 10/11) wurden Forschung und Entwicklung (ER: 2/9, WI: 2/8, BS: 1/11) sowie Infrastruktur (WI: 4/8, BS: 1/11) genannt. Die öffentlichen Güter sollten aber nicht nur die Angebotsbedingungen der Wirtschaft verbessern, sondern - zum anderen - explizit auch als Nachfrageelement eingesetzt werden. »Ein Wiederanstieg der volkswirtschaftlich rentablen öffentlichen Investitionen könnte, zusätzlich zur Erholung der privaten Investitionen, die Modernisierung der europäischen Produktionskapazitäten fördern. Außerdem würde er das Wachstum direkt unterstützen« (86/667/EWG: 41). In der Hälfte der wirtschaftspolitischen Leitlinien (4/8) fanden sich entsprechende Empfehlungen.

Bezüglich der Sozialausgaben ist ein Zitat aus dem Jahresbericht von 1984 aufschlussreich:

»Gewiß gibt es viele unerfüllte und wohlbegründete Forderungen nach besseren sozialen Leistungen, beispielsweise im Gesundheitswesen. Weit verbreitet ist jedoch heute die Erkenntnis, daß [...] Sozialversicherungsbeiträge und soziale Transferleistungen in der Gemeinschaft zusammengenommen im Verhältnis zur Leistungsfähigkeit der Wirtschaft zu rasch gestiegen sind und auf diese Weise das Wachstumspotential der Wirtschaft selbst geschwächt haben. Deshalb sollte eine Umkehr der bisherigen Trends in der Zunahme der öffentlichen Ausgaben nunmehr einen wesentlicher Faktor bei der mittelfristigen Erholung der europäischen Volkswirtschaften bilden« (85/105/EWG: 21).

Dem entsprechend wurde in den wirtschaftspolitischen Leitlinien ein Abbau von Sozialleistungen zur Erhöhung von Anreizen empfohlen (4/8), während laut einiger beschäftigungs- und sozialpolitischer Dokumente auf ihre Angemessenheit geachtet werden sollte (3/11). Öffentliche Güter mit distributiver Funktion wurden nur selten erwähnt: Städtebau wurde in zwei wirtschaftspolitischen, Gesundheit in je einem wirtschafts- und einem beschäftigungspolitischen Dokument empfohlen, bei 
letzteren fand sich überdies einmal das Gut Kinderbetreuung und einmal sozialer Wohnungsbau.

Stabilisierungspolitik sollte - wie oben bereits erwähnt - je nach Haushaltslage der Mitgliedstaaten eine unterschiedliche Rolle spielen: Diskretionäre Politik war bei einer guten Haushaltslage durchaus erwünscht, um über öffentliche Investitionen die Nachfrage (wenn notwendig) zu stabilisieren (WI: 7/8). Nur im letzten Jahr dieser Phase wurde dies nicht mehr empfohlen. Die automatischen Stabilisatoren tauchten nur in drei wirtschaftspolitischen Dokumenten auf, zweimal mit der Einschränkung, dass durch ihr Wirkenlassen keine zu großen Haushaltsdefizite entstehen sollten.

Zusammenfassend lässt sich feststellen, dass das Staatsverständnis in dieser Phase recht uneindeutig war, es machte Anleihen bei verschiedenen Wirtschaftstheorien. Von der positiven Einstellung gegenüber dem Markt, der negativen in Bezug auf den Staat, vor allem aber von den Mitteln zur Lösung des zentralen Problems der Arbeitslosigkeit ausgehend, kann man auf ein zurückhaltendes Staatsverständnis schließen. Empfohlen wurden fast durchweg angebotspolitische Maßnahmen, die Nachfrageseite spielte als Ursache für die mangelnde Beschäftigung kaum eine Rolle. Insbesondere das Mittel, die Löhne zu mäßigen, um dadurch die Beschäftigung zu erhöhen, wird bei Keynes klar abgelehnt. Hier fand sich in den Leitlinien jedoch ebenfalls eine Einschränkung: Die Keynes'sche Argumentation, eine Senkung der Löhne würde die Nachfrage mindern und damit die Krise verschärfen, wurde aufgegriffen. Auf diese Weise wurde der Nachfrage, die weder im Monetarismus noch in der NKM/Angebotsökonomie als relevant erachtet wird, doch eine wichtige Bedeutung zugemessen - und damit gleichzeitig dem Staat, der die Nachfrageausfälle kompensieren sollte. »Was die Gewährleistung einer angemessenen Nachfrageentwicklung betrifft, so ist dies eine Aufgabe der Regierungen. Sie stellt sich so lange, bis sich der Prozeß durch kräftige Investitionstätigkeit und einen angemessenen Anstieg des privaten Verbrauchs selbst trägt« (85/619/EWG: 4). Ein ähnlich unklares Bild zeigte sich bei der empfohlenen Umgangsweise mit Haushaltsdefiziten. Diese sollten - über Crowding-Out - eine negative Wirkung auf das Zinsniveau haben, was Keynes bestritten hat. Dennoch sollten die Mitgliedstaaten - nach Keynes'scher Art - das Haushaltsdefizit zur Steigerung der Nachfrage einsetzen. Bei den Gütern, die der Staat zur Steigerung der Nachfrage bereitstellen soll, wird dann wieder ein Bogen zur Angebotsökonomie deutlich, empfohlen wurden insbesondere öffentliche Güter mit allokativer Funktion, wie Forschung und Entwicklung, Bildung und Infrastruktur, die als Grundlage für die privatwirtschaftliche Entwicklung dienen. 


\section{Fazit}

Das Staatsverständnis, welches den Vorgaben in dieser dritten Untersuchungsphase zugrunde lag, kann nicht eindeutig zugeordnet werden. Obwohl die untersuchten Jahre sehr stark vom (Binnen-)Markt und dessen vermutet positiven Folgen geprägt waren, wurde dem Staat weiterhin eine wichtige Rolle zugeschrieben. Gleichzeitig wurde festgestellt, dass »[i]n der Gemeinschaft [...] die Spielräume für die Wirtschaftspolitik der Mitgliedstaaten vor allem aufgrund von äußeren Sachzwängen sehr eng [seien]. [...] [Daher] ist die Effizienz der europäischen Politik insbesondere vom Grad ihrer Koordinierung abhängig« (83/674/EWG: 4). Die Vorgaben empfahlen den Mitgliedstaaten somit ein eher interventionistisches Verhalten, welches durch ein koordiniertes Vorgehen möglich gemacht werden sollte. Dies traf insbesondere auf den Bereich der Allokation sowie der Stabilisierung zu: In ersterem mussten sich die Mitgliedstaaten gemeinsam gegenüber den USA und Japan behaupten, indem sie den Binnenmarkt förderten, unter anderem durch die Bereitstellung öffentlicher Güter sowie teilweise Subventionen. Bei der Stabilisierung wurde ein gemeinsames Vorgehen ebenfalls als Wiedergewinnung bzw. Erweiterung der nationalstaatlichen Interventionsmöglichkeiten angesehen. Auch bei der Bekämpfung der Arbeitslosigkeit sollten die Staaten ihre Interventionsmöglichkeiten zum Teil ausbauen. Dies entspricht hauptsächlich einer kritischen Strategie; in Bezug auf öffentliche Güter mit allokativer Funktion, die Wachstum fördern sollen, ist auch eine affirmative oder einer revisionistische Strategie erkennbar.

Der Staat bzw. staatliches Handeln wurde jedoch auch als problematisch angesehen, sowohl was seine distributiven Aufgaben betraf als auch mit Blick auf die beiden gerade angesprochenen Bereiche Allokation und Stabilisierung. Daher wurde mit den Vorgaben auch die Absicht verfolgt, die Interventionsmöglichkeiten zu beschränken bzw. in gewissen Grenzen zu halten. So sollten die Beihilfen nicht den Wettbewerb oder Strukturwandel behindern, die Investitionen zur Stützung der Nachfrage nicht zu einer Erhöhung staatlicher Ausgaben oder zu hohen Defiziten führen - im Gegenteil, insgesamt sollten Subventionen, Staatsausgaben und Haushaltsdefizite zurückgeführt werden. Somit kann man davon sprechen, dass in dieser Phase neben Elementen der kritischen Strategie zur Stärkung eines interventionistischen Staates auch Aspekte der affirmativen und revisionistischen Strategie zu finden sind: Der Staat sollte zurückhaltender agieren, weshalb die Vorgaben auch die Absicht verfolgten, die staatlichen Interventionsmöglichkeiten einzuschränken bzw. die oben erwähnte Ausweitung in gewissen Grenzen zu halten. 


\subsection{Phase IV (1990-2004)}

\section{Umfeldbeschreibung}

Die vierte Phase beginnt 1990 mit der ersten Stufe der Wirtschafts- und Währungsunion und endet mit der Verabschiedung des Verfassungsvertrags durch die Staats- und Regierungschefs im Jahr 2004. Von großer Bedeutung waren in diesem Zeitraum sicherlich die Ereignisse, die aus dem Zusammenbruch des Ostblocks folgten: die Wiedervereinigung der beiden deutschen Staaten im Jahr 1990 und die Osterweiterung der Europäischen Union. Nachdem durch die sogenannte EFTA-Erweiterung von 1995 Österreich, Finnland und Schweden Mitglieder der EU geworden waren, traten 2004 zehn mittel- und osteuropäische Länder bei und vergrößerten die EU auf 25 Mitglieder. Dies führte zu einer deutlichen Heterogenisierung, sowohl bezogen auf die Traditionen der Mitgliedstaaten, als auch auf ihre wirtschaftliche Leistungsfähigkeit. Nicht nur politisch, auch wirtschaftlich schritt die Verflechtung der Welt in dieser Phase weiter voran, 1994 wurde die Welthandelsorganisation gegründet und die Uruguay-Runde des GATT abgeschlossen, was den Welthandel unter anderem durch umfangreiche Zollsenkungen intensivierte (vgl. Gillingham 2003: 306).

Hinsichtlich der Ereignisse innerhalb der Europäischen Union ist neben den Erweiterungen die weitgehende Vollendung des Binnenmarktes - wie vorgesehen bis zum 31.12.1992 - zu nennen. In den Folgejahren wurde der Markt weiter ausgebaut, z.B. durch die im Prozess von Cardiff koordinierten Strukturreformen und Liberalisierungsbestrebungen der Mitgliedstaaten (vgl. Europäischer Rat 1998a: Ziff. 11; Heise 2005: 233). Die wirtschaftliche Verflechtung nahm somit weiter zu. Sie zu schützen und zu vertiefen war das Ziel des zentralen Großprojekts der 1990er Jahre, der Wirtschafts- und Währungsunion (WWU). Eine gemeinsame Währung sollte eine Störung des Handels durch Wechselkursschwankungen endgültig verhindern. Nach den Erfahrungen, die man mit dem EWS gesammelt hatte, jedoch auch aufgrund der Spannungen zwischen Deutschland und Frankreich bezüglich der Wechselkurspolitik bzw. der Hegemonie der Deutschen Bundesbank mit der DM als europäischer Leitwährung, schlug die französische Regierung vor, einen zweiten Anlauf zur Einführung einer gemeinsamen Währung zu nehmen (vgl. Moravcsik 1999: 432f). Eine Arbeitsgruppe unter der Leitung des Kommissionspräsidenten Jacques Delors legte 1989 einen Zeitplan vor (vgl. Ausschuss zur Prüfung der Wirtschafts- und Währungsunion 1989), der im gleichen Jahr vom Europäischen Rat in Madrid angenommen wurde (vgl. Europäischer Rat 1989a: 9). Der Plan sah drei Stufen 
vor: 1990 wurde im Rahmen der ersten Stufe die währungspolitische Koordination verstärkt und der Kapitalverkehr vollständig liberalisiert. In der 1994 beginnenden zweiten Stufe wurden die nationalen Zentralbanken in die politische Unabhängigkeit entlassen und das Europäische Währungsinstitut gegründet. Letzteres wurde im Jahr 1999 von der Europäischen Zentralbank (EZB) abgelöst, in dieser dritten Stufe wurde der Euro als Buchgeld eingeführt, was die Wechselkurse unwiderruflich festschrieb. Die Einführung des Euro-Bargeldes erfolgte im Jahr 2002 (vgl. Weidenfeld 2006: 32, festgelegt wurden die Stufen in Art. 109j EGV-M).

Weitere wichtige Entwicklungen fanden Ende der 1990er Jahre statt: Zum einen rief der Europäische Rat auf dem Gipfel von Luxemburg die Europäische Beschäftigungsstrategie ins Leben (vgl. Europäischer Rat 1997b). Die dort beschlossenen »beschäftigungspolitischen Leitlinien« wurden in den beiden Folgejahren ergänzt um den bereits erwähnten Prozess von Cardiff sowie den makroökonomischen Dialog, mit dem die Sozialpartner, die EZB und der Rat (Wirtschaft- und Finanzen) die Lohn-, Geld- und Finanzpolitik besser aufeinander abstimmen sollten (vgl. Europäischer Rat 1999a: Ziff. 8). Im Jahr 2000 wurde die Lissabon-Strategie verabschiedet, die das ehrgeizige Ziel vorgab, bis zum Jahr 2010 der »wettbewerbsfähigste und dynamischste wissensbasierte Wirtschaftsraum in der Welt « (Europäischer Rat 2000a: Ziff. 5) zu werden. Die entsprechende Strategie umfasste Wirtschafts-, Beschäftigungsund Sozialpolitik; auf dem Gipfel von Göteborg kam auch die Umweltdimension hinzu (vgl. Europäischer Rat 2001b: Ziff. 19ff).

Sowohl die integrationspolitischen Großprojekte als auch die Erweiterungsrunden machten mehrere Vertragsänderungen notwendig. Im Jahr 1993 wurde mit dem in Maastricht unterzeichneten EU-Vertrag die Europäische Union gegründet, die neben der bisherigen EG die Gemeinsame Außen- und Sicherheitspolitik und die Gemeinsame Innen- und Justizpolitik umfasste. Der gleichzeitig verabschiedete EG-Vertrag übertrug der Gemeinschaft Kompetenzen in den Bereichen Bildung, Ausbildung, Jugend und öffentliche Gesundheit, überdies enthielt er ein Protokoll über Sozialpolitik, dessen Inhalt wegen des britischen Widerstands kein normaler Vertragsbestandteil geworden war und nur für alle anderen Mitgliedstaaten galt. Die Ratifizierung gestaltete sich schwierig: Die Franzosen stimmten nur sehr knapp zu, die Dänen nach Zugeständnissen erst in einer zweiten Volksabstimmung. In Großbritannien gab es heftige Diskussionen im Unterhaus und in Deutschland prüfte das Verfassungsgericht die Vereinbarkeit mit dem Grundgesetz (vgl. Weidenfeld 2002: 32). So trat der Vertrag erst Ende 1993, fast zwei Jahre nach seiner Unterzeichnung, in Kraft. Die nächste Vertragsrevision erfolgte bereits 
1997: In den EGV von Amsterdam wurde nach dem Regierungswechsel in Großbritannien sowohl das Sozialprotokoll integriert als auch ein eigenes Kapitel zu Beschäftigung eingeführt. Überdies dehnte der Vertrag die Mehrheitsentscheidungen im Rat aus (vgl. Weidenfeld 2006: 34). Nur zwei Jahre nach seinem Inkrafttreten wurde der Vertrag von Nizza verabschiedet, trat jedoch - nach irischer Ablehnung im ersten Referendum - erst 2003 in Kraft. Dieser Vertrag sollte eigentlich die im Angesicht der Osterweiterung notwendigen institutionellen Reformen, wie die Neubestimmung der Größe von Kommission und Parlament, die Stimmengewichtung im Rat sowie den weitestmöglichen Übergang von Einstimmigkeits- zu Mehrheitsentscheidungen, beinhalten. Diese institutionelle Vorbereitung auf die Osterweiterung gelang jedoch nur so unzureichend, dass schon vor Inkrafttreten dieses Vertrags ein neuer Anlauf genommen wurde. Diesmal wählte man nicht das übliche Verfahren der Regierungskonferenz, sondern rief einen sogenannten »Konvent zur Zukunft der Europäischen Union« ins Leben, der die grundlegenden Fragen diskutieren und einen Verfassungsentwurf vorlegen sollte (vgl. Europäischer Rat 2001c). Der Entwurf enthielt unter anderem erstmals einen Katalog von Grundrechten, er sah vor, das Mitentscheidungsverfahren zur Regel zu machen und beinhaltete zahlreiche weitere institutionelle Änderungen. Im Jahr 2004 unterzeichneten die Staats- und Regierungschefs den (überarbeiteten) Entwurf, weshalb dies den Schlusspunkt der Untersuchung bildet.

Auf der mitgliedstaatlichen Ebene ist vor allem die - wenn auch nur einige Jahre dauernde - Ablösung der konservativen Regierungen von mitte-links Koalitionen von Bedeutung: Der Sieg der Sozialdemokraten begann 1996 in Italien, 1997 löste Blair mit der Labour Party die regierenden Tories ab, in Frankreich kamen Jospin und die Gauche Plurielle an die Macht. 1998 wurde mit dem Regierungswechsel zu Rot-Grün im letzten großen Mitgliedsland Deutschland die konservative Regierung abgewählt, dreizehn von fünfzehn Mitgliedstaaten wurden von mittelinks Koalitionen geführt (vgl. Dräger 2003). Obwohl Großbritannien sich nach dem Regierungswechsel deutlich EU-freundlicher zeigte, was unter anderem zur Integration des Sozialprotokolls in den Vertrag von Amsterdam führte, und sich der deutsche Finanzminister Lafontaine um eine europäische Koordinierung der makroökonomischen Politik bemühte, blieb ein deutlicher Politikwechsel auf der europäischen Ebene aus. ${ }^{100}$ Einzig die Europäische Beschäftigungsstrategie und der makroökonomische Dialog könnten als sozialdemokratische Erfolge gewertet werden (vgl. Heise 2002: 3). Mit der Ablösung der großen Koalition in

100 Für eine Erklärung vgl. zum Beispiel Dräger 2003. 
Österreich durch eine rechts-konservative Koalition im Jahr 1999 war der Anfang vom Ende der mitte-links Regierungen eingeläutet. 2000 folgte Spanien, 2001 Italien und Dänemark, 2002 verloren die Sozialdemokraten in Portugal, den Niederlanden sowie in Frankreich (vgl. Dräger 2003). 2004 wurden die Sozialisten in Griechenland abgewählt, so dass im letzten Jahr dieser Phase nur noch Großbritannien, Deutschland, Schweden und Belgien von mitte-links Koalitionen regiert wurden.

Zuletzt ein kurzer Überblick über die wirtschaftliche Situation: Direkt in den Anfangsjahren (1992/93) verschlechterte sich die Konjunktur, unter anderem aufgrund der wiedervereinigungsbedingt restriktiven Geldpolitik der Deutschen Bundesbank (vgl. 92/180/EWG: 8). Hinzu kamen Turbulenzen im EWS im September 1992, welche für einige Länder zu starken Abwertungen und einer Erhöhung der Schwankungsbandbreite auf $15 \%$ führte. Die Arbeitslosigkeit stieg von 8,5\% im Jahr 1990 auf leicht über 10 \% (vgl. Europäische Kommission 2006: 38). Ein robuster Aufschwung setzte erst 1997 ein, im Jahr 2000 erreichten die Wachstumsraten einen Höchststand von durchschnittlich 3,9 \% (vgl. Eurostat 2006). Die Einbrüche an den internationalen Aktienmärkten im März 2001 setzten dieser Entwicklung ein jähes Ende, die Wachstumsraten erreichten nur mehr $2 \%$, in den beiden Folgejahren sogar lediglich $1,1 \%$ (vgl. Eurostat 2006). Erst im Jahr 2004 stieg die Rate wieder auf 2,3 \% bzw. für die EU-25 auf 2,4 \%. Die Arbeitslosigkeit veränderte sich in dieser Krise kaum, sie lag meist knapp unter $8 \%$ (EU-15) bzw. um $9 \%$ in der EU-25 (vgl. Europäische Kommission 2006: 39).

\section{Intendierter Einfluss der europäischen Vorgaben auf die Interventionsmöglichkeiten der Mitgliedstaaten und ihre Handlungsfähigkeit}

Für die folgende Auswertung werden die Vorgaben fünf Bereichen zugeordnet: Zum einen gab es Vorgaben zu den beiden Großprojekten dieser Phase, dem Binnenmarkt sowie der Wirtschafts- und Währungsunion. Flankierend hierzu entwickelte sich die beschäftigungs- und die sozialpolitische Koordinierung. Schließlich gab es Vorgaben, mit denen auf die wirtschaftlichen Krisen reagiert wurde.

\section{Binnenmarkt}

Die Maßnahmen zur Vollendung und Vertiefung des Binnenmarktes waren in erster Linie ordnungspolitischer Natur: die Abschaffung nicht-tarifärer Handelshemmnisse, Wettbewerbs- und Strukturpolitik etc. Die verhältnismäßig wenigen ausgabenrelevanten Vorgaben bezogen sich 
größtenteils auf staatliche Beihilfen. Beihilfen wurden als Hindernis für den Binnenmarkt eingestuft, weil sie den Wettbewerb verzerren, indem sie »konkurrierenden Unternehmen spezifische Vorteile verschaffen. Sie können auch die notwendige Umstrukturierung der Industrie verhindern« (92/180/EWG: 25). Überdies sah man die Gefahr, dass sie die wirtschaftlichen Unterschiede zwischen armen und reichen Ländern wieter erhöhten, da reiche Länder ihre Wirtschaft stärker subventionieren könnten (vgl. ebenda). Grundsätzlich waren wettbewerbsverzerrende Beihilfen laut Art. 87 und 88 EG-Vertrag (bzw. im EGV-M Art. 92 und 93) weiterhin verboten, die Kontrolle lag bei der Kommission. Um das Verfahren wirksamer und effizienter zu gestalten und die Transparenz und Rechtssicherheit zu erhöhen, kodifizierte der Rat 1999 das durch die Kommission entwickelte Kontrollverfahre (VO 659/1999). Die Kodifizierung schrieb im Wesentlichen das von der Kommission bereits seit 1985 bzw. $1987^{101}$ praktizierte Kontrollverfahren fest. Dieses umfasste unter anderem die Verpflichtung der Mitgliedstaaten, der Kommission jedes Jahr alle bestehenden Beihilfen mitzuteilen, was die Transparenz und damit die Überwachung verbessern sollte (vgl. ebenda, Art. 21). Wesentlicher war die Regelung, dass die Mitgliedstaaten unrechtmäßig gezahlte Beihilfen inklusive Zinsen von den betroffenen Unternehmen zurückfordern mußten (vgl. ebenda, Art. 11ff), was notfalls vor dem EuGH durchgesetzt werden konnte (vgl. ebenda, Art. 12).

Die Empfehlung, Subventionen abzubauen, tauchte in den Vorgaben sehr häufig auf, so z.B. in den Grundzügen der Wirtschaftspolitik (GdW) von 1999: »Beihilfen müssen von der Kommission streng überwacht werden und erfordern von den Mitgliedstaaten eine rigorose Selbstdisziplin « (1999/570/EG: 48). Ab dem Jahr 2000 erfolgte eine leichte Präzisierung: Die Mitgliedstaaten wurden aufgefordert, die Beihilfen in Relation zum BIP zu senken; die Schlussfolgerungen der Frühjahrsgipfel von 2001 und 2002 setzten das Jahr 2003 als Referenzwert (vgl. Europäischer Rat 2001a: Ziff. 21; Europäischer Rat 2002a: Ziff. 16). Quantifizierte Reduktionsvorgaben gab es allerdings nicht, nur bei den am stärksten wettbewerbsverzerrenden Beihilfen wurde eine vollständige Abschaffung gefordert (vgl. Europäischer Rat 2002a: Ziff. 2).

Subventionen wurden jedoch nicht nur negativ gesehen, eine zweite Gruppe von Empfehlungen bezog sich auf ihre Umgruppierung sowie Ausnahmeregelungen. Beim ersten Punkt ging es darum, die Beihilfen auf gemeinsame, sogenannte »horizontale Ziele« wie Beschäftigung, Regionalentwicklung, Umwelt, Ausbildung, Forschung (vgl. Europäi-

101 Obwohl schon vorher Rückforderungsentscheidungen ergingen, teilte die Kommission erst im Jahr 1987 mit, nunmehr mit einer systematischen Rückforderungspraxis zu beginnen (vgl. Gross 2003: 90). 
scher Rat 2000a: Ziff. 17), wirtschaftlichen und sozialen Zusammenhalt (vgl. Europäischer Rat 2002a: Ziff. 16) sowie die »Förderung der Kultur und der Erhaltung des kulturellen Erbes« auszurichten (vgl. Art. 92d EVG-M). Der Rat ermächtigte die Kommission in diesem Zusammenhang, allgemeine Vereinbarkeitskriterien festzulegen, um so ganze Gruppen von Beihilfen für vertragsgemäß zu erklären (sog. Gruppenfreistellungsverordnungen, VO 994/98). Dies förderte auch die Durchsetzung des Beihilfeverbots, da die Kommission auf diese Weise von Routinefällen befreit wurde und sich stärker auf die Kontrolle in anderen Bereichen konzentrieren konnte.

Auch die Ausnahmen vom Beihilfeverbot dienten der Erreichung gemeinsamer Ziele: Der innergemeinschaftliche Verkehr sollte gefördert werden, indem Subventionen für den kombinierten Verkehr (Straße, Schiene, Binnenschifffahrt) erlaubt wurden (vgl. VO 3578/92). Weiterhin sollte die Wettbewerbsfähigkeit der europäischen Schiffbauindustrie auf dem Weltmarkt durch Beihilfen gestärkt werden, ${ }^{102}$ solange die Handelspartner außerhalb von Europa sich nicht zu einem Subventionsabbau verpflichteten (vgl. 90/684/EWG; VO 3094/95; VO 1540/98). Vom Verbot ausgenommen waren auch die $»$ Dienste von allgemeinem wirtschaftlichen Interesse ${ }^{103}$ - zumindest sofern das Verbot ihre Aufgabenerfüllung behinderte (vgl. Art. 86 EGV). Seit dem Vertrag von Amsterdam sollten die Mitgliedstaaten überdies die Grundsätze und Bedingungen für das Funktionieren dieser Dienste so gestalten, dass sie ihren Aufgaben nachkommen können (vgl. Art. 16 EGV). Ausgabenrelevante Vorgaben entsprangen hieraus jedoch nicht, sowohl die Gewährleistung der Versorgungssicherheit wie auch die insbesondere im Rahmen des Cardiff-Prozesses verabschiedeten Vorgaben zur Liberalisierung dieser Dienste bezogen sich auf mitgliedstaatliche Regulierungen, d.h. Ordnungspolitik (vgl. bspw. 2002/39/EG).

Weitere ausgabenrelevante Vorgaben im Bereich Binnenmarkt zielten auf eine Stärkung der Wettbewerbsfähigkeit der europäischen Wirtschaft, da »vom Binnenmarkt und der Globalisierung allgemein [...] ein starker Druck zur Steigerung der Wettbewerbsfähigkeit aus[geht]« (98/ 454/EG: 41). Dieses Ziel sollte durch die Schaffung des großen gemeinsamen Wirtschaftsraums erreicht werden, ergänzt durch mitgliedstaatli-

$102 \mathrm{Ab} 1998$ waren jedoch keine Betriebsbeihilfen mehr erlaubt, sondern in engem Rahmen - nur noch Investitionsbeihilfen zur Innovationsförderung oder Stilllegungs- und Umstrukturierungsbeihilfen (VO 1540/98).

103 Dieser Begriff bezeichnet »marktbezogene Tätigkeiten, die im Interesse der Allgemeinheit erbracht und daher von den Mitgliedstaaten mit besonderen Gemeinwohlverpflichtungen verbunden werden. Gemeint sind insbesondere Verkehrs-, Energieversorgungs- und Telekommunikationsdienste« (96/C 281/03: 3). 
che Maßnahmen. Diese bezogen sich - neben der oben erwähnten strikten Beihilfenkontrolle und ihrer horizontalen Ausrichtung - vor allem auf staatliche Investitionen in Bereiche, die als Grundlagen für die privatwirtschaftliche Entwicklung dienen: das Bildungs-, Aus- und Fortbildungswesen, Forschung und Entwicklung (vgl. 97/479/EG: 17), Informations- und Kommunikationstechnologie sowie Infrastruktur (vgl. 98/ 454/EG: 41).

Im Rahmen des in Lissabon gesetzten Schwerpunkts auf die wissensbasierte Wirtschaft bekamen Investitionen in Forschung und Entwicklung einen besonderen Stellenwert: Der Staat sollte eine aktive Rolle bei der Stimulierung und Finanzierung von FuE einnehmen und die entsprechenden Ausgaben erhöhen. Dieses Ziel wurde in einigen Leitlinien spezifiziert, so sollten die Mitgliedstaaten vor allem Grundlagenforschung finanzieren (vgl. 2001/483/EG: 16) und einen Schwerpunkt »insbesondere auf die technologische Innovation einschließlich Umwelttechnologie und die Entwicklung des Humankapitals durch höhere Investitionen in Bildung und Forschung« legen (Europäischer Rat 2003c, Ziff 19). Im Jahr 2002 setzte der Europäische Rat in Barcelona das Ziel, bis zum Jahr 2010 für FuE-Ausgaben ein Niveau von $3 \%$ des BIP zu erreichen (vgl. Europäischer Rat 2002a: Ziff. 47). Die Mitgliedstaaten sollten ein Drittel davon aufbringen und Anreize für den Privatsektor setzen, die restlichen zwei Drittel beizusteuern (vgl. ebenda). ${ }^{104}$ Eine Zusammenarbeit mit dem privaten Sektor wurde auch allgemein empfohlen, so sollten die Mitgliedsländer die aufgeführten Investitionen nur zum »angemessenen« Teil selbst übernehmen (vgl. 98/454/EG: 41). Dass der Staat keine zu starke Rolle übernehmen sollte, wird weiterhin an den - eher vage formulierten - Empfehlungen deutlich, das Wettbewerbsumfeld durch Privatisierungen (vgl. 94/480/EG: 40) und eine Verringerung der Rolle des öffentlichen Sektors zu verbessern (vgl. 95/326/EG: 27). Grundlegend müsse »laufend untersucht werden, ob Interventionen des Staates notwendig sind, welche Kosten sie verursachen und welche Alternativen bestehen « (93/258/EWG: 27).

Durch den Verfassungsvertrag wurde die seit dem EUV bestehende rüstungspolitische Zusammenarbeit (vgl. Art. 17 EU-V) erweitert, insbesondere mit Blick auf den Binnenmarkt für Rüstungsgüter. Die Mitgliedstaaten wurden aufgefordert, ihre Ausgaben für das öffentliche Gut Sicherheit und Verteidigung zu erhöhen bzw. ihre »militärischen Fähig-

104 Zur Erreichung dieses Ziels wurde auf dem EU-Gipfel im März 2003 eine eigenständige $\mathrm{OMK}$ im Bereich FuE entwickelt, die sich jedoch hauptsächlich mit technischen Details und der Ermöglichung eines Lernprozesses beschäftigt, d.h. keine relevanten Empfehlungen für nationale Ausgabenpolitik enthält (vgl. CREST 2004). 
keiten schrittweise zu verbessern« (Art. I-41 VerfV). Dabei wurden sie von der neu geschaffenen »Europäischen Verteidigungsagentur« unterstützt, die auch die Einhaltung der gesetzten Ziele überwachte. Die Agentur hatte überdies die Aufgabe, auf eine »Harmonisierung des operativen Bedarfs« hinzuwirken, multilaterale Projekte vorzuschlagen und mitgliedstaatliche Programme zu koordinieren. Schließlich sollte die Forschung in diesem Gebiet unterstützt werden (vgl. Art. III-311 VerfV).

Im Rahmen der Vollendung und Vertiefung des Binnenmarktes wurde auch die Notwendigkeit der allgemeinen Koordinierung nationaler Wirtschaftspolitiken angesprochen, da der Binnenmarkt die wirtschaftliche und finanzielle Integration sowie den Wettbewerb und Strukturwandel vertiefe und dadurch die grenzüberschreitenden Effekte der Wirtschaftspolitik verschärfe (vgl. 90/141/EWG: 23). Diese Koordinierung wurde jedoch meist schon mit Blick auf die WWU betrachtet, weshalb sie dort behandelt wird.

\section{Wirtschafts- und Währungsunion}

Zur weiteren Vollendung des Binnenmarktes gehörte auch die Einführung der gemeinsamen Währung. Die entsprechenden Umsetzungsschritte werden hier nicht im Einzelnen dargestellt, da sie keine direkte ausgabenpolitische Relevanz haben. Die Bedeutung der WWU für die nationale Ausgabenpolitik liegt darin, dass eine Koordinierung der Wirtschaftspolitik in diesem Zusammenhang als besonders notwendig erachtet wurde. Dies bezog sich zum einen auf den Zeitraum vor der Einführung des Euro: »Der Europäische Rat hebt die Notwendigkeit hervor, bereits jetzt im Rahmen der ersten Phase der Wirtschafts- und Währungsunion zufrieden stellende und nachhaltige Fortschritte in Richtung auf die Konvergenz in Wirtschafts- und Währungsfragen [...] zu erzielen« (Europäischer Rat 1991: 10). Zum anderen erhöhe aber auch die »einheitliche Währung [...] den wirtschaftspolitischen Koordinierungsbedarf« (Europäischer Rat 1998b: Ziff. 9), da die Einführung des Euro die Verflechtung der Volkswirtschaften weiter verstärke und nationalstaatliche Politik - z.B. über die Inflationsrate - Einfluss auf die gemeinsame Geldpolitik haben könne (vgl. ebenda, Anlage II: Ziff. 2). Für die Koordinierung wurden mehrere Verfahren entwickelt:

\section{Konvergenzkriterien bzw. Stabilitäts- und Wachstumspakt}

Die Koordinierung auf dem Weg zur gemeinsamen Währung zielte vor allem darauf $\mathrm{ab}$, die nominale Konvergenz der nationalen Volkswirtschaften zu erhöhen. Zu diesem Zweck wurden im Vertrag von Maa- 
stricht die sogenannten Konvergenzkriterien als Zugangskriterien für den Beitritt zum Euro festgeschrieben (vgl. Art. 109j, Protokoll zum EGV über die Konvergenzkriterien nach Art. 121 EGV). Sie umfassten neben einer niedrigen Inflationsrate, einem niedrigen langfristigen Nominalzinssatz und stabilen Wechselkursen auch das Ziel einer »auf Dauer tragbaren Finanzlage der öffentlichen Hand « (Art. 109j, Abs. 1 EGV$\mathrm{M})$, präziser: eine Staatsverschuldung von maximal $60 \%$ und eine Neuverschuldung von maximal $3 \%$ des BIP (vgl. Art. 104c, Abs. 2 EGV-M sowie das Protokoll zum Verfahren bei einem übermäßigen Defizit).

Insbesondere Deutschland setzte sich dafür ein, die beiden letztgenannten Kriterien auch nach der Einführung des Euro (und damit dem Wegfall des Sanktionsmechanismus `Nicht-Beitritt zum Euro〈) weiter zu stärken. Gerechtfertigt wurde dies mit der Befürchtung, die Mitgliedstaaten könnten durch unsolide Haushaltspolitik die Inflationsrate und damit auch die einheitliche Geldpolitik beeinflussen (vgl. 98/C 35/01: 1). Überdies sah man in »gesunden« öffentlichen Finanzen eine Voraussetzung für Preisstabilität, Wachstum und eine geringe Arbeitslosigkeit (vgl. 97/C 236/01: 1), da sie vorteilhafte Auswirkungen auf die Zinssätze haben, das Investorenvertrauen stärken sowie Spielraum für die automatischen Stabilisatoren schaffen (vgl. 2001/ 483/EG: 9). Dem deutschen Anliegen wurde mit der Verabschiedung des Stabilitäts- und Wachstumspakts (SWP) im Jahr 1997 entsprochen. Dieser verschärfte das Defizitkriterium, indem »das mittelfristige Haushaltsziel eines nahe$\mathrm{zu}$ ausgeglichenen oder einen Überschuß ausweisenden Haushalt[s] (97/C 236/01: 1) festgeschrieben wurde. Auf diese Weise sollten die Mitgliedstaaten auch in konjunkturellen Abschwüngen bei Wirkenlassen der automatischen Stabilisatoren das $3 \%$-Kriterium nicht verletzen (vgl. VO 1467/97, (7)). Das Hauptaugenmerk des Pakts lag auf der Neuverschuldung, nicht auf der Gesamtverschuldung, weshalb sich auch das dort präzisierte Überwachungsverfahren auf die Einhaltung dieses Kriteriums konzentrierte (vgl. ebenda und VO 1466/97).

Die Einhaltung der Kriterien wird von der Kommission überwacht. Sie beobachtet die Entwicklung der Haushaltslage und die Höhe des öffentlichen Schuldenstands. Ergänzend erstellen die Mitgliedstaaten - je nachdem ob sie Mitglied der Eurozone sind oder nicht - jährlich Stabilitäts- bzw. Konvergenzprogramme. In diesen Programmen müssen sie »das mittelfristige Ziel für einen nahezu ausgeglichenen Haushalt oder einen Überschuß sowie den Anpassungspfad in Richtung auf dieses Ziel für den Saldo des öffentlichen Haushalts und die voraussichtliche Entwicklung der öffentlichen Schuldenquote« (VO 1466/97, Art. 3) darlegen. Für das Defizitkriterium ist auch ein detailliertes Sanktionsverfahren vorgesehen. Es umfasst nach Artikel 104 EGV insgesamt acht 
Schritte und geht von einer Empfehlung des Rates an den betroffenen Mitgliedstaat, die bei Nichtbeachtung veröffentlicht werden kann, über die Verpflichtung von Maßnahmen zur Defizitreduzierung bis hin zu Sanktionsmöglichkeiten wie unverzinsliche Einlagen bei der Gemeinschaft oder Geldbußen. Das Verfahren zur Koordination der Fiskalpolitiken verfügte somit nicht nur über klare, messbare Ziele, sondern auch über ein >schmerzhaftes`Sanktionsverfahren, was eine bedeutende Einschränkung der mitgliedstaatlichen Interventionsmöglichkeiten mit sich bringen sollte. Dies wird noch einmal besonders deutlich daran, dass für Länder, die bewusst ein übermäßiges Defizit einplanen, d.h. mit Absicht eine andere Politik verfolgen, im SWP ein Eil-Sanktionsverfahren vorgesehen ist (vgl. VO 1467/97, Art. 7).

Im Verfassungsvertrag wurde dem fast unverändert übernommenen Art. 104 (dort Art. III-184) eine Erklärung beigefügt, in der die Mitgliedstaaten sich erneut zum Stabilitäts- und Wachstumspakt bekennen und die Kommission auffordern, Vorschläge für eine verstärkte und klarere Umsetzung des Pakts vorzulegen (vgl. Erklärung zu Art. III-184 VerfV). Zum Teil wird dies bereits durch die größere Rolle der Kommission im Überwachungs- und Sanktionsverfahren gewährleistet (vgl. Art. III-184 VerfV). ${ }^{105}$

\section{Makroökonomische Politik/Grundzüge der Wirtschaftspolitik}

Mit Beginn der 1990er Jahre wurde der Ansatz der wirtschaftspolitischen Koordinierung geändert. Dies kann man an der Aufhebung der bisherigen Grundlage der Koordinierung (74/120/ EWG) festmachen, die noch die Möglichkeit rechtlich verbindlicher Richtlinien vorgesehen hatte. Die Begründung lautete, dass »ein Erfolg der Koordinierung der Wirtschaftspolitik [...] nicht durch einen zentralisierten Entscheidungsprozeß, der den Mitgliedsländern Verpflichtungen auferlegt, erreicht werden [könne] « (89/685/EWG: 14). Stattdessen sollte ein System multilateraler Überwachung geschaffen werden, bei dem die Wirtschaftspolitik der Mitgliedstaaten, darunter auch ihre Haushaltspolitik, vom Rat geprüft wird, wobei dieser auch Empfehlungen an einzelne Länder aussprechen kann (vgl. 90/141/EWG: 24). Zu Beginn der 2. Stufe der WWU, im Jahr 1994, lösten die »Grundzüge der Wirtschaftspolitik« (GdW) die bisherigen Jahresberichte ab. Das durch die oben genannten

105 Im Unterschied zu dem im EGV festgelegten Verfahren hat die Kommission bei der Entscheidung über das Vorliegen eines übermäßigen Defizits nun ein Vorschlagsrecht, d.h. der Rat kann nur mehr einstimmig von der Vorlage abweichen. Überdies bekam sie sowohl bei den Empfehlungen wie auch bei der Verhängung weiterer Sanktionen das Recht, eine Empfehlung vorzulegen, vorher war sie hier formal nicht involviert. 
Entscheidung zur Aufhebung der Konvergenzentscheidung (90/141/ EWG) geänderte Verfahren wurde nun auch vertraglich festgelegt: Nach Art. 102a des EGV-M (später Art. 98 EGV) betrachten die Mitgliedstaaten ihre Wirtschaftspolitik als »Angelegenheit von gemeinsamem Interesse «. Bei Wachstum, Inflation und Beschäftigung sollten vergleichbare Ergebnisse erzielt werden, denn ein »hoher Grad wirtschaftlicher Konvergenz [ist] eine Vorbedingung für die Erreichung des im Vertrag festgelegten Ziels der Schaffung einer stabilen einheitlichen Währung« (Europäischer Rat 1995b: Ziff. 1). Um dieses Ziel zu erreichen, sollten somit nicht nur die Fiskal-, sondern auch die übrigen Bereiche der Wirtschaftspolitik koordiniert werden. Die entsprechenden Leitlinien werden laut Art. 99, Abs. 2 EGV auf Empfehlung der Kommission und nach Erörterung des Europäischen Rates vom Rat mit qualifizierter Mehrheit ohne Beteiligung des Europäischen Parlaments - verabschiedet. Um ihre Einhaltung zu überwachen, erstellt die Kommission auf Grundlage mitgliedstaatlicher Informationen einen Bericht, anhand dessen der Rat die Vereinbarkeit der wirtschaftlichen Entwicklung der Mitgliedstaaten mit den Grundzügen überwacht (vgl. Art. 99, Abs. 3 EGV). Hält sich ein Mitgliedstaat nach Meinung des Rates nicht an die vereinbarten Leitlinien oder »droht seine Wirtschaftspolitik das ordnungsgemäße Funktionieren der Wirtschafts- und Währungsunion zu gefährden« (Art. 99 EGV), kann der Rat - wieder auf Empfehlung der Kommission - Empfehlungen an den betreffenden Staat richten. Diese können, wenn der Rat dies mit qualifizierter Mehrheit beschließt, auch veröffentlicht werden (vgl. Art. 99, Abs. 4 EGV). Im Verfassungsvertrag wurde zusätzlich festgelegt, dass die Kommission bei Nichteinhaltung der Grundzüge eine Verwarnung an den entsprechenden Mitgliedstaat richten könne (vgl. Art. III-177 VerfV). Überdies sollten die Mitglieder der Eurozone spezifische Leitlinien festlegen, um die Konvergenz im Euro-Raum zu erhöhen, besonderes Augenmerk lag hier auf der Haushaltsdisziplin (vgl. Art. III-194 VerfV).

Die Grundzüge der Wirtschaftspolitik bestehen aus zwei Teilen: Im ersten werden allgemeine wirtschaftspolitische Leitlinien aufgestellt, im zweiten länderspezifische, welche in dieser Arbeit nicht untersucht werden. Der erste Teil enthält, neben der Einleitung mit einer Darlegung der wirtschaftlichen Lage und den wichtigsten Entwicklungen, Empfehlungen zu den folgenden Bereichen: makroökonomische Politik, öffentliche Finanzen, Lohnentwicklung, Arbeitsmarkt und Produktmärkte/Strukturreformen. Da die Empfehlungen zum Arbeitsmarkt unter Beschäftigungspolitik behandelt werden und es für die anderen Bereiche keine ausgabenrelevanten Vorgaben gab, geht es im Folgenden nur um den zweiten Bereich, die öffentlichen Finanzen. Im Zentrum stand hier die 
Haushaltskonsolidierung gemäß den Konvergenzkriterien bzw. später des Stabilitäts- und Wachstumspakts. Zusätzlich zur Konsolidierung wurden die Mitgliedstaaten aufgefordert, ihre Haushaltspolitik stärker zu koordinieren, »damit eine Verbesserung des Wachstumspotenzials der europäischen Volkswirtschaften und eine bessere Vorbereitung auf die mittelfristigen Herausforderungen erreicht wird" (Europäischer Rat 2003a: Ziff. 16). Dies galt besonders für die Mitglieder der Eurozone, da sie auf asymmetrische Schocks nicht mehr mit Hilfe von Wechselkursänderungen reagieren können (vgl. 2001/483/EG: 10f). Die Euroländer, die noch keinen ausgeglichenen Haushalt vorweisen konnten, sollten ab 2003, »alle notwendigen Maßnahmen [...] ergreifen, um eine jährliche Verbesserung der konjunkturbereinigten Haushaltsposition um mindestens $0,5 \%$ des BIP sicherzustellen« (2003/555/EG: 14).

Neben der Defizitreduzierung wurde auch eine Senkung der Ausgaben empfohlen (vgl. bspw. 94/480/EG: 39), allerdings eine selektive. Mit »Qualität der öffentlichen Finanzen« war eine Umschichtung der öffentlichen Ausgaben gemeint: Die konsumtiven Ausgaben sollten reduziert, die investiven erhöht werden. Dies wurde in den Folgejahren immer detaillierter ausgeführt: Sparanstrengungen sollte es »in den Bereichen Staatsverbrauch, staatliche Altersversorgung, Gesundheitswesen, passive Arbeitsmarktmaßnahmen und Subventionen« (97/479/EG: 15) geben, ansonsten »ist eine restriktive Umschichtung von öffentlichen Ausgaben im Hinblick auf die Förderung von Investitionen in Humankapital, Forschung und Entwicklung, Innovation sowie die für die Wettbewerbsfähigkeit unentbehrliche Infrastruktur erforderlich« (Europäischer Rat 1997a: 11). Besonderen Nachdruck erhielt diese Empfehlung, nachdem 1998 eine Tendenz zur Verringerung der öffentlichen Investitionen festgestellt wurde (vgl. 98/454/EG: 37). Die Lissabon-Strategie stellte die Ausgabenumschichtung noch stärker in den Dienst der angestrebten »Wissensgesellschaft«, was insbesondere eine Verlagerung der Ausgaben zugunsten der Akkumulation von Sach- und Humankapital, Innovation, Informationstechnologie sowie Forschung und Entwicklung beinhaltete (vgl. Europäischer Rat 2000a: Ziff. 23). Insgesamt sollte der Ausgabenanstieg das Ziel des Haushaltsausgleichs nicht gefährden, er würde aber über die positiven Auswirkungen auf Wachstum und Beschäftigung mittelfristig auch zu einer Verbesserung der Haushaltslage beitragen (vgl. 98/454/EG: 37).

Schließlich tauchte 1995 zum ersten $\mathrm{Mal}^{106}$ das Ziel auf, die sogenannte »dauerhafte Tragfähigkeit» der öffentlichen Finanzen zu sichern:

106 Zumindest was die wirtschaftspolitische Koordinierung betrifft, bei der sozialpolitischen taucht das demographische Problem schon früher auf. 
Den Folgen der demographischen Entwicklung sollte begegnet werden, indem die Schulden durch Haushaltsüberschüsse reduziert (vgl. 95/326/ EG: 26) und die Renten- und Gesundheitssysteme modernisiert wurden (vgl. 2001/483/EG: 12). Hierauf wird beim Bereich Sozialpolitik genauer eingegangen.

\section{Beschäftigungsstrategie}

Auch in den 1990er Jahren blieb die Arbeitslosigkeit ein wichtiges Thema. Die Begründungen für ein gemeinschaftliches Vorgehen bei diesem Problem waren vielfältig: Zum einen wurde darauf verwiesen, dass sich das Ziel eines hohen Beschäftigungsniveaus im Vertrag zur Gründung der Europäischen Gemeinschaft (vgl. Art. 2 EGV) finde. Während es dort eines unter vielen ist, betonte der Europäische Rat immer wieder, Beschäftigung sei eine prioritäre Aufgabe der Gemeinschaft (vgl. Europäischer Rat 1996: 11; Europäischer Rat 1999a: Ziff. 7), da »die Union den legitimen Erwartungen der Bürger besser gerecht werden [muss], indem sie in erster Linie alle ihre Mittel - neben denen der Mitgliedstaaten - einsetzt, um die Geißel der Arbeitslosigkeit wirksam zu bekämpfen« (Europäischer Rat 1995a: 10). Überdies befürchte man, dass die Arbeitslosigkeit den Zusammenhalt der Union gefährde (vgl. Europäischer Rat 1997b: Ziff. 2). Auch der praktische Nutzen des gemeinsamen Vorgehens wurde hervorgehoben: »Die Europäische Union bietet als Wirtschaftseinheit einen zusätzlichen Handlungsspielraum und einen spezifischen zusätzlichen Nutzen bei der Schaffung dauerhafter Arbeitsplätze« (Europäischer Rat 1995a: 11). Schließlich setzten die Staats- und Regierungschefs in Lissabon das Ziel, neben Wettbewerbsfähigkeit auch Vollbeschäftigung zu erreichen, gemessen in Beschäftigungsquoten, allgemein sowie für bestimmte gesellschaftliche Gruppen wie Frauen und ältere Arbeitnehmer (vgl. Europäischer Rat 2000a: Ziff. 30; Europäischer Rat 2001a: Ziff. 8f).

Neben den Empfehlungen, die sich in den Jahresberichten bzw. ab 1994 in den Grundzügen der Wirtschaftspolitik fanden, wurden im Verlauf der 1990er Jahre eigenständige Verfahren zur Koordinierung der Beschäftigungspolitik entwickelt. Seit dem EU-Gipfel von Essen mussten die Mitgliedstaaten »Mehrjahresprogramme« für Beschäftigung vorlegen, die vom Rat evaluiert wurden (vgl. Europäischer Rat 1994b: 9). Dieses Verfahren wurde in den Vertrag von Amsterdam aufgenommen und spezifiziert: Vom Rat auf Vorschlag der Kommission festgelegte »beschäftigungspolitische Leitlinien« werden von den Mitgliedstaaten in nationale Aktionspläne umgesetzt. Auf Grundlage der Überprüfung dieser Pläne entstehen dann die neuen Empfehlungen (vgl. Art. 128 EGV). 
Das Sanktionsverfahren ist etwas weicher als bei den GdW, da die Empfehlungen bei Nichteinhaltung nicht veröffentlicht werden. Statt auf Sanktionen wird mehr Wert auf den Austausch von Informationen und Best-Practice gelegt. ${ }^{107}$

Inhaltlich ging es bei den Vorgaben zur Beschäftigungspolitik in erster Linie um aktive Arbeitsmarktpolitik. Dies machte bereits der entsprechende Titel VIII des EG-Vertrags deutlich, die dort aufgeführten Maßnahmen zur Erreichung des hohen Beschäftigungsniveaus lauten: »Förderung der Qualifizierung, Ausbildung und Anpassungsfähigkeit der Arbeitnehmer sowie der Fähigkeit der Arbeitsmärkte [...], auf die Erfordernisse des wirtschaftlichen Wandels zu reagieren« (Art. 125 EGV). In Bezug auf öffentliche Ausgaben lassen sich in den Mehrjahresprogrammen sowie den beschäftigungspolitischen Leitlinien drei Bereiche finden, mit denen die Beschäftigung erhöht werden sollte: Bildung, eine beschäftigungsfreundliche Umgestaltung der Sozialsysteme sowie eine bessere Vereinbarkeit von Familie und Beruf. Der erste Bereich umfasste sowohl Aus- wie Weiterbildung. In einer Reihe von Entschließungen und Aktionsprogrammen wurde den Mitgliedstaaten empfohlen, ihre Investitionen in diesen Bereichen zu erhöhen (vgl. z.B. 94/C 374/01: 2; Europäischer Rat 2003a: Ziff. 40), da dies eine sinnvolle Präventiv- und Anpassungsmaßnahme darstelle (vgl. 90/267/EWG: 2). So forderten die beschäftigungspolitischen Leitlinien dazu auf, nationale Vorgaben für die Steigerung der Investitionen in Humankapital zu setzen (vgl. 2001/63/EG: 20). Die Lissabon-Strategie zielte darauf ab, dass »Europas Bildungs- und Ausbildungssysteme [...] sich auf den Bedarf der Wissensgesellschaft und die Notwendigkeit von mehr und besserer Beschäftigung einstellen« (Europäischer Rat 2000a: Ziff. 25). Die Berufsbildung sollte durch die Zusammenarbeit zwischen den Mitgliedstaaten verbessert werden und eine europäische Dimension erhalten, dies wurde in mehreren Aktionsprogrammen, Beschlüssen (vgl. z.B. 90/267/ EWG; 95/C 207/07; 2000/C 8/04) sowie ab 2002 in einer Zusammenarbeit in Form der Offenen Methode der Koordinierung (vgl. 2002/C 142/01, vgl. zur Methode unten, Sozialpolitik) festgehalten. Die ausgabenrelevanten Vorgaben gingen jedoch nicht über die allgemeine Empfehlung hinaus, die Mitgliedstaaten sollten die berufliche Bildung ausbauen und ihre Qualität verbessern.

107 Die anderen beiden Ergänzungen der Europäischen Beschäftigungsstrategie, der Cardiff-Prozess sowie der makroökonomische Dialog, werden hier nicht näher betrachtet. Letzterer dient der Absprache der makroökonomischen Akteure, er gibt keine Empfehlungen ab, während der Prozess von Cardiff keine ausgabenrelevanten Empfehlungen beinhaltet, die darunter fallenden Strukturreformen sind nur indirekt ausgabenwirksam. 
Beim zweiten großen Bereich, der beschäftigungsfreundlichen Gestaltung der Sozialsysteme (vgl. z.B. Europäischer Rat 1996: 12), ging es darum, Anreize zu erhöhen: Anreize für die Arbeitgeber, aufgrund einer Senkung der Lohnnebenkosten mehr Menschen einzustellen (vgl. 97/479/EG: 18) und Anreize für Arbeitnehmer bzw. Arbeitslose, aufgrund von geringeren Sozialleistungen verstärkt »Arbeit zu suchen, eine Arbeit aufzunehmen und im Arbeitsleben zu verbleiben « (2003/578/EG: 20). Dies wurde teilweise recht detailliert ausgeführt: »Die Mitgliedstaaten sollten insbesondere [...] die Anreizeffekte der Leistungssysteme prüfen, wie beispielsweise die Anspruchsbedingungen, Anspruchsberechtigung, Leistungsdauer, Lohnersatzquote sowie die Existenz von Lohnergänzungsleistungen [...], um die Systeme beschäftigungsfreundlicher zu gestalten « (2002/549/EG: 14). Die Mitgliedstaaten sollten Zielvorgaben für die Senkung der Steuer- und Abgabenbelastung festlegen, ohne hierdurch jedoch die Erreichung des Haushaltsausgleichs sowie des finanziellen Gleichgewichts der Sozialversicherungssysteme zu gefährden (vgl. 98/C 30/01: 4).

Zur Förderung der Vereinbarkeit von Familie und Beruf verabschiedete der Rat 1992 eine Entschließung mit Anforderungen an Kinderbetreuungseinrichtungen: Diese sollten z.B. pädagogisch wertvoll, erschwinglich und den Bedürfnissen der Eltern entsprechend ausgestaltet sein (vgl. 92/241/EWG: 17f). In den Folgejahren gab es nur allgemeine Aufforderungen, die Pflege von bedürftigen Personen zu unterstützen. Erst im Jahr 2002 wurden die Vorgaben für Kinderbetreuung mit Zahlen versehen: Die Mitgliedstaaten sollten »bestrebt sein, nach Maßgabe der Nachfrage nach Kinderbetreuungseinrichtungen und im Einklang mit den einzelstaatlichen Vorgaben für das Versorgungsangebot bis 2010 für mindestens $90 \%$ der Kinder zwischen drei Jahren und dem Schulpflichtalter und für mindestens $33 \%$ der Kinder unter drei Jahren Betreuungsplätze zur Verfügung zu stellen« (Europäischer Rat 2002a: Ziff. 32; 2002/549/EG: 14). Anforderungen an die Einrichtungen wurden allerdings nicht mehr formuliert.

\section{Sozialpolitik}

Zu Beginn der 1990er Jahre wurden sozialpolitische Vorgaben vor allem im Zusammenhang mit der sozialen Dimension des Binnenmarktes verabschiedet. Dabei sah man die Bekämpfung der sozialen Ausgrenzung als wesentlich an (vgl. 92/441/EWG: 46), was auch durch die Aufnahme dieses Ziels in das Sozialkapitel des EGV-A seinen Ausdruck fand (vgl. Art. 136f EGV). Eine weitere Begründung für das gemeinsame Vorgehen war, dass die »Sozialschutzsysteme, die ein wesentlicher Teil des 
europäischen Sozialmodells sind, [...] - auch wenn sie nach wie vor in die Zuständigkeit der einzelnen Mitgliedstaaten fallen - alle vor denselben Herausforderungen [stünden] « (Europäischer Rat 2000b, Anlage I, IV). Als Herausforderungen wurden neben Armut und Ausgrenzung die Überalterung der Bevölkerung, die Veränderung der Familienstrukturen und die hohe Arbeitslosigkeit genannt (vgl. 92/442/ EWG: 49). Um diesen wirksam begegnen zu können, sollte die Zusammenarbeit zwischen den Mitgliedstaaten verstärkt werden. Eine Entschließung von 1992 empfahl, die Politiken im Bereich des sozialen Schutzes durch die Festlegung gemeinsamer Ziele anzunähern, die den Mitgliedstaaten als Anhaltspunkte für die Reform ihrer Systeme dienen können. In der Entschließung wurden recht detaillierte Ziele für die Bereiche Krankheit, Mutterschutz, Arbeitslosigkeit und -unfähigkeit sowie Alter und Familie niedergelegt. Zusätzlich sollten die Mitgliedstaaten eine Grundsicherung gewähren, die ein menschenwürdiges Leben ermöglicht, allerdings auch den Arbeitsanreiz nicht unterminiert (vgl. 92/ 441/EWG: 48); teilweise wurden auch statussichernde Sozialleistungen empfohlen (vgl. 92/442/ EG: 51; 93/C 343/01: 2).

Bei der Zusammenarbeit ging es nicht darum, die nationalen Systeme durch eine strikte Rechtsangleichung zu vereinheitlichen, sondern um einen Informationsaustausch - mit Hilfe mitgliedstaatlicher Berichte über getroffene Maßnahmen (vgl. 89/C 277/01: 1) - und eine schrittweise Konvergenz (vgl. 92/442/EWG: 52). Auf dem Gipfel von Lissabon einigten die Staats- und Regierungschefs sich auf die Einführung einer regelmäßigen Koordinierung im Sozialbereich, die sogenannte »Offene Methode der Koordinierung« (OMK). Hierbei handelt es sich um ein sehr weiches, bis zum Verfassungsvertrag nicht vertragsbasiertes Verfahren, ${ }^{108}$ bei dem auf der europäischen Ebene gemeinsame Ziele gesetzt werden, auf deren Grundlage die Mitgliedstaaten - ähnlich wie bei den beschäftigungspolitischen Leitlinien - nationale Aktionspläne erarbeiten (vgl. Europäischer Rat 2000a: Ziff. 37). Diese nationalen Aktionspläne werden von der Kommission bewertet und es werden Best-Practice herausgearbeitet; ein Sanktionsverfahren ist jedoch nicht vorgesehen. Für diese Arbeit relevant ist die Anwendung der Offenen Methode in den Bereichen Armut und soziale Ausgrenzung (OMKincl) sowie Pensionen. ${ }^{109}$ Für den Armutsbereich legte der Rat im Jahr 2000 erste Ziele vor

108 Erst im Verfassungsvertrag wird für die Sozialpolitik die Möglichkeit eines Leitlinienverfahrens beschlossen (vgl. Art. III-213 VerfV).

109 Die OMK im Bereich Gesundheitspolitik befand sich im Untersuchungszeitraum erst in der Einführungsphase, der Rat bzw. der Europäische Rat trafen hier keine inhaltlichen Entscheidungen (vgl. hierzu bspw. Hajen 2005: 13, Lamping 2007: 287). 
(vgl. 14110/00, Annahme: Europäischer Rat 2000b), die im Jahr 2002 überarbeitet wurden (vgl. 14164/1/02 Annahme: Europäischer Rat 2002b), gemeinsame Ziele für die Pensionen folgten im Jahr 2001 (vgl. 14098/01, Annahme: Europäischer Rat 2001c). Das gegenseitige Lernen im Rahmen der OMKincl sollte unter anderem durch einen verstärkten Informationsaustausch sowie die Erarbeitung von Vergleichsindikatoren gefördert werden. $\mathrm{Zu}$ diesem Zweck wurde ein »Ausschuss für Sozialschutz« eingerichtet (vgl. 2000/436/EG) und ein »Aktionsprogramm der Gemeinschaft zur Förderung der Zusammenarbeit der Mitgliedstaaten bei der Bekämpfung der sozialen Ausgrenzung« verabschiedet (50/2002/ EG).

Die wohl häufigste Empfehlung im Bereich der Sozialpolitik war die »Modernisierung« der Sozialsysteme. Hiermit wurden zwei Ziele verfolgt: Zum einen sollten Armut und soziale Ausgrenzung bekämpft werden, zum anderen die finanzielle Überlebensfähigkeit der Sozialsysteme sowie die langfristige Tragfähigkeit der öffentlichen Finanzen gesichert werden. Mit Blick auf das erste Ziel sollten die Mitgliedstaaten allen, die sich nicht (mehr) im Erwerbsleben befinden, einen menschenwürdigen Lebensstandard sichern (vgl. 14110/00: 8), z.B. in Form angemessener Renten (vgl. 14098/01: 6). Hierbei bezog man sich auch auf die Empfehlung von 1992 zur Garantie eines Mindesteinkommens (vgl. Europäischer Rat 2000b, Anlage I, III c). Weiterhin sollte der Zugang aller zu Ressourcen, Rechten, Gütern und Dienstleistungen, der für die Teilnahme an der Gesellschaft erforderlich ist, garantiert werden, (vgl. 14164/1/02: 8). Dies umfasste den »Zugang zu einer ordentlichen, die Gesundheit nicht beeinträchtigenden Wohnung und der für ein normales Leben in dieser Wohnung nach örtlichen Gegebenheiten erforderlichen Grundversorgung (Strom, Wasser, Heizung...)« sowie zu notwendiger medizinischer Versorgung (vgl. 14164/1/02: 11). Für die zunehmende Zahl der Rentner empfahl der Rat in einer Erklärung von 1993 neben einer Mindest- bzw. statussichernden Rente auch die Förderung zugänglicher Wohngebiete und entsprechender Verkehrsinfrastruktur sowie das Angebot von Pflegedienstleistungen (vgl. 93/C 343/01: 2f). Da der beste Schutz vor sozialer Exklusion in einem Arbeitsplatz gesehen wurde (vgl. 14110/00: 2), bezogen sich die sozialpolitischen Vorgaben nicht nur auf die Angemessenheit von Sozialleistungen, sondern auch auf ihre Anreizwirkungen (so z.B. auch in der Entschließung zur Rolle der Sozialschutzsysteme bei der Bekämpfung der Arbeitslosigkeit, 96/C 386/02). Hierauf wurde bei der Beschäftigungspolitik bereits ausführlich eingegangen.

Die Bedeutung des zweiten Ziels - die langfristige Tragfähigkeit der öffentlichen Finanzen - nahm vor dem Hintergrund der Bevölkerungsal- 
terung zu. In Folge der demographischen Entwicklung, die durch die Lissabon-Strategie eine besondere Betonung erfuhr, wurde ein starker Kostenanstieg bei den Renten- und Gesundheitssystemen prognostiziert (vgl. 2003/555/EG: 9). Um dem zu begegnen, empfahlen die Vorgaben eine Reform der Systeme, was nur für erstere genauer definiert wurde: Ihre Reform sollte drei Grundvoraussetzungen erfüllen: Sicherstellung der Erfüllung der sozialpolitischen Zwecke, finanzielle Zukunftsfähigkeit sowie Reaktion auf die sich ändernden Bedürfnisse der Gesellschaft (vgl. 14098/01: 2). Der zweite Punkt stand im Zentrum, was man auch daran sieht, dass die Überwachung dieses Ziels im Rahmen der Grundzüge der Wirtschaftspolitik und der Konvergenzprogramme erfolgte (vgl. ebenda: 2f), während die anderen Ziele nur im Rahmen der OMK verfolgt wurden. Um einen Anstieg der Staatsverschuldung (als Konsequenz steigender Staatszuschüsse) zu verhindern, empfahlen die Vorgaben, den Zugang zu zusätzlichen Altersversorgungssystemen zu erleichtern (vgl. 2003/555/EG: 9), eine größere Stützung durch kapitalgedeckte Systeme in Betracht zu ziehen und eventuell Rentenreservefonds einzurichten (vgl. 2002/ 549/EG: 11). Dies sollte auch die Beiträge stabilisieren. Weiterhin forderte der Rat die Mitgliedstaaten auf, die Leistungen zu senken und das effektive Rentenalter heraufzusetzen (vgl. 2003/555/ EG: 9). Für das Gesundheitssystem fand sich nur die Empfehlung, den Kostenanstieg einzudämmen (vgl. 96/431/EG: 49).

\section{Reaktionen auf die wirtschaftlichen Krisen}

Zum Abschluss wird untersucht, wie die Gemeinschaft auf Verschlechterungen der konjunkturellen Lage reagiert hat. Die erste Krise der Untersuchungsphase begann im Jahr 1991 mit schwächerem Wachstum und steigender Arbeitslosigkeit, beides verschärfte sich in den Folgemonaten. Die Gemeinschaft begegnete der Entwicklung mit der »Erklärung zur Förderung des wirtschaftlichen Aufschwungs in Europa«, verabschiedet Ende 1992 vom Europäischen Rat in Edinburgh. Weitere Maßnahmen fanden sich in den wirtschaftspolitischen Leitlinien 1993 sowie den Schlussfolgerungen des Europäischen Rates aus dem gleichen Jahr. Hierbei lassen sich zwei Strategien erkennen: Zum einen sollte der bisherige wirtschaftspolitische Kurs gehalten und somit das Vertrauen wiedergewonnen werden. Der Gemeinschaft kam dabei eine besondere Bedeutung zu, da sie die Mitgliedstaaten dabei unterstützen konnte, »der Versuchung kurzfristiger Lösungen $\mathrm{zu}$ widerstehen, von denen man weiß, dass sie auf mittlere Sicht noch ernstere Probleme schaffen« (93/ 258/EWG: 28). Zum anderen sah man aber auch, dass die europäischen »Volkswirtschaften [...] heute so miteinander verflochten [sind], dass 
ein Wideraufschwung nur gemeinsam erreicht werden kann« (Europäischer Rat 1993b: 10). In diesem Sinne wurden koordinierte Maßnahmen zur Stützung der Nachfrage beschlossen: Hierbei ging es einmal darum, die automatischen Stabilisatoren wirken zu lassen und die Staatsausgaben wachstumsfreundlich umzuschichten (vgl. Europäischer Rat 1992b: 21). Eine Stärkung der Investitionsnachfrage sollte dadurch erreicht werden, dass die Mitgliedstaaten den Investitionen bei der Aufstellung ihrer Haushaltspläne besondere Bedeutung zumessen: »Öffentliche Investitionen zur rechten Zeit - insbesondere im Bereich der Infrastrukturen, des Umweltschutzes und der Stadterneuerung - sind ebenso wie die Förderung privater Investitionen [...] in der derzeitigen Phase des Wirtschaftszyklus in Europa von besonderer Bedeutung« (Europäischer Rat 1993a: 9) - vor allem, da sie durch den Multiplikatoreffekt des Binnenmarktes weiter verstärkt würden (vgl. ebenda). Darüber hinaus wurde die gleichzeitige und koordinierte Bekanntgabe derartiger Investitionen empfohlen (vgl. 93/258/EWG: 20).

Auf die nächste bedeutende konjunkturelle Abschwächung 2002/03 reagierte die Gemeinschaft mit dem gleichen Muster: Zum einen wurde den Mitgliedstaaten empfohlen, die »bereits eingegangenen Verpflichtungen besser umzusetzen«, was eine stärkere Überwachung durch die Gemeinschaft mit einschloss (vgl. Europäischer Rat 2004: Ziff. 16). Zum anderen sollte aber auch hier wieder die Nachfrage gestärkt werden. Zu diesem Zweck wurde auf dem Europäischen Rat von Brüssel im Oktober 2003 eine Wachstumsinitiative zur >Ankurbelung schaft (vgl. Europäischer Rat 2003c: Ziff. 4) verabschiedet, die finanzielle Anreize für private sowie öffentliche Investitionen umfasste. Zusätzlich sollten die Mitgliedstaaten im Einklang mit dem Stabilitäts- und Wachstumspakt »die Aktion für Wachstum durch nationale Maßnahmen und Programme [...] ergänzen« (Europäischer Rat 2003d: Ziff. 5).

\section{Schlussfolgerungen}

Bezüglich der Frage, ob die europäischen Vorgaben die mitgliedstaatlichen Interventionsmöglichkeiten erweitern oder beschränken sollten, ergibt sich ein auf den ersten Blick uneindeutiges Bild: Bezüglich der allokative Funktion kann von einer klaren Einschränkung der Interventionsmöglichkeiten gesprochen werden, da Beihilfen verboten waren. Dies ist Teil des EG-Vertrags, demnach rechtlich verbindlich, die Schlussfolgerungen des Rates und die Grundzüge der Wirtschaftspolitik forderten eine weitere Reduktion der Beihilfen. Das Kontrollverfahren wurde sowohl durch die Kodifizierung als auch die Gruppenfreistellungsverordnung vereinfacht und verschärft, insbesondere durch die 
Rückforderungsregelung für unrechtmäßig gezahlte Subventionen, die auch über den EuGH durchgesetzt werden konnte. Die Empfehlungen zur Neuausrichtung der Subventionen beließen den Mitgliedstaaten allerdings einen gewissen Spielraum, da die Definition der »horizontalen Ziele« recht vage blieb, wobei die Politik auch in diesem Fall regelgebundener werden sollte: Abkehr von ad-hoc Beihilfen zur Rettung von Unternehmen, hin zu Beihilfen mit langfristigeren Zielen.

Im Hinblick auf öffentliche Güter mit allokativer Funktion sollten die Interventionsmöglichkeiten erweitert werden, indem eine vermehrte Bereitstellung vor allem im Bereich FuE, Bildung und Infrastruktur gefordert wurde. Alle Empfehlungen in diesem Bereich fanden sich (auch) in den Grundzügen der Wirtschaftspolitik oder den beschäftigungspolitischen Leitlinien, d.h. es gab gewisse Sanktionsmechanismen bei Nichtbefolgung.

Die meisten Vorgaben im Bereich Distribution zielten auf eine Einschränkung staatlicher Interventionsmöglichkeiten. Ein bestimmter Lebensstandard sollte garantiert werden, das übergreifende Ziel war jedoch die Senkung der Sozialausgaben bzw. -leistungen. Es gab zwar Empfehlungen für öffentliche Güter mit distributiver Funktion, z.B. das Gesundheitssystem, im Gegensatz zu den Empfehlungen für öffentliche Güter mit allokativer Funktion und Sozialausgaben befanden sich diese jedoch hauptsächlich in den Leitlinien der OMK. Das bedeutet aufgrund des fehlenden Sanktionsverfahrens eine geringere Verbindlichkeit. Überdies waren sie eher vage formuliert, mit Ausnahme des öffentlichen Gutes Kinderbetreuung, für das es präzise Vorgaben gab. Der Staat sollte sich demnach von seinen distributiven Aufgaben eher zurückziehen, weniger in den Markt eingreifen.

Stabilisierungspolitik wurde selten explizit angesprochen, nur in den beiden größeren Wirtschaftsabschwüngen empfahlen die Vorgaben zaghaft und unverbindlich ein gemeinsames Vorgehen zur Stimulierung der Nachfrage. Hauptsächlich wurde jedoch auf eine regelgeleitete Stabilisierungspolitik gesetzt und dabei Bezug auf die automatischen Stabilisatoren genommen, die wirken sollten, ohne das $3 \%$-Kriterium zu verletzen. Diese >Konsolidierungsempfehlung - die durch ihre Festschreibung im Vertrag sowie zwei Verordnungen rechtlich verbindlich war sollte die mitgliedstaatlichen Interventionsmöglichkeiten einschränken, da sie eine Keynes'sche Nachfragepolitik mit Defiziten über $3 \%$ verbot.

Zusammenfassend kann man sagen, dass die Interventionsmöglichkeiten der Staaten in den Bereichen Stabilisierung, Distribution und Allokation in Bezug auf Beihilfen durch die Vorgaben eingeschränkt, dass sie jedoch im Bereich öffentliche Güter, insbesondere mit allokativer Funktion, ausgedehnt werden sollten. 


\section{Staatsverständnis}

Für die nun folgende Inhaltsanalyse, mit der auf das den europäischen Vorgaben zugrunde liegende Staatsverständnis geschlossen werden soll, werden die Vorgaben nach Typen geordnet: Schlussfolgerungen des Rates $(\mathrm{ER})^{110}$, wirtschaftspolitische Vorgaben (WI), ${ }^{111}$ beschäftigungspolitische Vorgaben (BE) ${ }^{112}$ und sozialpolitische Vorgaben (SOZ). ${ }^{113}$ Dies ist sinnvoll, da die Dokumente unterschiedliche Schwerpunkte legen, die Schlussfolgerungen des Europäischen Rates waren z.B. recht allgemein gehalten und beschäftigten sich mit einer Vielzahl von Fragestellungen, so dass die für diese Arbeit relevanten Aspekte oft nur ausschnittsweise oder lückenhaft vorkamen. Während die Grundzüge der Wirtschaftspolitik meist alle in dieser Arbeit analysierten Politikfelder umfassten, behandelten die Dokumente zur Beschäftigungs- und Sozialpolitik meist nur einen kleinen Ausschnitt. Würden die Häufigkeitsanalyse für alle Dokumente gemeinsam durchgeführt, käme es demnach zu einem verzerrten Bild.

In den Dokumenten fand sich nicht viel, was auf die Einstellung gegenüber dem Staat schließen lässt. Weder schrieb man ihm einen positiven Einfluss zu, noch wurden staatliche Interventionen als generell wünschenswert dargestellt, es gab jedoch auch nur zwei explizit negative Nennungen (WI: 2/14). Man kann somit schließen, dass der Staat weder eine wichtige Rolle spielen noch eine aktive Steuerung oder gar moderate Planung der Wirtschaft betreiben sollte. Damit einhergehend wurde empfohlen, den Staatshaushalt in Richtung marktfördernder Ausgaben umzuschichten (ER: 5/24, WI: 14/14, SOZ: 1/6). Im Gegensatz dazu war die Einstellung gegenüber dem Markt klar positiv (ER: 12/24, WI:

110 Europäischer Rat 1992a, Europäischer Rat 1992b, Europäischer Rat 1993a, Europäischer Rat 1993c, Europäischer Rat 1994a, Europäischer Rat 1994b, Europäischer Rat 1995a, Europäischer Rat 1995b, Europäischer Rat 1997a, Europäischer Rat 1997b, Europäischer Rat 1998a, Europäischer Rat 1998b, Europäischer Rat 1999a, Europäischer Rat 1999b, Europäischer Rat 2000a, Europäischer Rat 2001a, Europäischer Rat 2001b, Europäischer Rat 2001c, Europäischer Rat 2002a Europäischer Rat 2003a, Europäischer Rat 2003b, Europäischer Rat 2003c, Europäischer Rat 2003d, Europäischer Rat 2004.

111 91/464/EWG, 92/180/EWG, 93/258/EWG (wirtschaftspolitische Leitlinien) sowie 94/7/EG, 94/480/EG, 95/326/EG, 96/431/EG, 97/479/EG, 98/454/EG, 1999/570/EG, 2000/517/EG, 2001/483/EG, 2002/549/EG, 2003/ 555/EG (Grundzüge der Wirtschaftspolitik).

112 92/C 49/03, 97/C 236/02, 98/C 30/01, 1999/C 69/92, 2000/228/EG, 2001/ 163/EG, 2002/177/EG, 2003/578/EG, 2004/740/EG.

113 94/C 368/03, 96/C 386/02, Europäischer Rat 2000b, Anlage I, 14110/00, $14164 / 1 / 02,14098 / 01$. 
11/14, BE: 1/9, SOZ: 1/6, keine negativen Nennungen). Dieser Einstellung entsprechend wurden auch Unternehmer bzw. das Unternehmertum sehr positiv gesehen, allerdings tauchten die Nennungen erst ab dem Jahr 2000 auf - dann aber in nahezu allen Vorgaben (ER: 9/24, WI: 5/14, BE: 7/9): »Bemühungen müssen auch gezielt darauf gerichtet werden, eine Kultur des Unternehmertums zu unterstützen und den Unternehmungsgeist zu fördern. Beide spielen eine Schlüsselrolle für Wachstum, Beschäftigung und Wettbewerbsfähigkeit in der Gemeinschaft« (98/454/EG: 41).

Bezüglich der Ziele bzw. Probleme wurde das der Arbeitslosigkeit in fast jedem Dokument genannt (ER: 22/24, WI: 14/14, BE: 9/9, SOZ: 2/6), was aufgrund der Situation am Arbeitsmarkt in dieser Phase zu vermuten war und insofern noch keine Rückschlüsse auf das Staatsverständnis zulässt. Dies ermöglicht erst die Betrachtung der Umgangsweise mit diesem Problem: Sie war recht einheitlich, nahezu alle Vorgaben empfahlen eine angebotsseitige Lösung, d.h. eine Flexibilisierung der Arbeitsmärkte und Lohnzurückhaltung (ER: 17/24, WI: 14/14, BE: 9/9, SOZ: 2/6).

»Die in den Vorjahren erzielten Fortschritte bei den Strukturreformen am Arbeitsmarkt $[\ldots]$, haben sich in einem beschäftigungsintensiveren Wachstum niedergeschlagen. So konnte die Beschäftigung dank der anhaltenden Lohnzurückhaltung erheblich zunehmen $[\ldots]$; die stärkere Nutzung von Zeit- und Teilzeitbeschäftigungsverhältnissen hat die Arbeitsmärkte flexibler und integrativer gemacht; $[\ldots]$ und die Mitgliedstaaten haben begonnen, von passiven zu aktiven Arbeitsmarktmaßnahmen überzugehen« (2002/549/EG: 12).

Dass Arbeitslosigkeit auch ein Problem der Nachfrageseite sein kann, kam nur in je einem der drei relevanten Dokumententypen vor (vgl. 92/C 49/03, Europäischer Rat 1995a, 97/479/EG).

Höheres Wachstum wurde als Ziel ebenfalls sehr häufig angeführt (ER: 21/24, WI: 14/14, BE: 4/9), um es zu erreichen setzte man in erster Linie auf eine stabilitätsorientierte Politik (ER: 18/24, WI: 14/14), d.h. ausgeglichene Haushalte und Preisstabilität, sowie ein gutes unternehmerisches Klima und Innovationen. Überdies wurde ab dem Jahr 1995 in fast jeder Vorgabe auch Angebotspolitik zur Steigerung des Wachstumspotentials empfohlen (ER: 15/24, WI: 14/14), insbesondere Strukturreformen: »Eine rasche Durchführung der Strukturreformen, die auf einen stärkeren Wettbewerb auf den Märkten für Güter, Dienstleistungen und Kapital ausgerichtet sind, ist von entscheidender Bedeutung« (Europäischer Rat 2001b: Ziff. 35). Wie beim Beschäftigungsziel tauchte auch hier die Nachfrageseite kaum auf. Die Keynes'sche Idee, zur 
Steigerung von Wachstum und Beschäftigung die Nachfrage zu erhöhen, wurde zwar teilweise erwähnt (ER: 3/24, WI: 5/14), explizit empfohlen wurde sie jedoch nur zweimal (vgl. Europäischer Rat 1993a: 9, Europäischer Rat 2003d: Ziff. 5).

Haushaltsdefizite sind der eindeutigste Indikator für ein bestimmtes Staatsverständnis: Einem Keynes'schen Staatsverständnis folgend würden Defizite positiv gesehen, wenn sie dazu genutzt werden, im Abschwung mehr Nachfrage zu schaffen. In den Dokumenten entdeckt man das Gegenteil: Übermäßige Defizite wurden nirgendwo als unproblematisch gesehen. Wurden die Probleme spezifiziert und nicht nur der Haushaltsausgleich als Ziel genannt (dies in ER: 21/24, WI: 14/14, BE: 6/9), so fanden sich Crowding-Out-Effekte sowie Nachfrageinflation (ER: 10/24, WI: 12/14). Ausgeglichene Haushalte hingegen

»haben $[\ldots]$ günstige Auswirkungen auf die Zinsen und tragen zum >crowding-in< von Privatinvestitionen, zur weiteren Rückführung des gesamtstaatlichen Schuldenstandes in Relation zum BIP - und damit zur Vorbereitung auf die durch die demografischen Veränderungen entstehenden Kosten und durch eine Erhöhung der Glaubwürdigkeit des haushaltspolitischen Rahmens der WWU zur Stärkung des Anlegervertrauens bei« (2001/483/EG: 9).

Inflation wurde in vielen Dokumenten als - aktuelles oder potentielles Problem beschrieben (ER: 15/24, WI: 14/14, BE: 2/9), wenn Ursachen genannt wurden, so waren dies diskretionäre Politik (ER: 1/24, Wi 2/14) oder zu hohe Kosten, z.B. durch überhöhte Lohnsteigerungen (ER: 1/24, WI: 7/14, BE: 2/9).

Vor allem bei der Frage nach den Staatsaufgaben in den drei Bereichen Allokation, Distribution und Stabilisierung muss bei der Häufigkeitsauswertung beachtet werden, dass nicht alle Dokumente sich mit diesen Fragen beschäftigten.

Die Allokation stand klar im Zentrum aller Empfehlungen: Subventionen wurden abgelehnt, am häufigsten mit der Begründung, sie verzerrten den Wettbewerb und damit die marktliche Koordination (ER: 8/24, WI: 11/14). Weiterhin wurden die Behinderung des Strukturwandels (WI: 4/14) und die Belastung der Staatshaushalte (WI: 2/14) als Gründe angeführt. Ausnahmen vom Verbot gab es nur, wenn mit den Subventionen gemeinsame Ziele verfolgt wurden. Die staatliche Bereitstellung öffentlicher Güter mit allokativer Funktion, insbesondere Bildung und Infrastruktur, überdies - wenn auch seltener - Forschung und Entwicklung, empfahlen nahezu alle Dokumente (ER: 17/24, WI: 14/14, BE: 9/9, SOZ: 3/6). Damit sollte allerdings nicht die Nachfrage staatlich stabilisiert, sondern die Basis für die privatwirtschaftliche ökonomische 
Entwicklung sowie die Wettbewerbsfähigkeit gestärkt werden. Ebenso wurde Distribution nicht in dem Sinn diskutiert, dass durch eine Umverteilung zu den ärmeren Schichten die private Nachfrage gestützt werden kann, das Ziel war auch hier eine Verbesserung der Allokation. Der Fokus lag dabei auf der Setzung von Anreizen durch eine Umschichtung bzw. Senkung von Sozialausgaben (ER: 14/24, WI: 11/14, BE: 8/9, SOZ: 6/6). Auch das am häufigsten genannte öffentliche Gut mit distributiver Funktion hatte eher eine allokative Zielsetzung: Kinderbetreuung sollte Frauen die Erwerbstätigkeit erleichtern (WI: 3/14, BE: 6/9, SOZ: 2/6).

Stabilisierungspolitik wurde nur selten angesprochen, zur Überwindung von Konjunkturkrisen mahnten die Vorgaben eine regelgeleitete Politik an (ER: 3/24, WI: 5/14), nur zweimal ergänzt durch Empfehlungen zur Nachfragestimulierung (s.o.). Passend zur regelgeleiteten Stabilisierung wurden die automatischen Stabilisatoren als Instrument empfohlen, allerdings nur bedingt, d.h. bei Nichtverletzung des $3 \%$ Kriteriums (ER: 5/24, WI: 9/14). Eine diskretionäre Stabilisierungspolitik sollte durch dieses Kriterium unmöglich gemacht werden.

Zusammenfassend kann man sagen, dass in dieser Phase zwar kein >reines`, aber dennoch ein ziemlich deutliches angebotsökonomisches Staatsverständnis vorherrschte. Die positive Einstellung gegenüber dem Markt und die große Bedeutung, die dem Unternehmertum zugeschrieben wurde, deuten unverkennbar in diese Richtung. Das gleiche gilt für die Strategien der Zielerreichung, bei der die Angebotsseite sowie die Überlassung von Aufgaben an den Markt überwogen. Die Nachfrageseite tauchte zwar manchmal auf, wurde aber überwiegend nur als Problem, kaum als Lösung angesehen. Vollbeschäftigung sollte sich über eine Flexibilisierung der Märkte von selber einstellen, Konjunkturstabilisierung wurde kaum angesprochen. Stattdessen stand das Ziel der mittelfristigen Wachstumssteigerung im Mittelpunkt, welches ebenfalls durch eine Stärkung der Marktkräfte erreicht werden sollte. Dies umfasste sowohl den Abbau von Subventionen wie auch von Sozialleistungen, um keine Fehlanreize zu setzen. Der Staat sollte sich allerdings nicht völlig zurückziehen, dies sieht man daran, welche Aufgaben ihm noch zugeschrieben wurden: Im Zentrum stand die Bereitstellung der Grundlagen für die privatwirtschaftliche Tätigkeit in Form von öffentlichen Gütern mit allokativer Funktion. Dem entspricht auch die Einstellung, dass der Staatshaushalt umgeschichtet werden sollte. Ein wenig heraus fallen nur die Vorgaben in den beiden Wirtschaftskrisen, in denen die Nachfrageseite doch wieder eine Rolle spielte. 


\section{Fazit}

In der vierten Phase herrschte ein angebotsökonomisches Staatsverständnis vor. Die Strategie zur Stärkung der Handlungsfähigkeit eines angebotsökonomischen Staates kann sowohl affirmativ wie revisionistisch sein, sie liegt in der Begrenzung seiner Interventionsmöglichkeiten, denn ein angebotsökonomischer Staat soll möglichst wenig in die Wirtschaft eingreifen. Diese Strategie fand sich auch in den Vorgaben: Zwar wurde eine stärkere wirtschaftliche Verflechtung festgestellt, die eine Einschränkung der nationalstaatlichen Interventionsmöglichkeiten zur Folge hat. Es wurden jedoch keine Schritte unternommen, die solcherart eingeschränkten Interventionsmöglichkeiten wieder auszubauen. Im Gegenteil - und dies macht die Strategie zu einer revisionistischen hatten die Vorgaben das Ziel, die Möglichkeiten der Mitgliedstaaten, in die Wirtschaft einzugreifen, weiter zu verringern. Dies betraf insbesondere den Bereich Stabilisierung: Nicht nur vertraglich banden sich die Mitgliedstaaten an das Ziel der Defizitbeschränkung und damit regelgeleiteten Stabilisierung, auch die Vorgaben des Sekundärrechts sollten den zurückhaltenden wirtschaftspolitischen Kurs forcieren, was teilweise explizit so formuliert wurde: »Ein sehr wirkungsvoller Beitrag, den die Gemeinschaft [...] leisten kann, besteht darin, die Mitgliedstaaten beim Halten des Kurses zu unterstützen« (93/258/EWG: 28). Die Einschränkung von Interventionsmöglichkeiten war jedoch nicht durchgehend, was an dem uneindeutigen Bild deutlich wird, dass sich bei der Untersuchung der intendierten Auswirkungen der Vorgaben auf die Interventionsmöglichkeiten zeigte: In Bezug auf öffentliche Güter mit allokativer Funktion wurde den Mitgliedstaaten empfohlen, weiter zu intervenieren. »Die Mitgliedstaaten sollen [...] der Verbesserung der Angebotsbedingungen einen hervorragenden Platz in ihrem wirtschaftspolitischen Konzept einräumen« (92/180/EWG: 6). Dies fügt sich wiederum sehr gut in das vorherrschende angebotsökonomischen Staatsverständnis und die revisionistischen Strategie ein. 


\section{Gesamtschau der ERgEBNisSe}

Auf Grundlage der empirischen Untersuchung können nun die Forschungsfragen der Arbeit beantwortet werden. Zu diesem Zweck wird in einem ersten Schritt die Entwicklung in den vier Politikfeldern kurz zusammengefasst. Danach wird zuerst der Wandel bei der Beeinflussung von Handlungsfähigkeit, als zweites die Entwicklung des zugrunde liegenden Staatsverständnisses dargestellt. Abschließend wird danach gefragt, welche der in Kapitel 3.2 entwickelten Strategien zu welcher Zeit mit den Vorgaben verfolgt wurde.

\subsection{Entwicklungen in den drei Interventionsbereichen}

\section{Interventionsbereich Allokation: Beihilfen}

Hinsichtlich der Vorgaben für die nationale Beihilfenpolitik ist sowohl ein Wandel des Inhalts wie auch des Verfahrens erkennbar. Seit den Römischen Verträgen sind Beihilfen, die den Wettbewerb zwischen den Mitgliedstaaten verzerren und den Handel beeinträchtigen, verboten (vgl. Art. 92 EWGV). Ebenfalls vertraglich festgelegt waren jedoch immer auch einige Ausnahmebereiche (vgl. Art. 92, Abs. 2 und 3 EWGV). Beides wurde durch die Vorgaben weiter präzisiert, hauptsächlich im Zusammenhang mit der Schaffung eines Gemeinsamen bzw. Binnenmarktes sowie dem damit einhergehenden Strukturwandel.

Für die Errichtung eines gemeinsamen Wirtschaftsraumes mit unverfälschten Wettbewerb war es notwendig, protektionistische Beihilfen abzubauen. Hierauf bezog sich auch das vertraglich festgelegte Verbot, das 
die Vorgaben allerdings erst zum Ende der 1970er Jahre verstärkt aufgriffen. In dieser Zeit wuchs die »Neigung zu protektionistischen Verhaltensweisen und punktuellen Abwehrreaktionen« (77/778/EWG: 13) aufgrund der ölkrisenbedingten Rezessionen, was die Gefahr einer Segmentierung der Märkte mit sich brachte (vgl. 81/1056/EWG: 10). Bei den Vorbereitungen für den Binnenmarkt - der unter anderem die europäische Wettbewerbsfähigkeit durch einen intensiveren Wettbewerb zwischen den Mitgliedstaaten fördern sollte (vgl. 87/609/EWG: 15) traten die Vorgaben der mitgliedstaatlichen Versuchung entgegen, ihrer nationalen Industrie durch Subventionen eine gute Startposition zu verschaffen. Das Verbot wettbewerbsverzerrender Beihilfen zum Schutz des Binnenmarktes wurde bis zum Ende des Untersuchungszeitraums in den Vorgaben immer wieder aufgegriffen. Es ging demnach klar um eine Einschränkung der mitgliedstaatlichen Interventionsmöglichkeiten durch die europäischen Vorgaben, die ab dem Ende der 1970er Jahre, vor allem jedoch mit der Verabschiedung des Binnenmarktprojekts, verstärkt wurde. Die einzige Ausnahme bildeten die Vorgaben zur Förderung des gemeinsamen Verkehrsmarktes, der ebenfalls der Errichtung des integrierten Wirtschaftsraums dienen sollte. Zu diesem Zweck wurden nationale Beihilfen für den kombinierten sowie den öffentlichen Verkehr geduldet (vgl. z.B. 65/271/EWG; 75/327/EWG; VO 3578/92), allerdings ging es hier eher um eine Harmonisierung der nationalen Regelungen als um eine generelle Ausweitung der Beihilfen und damit der Interventionsmöglichkeiten.

Die Schaffung des gemeinsamen Wirtschaftsraums führte nach Ansicht der Mitgliedstaaten gemeinsam mit der zunehmenden wirtschaftlichen Verflechtung und dem technologischen Wandel zu einem beschleunigten Strukturwandel. Das gemeinsame Vorgehen zur Gestaltung dieses Prozesses wurde damit begründet, dass nur auf diese Weise eine gleichmäßige Entwicklung in der Gemeinschaft möglich sei, bei der die Länder sich nicht voneinander abschotten (vgl. 71/ 107/EWG: 12) und ärmere Länder, die über weniger Ressourcen zur Subventionierung ihrer Industrien verfügen, aufholen können (vgl. 92/180/EWG: 25). Die Mitgliedstaaten sollten den Strukturwandel in gewissem Maße durch Beihilfen gestalten, um so zu mehr Wachstum, Beschäftigung, aber auch Wettbewerbsfähigkeit beizutragen. Dies umfasste zum einen die Förderung technologisch fortschrittlicher oder zukunftsträchtiger Sektoren. Durch die Festlegung einheitlicher Förderkriterien und gemeinsame Anstrengungen wollte die Gemeinschaft in diesen Bereichen eine weltweite Spitzenstellung erreichen (vgl. 69/157/EWG: 36ff). Zum anderen wurden auch Umstellungs- und Erhaltungssubventionen empfohlen. Die allgemeine Vorgabe, Beihilfen zur sozialverträglichen Umstrukturierung 
nicht mehr wettbewerbsfähiger Sektoren einzusetzen, fand sich jedoch nur im 2. Programm für die mittelfristige Wirtschaftspolitik, das sich ausführlich mit der Strukturpolitik beschäftigte (vgl. 69/157/EWG: 32). Schon zwei Jahre später gab es einen Wandel: Zwar wurde die soziale Problematik des Strukturwandels weiterhin anerkannt, die Umstrukturierung der Wirtschaft sollte jedoch nicht mehr behindert werden. Erhaltungssubventionen waren nur noch für die Schiffbauindustrie erlaubt, rechtfertigt mit den weltweiten Wettbewerbsverzerrungen auf diesem Sektor; eine gemeinsame Reaktion sollte zumindest innerhalb der Gemeinschaft gleiche Bedingungen schaffen. Ab den 1980er Jahren strebte man auch hier eine Senkung der Beihilfen an (vgl. 81/363/EWG, Art. 6).

$\mathrm{Ab}$ Mitte der 1980er Jahre ist eine grundlegende Veränderung feststellbar, von nun an sollte der Strukturwandel durch eine generelle Abschaffung staatlicher Beihilfen gefördert werden. Erst in den letzten Jahren des Untersuchungszeitraums griffen einige Vorgaben eine vertragliche Ausnahmeregelung auf und empfahlen eine Umschichtung der Beihilfen hin zu Forschung, Ausbildung oder ähnlichen »Vorhaben von gemeinsamem europäischen Interesse (Art. 87, Abs. 3 EGV). Am Ziel der allgemeinen Senkung der Beihilfen hielt man jedoch fest (vgl. Europäischer Rat 2000a: Ziff. 17).

Bei der Beeinflussung des Strukturwandels ging es demnach zum einen darum, durch ein gemeinsames Vorgehen mitgliedstaatliche Interventionsmöglichkeiten auszuweiten. Diese wurden als eingeschränkt wahrgenommen, da die zunehmende Mobilität der Produktionsfaktoren beihilfenbedingte Produktionsverlagerungen vereinfachte (vgl. 69/157/ EWG: 33), weiterhin drohte die Gefahr, dass nationale Beihilfen sich gegenseitig neutralisieren oder aufschaukeln, wodurch ihre Wirksamkeit gemindert würde. Eine (Wieder-)Ausweitung sollte erreicht werden, indem die Beihilfen durch Abstimmungen optimal und ohne Ressourcenverschwendung eingesetzt und somit die Effizienz staatlicher Interventionen gestärkt werden konnte. Im Laufe der Zeit wurden zuerst die Ausnahmeregelungen für strukturschwache, im Folgenden für fortschrittliche Sektoren zurückgenommen. Beihilfen waren einige Jahre fast völlig verboten (mit Ausnahme der vertraglichen Regelungen, die jedoch in diesem Zeitraum von den Vorgaben nicht aufgegriffen wurden), was die mitgliedstaatlichen Interventionsmöglichkeiten einschränken sollte. Erst ab 2000 ist wieder eine gewisse Ausdehnung erkennbar, als die Mitgliedstaaten sich bemühten, Beihilfen für gemeinsame Ziele gebündelt und damit effektiver - einzusetzen.

Zusammenfassend kann man für den Beihilfenbereich feststellen, dass die Vorgaben die mitgliedstaatliche Handlungsfähigkeit bis 1985 durch einen Ausbau von Interventionsmöglichkeiten stärken sollten. 
Von der sehr weitgehenden Intervention in Form von Umstellungs- bzw. Erhaltungssubventionen (mit Ausnahme des Schiffbausektors) rückte man allerdings schnell wieder ab, nur die Subventionierung fortschrittlicher Sektoren sollte durch ein abgestimmtes Vorgehen noch effizienter gestaltet werden. Der Wandel begann Ende der 1970er Jahre, Subventionen wurden negativer gesehen und ab 1985 gänzlich abgelehnt. Die Vorgaben sollten die Interventionsmöglichkeiten insbesondere mit Blick auf die Schaffung des Binnenmarktes, aber auch im Rahmen der Strukturpolitik immer stärker einschränken. Auch die ab 2000 aufgegriffenen Ausnahmeregeln hatten das Ziel, dass die Mitgliedstaaten die Beihilfen nicht mehr punktuell oder sektoral, sondern stärker regelgeleitet vergeben (vgl. 2001/483/EG: 14). Dies sowie das Verbot können die Handlungsfähigkeit der einzelnen Staaten insofern stärken, als dass diese den an sie gestellten Subventionsforderungen mit Hinweis auf die europäische Ebene leichter entgegen treten können.

$\mathrm{Zu}$ den Verfahren und ihrer Verbindlichkeit ist grundsätzlich zu sagen, dass mit der Vertragsbasierung eine hohe Verbindlichkeit gegeben war. Die Einhaltung des Beihilfenverbots wurde von der Kommission überwacht, die Mitgliedstaaten durften ihre Subventionen erst nach Genehmigung auszahlen. Viele der Vorgaben im Beihilfenbereich waren in Form von Richtlinien oder Verordnungen - rechtlich verbindlich, darüber hinaus wurden das Verbot sowie die Ausnahmeregeln in vielen unverbindlichen oder gering verbindlichen Leitlinien aufgegriffen. Ende der 1990er Jahre verstärkte der Rat das Beihilfenverbot, indem er das Kontrollverfahren vereinfachte (vgl. VO 994/98 - Gruppenfreistellungsverordnung) und kodifizierte (vgl. VO 659/1999). Mit letzterem wurde die seit 1985/87 vorgenommene Praxis der Kommission, die Mitgliedstaaten dazu zu verpflichten, unrechtmäßig gezahlte Beihilfen mit Zinsen zurückzufordern, durch den Rat bestätigt. Die unverbindlichen Vorgaben präzisierten das Beihilfenverbot erst ab dem Jahr 2000, als festgehalten wurde, dass die nationalen Beihilfen in Relation zum BIP sinken sollten, in den Folgejahren wurde das Jahr 2003 als Referenz angegeben. Die zunehmende intendierte Einschränkung der mitgliedstaatlichen Interventionsmöglichkeiten ging demnach - wenn auch zeitversetzt - mit einer Stärkung der Verbindlichkeit einher.

\section{Interventionsbereich Allokation: Öffentliche Güter mit allokativer Funktion}

Bei den Vorgaben für öffentliche Güter mit allokativer Funktion lässt sich im Verlauf der Integration nur ein schwacher Wandel feststellen. Drei Bereiche öffentlicher Güter fanden eine besondere Beachtung: Bil- 
dung, Forschung und Entwicklung sowie Verkehrsinfrastruktur. Die entsprechenden Vorgaben werden im Folgenden noch einmal in ihrer Entwicklung dargestellt, bevor auf die allgemeinen Empfehlungen für die öffentlichen Güter eingegangen wird.

Die meisten Vorgaben für öffentliche Güter mit allokativer Funktion gab es im Bereich der beruflichen Bildung. Das gemeinsame Vorgehen verfolgte hauptsächlich zwei Ziele: Zur Förderung der Personenfreizügigkeit sollten die nationalen Berufsbildungssysteme angeglichen werden, was die mitgliedstaatlichen Ausgaben nicht direkt beeinflusste. Zweitens wurden - ausgabenrelevante - Vorgaben zum Ausbau der beruflichen Bildung in den Mitgliedstaaten und für ihre Anpassung an die jeweiligen wirtschaftlichen und sozialen Erfordernisse verabschiedet. Dies sollte insbesondere der Bekämpfung der strukturellen Arbeitslosigkeit bzw. in den 1960er Jahren (die erste Vorgabe stammt aus dem Jahr 1963) der bestmöglichen Verwendung der knappen Arbeitskräfte dienen (vgl. 67/264/EWG: 1540). Im Angesicht des technischen Fortschritts, des durch die wirtschaftliche Verflechtung beschleunigten Strukturwandels und schließlich in den 2000ern der Entwicklung zu einer »Wissensgesellschaft« sollte eine breite und qualitativ hochwertige Aus- und Weiterbildung die Beschäftigungsfähigkeit und Mobilität der Arbeitskräfte steigern. Dahinter verbarg sich zum einen eine soziale Intention: Da die »Risiken eines Arbeitsplatzwechsels« (74/374/EWG: 2) zunehmen würden, sollten die Beschäftigungssicherheit sowie die Chancengleichheit durch vermehrte Qualifizierung gefördert werden (vgl. 83/C 193/02: 2). Auch im Rahmen der OMK im Bereich Armut und soziale Ausgrenzung wurde Bildung als wichtiges Instrument aufgeführt (vgl. 14110/00: 7). Die verstärkten Anstrengungen der Mitgliedstaaten wurden jedoch zum anderen auch unter wirtschaftlichen Gesichtspunkten betrachtet: Durch den optimalen Einsatz gut qualifizierter Arbeitskräfte sollten Wachstum, Innovation und Wettbewerbsfähigkeit gestärkt werden. »Investitionen in Humanressourcen sind Voraussetzung für die Förderung der Wettbewerbsfähigkeit Europas, für die Erreichung hoher Wachstums- und Beschäftigungsraten und den Übergang zu einer wissensbasierten Wirtschaft« (Europäischer Rat 2003a: Ziff. 40).

Die wirtschaftlichen und die sozialen Ziele fanden sich in leicht abgewandelten Formulierungen im gesamten Verlauf der Integration. Die Vorgaben hielten die Mitgliedstaaten demnach ununterbrochen dazu an, ihre Interventionen im Bereich der beruflichen Bildung quantitativ wie qualitativ auszuweiten. Durch die Koordination sollte insbesondere die Qualität der Berufsbildungssysteme verbessert und somit die Effektivität gesteigert werden. Das gemeinsame Vorgehen war von Beginn an vertraglich verankert (vgl. Art. 128 EWGV), die zahlreichen auf diesem Ar- 
tikel basierenden Vorgaben waren jedoch nicht sehr verbindlich. Zum großen Teil handelte es sich um Entschließungen, auch in den wirtschaftspolitischen Leitlinien tauchten die entsprechenden Empfehlungen häufig auf. Detailliertere Vorgaben fanden sich erst im Rahmen der Lissabon-Strategie: Die Mitgliedstaaten sollten ihre »Humankapitalinvestitionen pro Kopf [...] von Jahr zu Jahr substantiell [steigern] « (Europäischer Rat 2000a: Ziff. 26), die beschäftigungspolitischen Leitlinien von 2001 und 2002 forderten die Mitgliedstaaten auf, sich »nationale Zielvorgaben [...] für eine Erhöhung der Investitionen in Humanressourcen [zu setzen]« (2001/63/EG: 20). Eine Verbindlichkeit konnte somit nur über den vereinbarten Informations- und Erfahrungsaustausch entstehen.

Neben der Bildung waren öffentliche Güter auch im Bereich Forschung und Entwicklung von großer Bedeutung. Dies wurde 1967 im 1. Programm für die mittelfristige Wirtschaftspolitik - wo sie zum ersten Mal auftauchten - folgendermaßen erklärt:

»Der Fortschritt in der modernen Gesellschaft ist mit dem Fortschritt der Wissenschaft und ihrer technischen Anwendung verbunden; diese spielen heute eine ähnliche Rolle wie der Besitz von Rohstoffen und Energiequellen in der Vergangenheit. Die Forschung ist die Investition par excellence; ihr Stand bestimmt die Entwicklung und Wettbewerbsfähigkeit der Wirtschaft in der $\mathrm{Zu}$ kunft« (67/264/EWG: 1516).

Gleichzeitig wurde ein Rückstand der Gemeinschaft im Bereich Wissenschaft und Technologie gegenüber anderen Industrieländern festgestellt und entsprechende Anstrengungen zur Aufholung dieses Rückstands angemahnt. Diese Argumentation wurde im Rahmen des Binnenmarktprojekts wieder aufgegriffen, da Europa »bei den wichtigsten industriellen Technologien [...] nach wie vor im Rückstand [sei] (83/674/EWG: 8). Hierbei ging es vor allem um die Konkurrenz mit Japan und den USA. Ab dem Jahr 2000 erhielten Investitionen in diesem Bereich einen noch höheren Stellenwert, da sie auch für den Aufbau der wissensbasierten Wirtschaft unersetzlich seien (vgl. Europäischer Rat 2000a: Ziff. 5). Hauptziel des gemeinsamen Vorgehens war somit die Erlangung von Wettbewerbsfähigkeit: »Die Förderung des technischen Fortschritts ist entscheidend, um die Position der Gemeinschaft unter den am höchsten entwickelten Wirtschaftsnationen der Welt zu sichern und zu fördern« (85/619/EWG: 5, ähnlich: Europäischer Rat 2002a: Ziff. 47). Überdies wurde der Beitrag zur wirtschaftlichen Entwicklung (vgl. 82/950/EWG: 7) sowie die Schaffung von Arbeitsplätzen in neuen Wachstumsindustrien (vgl. 81/1056/EWG: 10) genannt. 
Ein gemeinsames Vorgehen im Bereich FuE-Ausgaben sollte die (eingeschränkten) Interventionsmöglichkeiten der Mitgliedstaaten im gesamten Untersuchungszeitraum ausweiten: Bereits 1969 wurde festgestellt, dass die einzelnen Länder im Zuge der weltwirtschaftlichen Verflechtung nicht mehr in der Lage seien, die notwendigen finanziellen Mittel für Forschung und Entwicklung alleine aufzubringen (vgl. 69/ 157/EWG: 62, die gleiche Argumentation findet sich z.B. auch 1998: 98/454/EG: 41). Eine Koordinierung wurde überdies für sinnvoll gehalten, um ein Hochschaukeln der mitgliedstaatlichen Bemühungen auf diesem Gebiet (vgl. 69/157/ EWG: 67) sowie Doppelarbeit zu vermeiden (vgl. 74/C 07/02, Art. 1) und so die Effektivität der einzelstaatlichen Maßnahmen zu erhöhen (vgl. ebenda). Zu diesem Zweck entwickelte das 2. Programm für die mittelfristige Wirtschaftspolitik ein Verfahren, das jedoch nur einen Informationsaustausch, keine konkreten Vorgaben oder Überwachungsverfahren beinhaltete (vgl. 69/ 157/EWG: 67ff). 1974 wurde ein Ausschuss eingesetzt, der die mitgliedstaatliche Abstimmung erleichtern sollte (vgl. 74/C 07/02, Art. 2), 1987 schrieb die EEA die Koordination im Bereich Forschung und Technologie vertraglich fest (Art. 130h EEA). Erst im Jahr 2002 erfolgte die Setzung eines konkreten Ziels: Die Mitgliedstaaten sollten bis 2010 die Ausgaben für FuE auf $3 \%$ des BIP steigern, wovon die Privatwirtschaft $2 / 3$ übernehmen sollte (vgl. 2002/549/EG: 18). Insgesamt waren die Vorgaben demnach rechtlich unverbindlich, es gab jedoch gewisse Verfahren zur Überwachung der Umsetzung. Besonders detailliert waren die Empfehlungen nicht, nur selten gaben sie an, in welchen FuE-Bereichen die staatlichen Ausgaben genau erhöht werden sollten, ein quantifiziertes Ziel fand sich erst im Jahr 2002. Somit ist hier kaum ein Wandel feststellbar, weder bei den Zielen und Instrumenten, noch bei der Begründung oder der Verbindlichkeit des gemeinsamen Vorgehens.

Schließlich gab es eine Reihe von Vorgaben für die Verkehrsinfrastruktur, vor allem im Rahmen der Schaffung des Gemeinsamen bzw. später des Binnenmarktes oder anders gesagt: Zur Entwicklung »reibungslos funktionierender grenzüberschreitender Märkte« (Europäischer Rat 2001a: Ziff. 16). Bereits 1966 wurde ein »Beratungsverfahren auf dem Gebiet der Infrastruktur-Investitionen für den Verkehr« (66/161/ EWG) verabschiedet: Die Mitgliedstaaten mussten der Kommission wichtige Vorhaben melden, um auf diese Weise die Entwicklung harmonischer Verkehrsbedingungen in der Gemeinschaft zu fördern und eine Verschwendung von Ressourcen durch Abstimmungen zu vermeiden (vgl. 67/264/EWG: 1559). Ähnliche Vorgaben fanden sich im Zusammenhang mit der Entwicklung der Transeuropäischen Netze Anfang der 1990er Jahre. Hier wurde den Mitgliedstaaten empfohlen, Investitionen 
zu tätigen, die sich in den europäischen Rahmen einfügten (vgl. Europäischer Rat 1993c: 8). Weiterhin wurde die Bedeutung der Verkehrsinfrastruktur für das Wachstum und die Steigerung der gesamtwirtschaftlichen Produktivität hervorgehoben (vgl. 67/264/EWG: 1545). Differenzierungen fanden sich selten, nur 1982 wurde eine Verlagerung von Investitionen in Autobahnen zu öffentlichen Transportmitteln empfohlen, da letzteres das Wachstum direkter fördern würde (vgl. 82/950/EWG: 7). Insgesamt ist weder ein Wandel in der Zielstellung noch bei den Instrumenten feststellbar. Die Vorgaben hatten - unverbindlich und vage formuliert - eine Ausweitung mitgliedstaatlicher Interventionsmöglichkeiten zum Ziel, indem durch ein abgestimmtes Verfahren die Effizienz gesteigert und Ressourcen gespart werden.

Neben den Empfehlungen in den drei beschriebenen Bereichen gab es auch allgemeine Vorgaben für die Bereitstellung öffentlicher Güter mit allokativer Funktion durch die Mitgliedstaaten. Bis 1977 fanden sie sich unter der Überschrift »kollektive Bedürfnisse«, für deren Befriedigung der Staat zuständig erklärt wurde. In allen Phasen wurde mit den Vorgaben einer festgestellten Einschränkung der staatlichen Interventionsmöglichkeiten entgegen getreten: In den 1960er Jahren war es die allgemein hohe Nachfrage und die Gefahr inflationistischer Tendenzen, die durch einen Anstieg der öffentlichen Nachfrage noch verstärkt würden. Da die kollektiven Bedürfnisse jedoch als noch lange nicht befriedigt angesehen wurden, empfahlen die Vorgaben in diesem Zeitraum eine Verringerung des privaten Konsums und - sofern Einsparungen bei den öffentlichen Ausgaben unumgänglich waren - Kürzungen der laufenden Ausgaben. Die Vorgabe zur Umschichtung der Staatshaushalte von konsumtiven zu investiven Ausgaben fand sich auch in den von hohen Inflationsraten geprägten 1970ern (vgl. z.B. 76/440/EWG: 13), sowie den folgenden, preisstabilen Jahrzehnten, in denen es darum ging, den Anteil der Staatsausgaben am BIP zu reduzieren (vgl. z.B. 1999/ 570/EG: 43ff). Priorität sollte den beschäftigungsintensiven, wachstumsfördernden Ausgaben zukommen (vgl. z.B. 81/1056/EWG: 7), wobei die »unmittelbar wachstumsschaffenden« einen besonderen Vorrang genießen sollten (vgl. 82/950/EWG: 7). Die kollektiven Bedürfnisse wurden demnach ab Mitte der 1970er Jahre schrittweise enger gefasst und auf ihren Beitrag für Wachstum, Beschäftigung und Wettbewerbsfähigkeit geprüft. Mitte der 1980er wurde festgestellt, dass die Bereitstellung öffentlicher Güter unter der (auch europäisch empfohlenen) Konsolidierung der Haushalte gelitten habe (vgl. 86/667/EWG: 9). Hierauf wurde ebenfalls mit der Vorgabe reagiert, die Staatshaushalte umzuschichten, um beide Ziele - Konsolidierung und mehr investive Ausgaben - erreichen zu können. Weiterhin wurden zum ersten Mal Privatisierungen lo- 
bend erwähnt (vgl. ebenda: 67). Ab dem Ende der 1990er Jahre fanden sich die entsprechenden Empfehlungen unter der Überschrift »qualitativ solide öffentliche Finanzen« (z.B. 1999/570/EWG: 43).

Die Vorgaben für öffentliche Güter mit allokativer Funktion sollten insgesamt die Interventionsmöglichkeiten der Mitgliedstaaten ausweiten. Zum einen versprach das gemeinsame Vorgehen, insbesondere im Bereich FuE, Bildung und Verkehrsinfrastruktur, eine höhere Effektivität. Zum anderen wurde die Umschichtung der öffentlichen Haushalte durch die Vorgaben erleichtert: Die Mitgliedstaaten konnten sich sowohl bei der Bereitstellung der >wichtigsten< öffentlichen Güter, für die es - wenn auch selten - präzise Vorgaben gab als auch bei den dafür zunehmend als notwendig angesehenen Einsparungen in anderen Bereichen (vgl. 5.1.3) auf die europäischen Vorgaben berufen, was ihre Handlungsfähigkeit stärkte. Diese Intention wurde teilweise etwas zurückgenommen, da die Bereitstellung der öffentlichen Güter im Laufe der Zeit nicht mehr als selbstverständliche Aufgabe des Staates angesehen, vielmehr auch die Rolle privater Akteure angesprochen wurde. Bereits 1985 empfahlen die Vorgaben Beihilfen für private Infrastrukturprojekte (vgl. 85/C 165/ 02: 2), bei der Zielvorgabe für die FuE-Investitionen sollte der Staat nur $1 / 3$ bereitstellen, der Rest sollte - staatlich angeregt - von der Privatwirtschaft kommen. Die Empfehlungen fanden sich überwiegend in den Programmen für die mittelfristige Wirtschaftspolitik sowie den beschäftigungs- und wirtschaftspolitischen Leitlinien, erhielten somit erst durch die Grundzüge der Wirtschaftspolitik eine gewisse Verbindlichkeit. Quantifizierte Vorgaben gab es, neben der oben genannten für FuE, nur im Jahresbericht von 1984, der forderte, dass der Anteil der Investitionsausgaben (inkl. der vermögenswirksamen Leistungen) am BIP bis 1987 um einen Prozentpunkt auf $5 \%$ zunehmen sollte (vgl. 85/105/ EWG: 22) sowie 1986, als das Ziel gesetzt wurde, den Anteil der Investitionen am BIP auf $3 \%$ zu steigern (vgl. 86/667/EWG: 39). Eine Überwachung durch einen Ausschuss war nur bei den FuE- sowie den durch den Verfassungsvertrag hinzugekommenen Rüstungsausgaben vorgesehen.

\section{Interventionsbereich Distribution}

Bei den europäischen Vorgaben für Sozialausgaben und öffentliche Güter mit distributiver Funktion lässt sich ein Wandel bei den Zielen sowie den empfohlenen Instrumenten feststellen. Auch die Bewertung von Sozialleistungen veränderte sich im Laufe der europäischen Einigung. $\mathrm{Zu}$ Beginn des Integrationsprozesses war das vorherrschende Ziel eine allgemeine Verbesserung der Lebensbedingungen. Dies fand sich bereits in Artikel 2 des EWGV, wo es hieß: »Aufgabe der Gemeinschaft ist es [...] 
eine beschleunigte Hebung der Lebenshaltung [...] zu fördern.« In den ersten beiden Jahrzehnten wollten die Mitgliedstaaten dieses Ziel hauptsächlich über einen Ausbau der Sozialsysteme erreichen. Die Vorgaben empfahlen unter anderem eine gerechtere Einkommensverteilung (vgl. 69/157/EWG: 89), eine Anpassung des sozialen an den wirtschaftlichen Fortschritt (vgl. 74/C 13/01: 3) sowie der Sozialsysteme an die neuen gesellschaftlichen Erfordernisse (vgl. 71/107/EWG: 10). Konkreter wurden die Mitgliedstaaten aufgefordert, die Sozialsysteme auf Personengruppen auszuweiten, die bisher nicht ausreichend gesichert waren (vgl. 74/C 13/01: 3) und eine angemessene Arbeitslosenunterstützung zu gewähren, insbesondere für Umschulungszeiten (vgl. 71/371/EWG: 21). Die Bereitstellung öffentlicher Güter wurde vor allem im Bereich Gesundheit und sozialer Wohnungsbau empfohlen (vgl. u.a. 64/246/EWG: 1030; 77/294/EWG: 24), überdies - allerdings nur in einer Vorgabe für die Kinderbetreuung (vgl. 67/264/EWG: 1553).

In den ersten beiden Jahrzehnten der Integration hielten die Vorgaben die Mitgliedstaaten demnach dazu an, ihre Interventionen im Bereich Distribution auszudehnen. Sie waren jedoch relativ unverbindlich. Dies bezieht sich zum einen auf ihren rechtlichen Status: Es handelte sich hauptsächlich um die Programme für die mittelfristige Wirtschaftspolitik und Empfehlungen des Rates, für beide Vorgabentypen waren keine Sanktionsmechanismen vorgesehen. Auch ein Leitlinienverfahren mit einer regelmäßigen Überwachung wurde für den Sozialbereich nicht eingeführt. Zum anderen waren die Vorgaben sehr vage formuliert, es gab keine konkreten Ziele, anhand derer zumindest eine gegenseitige oder öffentliche Überprüfung ihrer Einhaltung möglich gewesen wäre. Einzig im 2. Programm für die mittelfristige Wirtschaftspolitik wurde empfohlen, auf Basis der Lohn- bzw. Produktivitätsentwicklung Orientierungsdaten für die Entwicklung der Sozialleistungen zu erstellen. Diese sollten jedoch nur indikativ sein (vgl. 69/157/EWG: 88f). Eine mögliche Erklärung hierfür ist, dass das gemeinsame Vorgehen in diesen Jahren noch in den Kinderschuhen steckte, das erste sozialpolitische Aktionsprogramm wurde erst 1974 verabschiedet (vgl. 74/C 13/01).

Anfang der 1980er Jahre ist ein Wandel in der Intention der Vorgaben feststellbar: Sie beschäftigen sich zunehmend mit den negativen Auswirkungen von Sozialleistungen. Ein Thema war die Belastung der Staatshaushalte durch Sozialausgaben, ${ }^{114}$ weshalb die Mitgliedstaaten aufgefordert wurden, vor allem bei den Renten keine langfristigen Verpflichtungen einzugehen (vgl. 82/950/EWG: 9). Entsprechend sollten

114 Dies war bereits 1967 als mögliches Problem genannt, aber nicht weiter verfolgt worden (vgl. 67/264/EWG: 1563). 
z.B. die im Jahr 1982 empfohlenen Vorruhestandsregelungen (vgl. 82/ 857/EWG: 27) nur noch für Langzeitarbeitslose gelten (vgl. 85/C 02/03: 4). Eine größere Beachtung fanden die durch Sozialleistungen verursachten Fehlanreize für Wachstum und insbesondere Beschäftigung. Nach einer ersten Empfehlung im Jahr 1981, »[d]ie finanzielle Belastung der Arbeitgeber durch besondere Finanzierungsmethoden der sozialen Sicherheit« zu überprüfen (81/1056/EWG: 11), wurde bereits 1983 die Herabsetzung der Arbeitgeberbeiträge zur Sozialversicherung angemahnt (vgl. 83/674/EWG: 15), ähnliche Empfehlungen fanden sich auch in den Folgejahren. Im Bereich öffentlicher Güter mit distributiver Funktion gab es in den 1980ern nur sehr wenige Vorgaben: Der Ausgabenanstieg im Gesundheitswesen sollte überprüft werden (vgl. 84/C 175/ 01: 2), eine Privatisierung wurde aber weder hier noch bei der Rentenversicherung für sinnvoll erachtet, da dies keine Senkung der Lohnnebenkosten erwarten ließe (86/667/EWG: 57).

Was die allgemeine Zielsetzung angeht, wurde zwar weiterhin davon gesprochen, dass an der Verbesserung der Lebensbedingungen festgehalten werde, dies »hänge[.] jedoch untrennbar mit dem Streben nach einem stärkeren Wirtschaftswachstum zusammen, das sich auf wettbewerbsfähigere Unternehmen [...] stützt« (84/C 175/01: 1). Obwohl die Sozialleistungen aus diesem Blickwinkel als Wettbewerbsfaktor gesehen wurden - »[d]ie Sozialversicherungskosten [...] sind in Europa im Vergleich zu anderen Industrieländern außerordentlich hoch « (83/674/ EWG: 13) - sollten sie innerhalb der Union nicht als solcher genutzt werden (vgl. 84/C 175/01: 2). Für die 1980er Jahren kann man demnach davon sprechen, dass die Vorgaben das Ziel hatten, die mitgliedstaatlichen Interventionsmöglichkeiten in gewissem Umfang einzuschränken. Die rechtliche Verbindlichkeit blieb allerdings gering: Die Empfehlungen fanden sich hauptsächlich in den Programmen für die mittelfristige Wirtschaftspolitik und den Jahresberichten, und auch die Detailliertheit bzw. Konkretisierung der Vorgaben nahm nicht zu.

In der Diskussionen um die soziale Dimension des Binnenmarktes kam in der zweiten Hälfte der 1980er Jahre das Thema Armutsbekämpfung auf die europäische Tagesordnung (vgl. 89/C 277/01: 1). Es gewann schnell an Bedeutung, ab 1989/90 hatte es sich als allgemeines Ziel des gemeinsamen Vorgehens durchgesetzt; 1997 wurde es in den Vertrag aufgenommen (vgl. Art. 136 und 137 EGV). Bei den Instrumenten, die den Mitgliedstaaten zum Zwecke der Armutsbekämpfung empfohlen wurden, handelte es sich im Wesentlichen um einen angemessenen Sozialschutz (vgl. Europäischer Rat 1989b, o.S.), präziser eine Grundsicherung, die den Arbeitsanreiz nicht unterminiert (vgl. 92/441/ EWG: 48). Teilweise wurde neben der Mindestsicherung auch eine ge- 
wisse statuserhaltende Funktion der Sozialleistungen angemahnt (vgl. ebenda: 51; 93/C 343/01: 2). Überdies empfahlen die Vorgaben gewisse öffentliche Güter wie Gesundheit oder sozialer Wohnungsbau (vgl. 89/C 277/01: 1). Diese Instrumente tauchten - allerdings (mit Ausnahme der Rente) ohne Bezug auf ihre statuserhaltende Funktion - erst 2000/2001 wieder auf, im Rahmen der Offenen Methode der Koordinierung sowie der in Nizza verabschiedeten Sozialagenda (vgl. 14110/00; 14164/1/02; 14098/01; Europäischer Rat 2000b, Anlage I). Sie waren somit durchgehend unverbindlich, allerdings war eine gewisse Überwachung gleichermaßen bei den frühen Vorgaben (vgl. 89/C 277/01: 1; Europäischer Rat 1989 b, o.S.) wie auch im Rahmen der OMK, dem ersten sozialpolitischen Leitlinienverfahren, vorgesehen. In den 1990er und 2000er Jahren gab es neben diesen Vorgaben zur Mindestabsicherung nur einen weiteren Bereich, in dem die Vorgaben auf einen Ausbau der mitgliedstaatlichen Interventionsmöglichkeiten zielten: Im Bereich Kinderbetreuung wurden sowohl quantifizierte Ziele gesetzt wie auch, durch ihre Festschreibung in den Grundzügen der Wirtschaftspolitik, eine gewisse Verbindlichkeit erzielt (vgl. z.B. 2002/549/EG: 14) - wobei damit eher allokative als distributive Ziele verfolgt wurden.

Abgesehen von diesen Empfehlungen, zumindest so weit in die Wirtschaft einzugreifen, dass allen ein menschenwürdiges Dasein gewährleistet sei, wurden in den 1990er Jahren vor allem Vorgaben verabschiedet, welche die Interventionsmöglichkeiten der Mitgliedstaaten einschränken sollten. Diese schlossen an die Vorgaben der 1980er Jahre an und stellten die negativen Auswirkungen der Sozialausgaben auf den Staatshaushalt sowie den Arbeitsmarkt in den Vordergrund. Letzteres passte auch zum neuen allgemeinen Ziel der Armutsvermeidung, da eine Beschäftigung als bester Schutz vor Armut angesehen wurde (vgl. Europäischer Rat 2000b, Anlage I: Ziff. 10). Alle Grundzüge der Wirtschaftspolitik, alle beschäftigungspolitischen Leitlinien und die meisten Schlussfolgerungen des Europäischen Rates zum Thema Wirtschaftspolitik empfahlen eine Senkung der Lohnnebenkosten und eine Erhöhung der Anreizwirkungen der Sozialtransfers - zusammengefasst unter dem Begriff »beschäftigungsfreundliche Gestaltung der Sozialsysteme«. Dies wurde teilweise sehr detailliert ausgeführt, sowohl für die Transferleistungen (vgl. z.B. 2002/549/EWG: 14) als auch für die Gesundheits- und Rentensysteme. Während in den 1960er und 1970er Jahren ein Ausbau der Gesundheitssysteme und Vorruhestandsregelungen empfohlen und in den 1980ern eine Privatisierung in diesem Bereich abgelehnt wurde, ging es nun, insbesondere ab 1995, im Wesentlichen um Einschränkungen. Begründet wurde dies mit der demographischen Entwicklung, welche die Renten- und Gesundheitssysteme stark belasten würde. Der EU- 
Gipfel von Stockholm legte eine dreigliedrige Strategie fest, um der sogenannten »demographischen Herausforderung« zu begegnen: Steigerung der Beschäftigungsquoten, Verringerung der öffentlichen Verschuldung und Anpassung der sozialen Sicherungssysteme (vgl. Europäischer Rat 2001a: Ziff. 7). Auch hier ging es demnach wieder um Beschäftigungsanreize und Staatshaushaltsbelastungen. Während sich für die Gesundheitssysteme nur allgemein gehaltene Sparvorgaben fanden (vgl. 96/431/EG: 49), wurde der Bereich Rente recht detailliert behandelt: Die Mitgliedstaaten sollten unter anderem die Vorruhestandsregelungen beschränken und zusätzliche - kapitalgedeckte - Altersvorsorgesysteme (vgl. 2003/555/EWG: 9) sowie Rentenreservefonds (vgl. 2002/549/EG: 11) einführen. Die Vorgaben, die sich mit den negativen Seiten der Sozialleistungen beschäftigen, hatten somit das Ziel, die Interventionsmöglichkeiten der Mitgliedstaaten einzuschränken. Da die entsprechenden Empfehlungen immer auch in den Grundzügen der Wirtschaftspolitik genannt wurden, waren gewisse Sanktionsmechanismen bei Nichtbeachtung vorhanden. Überdies waren die Vorgaben sehr detailliert und die Mitgliedstaaten wurden zusätzlich aufgefordert, sich eigene Ziele für die Senkung der Sozialabgaben zu setzen (vgl. 98/C 30/01: 4).

Zusammenfassend kann man für den Bereich Distribution folgendes festhalten: Bei der allgemeinen Zielsetzung gab es einen Wandel von der Verbesserung der Lebensbedingungen aller - zuerst über staatliche Umverteilung, später eine Steigerung von Wachstum und Wettbewerbsfähigkeit - hin zu der bescheideneren Absicht, Armut zu vermeiden, was zu Beginn der 1990er noch mit einer gewissen Statusabsicherung verbunden wurde. Dieser Wandel ging einher mit einer veränderten Sicht auf die Sozialausgaben, die sich ab den 1980er Jahren vom Positiven ins Negative verkehrte. Auch bei der intendierten Beeinflussung der Interventionsmöglichkeiten lässt sich ein Wandel feststellen: In den ersten Jahrzehnten hatten die Vorgaben das Ziel, die Interventionsmöglichkeiten der Mitgliedstaaten auszuweiten, was vor allem mit der vertraglich festgelegten Zielsetzung der Verbesserung der Lebensbedingungen begründet wurde. Der 1971 genannten Gefahr, dass eine Anhebung von Sozialleistungen im Rahmen der wirtschaftlichen Verflechtung zu einem Wettbewerbsnachteil werden könnte, sollte damals durch ein abgestimmtes Vorgehen (gleichzeitiges Eingehen präziser Verpflichtungen) entgegen gewirkt werden (vgl. 71/371/EWG: 21). Dass Sozialausgaben nicht als Wettbewerbsinstrument genutzt werden sollten, wird auch 1984 noch einmal festgehalten, wobei es hier nicht mehr um einen gemeinsamen Ausbau der Systeme ging, sondern eine Anpassung an neue Entwicklungen. Ansonsten ist jedoch ab dem Beginn der 1980er Jahre ein Wandel der Intention feststellbar: Die »gemeinsamen Herausforderun- 
gen « - hohe Arbeitslosigkeit, steigende Staatsverschuldung sowie demographische Entwicklung - wurden als (drohende) Einschränkung der mitgliedstaatlichen Interventionsmöglichkeiten wahrgenommen, da der Staat entsprechend weniger Sozialleistungen anbieten konnte und sollte. Hierauf wurde gemeinsam mit einer weiteren (in den 1990er Jahren zunehmenden) beabsichtigen Einschränkung durch die europäischen Vorgaben reagiert. Dies kann insofern zu einer Stärkung von Handlungsfähigkeit führen, als dass die Mitgliedstaaten bei Kürzungen im Sozialbereich auf die europäischen Vorgaben verweisen können. Eine völlige Einschränkung der staatlichen Interventionen im Bereich Distribution wurde nicht empfohlen; die Staaten sollten wenigstens eine Mindestsicherung gewährleisten.

\section{Interventionsbereich Stabilisierung}

Bei der Stabilisierungspolitik ist ein deutlicher Wandel in der Intention der europäischen Vorgaben bezüglich der Ausweitung bzw. Einschränkung mitgliedstaatlicher Interventionsmöglichkeiten zu verzeichnen. Bereits in den ersten Jahren der Integration war die Stabilisierung der Konjunktur über eine diskretionäre Steuerung der Nachfrage ein zentrales Anliegen des Rates. Zu diesem Zweck sollten die Mitgliedstaaten ein entsprechendes Instrumentarium aufbauen, mit dem schnell auf konjunkturelle Krisen reagiert werden konnte. Die Vorgaben forderten die Länder auf, dafür zu sorgen, dass »die Regierungsstellen erforderlichenfalls für befristete Zeit innerhalb von höchstens 90 Tagen die Entwicklung der öffentlichen Ausgaben verlangsamen oder beschleunigen können« (74/121/EWG, Art. 5). Als Instrumente wurden zum Beispiel Investitionsprogramme, Konjunkturausgleichsrücklagen und konjunkturpolitische Budget-Tranchen genannt. Zu Beginn stand eine Dämpfung der in diesen Jahren sehr hohen Nachfrage im Vordergrund, in Folge der Ölkrisen sollte die Nachfrage dann gesteigert werden. Die Vorgaben forderten die Mitgliedstaaten somit zu einem stark interventionistischen Verhalten auf. Nach Ansicht des Rates wurde dies jedoch durch die zunehmende wirtschaftliche Verflechtung erschwert, durch das koordinierte Vorgehen sollten die Interventionsmöglichkeiten entsprechend wiedergewonnen und - über den größeren Multiplikator - ausgebaut werden. Die Vorgaben waren insbesondere in den 1960er und der ersten Hälfte der 1970er Jahre zum Teil sehr detailliert, allerdings nur im Jahr 1974 rechtlich verbindlich in Form einer Richtlinie.

Die wirtschaftliche Verflechtung schränke nicht nur das autonome Handeln der Mitgliedstaaten ein, sondern führe auch dazu, dass »positive oder negative wirtschaftliche Impulse, die von einem einzelnen Land 
ausgehen, $[\ldots]$ sich $[\ldots]$ schnell und in verstärktem Maße auch in der Entwicklung der anderen Mitgliedstaaten nieder[schlagen]« (67/264/ EWG: 1522). Daher mussten die Mitgliedstaaten ihre Politik über Konsultationen miteinander abstimmen, was noch keine bestimmte Richtung vorgibt. Anders war dies bei dem Versuch, die Folgen der Vernetzung (positiv) zu nutzen, um Interventionsmöglichkeiten von Ländern, deren wirtschaftliche Situation besonders schlecht war, durch ein solidarisches Verhalten auszuweiten. Dies wurde 1968 zum ersten Mal praktiziert, als alle Mitgliedstaaten aufgefordert wurden, durch eine expansive Politik (und dadurch erhöhten Importen) dem von einer schweren Krise getroffenen Frankreich beizustehen (vgl. 68/310/EWG: 13). Insbesondere in den 1970er, aber auch noch in den 1980er Jahren (das letzte Mal im Jahresbericht von 1988) wurde empfohlen, dass die Länder, deren Interventionsmöglichkeiten durch besonders hohe Haushaltsdefizite, Inflationsraten und Zahlungsbilanzdefizite eingeschränkt waren, von den anderen Mitgliedstaaten unterstützt wurden. Letztere sollten expansiv vorgehen und es auf diese Weise den betroffenen Ländern erleichtern, zuerst eine notwendig restriktive, mittelfristig aber auch wieder eine expansive Politik zu verfolgen. Dies war auch im Interesse der stabilen Länder, da sie so ein Übergreifen der Krise zu verhindern suchten. Verbindlich waren die Vorgaben zum solidarischen Vorgehen nur im Falle der französischen Krise, hier wurden die anderen Mitgliedstaaten per Richtlinie zu einer expansiven Politik verpflichtet, danach fanden sich die Vorgaben nur noch - in den 1970ern mehr, in den 1980ern weniger detailliert - in den Jahresberichten.

Ab Mitte der 1970er Jahre wurde, unter anderem aufgrund der hohen Inflation, zunehmend Kritik an der kurzfristigen, diskretionären Stabilisierung der Konjunktur mit Hilfe von Budgetdefiziten laut. Die Gefahr einer Konkurrenz zwischen öffentlicher und privater Kreditaufnahme war bereits in den 1960er Jahren zweimal angesprochen worden (66/ 736/EWG: 4060; 67/264/ EWG: 1518), da die Gesamtnachfrage zu dieser Zeit insgesamt sehr hoch war, wurden eine zeitliche Staffelung der Ausgaben, aber durchaus auch Steuererhöhungen als Lösung empfohlen (vgl. ebenda). In den Jahren 1975 bis 1980 gab es zwar Bedenken gegenüber Haushaltsdefiziten, insbesondere wegen ihrer möglichen Crowding-Out-Effekte, eine Haushaltssanierung wurde in der damaligen Situation jedoch als nicht sinnvoll angesehen: »Zweifellos ersetzen diese Defizite angesichts der Rezession die mangelnden Investitionen, absorbieren den zeitweiligen Überschuß der privaten Ersparnis und wiegen gegebenenfalls saldenmechanisch auch das außenwirtschaftliche Defizit auf. Sie stützen somit kurzfristig Nachfrage und Wirtschaftstätigkeit« (77/294/EWG: 15). Der Jahresbericht des gleichen Jahres fügte hinzu, 
dass die Defizite in der vorliegenden Konjunktursituation ohne die Gefahr von Zinssteigerungen über den Kapitalmarkt finanziert werden könnten (vgl. 77/778/EWG: 6). Es wurde demnach weiterhin eine antizyklische Haushaltspolitik empfohlen (vgl. 80/67/EWG: 24; 80/1265/ EWG: 23). Der Sorge, die Expansionsmaßnahmen würden sich lediglich negativ auf die Inflations- und Wechselkurserwartungen auswirken, sollte durch eine verstärkte Abstimmung entgegen getreten werden, um über den größeren Multiplikatoreffekt die Wahrscheinlichkeit realer Effekte zu erhöhen (vgl. 79/19/EWG: 18).

Im Jahr 1981 überwogen sowohl beim Europäischen Rat als auch dem Ministerrat die Bedenken: Der Europäische Rat (1981a: 8) erklärte, eine kurzfristige Stimulierung der Nachfrage würde sich als unwirksam erweisen, der Jahresbericht lieferte die Begründung: »Die expansiven Effekte einer Haushaltspolitik, die auf ein steigendes Defizit hinausläuft, werden heute mit ziemlicher Wahrscheinlichkeit weitgehend durch steigende Zinssätze zunichte gemacht« (81/1056/EWG: 6). Eine zu strikte Sanierung der Staatsfinanzen wurde jedoch auch nicht empfohlen, da die negativen Auswirkungen auf die Nachfrage die positiven Zinseffekte kompensieren könnten (vgl. ebenda). Mit dieser Unwirksamkeitserklärung war aber noch kein endgültiger Wandel vollzogen, die Unsicherheit über die zu empfehlende Strategie fand sich auch in den Folgejahren, beispielsweise 1985:

»Schwankungen der Haushaltsdefizite und der Staatsverschuldung können erhebliche Auswirkungen auf die Angebots- und Nachfragebedingungen der Wirtschaft haben. Diese Effekte sind jedoch nicht ohne weiteres zu definieren. Steigende Staatsverschuldung führt tendenziell zu einer Erhöhung der Zinsen und - bei unveränderten sonstigen Bedingungen - zu einem Druck auf die privaten Investitionen. Dieser Zinseffekt ist jedoch nicht unbedingt ausschlaggebend, da unter bestimmten Voraussetzungen Schwankungen des Haushaltsdefizits sogar einen positiven Beitrag zum Wirtschaftswachstum leisten können. Führt eine geeignete Wirtschaftspolitik zu einer Vergrößerung des gesamtwirtschaftlichen Produktionspotentials, so kann ein zeitweiser Anstieg der Kreditaufnahme die Nachfrage in einer Weise steigern, die in etwa der vermehrten Steuerkraft der Volkswirtschaft entspricht. In diesem Fall wächst die strukturelle öffentliche Verschuldung [...] unter Umständen nicht an« (85/619/ EWG: 29).

Diese Verunsicherung schlug sich in den 1980er Jahren in eher vagen Vorgaben nieder. Diese forderten auf der einen Seite eine stärker regelgeleitete Stabilisierung mit Hilfe der automatischen Stabilisatoren (die 1981 zum ersten Mal erwähnt wurden) sowie einen mittelfristigen Haushaltsausgleich, der auch durch die automatischen Stabilisatoren nicht ge- 
fährdet werden sollte. Zum anderen wurde jedoch weiterhin - wenn dies notwendig würde und in der mitgliedstaatlichen Situation möglich wäre - eine kurzfristige Konjunkturstimulierung empfohlen (vgl. z.B. 85/105/ EWG: 22; 87/609/EWG: 18). Die Bedeutung, die man einer gemeinsamen Konjunkturpolitik immer noch beimaß, zeigt sich ebenfalls an der Übernahme des entsprechenden Artikels zur Koordinierung der Konjunkturpolitik in die Einheitliche Europäische Akte. Die Unsicherheit bezüglich der diskretionären Stabilisierung könnte dazu geführt haben, dass in den 1980er Jahren die Stabilisierungs- zunehmend mit der Allokationsfunktion der Finanzpolitik verbunden wurde. So verwies der Jahresbericht für 1981 darauf, dass die »rein makroökonomische, konjunkturbedingte Funktion der Nachfragesteuerung [...] mehr eingeschränkt werden [müsse] « (80/1265/EWG: 23). Immer wieder hoben die Vorgaben den angebotspolitischen Nutzen der zur Nachfragesteigerung getätigten öffentlichen Investitionen hervor. Damit wurde das Ziel der Konjunkturstabilisierung mit dem der mittelfristigen Wachstumsförderung verbunden. Als wichtige Vorbedingung für ein gesundes wirtschaftliches Umfeld wurde immer öfter allerdings auch eine solide Haushaltslage angemahnt.

Die Bedeutung des Haushaltsausgleichs nahm im Zeitverlauf zu. Während ein Abbau der Defizite bis zum Ende der 1980er Jahre nur bedingt empfohlen wurde, d.h. nur dann, wenn dies die wirtschaftliche Situation nicht noch zu verschlimmern drohte (bzw. für sehr stark verschuldete Länder dann, wenn andere Länder solidarisch-expansiv vorgingen), änderte sich dies im Rahmen der Vorbereitungen zur WWU, genauer gesagt ab dem Jahr 1989. Das Ziel des Haushaltsausgleichs wurde dem der diskretionären Konjunkturstabilisierung nun auch kurzfristig übergeordnet. Begründet wurde dies damit, dass ausgeglichene Haushalte eine wichtige Voraussetzung für eine stabile Geldpolitik seien und beides gemeinsam, Preisstabilität und Haushaltsausgleich, Bedingungen für Wachstum, Beschäftigung und Wettbewerbsfähigkeit. In diesem Zusammenhang wurde das Ziel der Haushaltssanierung Schritt für Schritt verbindlicher gemacht. Durch den Vertrag von Maastricht (1993) wurden die bisherigen Bestimmungen für die gemeinsame Konjunkturpolitik gestrichen, stattdessen wurde ein Defizitlimit von $3 \%$ des BIP festgeschrieben und mit einem detaillierten Überwachungs- und Sanktionsverfahren versehen, welches durch den Stabilitäts- und Wachstumspakt sowie im Verfassungsvertrag noch strenger gefasst wurde. Der SWP verschärfte das Defizitkriterium überdies, indem er einen ausgeglichenen oder überschüssigen Haushalt als Ziel vorschrieb. Weitere, wenn auch weniger verbindliche, Verschärfungen erfolgten über die Empfehlung, Mitglieder der Eurozone sollten »alle notwendigen Maßnahmen 
[...] ergreifen, um eine jährliche Verbesserung der konjunkturbereinigten Haushaltsposition um mindestens $0,5 \%$ des Bruttoinlandsprodukts sicherzustellen « (2003/555/EG: 13). All diese Vorgaben hatten das Ziel, eine diskretionäre Konjunkturstabilisierung mit Defiziten über $3 \%$ unmöglich zu machen. Stabilisierung sollte nur mehr regelgeleitet, über die automatischen Stabilisatoren erfolgen, d.h. ohne bewusste Intervention des Staates:

»Angesichts der Risiken und Unwägbarkeiten einer finanzpolitischen Feinsteuerung, insbesondere was den richtigen Zeitpunkt, die Wirksamkeit und Unumkehrbarkeit betrifft, sollte es sich die Haushaltspolitik zur Regel machen, die automatischen Stabilisatoren über einen Konjunkturzyklus hinweg symmetrisch wirken zu lassen, wobei die Grenze für ein übermäßiges Defizit von $3 \%$ einzuhalten ist $(2002 / 549 / \mathrm{EWG}$ : 5$)$.

Einzig in den beiden Konjunkturkrisen der vierten Phase griff man wieder auf die in den 1980ern empfohlene Strategie zurück, durch ein Vorziehen von Investitionsprojekten die Konjunktur anzukurbeln und damit gleichzeitig die Angebotsseite zu stärken - allerdings musste auch hier das $3 \%$-Kriterium beachtet werden, der Haushaltsausgleich stand somit im Vordergrund. Dass die Staaten nicht zu diskretionär intervenieren sollten, merkt man an der gleichzeitig getätigten Aussage, die EU solle die Mitgliedstaaten dazu bringen, ihren bisher eingeschlagenen Konsolidierungskurs zu halten (vgl. 93/258/EWG: 28).

Insgesamt wurde der Ansatz, die in Folge der wirtschaftlichen Verflechtung verminderten Interventionsmöglichkeiten der Mitgliedstaaten durch ein gemeinsames Vorgehen wieder auszuweiten und auf diese Weise ihre Handlungsfähigkeit zu stärken, immer mehr zurückgenommen. Gleichzeitig betonten die Vorgaben vermehrt die negativen Auswirkungen der Defizite, das Ziel des Haushaltsausgleichs gewann an Bedeutung. So fanden sich in den 1960er und 1970er Jahren detaillierte und teilweise verbindliche Vorgaben für eine gemeinsame (solidarische) und diskretionäre Steuerung der Nachfrage, in den 1980er und besonders in den 1990er und 2000er Jahren gingen diese Empfehlungen zurück, wurden weniger detailliert und es gab keine weiteren verbindlichen Vorgaben. Die Konjunkturstabilisierung wurde überdies stärker in den Dienst der Allokation gestellt, indem die Nachfrage über wachstumsfördernde öffentliche Investitionen angeregt werden sollte. Zwar ging man weiter von einer Einschränkung der Interventionsmöglichkeiten durch die wirtschaftliche Verflechtung aus und bewertete ein gemeinsames Vorgehen als effektiver, dies zeigte sich z.B. in den beiden letzten Wirtschaftskrisen des Untersuchungszeitraums. Dennoch schränkten die 
Vorgaben ab den 1980er Jahren, besonders jedoch im Rahmen der WWU, die verminderten konjunkturpolitischen Interventionsmöglichkeiten der Mitgliedstaaten noch zusätzlich ein, indem sie einen Abbau der - immer negativer betrachteten - Defizite empfahlen, zuerst noch unverbindlich und wenig detailliert, ab dem Vertrag von Maastricht jedoch sehr präzise, rechtlich verbindlich und mit einem >schmerzhaften Sanktionsverfahren versehen. Auf diese Weise sollten die vermutet negativen Effekte der Haushaltsdefizite auf das Zinsniveau, das Vertrauen etc. gemindert und eine kurzfristige, Keynes'sche Stabilisierung der Konjunktur mit Defiziten über $3 \%$ verhindert werden. Der Budgetsaldo sollte demnach nicht mehr mit dem Ziel der kurzfristigen Konjunkturstabilisierung diskretionär variiert werden, sondern nur mehr in gewissem Rahmen über die automatischen Stabilisatoren die Nachfrage stabilisieren, vor allem jedoch sollte der Haushalt ausgeglichen werden, um auf diese Weise für ein solides Wachstumsklima zu sorgen. Die Stärkung mitgliedstaatlicher Handlungsfähigkeit wurde somit überwiegend in einer Einschränkung ihrer Interventionsmöglichkeiten gesehen.

\subsection{Entwicklung der Beeinflussung von Handlungsfähigkeit}

Nach der Betrachtung des Wandels in den vier Politikfeldern kann nun zusammenfassend die erste Forschungsfrage - Auf welche Weise sollte mit den europäischen Vorgaben Einfluss auf die nationalstaatliche Handlungsfähigkeit genommen werden, durch einen Ausbau oder eine Einschränkung von Interventionsmöglichkeiten? - und ein Teil der dritten - Hat es bei der Beeinflussung von Handlungsfähigkeit sowie dem zugrunde liegenden Staatsverständnis einen Wandel gegeben, wenn ja, wie sieht dieser aus? - beantwortet werden.

In den ersten beiden Jahrzehnten der Integration - insbesondere den späten 1960ern und frühen 1970ern - hatten die Vorgaben das Ziel, die Handlungsfähigkeit der Mitgliedstaaten durch einen (Wieder-)Ausbau von Interventionsmöglichkeiten sowie eine höhere Effektivität des gemeinsamen Vorgehens zu stärken. Dies ist in allen vier Politikfeldern zu beobachten: Das Beihilfenverbot wurde nur selten erwähnt, stattdessen sollten Beihilfen eingesetzt werden, um den Strukturwandel zu gestalten, wobei eine Bremsung des Strukturwandels durch Erhaltungssubventionen (was einen stärkeren Eingriff darstellt) nur 1969 empfohlen wurde. Dies versprach insofern eine Ausweitung von Interventionsmöglichkeiten, als dass eine gegenseitige Neutralisierung der Beihilfen vermieden und durch eine Bündelung mehr Effizienz erreicht werden konnte. Diese 
Argumentation - höhere Effektivität und Qualität durch gemeinsames Vorgehen - galt auch für die Vorgaben zur Bereitstellung öffentlicher Güter mit allokativer Funktion. So sollte z.B. im Bereich FuE die Einschränkung nationaler Interventionsmöglichkeiten im zunehmend globalen Wettbewerb durch eine Koordinierung der einzelstaatlichen Bemühungen überwunden werden. Die Vorgaben im allokativen Bereich waren allerdings unverbindlich und nicht sehr detailliert. Die distributiven Vorgaben forderten die Mitgliedstaaten ebenfalls zu einem interventionistischeren Verhalten auf, sie sollten ihre Handlungsfähigkeit stärken, indem das gleichzeitige Anheben der Sozialleistungen keine Wettbewerbsnachteile mit sich brachte und die Interventionen durch einen Verweis auf die europäische Ebene gerechtfertigt werden konnten. Es gab hier jedoch nur recht wenige, vage und unverbindliche Vorgaben. Anders sah dies bei den Stabilisierungsvorgaben aus, die in diesem Zeitraum zahlreich, detailliert und in zwei Fällen rechtlich verbindlich waren. Mit ihrer Hilfe sollten die in Folge der wirtschaftlichen Verflechtung sowie der teilweise schlechten wirtschaftlichen Situation einzelner Mitgliedstaaten eingeschränkten Interventionsmöglichkeiten durch ein abgestimmtes und solidarisches Vorgehen bei der diskretionären Nachfragesteuerung wieder ausgeweitet werden.

Ende der 1970er/Anfang der 1980er Jahre ist in allen Politikfeldern ein Wandel feststellbar, allerdings leicht zeitversetzt und in unterschiedlicher Intensität. Zwar wurde nach wie vor eine Einschränkung mitgliedstaatlicher Interventionsmöglichkeiten festgestellt, dem wurde jedoch weniger entgegen gewirkt. Die erhöhte Effektivität des gemeinsamen Vorgehens - von der man ebenfalls weiter ausging - wurde sogar in einigen Bereichen für eine zusätzliche Einschränkung genutzt. Letzteres zeigte sich insbesondere bei den Sozialausgaben: Zwar empfahlen die Vorgaben weiterhin, die Sozialausgaben nicht als Wettbewerbsfaktor zu nutzen. Auf die wahrgenommene Einschränkung der mitgliedstaatlichen Interventionsmöglichkeiten durch die hohe Arbeitslosigkeit, die steigende Verschuldung etc. wurde ab 1980 jedoch mit einer weiteren Einschränkung durch die europäischen Vorgaben reagiert: Den Mitgliedstaaten wurde nahegelegt, ihre Sozialausgaben zu senken, um auf diese Weise Wachstum und Beschäftigung anzuregen. Das gemeinsame Vorgehen könnte den Kürzungen der zunehmend negativ bewerteten Sozialausgaben eine gewisse Legitimität verschaffen und so die staatliche Handlungsfähigkeit stärken.

Mit Blick auf die Beihilfen betonten die Vorgaben zum Ende der 1970er Jahre häufiger das vertraglich festgelegte Verbot, da die Mitgliedstaaten in Folge der Ölkrisen immer mehr protektionistische Subventionen vergaben. Der Wandel war jedoch erst 1986, im Rahmen des 
Binnenmarktprojekts, vollzogen, da ab diesem Zeitpunkt die Ausnahmeregelung für die Subventionierung fortschrittlicher Sektoren fiel und das Verbot (fast) vollständig war. Die Beihilfenvorgaben hatten nun nur noch das Ziel, die mitgliedstaatlichen Interventionsmöglichkeiten einzuschränken und ihre Handlungsfähigkeit zu stärken, indem sie den Strukturwandel dem Markt überlassen konnten.

Im Bereich Stabilisierung war der Wandel zu diesem Zeitpunkt noch uneindeutig: Zwar geriet die defizitfinanzierte Nachfragestimulierung wegen möglicher Crowding-Out-Effekte bereits ab 1975 in die Kritik und die Vorgaben empfahlen einen mittelfristigen Ausgleich der Haushalte, nach einer Unwirksamkeitserklärung im Jahr 1981 gab es jedoch weiterhin Vorgaben, die den Mitgliedstaaten eine solche Politik nahe legten. Allerdings wurde diese (Wieder-)Ausweitung der Interventionsmöglichkeiten vorsichtiger und weniger detailliert formuliert, was zu einer sinkenden Verbindlichkeit führte, die Handlungsfähigkeit demnach weniger stärken konnte als zuvor. Das einzige Feld, in dem die Vorgaben keine Einschränkung der mitgliedstaatlichen Interventionsmöglichkeiten zum Ziel hatten, waren öffentliche Güter mit allokativer Funktion. Man kann jedoch davon sprechen, dass die Ausweitung der Interventionsmöglichkeiten etwas zurückgenommen wurde, indem mehr auf den unmittelbaren Beitrag der Güter für die wirtschaftliche Entwicklung geachtet wurde. Es war nicht mehr allgemein von kollektiven Bedürfnissen die Rede, für deren Befriedigung ausschließlich der Staat zuständig war, stattdessen wurde ab 1985 vereinzelt auch die diesbezügliche Rolle privater Akteure angesprochen. Die Vorgaben blieben allerdings unverbindlich.

Ein weiterer Wendepunkt - bzw. eine Vertiefung/Vollendung des Wandels in bestimmten Bereichen - kann Ende der 1980er/Anfang der 1990 er festgemacht werden. Die Vorgaben im Bereich Stabilisierung hatten fortan vor allem das Ziel, die mitgliedstaatliche Handlungsfähigkeit durch eine Einschränkung von Interventionsmöglichkeiten zu stärken. Die negativen Effekte von Haushaltsdefiziten waren in den Vordergrund getreten, eine Feinsteuerung der Wirtschaft wurde als undurchführbar betrachtet, weshalb die Vorgaben eine regelgeleitete Stabilisierung sowie einen Ausgleich der Haushalte festschrieben. Die Intention, eine diskretionäre Nachfragesteuerung mit Defiziten von über $3 \% \mathrm{zu}$ verhindern, wurde auch in den beiden Wirtschaftskrisen deutlich, als die EU ihre Mitgliedstaaten von »kurzfristigen Lösungen« abhalten sollte. Das Verbot übermäßiger Defizite war, im Gegensatz zu den wenigen, vorsichtig formulierten Vorgaben, in den Konjunkturkrisen die Nachfrage über das Vorziehen öffentlicher Investitionen zu steigern, rechtlich 
verbindlich, quantifiziert und mit Sanktionen versehen. Es wurde im Laufe der folgenden Jahre durch Verfahrensänderungen noch verstärkt.

Die distributiven Vorgaben empfahlen zu Beginn der 1990er eine gewisse Status- oder zumindest Grundsicherung und damit - wenngleich unverbindlich - eine leichte Ausweitung der Interventionen. Anders sah dies bei den ab Mitte der 1990er auftauchenden Vorgaben zur (Teil-) Privatisierung der Rentensysteme aus. Dies war in den 1980ern noch abgelehnt worden; nun, im Angesicht der demographischen Entwicklung, begegnete man den hierdurch befürchteten Einschränkungen der mitgliedstaatlichen Interventionsmöglichkeiten mit einer weiteren Einschränkung durch die Vorgaben. Die Empfehlungen fanden sich, zum Teil sehr detailliert, in den Grundzügen der Wirtschaftspolitik, was sie etwas verbindlicher machte. Gleiches galt für die weiterhin bestehenden Vorgaben zur beschäftigungs- und staatshaushaltsfreundlichen Senkung der Sozialleistungen. Dass die Sozialausgaben nicht als Wettbewerbsfaktor genutzt werden sollen, fand keine Erwähnung mehr.

Während die Interventionsmöglichkeiten bei den Sozialausgaben und öffentlichen Gütern mit distributiver Funktion (Ausnahme: Kinderbetreuung) auf diese Weise eingeschränkt werden sollten, ging es bei den öffentlichen Gütern mit allokativer Funktion weiterhin um eine Ausweitung: über die Legitimierung von Kürzungen in anderen Bereichen (»Qualität der öffentlichen Finanzen«) sowie die höhere Effektivität des gemeinsamen Vorgehens. Diese Empfehlungen waren Bestandteil der GdW, was ihre Verbindlichkeit leicht erhöhte. Allerdings wurde weiterhin die Rolle privater Akteure betont; diese sollten sich z.B. mit 2/3 an der Erreichung des einzig quantifizierten Ziels in diesem Bereich - Ausgaben für FuE bei $3 \%$ des BIP - beteiligen. Hinsichtlich der Beihilfen wurde zum einen das Verbot nachdrücklicher durchgesetzt, indem das Verfahren in den Jahren 1998 und 1999 verbindlicher und einfacher gestaltet wurde. Ab 2000 griffen die Vorgaben zum anderen die vertraglich festgelegte Ausnahmeregelung für Vorhaben von gemeinsamem Interesse auf, was die Einschränkung der mitgliedstaatlichen Interventionsmöglichkeiten im Beihilfenbereich jedoch nur in geringem Maße wieder lokkerte, insbesondere da die entsprechenden Empfehlungen, im Gegensatz zu den Verfahrensänderungen, unverbindlich waren. Mit Ausnahme der öffentlichen Güter mit allokativer Funktion - und ab 2000 in gewissem Umfang für Beihilfen mit horizontaler Zielsetzung - lässt sich für die 1990er und 2000er Jahre demnach festhalten, dass die Vorgaben die mitgliedstaatliche Handlungsfähigkeit durch eine zusätzliche bzw. verbindlichere Einschränkung von Interventionsmöglichkeiten stärken sollten. 


\subsection{Entwicklung des Staatsverständnisses}

Im folgenden Abschnitt geht es um die zweite Forschungsfrage - Welches Staatsverständnis - bezogen auf die Nationalstaaten - lag den Vorgaben zugrunde? - sowie den noch nicht beantwortete Teil der dritten Frage - Hat es bei der Beeinflussung von Handlungsfähigkeit sowie dem zugrunde liegenden Staatsverständnis einen Wandel gegeben, wenn ja, wie sieht dieser aus? Der Wandel des Staatsverständnisses lässt sich am deutlichsten daran festmachen, wie sich die grundlegende Einstellung gegenüber dem Staat und dem Markt geändert hat, wem von beiden die Lösung der wirtschaftlichen Probleme zugetraut wurde und welche Gewichtung die drei Interventionsbereiche - Allokation, Distribution oder Stabilisierung - einzeln und gegeneinander erfahren haben. Betrachtet man die Entwicklung des Staatsverständnisses über den gesamten Untersuchungszeitraum hinweg, so lässt sich nur zwei Perioden ein recht eindeutiges Staatsverständnis zuordnen: Von den Römischen Verträgen bis zum Anfang der 1980er Jahre sowie von 1989/90 bis zum Ende der Untersuchungsphase. Als erstes Ergebnis kann somit festgehalten werden, dass nicht - wie ursprünglich angenommen - vier, sondern nur drei Phasen (im Folgenden: Perioden ${ }^{115}$ ) erkennbar sind.

In der ersten Periode (1957 - 1980) findet sich ein Keynes'sches Staatsverständnis, dem Staat wurde eine bedeutende und interventionistische Rolle zugeschrieben. Zentral waren seine stabilisierenden Aufgaben: Die Steuerung der Nachfrage sollte sowohl die Inflation mildern als auch zur Reaktion auf mögliche bzw. in Folge der Ölkrisen tatsächliche konjunkturelle Einbrüche und die damit einhergehenden Arbeitslosigkeit genutzt werden. Die Vorgaben empfahlen eine diskretionäre Vorgehensweise, was dem Staat eine gewichtigere Rolle zuschreibt als bei einer regelgeleiteten Stabilisierung. Überdies sollte der Staat durch einen Ausbau der sozialen Transferleistungen und öffentlichen Dienstleistungen sowie vermehrte Umverteilung die Lebensbedingungen der Bevölkerung verbessern. Zu diesem Zweck wurde teilweise auch die Allokation in den Dienst der Distribution gestellt: In den 1960ern erlaubten die Vorgaben einmal Erhaltungssubventionen als soziale Abfederung des Strukturwandels, die Empfehlungen für (allokative und distributive) öffentliche Güter firmierten unter der Überschrift »kollektive Bedürfnisse«, deren Befriedigung eindeutig dem Staat zukam.

115 Um Verwirrungen zu vermeiden, spreche ich im Folgenden von >Perioden<, wenn ich mich auf die drei empirisch bestimmten Zeiträume beziehe und von >Phasen<, wenn von den vier vor der Untersuchung festgelegten Zeitabschnitten die Rede ist. 
Eine Lösung der Probleme über den Markt oder eine Stärkung der Angebotskräfte wurden in dieser Periode deutlich seltener empfohlen: Dem Arbeitskräftemangel sowie der teilweise auftretenden strukturellen Arbeitslosigkeit sollte durch eine verstärkte Qualifizierung entgegen gewirkt werden. Eine Förderung des mittelfristigen Wachstums über die Angebotsseite fand sich nur in den Programmen für die mittelfristige Wirtschaftspolitik, was damit zusammenhängen kann, dass bis zur ersten Ölkrise die Wachstumsraten auf einem befriedigenden Niveau waren und danach der Stabilisierung der Konjunktur Priorität zukam. Die als selbstverständlich angesehene große Bedeutung des Staates wird an folgendem Zitat aus dem 2. Programm für die mittelfristige Wirtschaftspolitik deutlich:

»Einmal setzt er durch seine allgemeine Wirtschaftspolitik die grundlegenden Daten für das Verhalten der am Wirtschaftsleben Beteiligten, wobei er sowohl von der Kosten- als auch von der Nachfrageseite her inflationistischen, aber auch deflationistischen Tendenzen entgegenwirken muß. Zum anderen wird ein erheblicher Prozentsatz des Volkseinkommens in allen modernen Staaten auf Grund der von der öffentlichen Hand wahrgenommenen Aufgaben (Verwaltung, Ausbildung, Forschung, Gesundheitswesen, Justiz, Verteidigung usw.) bestimmt. Nicht zuletzt bewirkt der Staat im Rahmen der Politik auf dem Gebiet der sozialen Sicherheit und der Übertragung zugunsten bestimmter sozialer Schichten und Wirtschaftszweige eine erhebliche Einkommensumverteilung« (69/157/EWG: 87).

In diesem Sinne wurde eine Ausweitung der Staatstätigkeiten und -ausgaben für die Zukunft als natürlich und notwendig angesehen.

Der Wandel - und damit die zweite Periode - begann Anfang der 1980er Jahre. Nachdem in den 1970ern bereits Skepsis gegenüber dem damals zentralen Interventionsbereich Stabilisierung laut geworden war, wurde eine diskretionäre Nachfragesteuerung 1981 für unwirksam erklärt. Im gleichen Jahr wurden Sozialausgaben zum ersten Mal negativ bewertet. In der sukzessiven Betrachtung der Untersuchungsphasen konnte daher zuerst der Eindruck entstehen, der Wandel von einem Keynes'schen zu einem zurückhaltenden Staatsverständnis sei mit Beginn der 3. Untersuchungsphase abgeschlossen, was auch dazu gepasst hätte, dass in dieser Phase das Binnenmarktprojekt begann, welches mit einer entsprechend positiven Einstellung gegenüber dem Markt einherging. Dieser Eindruck erhärtete sich bei der Untersuchung der 1980er Jahre jedoch nicht: Ein zurückhaltendes, angebotsökonomisches oder monetaristisches Staatsverständnis konnte nicht bzw. nur ansatzweise gefunden werden, weshalb die Jahre 1981 bis 1988 nun zu einer >Periode des Wandels` zusammengefasst werden. In diesen Jahren gab es 
erstmals Bedenken gegen staatliche Interventionen und steigende Staatsausgaben. So wurde 1985 das Ziel gesetzt, den Anteil der Ausgaben am BIP jährlich um $1 \%$ zu reduzieren. 1983 und 1986 empfahlen die Vorgaben den Mitgliedstaaten, ihre Eingriffe in die Wirtschaft zu verringern, um so die wirtschaftliche Effizienz zu erhöhen. Eine bedeutende, interventionistische Rolle des Staates wurde somit - trotz der vielen ihm übertragenen Aufgaben - nicht mehr als selbstverständlich erachtet.

In den Mittelpunkt rückte in dieser Periode (nicht nur in den Programmen für die mittelfristige Wirtschaftspolitik, sondern auch in den Jahresberichten) die mittlere Frist, das Wachstum, welches über ein sogenanntes stabiles Umfeld, d.h. geringe Inflation und einen ausgeglichenen Haushalt gefördert werden sollte. Zusätzlich wurde die Bereitstellung öffentlicher Güter empfohlen, zu diesem Thema fanden sich ab 1980 deutlich mehr Vorgaben, die sich stärker auf den unmittelbaren Beitrag dieser Güter für die wirtschaftliche Entwicklung bezogen. Auch der Strukturwandel sollte ab 1986 vollständig dem Markt überlassen und nicht mehr durch Beihilfen gestaltet werden. Zur Bekämpfung der Arbeitslosigkeit empfahlen die Vorgaben in den 1980er Jahren ebenfalls immer weniger nachfrage-, sondern vor allem angebotspolitische Maßnahmen wie verstärkte Arbeitsanreize und eine Mäßigung der Löhne. Dies ist zwar insofern nachvollziehbar, als dass die konjunkturelle Arbeitslosigkeit (im Gegensatz zur strukturellen) in den 1980ern stark zurückging, widersprach aber dennoch einer Keynes'schen, interventionistischen Herangehensweise.

Die Erreichung der wirtschaftspolitischen Ziele wurde somit vermehrt den Marktkräften überlassen, der Staat sollte sich, insbesondere im distributiven Bereich, zurückziehen. Dem entsprechend sah die Mehrzahl der Vorgaben den Markt ab 1983 positiv. Dies ist allerdings auch mit den erwarteten Vorteilen des Binnenmarktes zu erklären, es bedeutet nicht, dass die Lösung der Probleme ganz und gar dem Markt überlassen wurde. Die Nachfragesteuerung durch den Staat wurde immer noch als sehr wichtig eingeschätzt: Zum einen sollte der Staat die durch die Lohnmäßigung ausgelöste Nachfrageschwäche kompensieren, zum anderen bei Konjunkturabschwächungen die Nachfrage diskretionär erhöhen. Letzteres sollte durch die staatliche Finanzierung produktiver öffentlicher Investitionen auch die Allokation verbessern. Haushaltsdefizite wurden zwar, vor allem wegen ihrer erwartet negativen Auswirkungen auf das Zinsniveau und damit die privaten Investitionen, als problematisch betrachtet und sollten mittelfristig abgebaut werden, dies hinderte den (Europäischen) Rat jedoch nicht daran, sie in Rezessionen weiterhin zu dulden bzw. zu befürworten. In dieser Phase gibt es somit eine größere Aufmerksamkeit für marktliche Lösungen und eine Verbes- 
serung der Allokation - auch über einen Rückzug des Staates aus seinen distributiven Aufgaben, die Umschichtung der Staatshaushalte sowie die Verbindung distributiver und stabilisierender mit allokativen Aufgaben.

Dem Staat wurden jedoch noch zu viele Aufgaben zugeschrieben, um ihn als zurückhaltend bezeichnen zu können.

Erst ab 1989/90 kann man von einem neuen Staatsverständnis sprechen. In der hier beginnenden dritten Periode herrschte ein weitgehend eindeutiges angebotsökonomisches Staatsverständnis vor. Dies lässt sich an der sehr häufig vorkommenden positiven Einstellung gegenüber dem Markt festmachen, dem die Lösung der wirtschaftlichen Probleme dieser Periode zugetraut wurde: Sowohl die Bekämpfung der Arbeitslosigkeit als auch die Sicherstellung eines angemessenen Wachstums sollten über eine Verbesserung der Angebotsbedingungen erreicht werden; nachfragepolitische Maßnahmen wurden nur noch sehr selten empfohlen. Dass es sich um ein angebotsökonomisches Staatsverständnis handelt, wird auch mit Blick auf die verbleibenden Staatsaufgaben und ihre Gewichtung zueinander bestätigt: Im Mittelpunkt stand die Allokation, die Staaten wurden aufgefordert, die Bedingungen für das freie Wirken der Marktkräfte zu verbessern, in erster Linie durch den Abbau wettbewerbsverzerrender und den Strukturwandel behindernder Beihilfen und die Bereitstellung öffentlicher Güter mit allokativer Funktion. Auch bei den öffentlichen Gütern beinhalteten die Vorgaben einen Rückzug des Staates, da diese vermehrt privat bereitgestellt werden sollten.

Im distributiven Bereich sollte der Staat noch weniger intervenieren als in der Vorperiode. Empfohlen wurden zwar Maßnahmen zur Armutsbekämpfung (und in zu Beginn auch vereinzelt zur Statussicherung), hauptsächlich sollten die Sozialtransfers jedoch im Sinne der »Beschäftigungsfreundlichkeit der Sozialsysteme« gesenkt werden, um die Allokation zu verbessern. Auch hier wurde ein Rückzug des Staates zu Gunsten bzw. Lasten der Privaten sichtbar: Zum einen im Rahmen der Diskussion um die langfristige Tragfähigkeit der Rentensysteme, bei der ab Mitte der 1990er Jahre ein Ausbau der privaten Vorsorge gefordert wurde, zum anderen bei der Armutsbekämpfung, die immer stärker darauf setzte, dass die Menschen sich über Erwerbsarbeit selbst aus dieser Situation befreien.

Der größte Unterschied zur Wandelperiode wird bei den stabilisierenden Aufgaben des Staates sichtbar: Das Ziel eines ausgeglichenen Haushalts war zentral geworden, was auch insofern einen Rückzug des Staates beinhaltet, als dass ausgeglichene bzw. überschüssige Haushalte zu einer Stabilisierung bzw. Rückführung der Staatsverschuldung führen, wodurch der Staat weniger Ressourcen bindet. Stabilisierung, die das Ziel des Haushaltsausgleichs unbedingt beachten musste, sollte vor 
allem regelgeleitet, d.h. ohne bewussten Eingriff des Staates, erfolgen. Nur in der konkreten Situation der beiden Wirtschaftskrisen empfahlen die Vorgaben eine (nicht ganz ins angebotsökonomische Bild passende) diskretionäre Stabilisierung der Nachfrage. Dies war jedoch recht vorsichtig formuliert: Die Mitgliedstaaten wurden aufgefordert, öffentliche Investitionen - die neben der Nachfrage- auch die Angebotsbedingungen verbessern sollten - vorzuziehen oder gemeinsam anzukündigen. Gleichzeitig sollte die EU allerdings als »Disziplinierungsrahmen« die Mitgliedstaaten von zu weitgehenden Interventionen abhalten. Der Staat sollte sich somit zurückziehen, seine früheren Aufgaben dem Markt bzw. den Individuen überlassen. Hierzu passt auch, dass nicht nur der Markt, sondern auch das Unternehmertum deutlich positiv gesehen wurden - was ebenfalls einem angebotsökonomischen Staatverständnis entspricht.

\subsection{Entwicklung der Beziehung zwischen den Staatsverständnissen und der Beeinflussung staatlicher Handlungsfähigkeit}

Zusammenfassend soll nun danach gefragt werden, ob bzw. wann sich die in Kapitel 3.2 entwickelten Strategien, welche - basierend auf unterschiedlichen Staatsverständnissen - mit Hilfe der Vorgaben in Bezug auf die nationalstaatliche Handlungsfähigkeit verfolgt werden können, wiederfinden lassen. Entwickelt wurde eine kritische, eine affirmative und eine revisionistische Strategie, erstere bezieht sich auf ein interventionistisches, Keynes'sches Staatsverständnis, die beiden letzteren auf ein zurückhaltendes, entweder monetaristisches oder angebotsökonomisches/NKM-Staatsverständnis.

Ein Keynes'sches Staatsverständnis lag den Vorgaben im Zeitraum 1957-1980 zugrunde. Bei diesem Staatsverständnis wird eine kritische Strategie erwartet, bei der mit den Vorgaben das Ziel verfolgt wird, nationalstaatliche Handlungsfähigkeit durch eine Wiedergewinnung sowie einen Ausbau von Interventionsmöglichkeiten (v.a. im Bereich diskretionäre Stabilisierungspolitik und Distribution) zu stärken. Die Absicht, die mitgliedstaatliche Handlungsfähigkeit durch eine (Wieder)Ausweitung von Interventionsmöglichkeiten zu stärken, nahm mit dem Aufund Ausbau des koordinierten Vorgehens zu und erlebte am Ende der 1960er/Anfang der 1970er Jahre einen Höhepunkt. Mit den Vorgaben wurde zum einen auf eine wahrgenommene Einschränkung von Interventionsmöglichkeiten - durch die zunehmende wirtschaftliche Ver- 
flechtung, aber auch gemeinsame oder einzelstaatliche Probleme wie Wirtschaftskrisen, Inflation o.ä. - reagiert. Zum anderen sollten die Interventionsmöglichkeiten ausgeweitet werden, indem durch ein gemeinsames Vorgehen ihre Effektivität und Qualität gestärkt wurde. Beispiele hierfür sind die solidarische Krisenbekämpfung sowie der gemeinsame Ausbau der Sozialsysteme, um auf diese Weise ohne die Gefahr von Wettbewerbsnachteilen die Lebensverhältnisse in der Gemeinschaft zu verbessern. Das gemeinsame - aktive oder reaktive - Vorgehen unterschied sich in Verbindlichkeit und Intensität, Ziel war jedoch immer, die Handlungsfähigkeit der Nationalstaaten durch eine Ausweitung von Interventionsmöglichkeiten zu stärken. Die Vorgaben waren im für das Keynes'sche Staatsverständnis zentralen Interventionsbereich, der diskretionären Stabilisierungspolitik, am detailliertesten, zahlreichsten und verbindlichsten. Auch im ebenfalls wichtigen Bereich Distribution gab es entsprechende Vorgaben, allerdings waren diese deutlich weniger verbindlich. Schließlich zielten auch die Vorgaben des für das Keynes'sche Staatsverständnis und die kritische Strategie nicht so bedeutsamen Bereichs der Allokation auf eine Ausweitung der Interventionsmöglichkeiten. Dies ist jedoch kein Widerspruch, da es in diesem Zeitraum noch nicht bzw. erst in den letzten Jahren beginnend um eine Steigerung von Wettbewerbsfähigkeit ging, sondern eher um eine interventionistische Allokationspolitik, bei der der Staat mit Hilfe von Subventionen den Strukturwandel gestalten und die wachsenden kollektiven (nicht nur privatwirtschaftlichen) Bedürfnisse befriedigen sollte.

Bereits in den späten 1970ern stieg die Skepsis gegenüber staatlichen Interventionen, vor allem im Bereich Stabilisierung und Beihilfen, ab den 1980er Jahren kann man von einem beginnenden Wandel im Staatsverständnis sprechen. In dieser Zeit begann in einigen Politikbereichen die intendierte Einschränkung der Interventionsmöglichkeiten durch europäische Vorgaben; dies war jedoch oft nicht sehr weitgehend, überdies meist vorsichtig formuliert und größtenteils unverbindlich. Insgesamt wurden dem Staat in den 1980ern noch zu viele Aufgaben zugeschrieben, als dass er als zurückhaltend bezeichnet werden kann. Ein solches Staatsverständnis findet sich eindeutig erst ab 1989. Präziser gesagt handelt es sich um ein angebotsökonomisches Staatsverständnis, ein monetaristisches Staatsverständnis lässt sich den Vorgaben zu keinem Zeitpunkt zuordnen. Bei einem angebotsökonomischen Staatsverständnis verfolgen die Mitgliedstaaten mit den europäischen Vorgaben entweder eine affirmative oder eine revisionistische Strategie, d.h. die Vorgaben setzen einer Einschränkung von Interventionsmöglichkeiten (v.a. im Bereich Distribution und diskretionäre Stabilisierungspolitik) nichts entgegen, um auf diese Weise passiv die nationalstaatliche Handlungsfä- 
higkeit zu stärken. Nur im Bereich öffentliche Güter mit allokativer Funktion ist eine Ausweitung von Interventionsmöglichkeiten durch supranationale Zusammenarbeit vorstellbar. Oder es wird - im Sinne einer revisionistischen Strategie - mit den Vorgaben das Ziel verfolgt, die Interventionsmöglichkeiten der Mitgliedstaaten aktiv einzuschränken mit Ausnahme des Bereichs der öffentlichen Güter mit allokativer Funktion, bei dem das gemeinsame Vorgehen eine Ausweitung von Interventionsmöglichkeiten zum Ziel haben kann.

Von 1989 bis zum Ende des Untersuchungszeitraums hatten die Vorgaben weitgehend die Absicht, die Interventionsmöglichkeiten im Bereich Distribution und Stabilisierung einzuschränken, um auf diese Weise die mitgliedstaatliche Handlungsfähigkeit zu stärken. Die intendierte Einschränkung war im Bereich Stabilisierung verbindlicher als bei der Distribution, vollkommen war sie in keinem der beiden Fälle: Der Staat sollte sowohl eine soziale Mindestsicherung garantieren wie in den zwei Wirtschaftskrisen die Nachfrage beleben; beides wurde allerdings nur unverbindlich empfohlen. Feststellbar war eine intendierte Einschränkung jedoch teilweise auch bei den allokativen Aufgaben des Staates: Beihilfen waren verboten, was im Verlauf der Periode strenger durchgesetzt wurde. Bei den öffentlichen Gütern mit allokativer Funktion gab es zwar ein gemeinsames Vorgehen, das die Interventionsmöglichkeiten der Mitgliedstaaten ausweiten sollte, es wurde jedoch auch ein Rückzug des Staates zugunsten privater Bereitstellung der Güter empfohlen. Dies widerspricht allerdings nicht dem angebotsökonomischen Staatsverständnis.

Man kann hierbei insofern von einer revisionistischen Strategie sprechen, als dass die Einschränkung mitgliedstaatlicher Interventionsmöglichkeiten, die vor allem auf die wirtschaftliche Verflechtung, aber auch auf die steigende Staatsverschuldung, die demographische Entwicklung etc. zurückgeführt wurde, nicht einfach nur wohlwollend hingenommen wurde, wie dies im Rahmen der affirmativen Strategie zu erwarten gewesen wäre. Stattdessen hatten die Vorgaben das Ziel, die Einschränkungen weiter zu verstärken. Dies war insbesondere im Bereich der Stabilisierung der Fall, wo die Vorgaben am verbindlichsten waren; aber auch bei den Beihilfen, Sozialausgaben und öffentlichen Gütern mit distributiver Funktion waren die Empfehlungen teilweise recht detailliert. Auf diese Weise hatten die Mitgliedstaaten die Möglichkeit, eine zurückhaltende Politik des Haushaltsausgleichs sowie der Einsparungen im Bereich von Sozialausgaben und Subventionen mit dem Argument der >gebundenen Hände < leichter zu legitimieren und auf diese Weise ihre Handlungsfähigkeit zu stärken. 
Die affirmative Strategie ist in den Vorgaben nicht auffindbar. Nun ließe sich einwenden, ein wohlwollendes Betrachten der Einschränkung von Interventionsmöglichkeiten drücke sich gerade in der Abwesenheit von Vorgaben aus. Auch dies ist jedoch nicht zu beobachten. Da es ab 1971 in jedem Jahr wirtschaftspolitische Leitlinien gab, die alle vier untersuchten Politikfelder umfassten, würde es auffallen, wenn die Vorgaben eines davon nicht ansprächen. Bei den Sozialausgaben ist dies in den 1980ern teilweise der Fall, schaut man sich die verbliebenen Vorgaben jedoch an, zeigt sich kein wohlwollendes Abwarten, sondern eine intendierte Einschränkung von Interventionsmöglichkeiten. Diese Einschränkung sollten die Mitgliedstaaten aktiv (d.h. im Sinne der revisionistischen Strategie) verfolgen, durch eine Senkung ihrer Sozialleistungen zur Erhöhung von Arbeitsanreizen. Die Einschränkung der sozialpolitischen Interventionsmöglichkeiten durch den wirtschaftlichen Wettbewerb wurde hingegen bis in die 1980er Jahre explizit nicht wohlwollend wahrgenommen, wie dies bei der affirmativen Strategie der Fall wäre. Vielmehr forderten die Vorgaben noch 1984, dass die Sozialausgaben nicht als Wettbewerbsfaktor nach innen genutzt werden sollten. Weiterhin wurde auch die Einschränkung der Interventionsmöglichkeiten durch die demographische Entwicklung bzw. die hohe Staatsverschuldung mit Hilfe der Vorgaben noch verstärkt und nicht einfach hingenommen.

Was die Empfehlungen bezüglich der Stabilisierungsaufgaben des Staates angeht, so könnte man durchaus argumentieren, dass in den 1980ern teilweise die affirmative Strategie zum Zuge kam: Die zunehmende Skepsis gegenüber bzw. Kritik an der Staatstätigkeit ging auch damit einher, dass die Vorgaben vager formuliert waren und weniger stark auf eine Wiedergewinnung von Interventionsmöglichkeiten abzielten. Allerdings ging es bis 1989 eben um eine Wiedergewinnung, einen Ausbau und keine Einschränkung von Interventionsmöglichkeiten - was somit eher einer abgeschwächten kritischen Strategie zugeordnet werden sollte. Bei den Beihilfen verließ man sich - als diese als problematisch angesehen wurden - ebenfalls nicht auf das Wirken der Marktkräfte, sondern unterstützte ihren Abbau durch Vorgaben. Allein beim gemeinsamen Vorgehen zur Bereitstellung öffentlicher Güter mit allokativer Funktion kann man nicht unterscheiden, ob es sich um eine revisionistische oder eine affirmative Strategie handelt, da hier beide Positionen eine Ausweitung von Interventionsmöglichkeiten durch eine supranationale Kooperation vorschlagen. 


\section{Der Wandel im SPIEgel DeR EuRopäischen VORGABEN UND VERFAHREN}

Wie im vorangegangenen Kapitel zusammenfassend gezeigt wurde, ist im Verlauf der europäischen Integration ein deutlicher Wandel zu beobachten: Von einem Keynes'schen zu einem angebotsökonomischen Staatsverständnis und damit einhergehend von einem intendierten Ausbau der nationalstaatlichen Interventionsmöglichkeiten zu ihrer Einschränkung durch europäische Vorgaben im Bereich der Ausgabenpolitik. Die ausführliche, analytische Darstellung des Wandels sowohl der intentionalen Beeinflussung der nationalstaatlichen Handlungsfähigkeit durch die europäischen Vorgaben als der ihnen zugrunde liegenden Staatsverständnisse, wirft sicherlich mindestens ebenso viele Fragen auf, wie sie beantwortet - was durchaus im Sinne einer solchen Arbeit liegt. Eine der großen Fragen, die sich nach der Lektüre dieser Arbeit stellt, ist sicherlich die nach den Gründen für diesen Wandel. Groß ist auch die Versuchung, sich dieser Frage nun anzunehmen, gerade auf Basis des ausgewerteten Materials und der daraus gewonnenen Erkenntnisse. Zurück hält die Einsicht, dass die möglichen Antworten entweder den Umfang einer weiteren Dissertation annehmen müssten oder aber unbefriedigend blieben. Am Ende dieser Arbeit steht daher nicht der Versuch, neue Fragen $\mathrm{zu}$ beantworten, sondern ein neuer Blick auf die empirischen Ergebnisse - aus einem gewissen Abstand.

Dieser Abstand wird im ersten Schritt durch die Hinzuziehung einer theoretischen Einordnung von Wandlungsprozessen gewonnen. Hierfür wird auf den bekannten Ansatz von Peter Hall (1992; 1993) zurückgegriffen. Hall beschäftigt sich mit dem Wandel wirtschaftspolitischer Paradigmen, sowohl unter klassifikatorischen Gesichtspunkten als auch 
mit Blick auf den Prozess des Wandels. Seine Klassifikation (für das Folgende Hall 1993: 278ff) bezieht sich auf die drei seines Erachtens zentralen Variablen des Politikprozesses: übergreifende Ziele, Instrumente und die Anpassung dieser Instrumente. Hall unterscheidet darauf bezogen drei Formen bzw. Ebenen des Wandels: First order, second order und third order change. Ein Wandel erster Ordnung beschreibt die unterste bzw. erste Stufe des Wandels, bei der die Instrumente neu justiert werden, wobei die Instrumente selbst wie auch die Ziele gleich bleiben. Als Wandel zweiter Ordnung wird die Entwicklung neuer oder Abschaffung alter Instrumente, die ohne eine Änderung der Ziele vonstatten geht, bezeichnet. Ein Wandel dritter Ordnung umfasst schließlich die Änderung aller drei Politikvariablen, d.h. der Ziele bzw. ihrer Hierarchie, der Instrumente sowie ihrer Anpassungen. Hall spricht in diesem Fall auch von einem Paradigmenwandel. Ein Wandel auf dieser höchsten Stufe umfasst immer auch einen auf den darunter liegenden, umgekehrt gilt jedoch nicht, dass ein Wandel der Instrumenteneinstellungen notwendig zu einer Veränderung der Instrumente führt oder diese zu einem Wandel der Ziele.

Hinsichtlich des Prozesses des Wandels differenziert Hall (1993: 280ff) ebenfalls zwischen den Ebenen: Wenn Instrumente angepasst werden, ist der Wandel inkrementell, es handelt sich um relativ routinierte Entscheidungen. Ein Wandel zweiter Ordnung geht ein Stück weiter in Richtung strategisches Handeln. Während ein Wandel auf diesen beiden Ebenen ein Fall von »normaler Politik« ist, bei dem gewisse Kontinuitäten beibehalten werden, ist ein Wandel dritter Ordnung radikal, diskontinuierlich. Hall stellt ihn - in Anlehnung an Kuhn (1962), der den Wandel von Paradigmen in der Wissenschaft beschrieben hat folgendermaßen dar:

»[T]he movement from one paradigm to another that characterizes third order change is likely to involve the accumulation of anomalies, experimentation with new forms of policy, and policy failures that precipitate a shift in the locus of authority over policy and initiate a wider contest between competing paradigms. This contest may well spill beyond the boundaries of state itself into the broader political arena. It will end only when the supporters of a new paradigm secure positions of authority over policymaking and are able to rearrange the organization and standard operating procedures of the policy process so as to institutionalize the new paradigm« (Hall 1993: 280f).

Zu Beginn des Wandels müssen sich demnach Anomalien finden, die mit dem vorherrschenden Paradigma nicht erklärbar sind. Wird weiterhin am alten Paradigma festgehalten, kommt es zu fehlerhaften Progno- 
sen und inadäquaten Politikentscheidungen (Hall 1992: 104). Dann beginnt eine Phase des Experimentierens, die die intellektuelle Kohärenz des alten Paradigmas überstrapaziert und es auf diese Weise zusätzlich diskreditiert. Schließlich bildet sich ein neues Paradigma heraus, es beginnt ein Kampf um Deutungshoheit, Autoritäten und Politikverfahren, bis das neue Paradigma institutionalisiert ist (Hall 1993: 285ff).

Dass es sich bei der in dieser Arbeit beschriebenen Entwicklung mit Blick auf den Inhalt der Vorgaben - um einen Wandel dritter Ordnung handelt, den Übergang von einem europäisch unterstützten Keynes'schen zu einem europäisch geförderten angebotsökonomischen Staatsverständnis, ist bereits in den vorangegangen Kapiteln, insbesondere Kapitel 5, deutlich geworden. Beließe man den Fokus auf dem Inhalt der Vorgaben, könnte man den Wandel zwar mit Hilfe der Hall'schen Klassifizierung noch stärker systematisieren, es bestünde jedoch die Gefahr der Redundanz. Daher soll im Folgenden nicht nur eine theoretische Distanz zu den bisher gewonnenen Erkenntnissen erreicht, sondern auch insofern ein Schritt von ihnen weg (und damit eventuell über sie hinaus) gemacht werden, als dass nicht der Inhalt der Vorgaben, sondern die Vorgaben, als Instrumente bzw. Koordinierungsverfahren der europäischen Ebene, selbst in den Mittelpunkt der Betrachtung gestellt werden. Dabei geht es hauptsächlich um ihre Form bzw. Ausgestaltung: Wie ausführlich waren sie, welche Bereiche deckten sie ab, wie oft wurden sie angepasst, mit welcher Verbindlichkeit ausgestattet etc. Die Fragen, die in diesem abschließenden Kapitel beantwortet werden sollen, lauten demnach: Wie stellt sich der im Verlauf der europäischen Integration beobachtete Prozess des Paradigmenwandels mit Blick auf die europäischen Vorgaben und Koordinierungsverfahren dar? Wann und wie wurden diese im Sinne eines Wandels erster Ordnung, angepasst/geändert, wo handelte es sich um eine darüber hinausgehende Änderungen der Instrumente und Verfahren (Wandel zweiter Ordnung) und schließlich der Ziele? Wie ist der Paradigmenwandel zu beschreiben, lässt sich der von Hall diagnostizierte Verlauf bzw. Prozess des Wandels von den Anomalien und Politikfehlern bis hin zur Institutionalisierung des neuen Paradigmas durch die Neugestaltung der Arbeitsabläufe auch in den europäischen Verfahren und Vorgaben wiederfinden? Den Fokus auf die Form bzw. Ausgestaltung der europäischen Vorgaben und Verfahren zu legen ist auch von daher sinnvoll, als dass eine Beschreibung des Integrationsprozesses anhand dieser, der intentionalen Beeinflussung von Handlungsfähigkeit, eher ungewöhnlich ist und aus diesem Grund am Ende der Arbeit durchaus noch einmal deutlich herausgestellt werden sollte. 


\subsection{Kurze Darstellung des Wandels anhand des Inhalts der Vorgaben}

Da die Vorgaben nicht losgelöst von ihrem Inhalt beschrieben werden können, sei hier - vor dem Hintergrund des ausführlichen 5. Kapitels noch einmal sehr kurz der entsprechende Wandel anhand der Hall'schen Klassifikation dargestellt: Die übergreifenden allokationspolitischen Ziele waren zu Beginn der Integration die Schaffung eines gemeinsamen Marktes sowie die staatliche Gestaltung und soziale Abfederung des hierdurch verstärkten Strukturwandels. Als Instrumente wurden Erhaltungssubventionen, Beihilfen für produktive Sektoren und öffentliche Güter, insbesondere im Bereich der beruflichen Bildung, Forschung und Entwicklung sowie Verkehrsinfrastruktur, empfohlen. Letztere sollten allerdings auch - und zum Teil sogar in erster Linie - die »kollektiven Bedürfnisse « befriedigen. Bereits in der ersten Periode beginnt bei den Beihilfen ein Wandel zweiter Ordnung: Zuerst wurden die Erhaltungsund Umstellungsbeihilfen (fast vollständig) verboten, später, in der zweiten Periode, auch die Subventionen für produktive Sektoren. Der Strukturwandel sollte ab Mitte der 1980er Jahre weitgehend dem Markt überlassen werden und durch den Staat nur noch indirekt, in Form der Bereitstellung öffentlicher Güter, unterstützt werden. Bei diesen Gütern wurde zunehmend Wert auf ihre wachstumsschaffenden Effekte und die Möglichkeit einer privaten Bereitstellung gelegt, beides kann als Wandel erster Ordnung klassifiziert werden. Ziel der staatlichen Aktivität war schließlich nicht mehr die Gestaltung des Strukturwandels und die Befriedigung der kollektiven Bedürfnisse, sondern die Schaffung einer guten Basis für die (privat-)wirtschaftliche Entwicklung im Binnenmarkt und die Wettbewerbsfähigkeit der europäischen Unternehmen.

Im Bereich Distribution stand in den ersten drei Jahrzehnten der Integration die Verbesserung der Lebensbedingungen aller im Zentrum der Anstrengungen. Als Instrumente wurden die Sozialversicherungen und öffentliche Güter wie Gesundheitsversorgung genannt. Auf der Ebene der Instrumentenanpassung forderten die europäischen Vorgaben beispielsweise einen Ausbau sowie eine stärkere Umverteilungswirkung der Sozialsysteme. Der Wandel begann auf dieser ersten Ebene: Die Vorgaben empfahlen ab den 1980er Jahren zunehmend Kürzungen im Gesundheitssystem und einen Abbau von Sozialleistungen. Ein Wandel zweiter Ordnung wurde ab Mitte der 1990er Jahre bei den Rentensystemen angestrebt, die teilprivatisiert werden sollten, insbesondere mit Blick auf die befürchtete Staatshaushaltsbelastung in Folge der demographischen Entwicklung. In diesem Zeitraum gab es auch Änderungen auf der dritten Ebene, indem das Ziel nicht mehr die Verbesserung der 
Lebensverhältnisse aller war, sondern nur mehr Armut vermieden werden sollte und ansonsten auf Beschäftigung und Wachstum zur Lösung der sozialen Probleme gesetzt wurde. Letzteres sollte über eine anreizfördernde Anpassungen der Sozialsysteme erreicht und gefördert werden (Wandel erster Ordnung).

$\mathrm{Zu}$ Beginn der Integration kam der Stabilisierung der Konjunktur eine große Bedeutung zu, als Instrumente wurden eine diskretionäre Nachfragesteuerung und deficit spending empfohlen. Dies sollte - auch hier wieder auf der (ersten) Ebene der Instrumentenanpassung - zunehmend regelgeleiteter gestaltet und eingeschränkt werden, was in eine Änderung der Instrumente selbst überging: Die Vorgaben empfahlen ab der zweiten Periode immer öfter automatische Stabilisatoren als angemessene Reaktion auf konjunkturelle Schwankungen, Haushaltsdefizite wurden immer negativer gesehen und schließlich weitgehend verboten. Damit einher ging eine Änderung der Ziele: Anstelle der Konjunktur sollte der Staat nun das Preisniveau stabilisieren.

\subsection{Darstellung des Wandels anhand der europäischen Vorgaben und Verfahren}

Im Folgenden wird der bisher hauptsächlich am Inhalt der Vorgaben festgemachte Wandel im Spiegel der europäischen Vorgaben und Koordinationsverfahren betrachtet. Der Hall'schen Klassifikation folgend werden diese als die Instrumente betrachtet, mit denen das jeweils vorherrschende Paradigma erreicht werden sollte. Demnach wird danach gefragt, wo und wie ein Wandel erster Ordnung (Anpassung der Form der Vorgaben bzw. Verfahren) und zweiter Ordnung (Neuentwicklung bzw. Abschaffung von Koordinierungsverfahren bzw. Vorgabenformen) stattgefunden hat. Die Veränderungen und Anpassungen sind selbstverständlich nicht ausschließlich durch einen Wandel des vorherrschenden Paradigmas zu erklären. So haben sicherlich auch die Vorbereitungen zur WWU I und II oder ähnliches eine Rolle gespielt, der Fokus soll jedoch dem Hall'schen Schema folgend auf dem Paradigmenwandel liegen. Andere Gründe für einen Wandel in der Form der Verfahren und Vorgaben werden im Folgenden daher nur implizit einbezogen, indem sie oft ebenfalls als Ausdruck oder Bestandteil des Paradigmas betrachtet werden können. Überdies wird ein gewisser Abstraktionsgrad bewahrt, so dass Gründe wie kleinere wirtschaftliche Krisen nicht berücksichtigt werden müssen. Dies ist auch insofern vertretbar, als dass die speziellen Gründe für die europäische Zusammenarbeit in den Kapiteln 4.2-4.5 ausführlich dargelegt wurden. 


\section{Blütezeit des alten Paradigmas}

Für die erste Periode (1957-1980) wurde in dieser Arbeit ein eindeutig Keynes'sches Staatsverständnis festgestellt. Dessen Handlungsfähigkeit sollte durch einen europäisch unterstützten (Wieder-)Ausbau von (national-)staatlichen Interventionsmöglichkeiten gestärkt werden, insbesondere im Bereich Distribution und diskretionäre Stabilisierung. Dies wurde in Kapitel 5.4 als die damals vorherrschende (kritische) Strategie bezeichnet, die man Hall folgend auch Paradigma nennen kann. Die Instrumente, mit denen diese übergreifenden Ziele erreicht werden sollten, die europäischen Vorgaben bzw. Koordinationsverfahren, nahmen ab Mitte der 1960er Jahre Form an, zuvor war die nationale Ausgabenpolitik kaum koordiniert. Zu Beginn ging es hauptsächlich um eine europäische Förderung der mitgliedstaatlichen Interventionsmöglichkeiten im Bereich der kurzfristigen Stabilisierung. Bereits 1959 sprach der Rat sich dafür aus, die Konjunkturpolitik europäisch zu koordinieren (Rat 1959: 40). 1964 wurde die erste Vorgabe zu diesem Thema verabschiedet (64/ 246/EWG), in den Jahren 1965-68 folgten jährlich sogenannte »Leitlinien der Konjunkturpolitik «, die aber nur einen sehr geringen Umfang von ein bis zwei Seiten hatten (65/192/EWG; 66/736/ EWG; 67/452/EWG; 68/147/EWG). Trotz der jeweils recht ähnlichen Titel handelte es sich hierbei nicht um ein feststehendes Koordinationsverfahren, Basis war lediglich der konjunkturpolitische Artikel 103 EWGV.

Im gleichen Zeitraum wurde auch mit der Zusammenarbeit im Bereich der mittelfristigen Wirtschaftspolitik begonnen. 1964 beschloss der Rat ein entsprechendes Koordinationsverfahren (64/247/EWG), das 1. Programm für die mittelfristige Wirtschaftspolitik wurde 1967 verabschiedet (67/264/EWG) und 1969 durch das 2. Programm aktualisiert und ergänzt (69/157/ EWG). Die Programme waren breit angelegt und umfassten alle in dieser Arbeit untersuchten Politikfelder. Für die Bereiche Allokation und Distribution wurden - deshalb und weil man sich erst in den Anfängen des gemeinsamen Vorgehens befand - in den 1960er Jahren kaum separate Vorgaben verabschiedet.

Ende der 1960er/Anfang der 1970er Jahre einigte man sich schließlich auch darauf, die Koordinierung der kurzfristigen Wirtschaftspolitik auszubauen und zu formalisieren, was eine noch stärkere Unterstützung der nationalstaatlichen Interventionsmöglichkeiten durch die europäische Ebene ermöglichte: 1969 wurden Konsultationen eingeführt, die zwingend vor solchen mitgliedstaatlichen Entscheidungen durchgeführt werden mussten, die von den gemeinsam festgelegten Zielen abwichen oder Auswirkungen auf die anderen Mitgliedstaaten haben konnten (69/ 227/EWG: 41). Das hierfür verabschiedeten Verfahren wurde in den bei- 
den Folgejahren präzisiert bzw. strenger gefasst (Rat 1970; 70/C 136/19; 72/C 38/03). Weiterhin verabschiedete der Rat 1971 ein Verfahren zur Koordinierung der kurzfristigen Wirtschaftspolitik (71/141/EWG): Im Rahmen von drei jährlichen Prüfungen der wirtschaftlichen Lage wollte er Leitlinien für die kurzfristige Wirtschaftspolitik der Mitgliedstaaten und qualitative Orientierungsdaten für die öffentlichen Haushalte festlegen (ebenda, Art. 3 bzw. 4). Die »Jahresberichte über die Wirtschaftslage der Gemeinschaft« lösten die konjunkturpolitischen Leitlinien der Vorjahre $a b$ und umfassten neben der Stabilisierungspolitik auch Empfehlungen $\mathrm{zu}$ den anderen beiden Interventionsbereichen. Sie wurden jährlich verabschiedet, mit der Möglichkeit der zwischenzeitlichen Anpassung, die jedoch in den Anfangsjahren nicht genutzt wurde.

Die beschriebenen Entwicklungen bei den Vorgaben und Verfahren, hauptsächlich Wandlungen zweiter, aber auch erster Ordnung, können als Institutionalisierung des vorherrschenden Paradigmas bezeichnet werden. Der Ansatz der mittelfristigen Programme - der Staat soll in allen drei Interventionsbereichen mittelfristig planend und steuernd in den Markt eingreifen - war Ausdruck der Keynes'schen Vorstellung, der Staat könne und solle diese Aufgaben (europäisch unterstützt) wahrnehmen. Gleiches gilt für den Bereich der kurzfristigen Wirtschaftspolitik, bei der die staatlichen Interventionen (in zunehmend formalisierten Verfahren) europäisch gefördert wurden. Ein besonders gutes Beispiel für die Institutionalisierung des Paradigmas ist die Koordinierung der diskretionären Stabilisierung: Diese ist bei Keynes eine wichtige Aufgabe des Staates, welche er, so wurde befürchtet, aufgrund der zunehmenden wirtschaftlichen Verflechtung weniger gut wahrnehmen konnte, weshalb man europäisch gegensteuern wollte - in Form der konjunkturpolitischen Leitlinien und später der an ihre Stelle getretenen Jahresberichte.

Insgesamt wurde die Koordinierung in den 1960er Jahren als erfolgreich angesehen. Dies lässt sich zum einen an ihrer Zunahme und der Formalisierung der Verfahren festmachen. Zum anderen zeigte sich der Erfolg daran, dass keine Unzufriedenheit über die Umsetzung der Vorgaben geäußert wurde. Dies könnte unter anderem darin begründet liegen, dass - zumindest ab der Mitte der 1960er Jahre, als die Koordinierung richtig beginnt - »die wirtschaftlichen und sozialen Ziele, die den Maßnahmen der Regierungen der Mitgliedstaaten zugrunde liegen, die gleichen sind« (Rat 1967: 49). 


\section{Anomalien und Politikexperimente: Der Beginn des Wandlungsprozesses}

Ein Wandel des Paradigmas beginnt laut Hall (1993: 285) oft mit einer Änderung der ökonomischen Lage. Dies trifft auch im Untersuchungszeitraum zu: Anfang der 1970er Jahre ist bereits eine Wachstumsabschwächung mit steigenden Inflationsraten zu verzeichnen, die Ölkrise von 1973 beendete den Nachkriegsboom endgültig. Überdies wurde das internationale Umfeld in dieser Zeit - Stichwort Ende von Bretton Woods - deutlich instabiler. Gleichzeitig äußerte das 3. Programm für die mittelfristige Wirtschaftspolitik zum ersten Mal Kritik an der bisherigen Koordinierung: »Die Interdependenz zwischen den Mitgliedsländern hat sich weit schneller verstärkt als die Annäherung ihrer Verhaltensweisen, ihrer Zielsetzungen und ihrer Politik« (71/ 107/EWG: 8). Die Gemeinschaft reagierte auf die neue Situation zuerst mit einer stärkeren Formalisierung, einer besseren Verknüpfung und einer Erhöhung der Verbindlichkeit der Koordinationsverfahren: In der Entscheidung zur Erreichung eines hohen Grades an Konvergenz der Wirtschaftspolitik (74/120/EWG) wurden die bisherigen Koordinationsverfahren gemeinsam aufgeführt, im gleichen Jahr wurden die Ausschüsse für Konjunkturpolitik, Haushaltspolitik und mittelfristige Wirtschaftspolitik zum »Ausschuss für Wirtschaftspolitik« zusammengefasst, um die Koordinierung der kurz- und mittelfristigen Wirtschaftspolitik zu fördern (74/ 122/EWG, Art. 1). Dies änderte - mit Ausnahme der Ausschusszuständigkeiten - nichts an den Erstellungs- und Überprüfungsverfahren der Leitlinien. Allerdings wurde durch die genannte Entscheidung die Möglichkeit verbindlicher Vorgaben für die Koordinierung der mittelfristigen Wirtschaftspolitik geschaffen ${ }^{116}$ (74/120/EWG, Art. 6). Eine solche Richtlinie wurde noch am gleichen Tag verabschiedet (74/121/EWG). Sie verpflichtete die Mitgliedstaaten auf die Einhaltung der europäischen Vorgaben für die kurz- und mittelfristige Wirtschaftspolitik und schrieb ihnen vor, im Rahmen der Koordinierung der diskretionären Konjunkturpolitik ein angemessenes Instrumentarium bereitzuhalten und einen schnellen Einsatz zu ermöglichen (ebenda, Art. 5-7). Das Instrument der Richtlinie war zuvor nur einmal, während der französischen Krise von 1968, genutzt worden. Schließlich wurden auch die Konsultationen verschärft, indem beim Rat eine ständige Gruppe hierfür eingerichtet (72/C 38/03: 3) und kurz darauf permanente Konsultationen vorgeschrieben wurden (74/120/EWG, Art. 9).

116 Für die Konjunkturpolitik war diese Möglichkeit vertraglich gegeben, Art. 103, Abs. 3 EWGV. 
Diese Veränderungen lösten jedoch nicht den Interessenkonflikt, der sich aus der veränderten wirtschaftlichen Situation ergab: Um die Krise besser bewältigen zu können, erschien eine Koordination der einzelstaatlichen Maßnahmen als besonders sinnvoll. Ein solches gemeinsames Vorgehen wurde jedoch gleichzeitig durch die schlechtere ökonomische Lage erschwert, da jedes Land zuerst an seine eigene Wirtschaft und damit eher protektionistisch dachte, ein koordiniertes, solidarisches Vorgehen hingegen erst in zweiter Linie in Betracht zog. Von daher ist es in einer solchen Situation nicht sehr wahrscheinlich, dass sich die Mitgliedstaaten stärker auf eine bestimmte Politik festlegen (lassen). Dies kann eine Erklärung dafür sein, dass nach 1974 keine weiteren verbindlichen Vorgaben erlassen und damit die neu geschaffenen Möglichkeiten nicht genutzt wurden. Stattdessen wurde das bestehende Instrumentarium insbesondere die Jahresberichte und die Programme für die mittelfristige Wirtschaftspolitik - angepasst: Die Vorgaben wurden zunehmend differenziert, um so die regionale sowie konjunkturelle Situation besser zu berücksichtigen. Ersteres drückte sich darin aus, dass die Empfehlungen öfter auf die Situation in den einzelnen Ländern zugeschnitten wurden, ohne dabei jedoch das Ziel aufzugeben, sich bei den wirtschaftspolitischen Zielen weiter anzunähern (75/C 297/01: 8). Bei der mittelfristigen Politik ging man von dem im 3. Programm (71/107/EWG) angewandten Instrument der Länderleitlinien allerdings bereits im 4. Programm (77/ 294/EWG) wieder ab, legte aber weiterhin nach Ländern aufgeschlüsselte Orientierungsdaten und Empfehlungen fest.

Die bessere Berücksichtigung der konjunkturellen Situation sollte durch eine schnellere Anpassung der Vorgaben gewährleistet werden. Die Ratstreffen zur Begutachtung der wirtschaftlichen Lage wurden von drei auf zwölf ausgeweitet (74/120/EWG, Art. 1), sichtbares Ergebnis war eine häufigere Änderung der Jahresberichte: in den Jahren 1974 und 1975 je einmal, in den beiden Folgejahren zweimal, 1978 wiederum nur einmal. Die zunehmende räumliche und zeitliche Differenzierung der europäischen Vorgaben ging jedoch mit einer Verminderung von quantifizierten Zielen einher. Interessant ist in diesem Zusammenhang, dass hauptsächlich das bestehende Instrumentarium genutzt wurde, zusätzliche Vorgaben gab es nur sehr selten, hauptsächlich im Bereich der Beihilfen für bestimmte Sektoren, überdies wurde 1974 das erste sozialpolitische Aktionsprogramm verabschiedet (74/C 13/01).

Trotz dieser Anpassungen wurde das gemeinsame Vorgehen als unzureichend empfunden und beschrieben. So stellte der Jahresbericht von 1977 fest, dass die Länder selbst den auf sie zugeschnittenen Empfehlungen nicht gefolgt waren und verstärkt protektionistische Verhaltensweisen an den Tag legten (77/778/EWG: 3 bzw. 13). Auch wurde das 3. 
Programm für die mittelfristige Wirtschaftspolitik als Misserfolg bewertet: »Das Ziel einer Wachstums- und Stabilitätsgemeinschaft wurde nicht erreicht, die Wirtschafts- und Währungsunion stagnierte und die Gemeinschaft war unfähig, gemeinsame konstruktive Antworten auf die mit der Krise zusammenhängenden Fragen zu finden« (77/294/EWG: 9). Den immer wieder angesprochenen notwendigen Verbesserungen bzw. Verstärkungen der Koordinierung folgten keine Taten, 1979 verabschiedete der Rat noch einmal eine Entschließung, in der er die Kommission aufforderte, Vorschläge zu einer weiteren Verbesserung der Konsultationen und einer stärkeren Verpflichtung der Mitgliedstaaten auf die gemeinsamen Empfehlungen vorzulegen (Rat 1979: 81f), von ihm gingen jedoch keine weiteren Initiativen aus.

Man kann somit für die 1970er Jahre von einem deutlichen Wandel erster Ordnung sprechen. Die bestehenden Instrumente wurden angepasst, zuerst in Form einer stärkeren Formalisierung und Verbindlichkeit, dann durch eine zunehmende Differenzierung. Der Wandel blieb allerdings weitgehend auf dieser Ebene, zwar wurde 1974 die Grundlage für die Einführung neuer Instrumente geschaffen, was einem Wandel zweiter Ordnung entsprechen würde, diese wurde jedoch nur einmal, mit der Richtlinie aus dem gleichen Jahr, genutzt. Erfolg war den beschriebenen Reaktionen auf die aufgetretenen Anomalien - Hall (1993: 280) würde von Experimenten sprechen - nicht beschieden. Dies schien auch der Rat zu merken, der in seinen Bemühungen um eine Anpassung der Instrumente zum Ende der 1970er Jahre nachließ, wenngleich er es immer noch für notwendig erklärte, die Koordinierung zu verstärken.

\section{Herausbildung des neuen Paradigmas}

Die Jahre 1981 bis 1989 wurden in der Arbeit als eine Periode des Wandels charakterisiert. Dies trifft nicht nur auf den Inhalt der Vorgaben zu, sondern auch auf ihre Form. In dieser Zeit wurde der Wandel erster Ordnung fortgesetzt, darüber hinaus erfolgte ein Wandel zweiter Ordnung, d.h. eine Änderung auf Ebene der Instrumente. Markantestes Beispiel sind die Programme für die mittelfristige Wirtschaftspolitik: Nachdem diese Art der Koordination bereits im 4. Programm (mit Blick auf das 3.) als Misserfolg bezeichnet worden war, ging es beim 5. Programm nur mehr dem Titel nach um Vorgaben für die mittelfristige Wirtschaftspolitik. In dem 1982 verabschiedeten, zwei Seiten umfassenden Dokument wurde lediglich festgehalten, dass man sich auf die Ziele Wachstum, Beschäftigung und Inflationsbekämpfung einigen könne, nicht jedoch auf eine Rangfolge zwischen diesen oder Strategien zu ihrer Erreichung (82/ 534/EWG: 11). Konsequenterweise wurden keine weiteren Programme 
dieser Art verabschiedet. Die Differenzen zwischen den Mitgliedstaaten in Bezug auf die >richtige< wirtschaftspolitische Strategie wurden Anfang der 1980er Jahre auch in den Jahresberichten thematisiert.

An diesen Entwicklungen kann man erkennen, dass sich (zumindest auf Ebene der Mitgliedstaaten) neben dem alten bereits immer klarer ein neues Staatsverständnis herauskristallisierte, welches eine europäische Unterstützung erforderte - ein neues Paradigma nahm Form an. Dies erschwerte eine Einigung zwischen den Mitgliedstaaten auf ein gemeinsames Vorgehen deutlich und führte zu einer entsprechenden Unzufriedenheit mit der europäischen Koordination der Wirtschaftspolitik (z.B. 82/950/EWG: 5). Ab Mitte der 1980er Jahre schien sich das neue Staatsverständnis jedoch in immer mehr Ländern durchzusetzen, es wurde eine immer größere Konvergenz der wirtschaftspolitischen Ausrichtung der Mitgliedstaaten festgestellt (z.B. 85/619/EWG: 33), die aber, so z.B. der Jahresbericht von 1988, noch weiter ausgebaut werden müsse. Der für die Koordinierung notwendige »Konsens über die Grundlinien der [...] Wirtschaftspolitik« (88/655/EWG: 30) sollte unter anderem durch das koordinierte Vorgehen weiter gestärkt werden - was selbiges im Umkehrschluss aber auch wieder erleichterte, da man sich einfacher auf gemeinsame Strategien einigen konnte.

Das europäische Vorgehen erfolgte in dieser Periode zum einen über die Jahresberichte, dem einzigen etablierten Koordinationsverfahren dieser Zeit. Sie wurden weiterhin einmal im Jahr vom Rat verabschiedet, es gab allerdings - mit Ausnahme von 1983 - keine Zwischenanpassungen mehr. Dafür nahm der Umfang der Jahresberichte zu, unter anderem, weil sie zunehmend Aspekte der mittelfristigen Wirtschaftspolitik mit einbezogen. Zusätzlich zu diesem Leitlinienverfahren wurden in den 1980er Jahren zahlreiche Vorgaben zur Beschäftigungspolitik verabschiedet. Daraus lässt sich schließen, dass es sich bei der Arbeitslosigkeit um ein zentrales Problem dieser Jahre handelte und dass man sich in diesem Bereich leichter einigen konnte. Bereits 1980 waren zum ersten Mal Leitlinien zur Arbeitsmarktpolitik verabschiedet worden (80/C 168/01), ohne jedoch ein spezielles Koordinierungsverfahren einzuführen. Auch hier könnte man im Hall'schen Sinne von »Politikexperimenten« sprechen. Die übrigen Vorgaben in diesem Bereich waren ebenfalls unverbindlich und unverbunden, es handelte sich hauptsächlich um Entschließungen des Rates. Die Strategie, auf die man sich bei der Lösung des Beschäftigungsproblems einigen konnte, war demnach nicht so sehr ein mittelfristiges makroökonomisch ausgerichtetes Gesamtkonzept (was man auch am Fehlen weiterer Programme für die mittelfristige Wirtschaftspolitik festmachen kann), sondern stärker punktuell, bei be- 
stimmten Gruppen ansetzend, mikroökonomisch. Auch hier scheint demnach bereits das neue Paradigma auf.

Insgesamt kann man für die zweite Periode davon sprechen, dass der Paradigmenwandel voranschreitet bzw. an Deutlichkeit gewinnt. Nach den Anomalien, Politikfehlern und ersten Experimenten in den 1970ern auf der Ebene der Instrumentenanpassung fanden sich in diesen Jahren weitere Experimente, auch auf der zweiten Ebene der Instrumente (insbesondere im Bereich der Beschäftigungspolitik). Die europäischen Vorgaben hatten weniger als in den vorangegangenen Jahren das Ziel, nationalstaatliche Eingriffe in die Wirtschaft und damit ein Keynes'sches Staatsverständnis zu stützen, vielmehr ging es teilweise bereits darum, diese Interventionen europäisch zu verhindern. Dass sich das neue Paradigma in den 1980er Jahren noch nicht vollständig durchsetzen konnte, lässt sich unter anderem an der Einheitlichen Europäischen Akte, der ersten Revision des EWG-Vertrags, festmachen, die weiterhin an dem Artikel zur Koordinierung der Konjunkturpolitik festhielt und im Bereich der staatlichen Ausgabenpolitik kaum relevante Änderungen festschrieb.

\section{Durchsetzung und Institutionalisierung des neuen Paradigmas}

Bereits zu Anfang dieser die Jahre 1990 bis 2004 umfassenden dritten Periode vollzieht sich der Wandel dritter Ordnung. Das neue Paradigma kann - auch dies wieder in Anlehnung an die in 5.4 dargelegte (revisionistische) Strategie - als eine europäisch forcierte Einschränkung (national-)staatlicher Interventionsmöglichkeiten in den Bereichen Distribution und diskretionäre Stabilisierung zur Stützung eines angebotsökonomischen Staatsverständnisses bezeichnet werden. Der Paradigmenwandel lässt sich insbesondere an zwei Ereignissen festmachen: 1990 wurde die bisherige Grundlage zur Koordinierung der kurz- und mittelfristigen Wirtschaftspolitik von 1974 ersetzt (90/141/EWG). Wesentliche Neuerungen waren, dass die Programme für die mittelfristige Wirtschaftspolitik nun auch formal abgeschafft wurden, ebenso wie die Möglichkeit, verbindliche Richtlinien zur Koordinierung in diesem Bereich zu erlassen. Das zweite - für die Festschreibung des neuen Paradigmas noch bedeutsamere - Ereignis führte dies fort: Der konjunkturpolitische Artikel 103 wurde nicht in den EG-Vertrag von Maastricht übernommen, wodurch auch für die kurzfristige Wirtschaftspolitik das Instrument der Richtlinien entfiel. Dafür wurde das Ziel der Haushaltsdefizitbegrenzung nicht nur vertraglich festgeschrieben, sondern auch mit sschmerzhaften S Sanktionen versehen, sowohl im Rahmen der Konvergenzkriterien (Art. 109j EGV-M) als auch in einem eigenständigen Arti- 
kel (104c EGV-M). In beiden Fällen handelt es sich um einen Wandel zweiter Ordnung.

In den Folgejahren lässt sich sehr schön eine Institutionalisierung des neuen Paradigmas beobachten, die Hall (1993: 209) als »rearrange[ment of] the organization and standard operating procedures of the policy process « bezeichnet. Diese Neugestaltung umfasste sowohl einen Wandel auf Ebene der Instrumente als auch in ihrer Anpassung:

Der Wandel zweiter Ordnung manifestierte sich zum einen in wichtigen Einzelentscheidungen, zum anderen in einer Reihe von umgestalteten bzw. neuen Koordinierungsverfahren. Was ersteres betrifft, so sind vor allem die Entscheidungen zur Haushaltskonsolidierung aus dem Jahr 1997 hervorzuheben. Mit der Entschließung des Europäischen Rates über den Stabilitäts- und Wachstumspakt (97/C 236/01) waren zwei Verordnungen verbunden. Das bedeutet, dass in diesem Jahr nach langer Zeit wieder rechtlich verbindliche Vorgaben im Bereich der Stabilisierung verabschiedet wurden (VO 1466/97; VO 1467/97). Im Gegensatz zu den beiden Richtlinien aus der ersten Periode ging es diesmal jedoch nicht um eine expansive, diskretionäre Stabilisierungspolitik, im Gegenteil, die beiden Verordnungen festigten das vertraglich vorgeschriebene Ziel des Haushaltsausgleichs durch eine Präzisierung des Überwachungs- und Sanktionsverfahrens. An der Verbindlichkeit dieser Vorgaben lässt sich festmachen, dass es sich hierbei um eines der zentralen Themen dieser Periode handelte, welches sehr gut zum vorherrschenden Paradigma passte: Die staatliche Zurückhaltung im Bereich der diskretionären Stabilisierung wurde europäisch eingefordert und damit gestützt.

Die Neugestaltung bzw. Neueinführung von Koordinierungsverfahren begann bereits mit der oben beschriebenen Entscheidung von 1990. Vier Jahre später, 1994, wurden die dort noch aufgeführten Jahresberichte durch die »Grundzüge der Wirtschaftspolitik« ersetzt. Das Erstellungsverfahren, welches nun auch vertraglich festgelegt wurde, blieb weitgehend gleich, bei der Überwachung der Umsetzung wurde die Möglichkeit eingeführt, dass der Rat gegenüber jenen Mitgliedstaaten, die sich nicht an die Vorgaben halten, eine Empfehlung ausspricht, die in einem weiteren Schritt veröffentlicht werden konnte (Art. 99 EGV). Dieses - wenn auch eher milde - Sanktionsverfahren erhöhte die Verbindlichkeit der Koordinierung in diesem Bereich.

Auch im Rahmen der Beschäftigungspolitik einigte man sich nach zahlreichen Einzelvorgaben sowie der Einführung von »Mehrjahresprogrammen« durch den Europäischen Rat von Essen (ders. 1994b: 9) im Jahr 1997 auf eine vertraglich festgeschriebene Koordinierung, die sogenannten beschäftigungspolitischen Leitlinien (Art. 128 EGV). Das Er- 
stellungsverfahren ähnelte dem der GdW, das Sanktionsverfahren umfasste jedoch nur die unveröffentlichte Empfehlung bei Nichteinhaltung (ebenda).

Bei der europäischen Koordinierung im Bereich Distribution gab es ebenfalls Veränderungen. Anfang der 1990er Jahre hatte es bereits einige unverbindliche sozialpolitische Empfehlungen und Entschließungen des Rates gegeben, ein Leitlinienverfahren wurde jedoch erst im Jahr 2000 beschlossen. Bei dieser Offenen Methode der Koordinierung handelte es sich um das unverbindlichste Koordinationsverfahren, welches nicht vertraglich festgeschrieben war $^{17}$ und keinerlei Sanktionsmöglichkeiten vorsah. Im Rahmen der OMK einigten die Mitgliedstaaten sich auf gemeinsame Ziele bei der Armutsbekämpfung (14110/00; 14164/1/ 02) sowie der Alterssicherung (14098/01).

Schließlich wurde 1999 ein weiteres Koordinationsverfahren eingeführt, das gewissermaßen aus dem Rahmen fällt: In einem sogenannten makroökonomischen Dialog sollten die Finanz-, Geld- und Lohnpolitik durch einen engeren Austausch der relevanten Akteure besser aufeinander abgestimmt werden (Europäischer Rat 1999a: Ziff. 8). Dies entsprach nicht dem angebotsökonomischen Staatsverständnis und könnte somit als Bruch mit dem vorherrschenden bzw. als Aufscheinen eines neuen Paradigmas bezeichnet werden - allerdings wurde der Dialog (vielleicht genau deshalb) nie handlungsmächtig, ging nicht über einen Informationsaustausch hinaus. Daher kann er eher als Ausreißer oder Episode bezeichnet werden und deutet auf die Stärke des bestehenden Paradigmas hin. ${ }^{118}$ Der episodenhafte Charakter zeigt sich auch daran, dass der Dialog im Rahmen des nun zu beschreibenden Wandels erster Ordnung nicht mehr auftaucht.

Nach bzw. teilweise überlappend zu dem dargestellten Wandel zweiter Ordnung kam es auch zu einem Wandel erster Ordnung. Dieser folgte dem Aufruf des Europäischen Rates von 1999: »Der Schwerpunkt sollte nun darauf liegen, daß die bestehenden Verfahren und Regelungen wirksam angewandt und gestrafft werden und die Umsetzung der Politik eingehend überwacht wird« (Europäischer Rat 1999b: Ziff. 32). Dies sollte auch dazu beitragen, die Fortschritte des gemeinsamen Vorgehens, die teilweise als zu langsam angesehen wurden, zu verbessern (bspw. Europäischer Rat 2002a: Ziff. 4). Bei der Straffung der Verfahren ging es hauptsächlich um die für die Institutionalisierung des neuen Paradig-

117 Eine Vertragsbasierung war erst im Verfassungsvertrag vorgesehen (Art. III-213 VerfV).

118 Auf diesen Prozess wurde in der Arbeit aufgrund fehlender Leitlinien nicht näher eingegangen, vgl. ausführlicher z.B. Heise 2002; Niechoj 2004. 
mas wichtige Hierarchie zwischen den verschiedenen Verfahren. Diese wird zum einen an den unterschiedlichen Verbindlichkeiten deutlich, die sich in den Sanktionsverfahren widerspiegeln: Demnach stand das Ziel des Haushaltsausgleichs an erster Stelle, gefolgt von den GdW und den beschäftigungspolitischen Leitlinien, an letzter Stelle stand die OMK im Sozialbereich. Das im Rahmen der Lissabon-Strategie angesprochene (Europäischer Rat 2000a: Ziff. 35) und im Jahr 2002 vom Europäischen Rat beschlossene »Streamlining « stärkte die GdW als zentrales Instrument, indem ihnen die beschäftigungspolitischen Leitlinien auch vom Erstellungsverfahren her untergeordnet wurden (Europäischer Rat 2002a: Ziff. 49). Auf diese Weise wurde die vertraglich vereinbarte Rangfolge (Art. $126 \mathrm{EGV}$ ) vertieft.

Neben der Festschreibung der Hierarchien ist in dieser Periode ein weiterer Wandel erster Ordnung zur Verankerung des neuen Paradigmas zu beobachten. Dieser bestand darin, die neu geschaffenen Leitlinien durch eine Präzisierung bzw. Quantifizierung der darin enthaltenen Ziele und/oder einer Verschärfung der Sanktionsverfahren in ihrer Verbindlichkeit zu stärken bzw. in den oben zitierten Worten des Europäischen Rates wirksam anzuwenden und zu überprüfen. So wurde das vertraglich festgelegte Defizitkriterium bereits 1997 strenger gefasst, die Mitgliedstaaten auf einen ausgeglichenen oder überschüssigen Haushalt verpflichtet (97/C 236/01: 1). Für die Beschäftigungspolitik wurden vom Europäischen Rat im Jahr 2000 und 2001 zu erreichende Beschäftigungsquoten für bestimmte Gruppen verabschiedet (Europäischer Rat 2000a: Ziff. 30; Europäischer Rat 2001a: Ziff. 8f). Weiterhin fanden sich unter anderem konkrete Vorgaben für Investitionen in Forschungund Entwicklung (bspw. 2002/549/EG: 18), Kinderbetreuung (z.B. Europäischer Rat 2002a: Ziff. 32) sowie ein Referenzjahr für die Senkung der Beihilfen (bspw. Europäischer Rat 2001a: Ziff. 21). Eine Verschärfung der Sanktionsverfahren gab es unter anderem bei den Beihilfen: 1999 wurde das Kontrollverfahren kodifiziert, welches die Rückzahlung von unrechtmäßig gezahlten Beihilfen beinhaltete (VO 659/1999). Auch der Verfassungsvertrag sah derartige Änderungen vor: Die Kommission erhielt im Sanktionsverfahren für die Grundzüge der Wirtschaftspolitik und die Einhaltung des Defizitkriteriums eine größere Rolle (Art. III-177 sowie Art. III-184 VerfV), was die Verfahren durch eine Entpolitisierung verschärfen sollte. Neu eingeführt wurden spezifische wirtschaftspolitische Leitlinien für die Eurozone, bei der insbesondere auf die Haushaltsdisziplin geachtet werden sollte (Art. III-194 VerfV).

Man kann somit sagen, dass die Institutionalisierung des neuen Paradigmas in dieser dritten Periode zuerst über die Einführung neuer Instrumente und Koordinationsverfahren, d.h. einen Wandel zweiter Ordnung, 
vonstatten ging. Hierauf folgte ein Wandel erster Ordnung, die Instrumente wurden besser verzahnt, hierarchisiert und teilweise verbindlicher gestaltet.

\subsection{Fazit}

Insgesamt kann man davon sprechen, dass sich die von Peter Hall systematisierte Beschreibung des Wandels von wirtschaftspolitischen Paradigmen sehr gut dazu eignet, die untersuchten Prozesse auf der europäischen Ebene einzuordnen: Die 1960er Jahre waren davon geprägt, das damals vorherrschende Paradigma - europäisch geförderter (Wieder-)Ausbau von Interventionsmöglichkeiten zur Unterstützung eines Keynes'schen Staatsverständnisses - durch die Einführung und Anpassung neuer Instrumente zu institutionalisieren. Auf die zu Beginn der 1970er Jahre in Folge der veränderten ökonomischen Bedingungen auftretenden Anomalien (in Form von hoher Arbeitslosigkeit und hoher Inflation) reagierte die Gemeinschaft mit einer Anpassung ihrer Instrumente (Wandel erster Ordnung). Dies kann als Phase des Experimentierens beschrieben werden: Zuerst wurden die Vorgaben verbindlicher gestaltet, dann stärker ausdifferenziert. Diesen Experimenten war allerdings kein Erfolg beschieden, es kam zu den von Hall beschriebenen Prognose- und Politikfehlern. Die gemeinschaftliche Antwort hierauf kann als Wandel zweiter Ordnung bezeichnet werden: Einige Instrumente wurden abgeschafft, bestehende seltener genutzt, stattdessen wurde verstärkt auf eine nicht verfahrensbasierte bzw. punktuellere Koordinierung, insbesondere im Bereich der Beschäftigung, gesetzt. Auch hierbei handelt es sich um Experimente.

In den 1980er Jahren ist neben der Abschwächung des alten das Aufscheinen eines neuen Paradigmas zu beobachten: Die Vorgaben unterstützten immer weniger den (Wieder-)Ausbau nationalstaatlicher Interventionsmöglichkeiten zur Stärkung der Handlungsfähigkeit eines Keynes'schen Staatsverständnisses, vielmehr begann die intendierte Einschränkung der mitgliedstaatlichen Möglichkeiten, in die Wirtschaft einzugreifen. Zu Beginn der 1990er Jahre lässt sich der Paradigmenwandel festmachen, die Folgejahre sind - wie die 1960er Jahre - gekennzeichnet von einer Institutionalisierung des neuen Paradigmas durch die »Neugestaltung der Arbeitsabläufe« (Hall 1993: 280f): Zuerst durch die Schaffung neuer Instrumente bzw. Koordinierungsverfahren, danach durch ihre Anpassung (Hierarchisierung, stärkere Verbindlichkeit der wichtigsten Verfahren und Ziele). 
Betrachtet man die Institutionalisierung der beiden Paradigmen im Vergleich, kann jedoch noch eine weitere Interpretation der jüngsten Wandelprozesse auf der europäischen Ebene in Erwägung gezogen werden: In den 1960er wie den 1990er Jahren lässt sich eine Veränderung und Neueinführung von Instrumenten und Verfahren feststellen, mit denen das jeweilige Paradigma gefestigt werden sollte. Hierauf folgte jeweils eine Anpassung dieser Instrumente, z.B. die Herstellung von mehr Verbindlichkeit und die Differenzierung nach Ländern. Im Rückblick konnte dies für die 1970er Jahre als beginnender Wandel bezeichnet werden, als Experimente, um den unzureichenden Koordinierungserfolgen und der veränderten ökonomischen Lage zu begegnen. In der jetzigen Situation lässt sich noch nicht sagen, ob der Wandel erster Ordnung, der seit wenigen Jahren auf der europäischen Ebene zu beobachten ist, eine weitere Institutionalisierung des vorherrschenden Paradigmas darstellt, oder ob es sich bei diesen Prozessen bereits um die ersten kleinen Schritte hin zu einem neuerlichen Paradigmenwandel handelt. 



\section{SCHLUSSBETRACHTUNGEN}

$\mathrm{Zu}$ Beginn dieser Arbeit wurde die Krise des europäischen Integrationsprozesses angesprochen, welche durch die ablehnenden Verfassungsreferenden in Frankreich und den Niederlanden ausgelöst oder vielmehr sichtbar wurde. Das Schreiben des Schlusskapitels dieser Arbeit fällt mit dem EU-Gipfel in Lissabon vom 18.-19.10.2007 zusammen, auf dem die Staats- und Regierungschefs diese Krise für beendet erklärt haben (vgl. European Council 2007). Nach einer langen Phase der Reflexion wurde das Projekt einer Europäischen Verfassung offiziell beerdigt, stattdessen einigte man sich auf einen »Reformvertrag«. Ob dieser die Europäische Union aus der Krise führen kann, bleibt allerdings fraglich. Die Konflikte, die es im Vorfeld zwischen den Mitgliedstaaten zu klären gab, waren hauptsächlich altbekannt: Wie werden die Kompetenzen zwischen der EU und ihren Mitgliedstaaten verteilt, wie viel Macht soll die EU erhalten und wie viel soll bei (einzelnen) Mitgliedstaaten verbleiben? Das Verhältnis zwischen der Europäischen Union und den Nationalstaaten ist jedoch - wie in der Einleitung bereits angesprochen - höchstens vordergründig der Punkt, an der sich der Unmut der Bevölkerung entzündet: Es geht nicht in erster Linie darum, wie viele Zuständigkeiten im Prozess der Integration auf die europäische Ebene transferiert wurden, ob es nun ein >zu viel EU/ gibt. Im Zentrum der Kritik steht vielmehr die Frage, wie sich das Integrationsprojekt auf die Kompetenzverteilung zwischen Staat und Markt ausgewirkt hat und auswirken wird.

Der Reformvertrag - genauer gesagt der revidierte $»$ Vertrag über die Europäische Union« und der neu betitelte »Vertrag über die Arbeitsweise der Europäischen Union « (ehemals EG-Vertrag) - sieht mit Blick auf diese Zuständigkeitsverteilung aber kaum Veränderungen vor. Was die mittelbare Beeinflussung der (national-)staatlichen Interventionsmög- 
lichkeiten durch die zunehmende wirtschaftliche Verflechtung angeht, wurde zwar medienwirksam der »freie und unverfälschte Wettbewerb« aus den Zielbestimmungen entfernt (vgl. Konferenz der Vertreter der Regierungen der Mitgliedstaaten 2007a: 4). Protokoll 6 hält jedoch fest, »dass zu dem Binnenmarkt, wie er in Artikel 3 des Vertrags über die Europäische Union beschrieben wird, ein System gehört, das den Wettbewerb vor Verfälschungen schützt « - womit die Veränderung durch die Hintertür wieder zurückgenommen wird (Konferenz der Vertreter der Regierungen der Mitgliedstaaten 2007b: 19). Mit Blick auf die intentionale Beeinflussung bleibt es bei den marginalen Änderungen, z.B. beim Sanktionsverfahren für die Grundzüge der Wirtschaftspolitik und das Haushaltsdefizit, die bereits für den Verfassungsvertrag beschrieben wurden. Der in Kapitel 6 beschriebene Wandel erster Ordnung der letzten Jahre hat noch keine weiteren Kreise gezogen. Die europäische Integration wird somit weiter dazu beitragen, den Staat zugunsten des Marktes zu schwächen, mittelbar und - zumindest im Bereich der hier untersuchten Politikfelder - auch intentional. Die Verkündigungen vom Ende der Krise könnte demnach durchaus ein wenig voreilig sein.

Nun ist es nicht Aufgabe einer Dissertation, Auswege aus politischen Krisen vorzuschlagen. Wissenschaft spielt sich jedoch auch nicht im luftleeren Raum ab, ist immer Teil von gesellschaftlichen Prozessen, und kann insbesondere Grundlagen für fundierte Auseinandersetzungen mit bestimmten Themen bereitstellen. Auch diese Arbeit möchte hier einen entsprechenden Beitrag leisten. Für die notwendige Diskussion um das Verhältnis von Markt und Staat im Rahmen der europäischen Einigung zeigt sie vor allem zweierlei: Die seit dem Beginn der 1990er Jahren verstärkt zu beobachtende Zurückdrängung des Staates im Prozess der europäischen Integration ist nicht nur mittelbar, sondern auch direkt und intentional. Und zweitens: Dies war nicht immer so, im Gegenteil, über viele Jahre hatten die europäischen Vorgaben das Ziel, die Interventionsmöglichkeiten der Nationalstaaten auszubauen, es wurde nicht nur ein angebotsökonomisches, sondern bis in die 1980er Jahre hinein auch ein Keynes'sches Staatsverständnis gestützt. Natürlich trifft die Arbeit diese Aussage nur für den untersuchten Ausschnitt, die Ausgabenpolitik in den vier Politikfeldern Beihilfen, öffentliche Güter, Sozialausgaben und Stabilisierung. Sie kann und soll jedoch - um wieder zur wissenschaftlichen Bedeutung der Arbeit zurückzukehren - Anstoß und vor allem Basis dafür sein, diese beiden Hauptaussagen weiter zu untersuchen, zu verfeinern und ein differenzierteres großes Bild zu zeichnen.

Mit Blick auf die erste Aussage der Arbeit - die intentionale Einschränkung von Interventionsmöglichkeiten - gälte es, diese auch für andere Politikfelder untersuchen, vor allem auch solche, bei denen viele 
Zuständigkeiten auf der europäischen Ebene liegen. Auch der Versuch, die Wirkungen insbesondere der rechtlich nicht oder nur schwach verbindlichen europäischen Vorgaben zu untersuchen, wäre ein wichtiges, wenngleich schwierig zu bearbeitendes (vgl. Kapitel 1) Feld für die weitere Forschung. Besonders interessant erscheint hierbei die Frage, inwiefern sich die These von einer Selbstbindung der Mitgliedstaaten über die europäischen Vorgaben, in dieser Arbeit >revisionistische Strategie< genannt, stützen lässt. Finden sich beispielsweise in nationalen Diskussionen Verweise auf die europäischen Vorgaben? Neben der Wirkungsanalyse wären auch Untersuchungen zur Entstehung der europäischen Vorgaben interessant, die Diskussionen im Vorfeld der Verabschiedung und die Rolle der verschiedenen Akteure, insbesondere der Europäischen Kommission. Hinsichtlich der zweiten Aussage dieser Arbeit - den Wandel in der intentionalen Beeinflussung der nationalstaatlichen Interventionsmöglichkeiten - stellt sich die Frage nach den Bedingungen: Wann wirkt die EU eher interventionsfördernd, wann -hemmend. Dies ist sicherlich zum einen aus dem Zeitkontext zu erschließen, kann aber auch durch den Vergleich mit anderen Politikfeldern ergänzt werden. So scheint es Bereiche zu geben, in denen die EU auch heute noch deutlich interventionsfreundlicher ist, wie beispielsweise bei der Agrarpolitik.

Eine derartige Auseinandersetzung um die horizontale Dimension der europäischen Integration - das Verhältnis von Staat und Markt könnte nicht nur in der Wissenschaft neue Perspektiven eröffnen, sondern auch in der politischen Auseinandersetzung um die Europäische Union - und auf diese Weise eine gute Grundlage sein für die kritische, aber gleichwohl konstruktive Begleitung 50 weiterer Jahre europäischer Integration. 



\section{LITERATUR}

Abbott, Kenneth W./Snidal, Duncan (2000): Hard and Soft Law in International Governance. International Organization 54 (3): $421 \mathrm{ff}$.

Ahrns, Hans-Jürgen/Feser, Hans-Dieter (1997): Wirtschaftspolitik. Problemorientierte Einführung, 7. Auflage, München/Wien.

Allsopp, Christopher (1989): The Macro-economic Role of the State. In: Helm, Dieter (Hg.) (1989): The Economic Borders of the State, Oxford: 180ff.

Altvater, Elmar/Mahnkopf, Birgit (1996): Grenzen der Globalisierung Ökonomie, Ökologie und Politik in der Weltgesellschaft, Münster.

Altvater, Elmar/Mahnkopf, Birgit (2007): Grenzen der Globalisierung Ökonomie, Ökologie und Politik in der Weltgesellschaft, 7. Auflage, Münster.

Ambrosius, Gerold (1996): Staat und Wirtschaft. In: ders., Dietmar Petzina, Werner Plumpe (Hg.): Moderne Wirtschaftsgeschichte, München: $355 \mathrm{ff}$.

Ausschuss zur Prüfung der Wirtschafts- und Währungsunion (1989): Bericht zur Wirtschafts- und Währungsunion in der Europäischen Gemeinschaft, Brüssel.

Bajohr, Stefan (2003): Grundriss staatliche Finanzpolitik. Eine praktische Einführung, Opladen.

Barro, Robert J./Gordon, David B. (1983): Rules, Discretion and Reputation in a Model of Monetary Policy. Journal of Monetary Economics 12 (1): $123 \mathrm{ff}$.

Beisheim, Marianne/Dreher, Sabine/Walter, Georg/Zangl, Bernhard/ Zürn, Michael (1998): Im Zeitalter der Globalisierung? Thesen und Daten zur gesellschaftlichen und politischen Denationalisierung, Baden-Baden. 
Bernauer, Thomas (2000): Staaten im Weltmarkt, Opladen.

Bernhard, William/Leblang, David (2002): Political Parties and Monetary Commitments. International Organization 56 (4): $803 \mathrm{ff}$.

Bieling, Hans-Jürgen/Steinhilber, Jochen (2000): Hegemoniale Projekte im Prozeß der europäischen Integration. In: dies. (Hg.): Die Konfiguration Europas. Dimensionen einer kritischen Integrationstheorie, Münster: $102 \mathrm{ff}$.

Blankart, Charles B. (2006): Öffentliche Finanzen in der Demokratie. Eine Einführung in die Finanzwissenschaft, 6. Auflage, München.

Blaug, Mark (1999): Economic theory in retrospect, 5. Auflage, Cambridge.

Bohnet, Armin (1989): Die Rolle des Staates in den wirtschaftspolitischen Leitbildern des Liberalismus, des Neoliberalismus und des Interventionismus, Finanzwissenschaftliche Arbeitspapiere der Universität Gießen.

Bortz, Jürgen/Döring, Nicola (2002): Forschungsmethoden und Evaluationen, Berlin/Heidelberg.

Brümmerhoff, Dieter (2001): Finanzwissenschaft, 8. Auflage, München/ Wien.

Busch, Klaus (1998): Das Korridormodell. Ein Konzept zur Weiterentwicklung der EU-Sozialpolitik. Politik und Gesellschaft online 2/98.

Caspers, Rolf (1999): Globalisierung der Wirtschaft und Anpassungsdruck in Deutschland. In: Apolte, Thomas/Caspers, Rolf/Welfens, Paul J.J. (Hg): Standortwettbewerb, wirtschaftspolitische Rationalität und internationale Ordnungspolitik, Baden-Baden: $45 \mathrm{ff}$.

Collignon, Stefan (2003): The European Republic, London.

De Vries, Michiel (2001): The attack on the state: a comparison of arguments. International Review of Administrative Sciences 67 (3): 389ff.

Donges, Jürgen B. (1998): Was heißt Globalisierung?. In: ders./Freytag, Andreas (Hg.), a.a.O.: $1 \mathrm{ff}$.

Donges, Jürgen B. (2002): Deregulierung von Märkten, globaler Wettbewerb und Ökonomie, Paderborn.

Donges, Jürgen B./Freytag, Andreas (Hg.) (1998): Die Rolle des Staates in der globalisierten Wirtschaft, Stuttgart.

Donges, Jürgen B./Freytag, Andreas (2001): Allgemeine Wirtschaftspolitik, Stuttgart.

Donges, Jürgen B./Menzel, Kai/Paulus, Philipp (2003): Globalisierungskritik auf dem Prüfstand, Stuttgart. 
Dräger, Klaus (2003): Eine Heilige Allianz der Modernisierer? Die EU nach dem Scheitern des Mitte-Links-Projekts. In: Beckmann, Martin/Bieling, Hans-Jürgen/Deppe, Frank (Hg.): Euro-Kapitalismus und globale politische Ökonomie, Hamburg: 196ff.

Dyson, Kenneth (2003): Die WWU als Prozess der Europäisierung: Konvergenz, Unterschiede und Unvorhersehbarkeit. In: Jachtenfuchs, Markus/Kohler-Koch, Beate: Europäische Integration, Opladen, 2. Auflage: 449ff.

Eijffinger, Sylvester/de Haan, Jakob (2000): European monetary and fiscal policy, New York.

Etxezarreta, Miren/Grahl, John/Huffschmid, Jörg/Mazier, Jacques et al. (Europäische Memorandum-Gruppe) (Hg.) (2003): EuroMemo 2002. Bessere Institutionen, Regeln und Instrumente für Vollbeschäftigung und sozialen Wohlstand in Europa, Hamburg.

Europäische Kommission (1985): Weißbuch zur Vollendung des Binnenmarktes, KOM (85) 319endg, Brüssel.

Europäische Kommission (1993): Europäische Wirtschaft, 54/1993, Luxemburg.

Europäische Kommission (2006): Statistischer Anhang zu »Europäische Wirtschaft« Frühjahr 2006, ECFIN/REP/52683/2006 - DE.

Eurostat (2006): Wachstumsraten des BIP in \%, http://epp.eurostat.ec. europa.eu/portal/page?_pageid $=1996,39140985 \&$ dad=portal\& _schema $=$ PORTAL\&screen $=$ detailref\&language $=$ de $\&$ product $=$ SDI MAIN\&root=SDI_MAIN/sdi/sdi_ed/sdi_ed_inv/sdi_ed 1110 (26.07.06).

Färber, Gisela (1993): Subventionen vor dem EG-Binnenmarkt. Eine Bestandsaufnahme von nationalen Beihilfen und EU-Interventionen in Deutschland, Frankreich und Großbritannien, Speyer.

Fees, Eberhard/Tibitanzl, Frank (1997): Makroökonomie, München

Felderer, Bernhard/Homburg, Stefan (2003): Makroökonomik und neue Makroökonomik, 8. Auflage, Berlin.

Feldstein, Martin (1986): Supply Side Economics: Old Truths and New Claims. The American Economic Review 76 (2): $26 \mathrm{ff}$.

Flassbeck, Heiner (1982): Was ist Angebotspolitik? Konjunkturpolitik $28(2 / 3): 75 f f$.

Freytag, Andreas/Meyer, Carsten-Patrick/Weiß, Pia (1998): Die Vertiefung der internationalen Verflechtung. In: Donges, Jürgen B./Freytag, Andreas (Hg.), a.a.O.: 9ff.

Friedman, Milton (1948): A Monetary and Fiscal Framework for Economic Stability. The American Economic Review 38 (3): $245 \mathrm{ff}$.

Friedman, Milton (1970): The Counter-Revolution in Monetary Theory, First Wincott Memorial Lecture, IEA Occasional Paper 33, London. 
Friedman, Milton (1976): Die Rolle der Geldpolitik. In: ders: Die optimale Geldmenge und andere Essays, München: $135 \mathrm{ff}$.

Friedman, Milton (1979): Es gibt nichts umsonst, München.

Friedman, Milton (2002/1962): Kapitalismus und Freiheit, Frankfurt am Main.

Friedman, Milton/Friedman, Rose (1983): Chancen die ich meine, Frankfurt am Main/Berlin/Wien.

Friedman, Milton/Heller, Walter (1969): Monetary vs Fiscal Policy. A Dialogue, New York.

Früh, Werner (1998): Inhaltsanalyse. Theorie und Praxis, 4. Auflage, Konstanz.

Fürst, Volker/Prange, Heiko/Wolf, Dieter (2002): Globalization, Europeanization and All That: Sorting Out the Issues. The Example of European States, Paper presented at the ECSA-Canada Fifth Biennial Conference, Toronto May 31th-June $1^{\text {st }}$.

Garrett, Geoffrey (1998): Global Markets and National Politics: Collision Course or Vicious Circle. International Organization 52 (4): $787 \mathrm{ff}$.

Genschel, Philipp (1998): Markt und Staat in Europa. Politische Vierteljahresschrift 39 (1): $55 \mathrm{ff}$.

Genschel, Philipp (2000): Der Wohlfahrtsstaat im Steuerwettbewerb, MPIfG Working Paper 00/5.

Genschel, Philipp (2003): Globalisierung als Problem, als Lösung und als Staffage. In: Hellmann, Gunther/Wolf, Klaus Dieter/Zürn, Michael (Hg.): Die neuen Internationalen Beziehungen. Forschungsstand und Perspektiven in Deutschland, Baden-Baden: 429ff.

Gillingham, John (2003): European Integration 1950-2003, Cambridge.

Gläser, Jochen/Laudel, Grit (1999): Theoriegeleitete Textanalyse? Das Potential einer variablenorientierten qualitativen Inhaltsanalyse, WZB-Paper P99-401.

Goldberg, Jörg (2000): Globalisierung und Nationalstaat. In: Hickel, Rudolf/Kisker, Klaus Peter/Mattfeld, Harald/Troost, Axel (Hg): Politik des Kapitals - heute, Hamburg: $173 \mathrm{ff}$.

Gros, Jürgen (2002): Deutschland. In: Weidenfeld, Werner (Hg.): a.a.O.: 99ff.

Gross, Ivo (2003): Das europäische Beihilfenrecht im Wandel, St. Gallen.

Grunwald, Jürgen (2007): Beitrag zum Hearing des Europäischen Parlaments »Assessing Euratom - 50 years of Europaen Nuclear Policy«, 01.02.2007, www.europarl.europa.eu/hearings/20070201/itre/grunwald_de.pdf (16.10.07). 
Hagemann, Harald (1988): Lohnhöhe und Beschäftigung aus Keynes'scher Sicht. In: ders./Steiger, Otto (Hg.): Keynes General Theory nach fünfzig Jahren, Berlin: $183 \mathrm{ff}$.

Hajen, Leonhard (2005): Sozialpolitik als Umverteilung von Macht und Strategien der Privatisierung in der Europäischen Union, CIS-Paper No. 5, Hamburg.

Hall, Peter A. (1992): The movement from Keynesianism to monetarism: Institutional analysis and British economic policy in the 1970s. In: Steinmo, Sven/Thelen, Kathleen/Longstreth, Frank (Hg.): Structuring politics. Historical institutionalism in comparative analysis, Cambridge: $90 \mathrm{ff}$.

Hall, Peter A. (1993): Policy paradigms, social learning, and the state. The case of economic policy making in Britain. Comparative Politics 25 (3): $275 \mathrm{ff}$.

Hansmeyer, Karl Heinrich (1977): Transferzahlungen an Unternehmen (Subventionen). In: Neumark, Fritz (Hg.): Handbuch der Finanzwissenschaft, 3. Auflage, Bd. 1, Tübingen: 963.

Hay, Colin/Rosamond, Ben (2002): Globalisation, European Integration and the discursive construction of economic imperatives. Journal of European Public Policy 9 (2): 147ff.

Hayes-Renshaw, Fiona (2002): The Council of Ministers. In: Peterson, John/Shackleton, Michael (Hg.): The Institutions of the European Union, Oxford: 47ff.

Hefeker, Carsten (2003): Handels- und Finanzarchitektur im Umbruch. Globale Integration und die institutionelle Arbeitsteilung von IWF, Weltbank und WTO, HWWA Discussion Paper 225.

Heine, Michael/Herr, Hansjörg (2003): Volkswirtschaftslehre, 3. Auflage, München/Wien.

Heise, Arne (1993): Capital-Budgeting - Ein verschütteter Keynes'scher Baustein oder: Wie Beschäftigungspolitik Handlungsspielräume schaffen kann. WSI-Mitteilungen 11/1993: 709ff.

Heise, Arne (2001): Das Konzept einer nachhaltigen Finanzpolitik aus heterodoxer Sicht - ein Diskussionsbeitrag. Vienna University of Economics \& B.A. Department of Economics Working Paper Series, Working Paper No. 76, April 2001.

Heise, Arne (2002): The »cologne process «: a neglected aspect of European employment policy. Internationale Politik und Gesellschaft online $2 / 02$.

Heise, Arne (2004): Economic Governance in the European Union: Possibilities and Problems of Supranational Policy Coordination, CIS-Paper No. 1, Hamburg. 
Heise, Arne (2005): Einführung in die Wirtschaftspolitik. Grundlagen, Institutionen, Paradigmen, München.

Heise, Arne (2005): European Economic Governance - Wirtschaftspolitik jenseits der Nationalstaaten. Wirtschaftsdienst 85 (4): $230 \mathrm{ff}$.

Held, David/McGrew, Anthony/Goldblatt, David/Perraton, Jonathan (1999): Global Transformations. Politics, Economics and Culture, Oxford.

Hicks, John R. (1937): Mr. Keynes and the >Classicsく. A Suggested Interpretation. Econometrica 5 (2): $147 \mathrm{ff}$.

Hirsch, Joachim (1995): Der nationale Wettbewerbsstaat. Staat, Demokratie und Politik im globalen Kapitalismus, Berlin/Amsterdam.

Hirst, Paul/Thompson, Grahame (1996): Globalization in Question: The International Economy and the Possibilities of Governance, Cambridge.

Hirst, Paul/Thompson, Grahame (2002): The Future of Globalization. Cooperation and Conflict 37 (3): $247 \mathrm{ff}$.

Hödl, Erich (1988): Der Staat in der Keynes'schen Theorie. In: Hagemann, Harald/Steiger, Otto (Hg.): Keynes General Theory nach fünfzig Jahren, Berlin: 435ff.

Hrbek, Rudolf (2005): EU: quo vadis? Das Europäische Einigungsprojekt in der Krise. Wirtschaftsdienst 85 (8): $483 \mathrm{ff}$.

Huffschmid, Jörg (1994): Wem gehört Europa? Band 1: Wirtschaftspolitik in der EG, Heilbronn.

Huffschmid, Jörg (2003): Finanzmärkte und alternative Wirtschaftspolitik. In: Bischoff, Joachim/Steinitz, Klaus (Hg.): Linke Wirtschaftspolitik, Hamburg: 27ff.

Huffschmid, Jörg/Eißl, Dieter/ Koch, Hannes/Walter, Margit (2004): Öffentliche Finanzen: gerecht gestalten!, Hamburg.

Jessop, Bob (2003): The Future of the State in an Era of Globalization. Internationale Politik und Gesellschaft 3/2003: $30 \mathrm{ff}$.

Johnson, Harry G. (1971): The Keynesian Revolution and the Monetarist Counter-Revolution. The American Economic Review 61 (2): $1 \mathrm{ff}$.

Kalmbach, Peter (Hg.) (1973): Der neue Monetarismus, München.

Kalmbach, Peter (1981): »Mehr Markt - weniger Staat« - eine neokonservative Offensive. Darstellung und Kritik gegenwärtiger Revisionsversuche der Rollenverteilung zwischen Staat und Markt. Zur Privatisierung öffentlicher Dienstleistungen, Heft 10.

Kaufer, Erich (1982): Forschungs- und Technologiepolitik im Rahmen einer angebotsorientierten Wirtschaftspolitik. In: Vogel, Otto (Hg.), a.a.O.: $175 \mathrm{ff}$. 
Keynes, John M. (versch. Jahrgänge): The Collected Writings of John Maynard Keynes, herausgegeben von Donald Moggridge, Bände IX, XIX, XXI, XXV, XXVI, XXVII und XXIX, Cambridge (zitiert: CW).

Keynes, John M. (1925): Bin ich ein Liberaler?, Ansprache an die liberale Sommerschule in Cambridge, abgedruckt in: ders. (1956), a.a.O.: $246 \mathrm{ff}$.

Keynes, John M. (1926): Das Ende des Laissez-Faire. Ideen zur Verbindung von Privat- und Gemeinwirtschaft, München/Leipzig.

Keynes, John M. (1929): Ein Programm der Ausweitung, abgedruckt in: ders. (1956), a.a.O.: 184ff.

Keynes, John M. (1930): Wirtschaftliche Möglichkeiten für unsere Enkelkinder, abgedruckt in: ders. (1956), a.a.O.: $263 \mathrm{ff}$.

Keynes, John M. (1933): Wege zur Wiedererlangung der Prosperität, London, abgedruckt in: Mattfeldt, Harald (1985), a.a.O.: $143 \mathrm{ff}$.

Keynes, John M. (1936): Allgemeine Theorie der Beschäftigung, des Zinses und des Geldes, München/Leipzig.

Keynes, John M. (1956): Politik und Wirtschaft: Männer und Probleme; ausgewählte Abhandlungen, Tübingen.

Knapp, Werner (2005): Die Inhaltsanalyse aus linguistischer Sicht. In: Mayring, Philipp/Gläser-Zikuda, Michaela (Hg.), a.a.O.: $20 \mathrm{ff}$.

Krätke, Michael (1999): Der Sozialstaat im Zeitalter des globalen Kapitalismus. In: Eichel, Hans/Hoffmann, Hilmar (Hg.): Ende des Staates - Anfang der Bürgergesellschaft, Reinbek bei Hamburg: $65 \mathrm{ff}$.

Kromphardt, Jürgen (2004): Konzeptionen und Analysen des Kapitalismus. Von seiner Entstehung bis zur Gegenwart, 4. Auflage, Göttingen.

Kuckartz, Udo (1999): Computergestützte Analyse qualitativer Daten. Eine Einführung in Methoden und Arbeitstechniken, Opladen.

Kuhn, Thomas S. (1962): The Structure of Scientific Revolutions, Chicago.

Kumpmann, Ingmar (2005): Systemwettbewerb und Umverteilung, Frankfurt am Main et al.

Kydland, Finn E., Edward C. Prescott (1977): Rules Rather than Discretion: The Inconsistency of Optimal Plans. Journal of Political Economy 85 (3): 473ff.

Lamping, Wolfram (2007): Die Kunst des Bohrens dicker Bretter. Die Europäische Kommission und die Europäisierung von Gesundheitspolitik. In: Fischer, Robert/Karrass, Anne/Kröger, Sandra (Hg.): Die Europäische Kommission und die Zukunft der EU. Ideenfabrik zwischen europäischem Auftrag und nationalen Interessen, Opladen: $275 \mathrm{ff}$. 
Legewie, Heiner (1994): Globalauswertung von Dokumenten. In: Boehm, Andreas/Mengel, Andreas/Muhr, Thomas (Hg.): Texte verstehen. Konzepte, Methoden, Werkzeuge, Konstanz: $177 \mathrm{ff}$.

Lübke, Gerhard (1989): Die Staatsverschuldung im Kontext alternativer Wirtschaftspolitik. Zur Erweiterung des finanzpolitisches Handlungsspielraums des Staates durch alternative Finanzierungsstrategien, Frankfurt am Main/Bern/New York/Paris.

Mansfeld, Werner (1980): Interventionismus. In: Glasstetter, Werner (Hg.): Handwörterbuch der Volkswirtschaft, Wiesbaden, 2. Auflage, Spalte 553ff.

Mattfeldt, Harald (1985): Keynes. Kommentierte Werkauswahl, Hamburg.

Mayer, Thomas (1978): Die Struktur des Monetarismus. Die Monetarismus-Kontroverse, Beihefte zu Kredit und Kapital, H. 4, hg. von W. Ehrlicher und W.D. Becker, Berlin: 9ff.

Mayring, Philipp (2007): Qualitative Inhaltsanalyse. Grundlagen und Techniken, 9. Auflage, Weinheim/ Basel.

Mayring, Philipp (2005): Neuere Entwicklungen in der qualitativen Forschung und der qualitativen Inhaltsanalyse. In: ders./Gläser-Zikuda, Michaela (Hg.), a.a.O.: 7ff.

Mayring, Philipp/Gläser-Zikuda, Michaela (2005) (Hg.): Die Praxis der Qualitativen Inhaltsanalyse, Weinheim.

Mazey, Sonia (1996): The development of the European idea. From sectoral integration to political union. In: Richardson, Jeremy (Hg.): European Union: Power and Policy-Making, London: 24ff.

Ménudier, Henri (2002): Frankreich. In: Weidenfeld, Werner (Hg.), a.a.O.: $127 \mathrm{ff}$.

Milbradt, Georg H. (1982): Steuer- und Finanzpolitik. In: Vogel, Otto (Hg.), a.a.O.: 122ff.

Mill, John Stuart (1924): On Liberty, London.

Moravcsik, Andrew (1997): Warum die Europäische Union die Exekutive stärkt: Innenpolitik und internationale Kooperation. In: Wolf, Klaus-Dieter (Hg): Projekt Europa im Übergang?, Baden-Baden: $211 \mathrm{ff}$.

Moravcsik, Andrew (1999): The Choice for Europe, London.

Musgrave, Richard (1969): Finanztheorie, Tübingen.

Musgrave, Richard A./Musgrave, Peggy B./Kullmer, Lore (1994): Die öffentlichen Finanzen in Theorie und Praxis. Band 1, Opladen.

Muth, John F. (1961): Rational Expectations and the Theory of Price Movements. Econometrica 29 (3): $315 \mathrm{ff}$.

Narr, Wolf-Dieter/Schuber, Alexandra (1994): Weltökonomie. Die Misere der Politik, Frankfurt am Main. 
Niechoj, Torsten (2004): Fünf Jahre makroökonomischer Dialog. Was wurde aus den ursprünglichen Intentionen?, WSI-Diskussionspapier 123.

Nielen, Jochen (2000): Das Leitbild des Laisser-faire in der Politischen Ökonomie von Smith bis Keynes, dargestellt anhand der Hauptwerke von Smith, Malthus, Ricardo, Mill, Marshall und Keynes, Bonn.

Nolte, Dirk/Schaaff, Herbert (1994): Wirtschaft ohne Wachstum? Zur Aktualität des Keynesschen Beitrags zu einer Wirtschaftspolitik der Stagnation. WSI-Mitteilungen 5/1994: 299ff.

Nowotny, Ewald (1999): Der öffentliche Sektor. Einführung in die Finanzwissenschaft, 4. Auflage, Berlin et al.

Ohr, Renate (Hg.) (2004): Globalisierung - Herausforderung an die Wirtschaftspolitik, Berlin.

Ohr, Renate/Schmidt, André (2004): Regelgebundene versus diskretionäre Wirtschaftspolitik: Das Beispiel des Stabilitäts- und Wachstumspaktes. Vierteljahreshefte zur Wirtschaftsforschung 73 (3): $381 \mathrm{ff}$.

Padoa-Schioppa, Tommaso (1999): Reflections on the Globalisation and Europeanisation of the Economy, CeGE-Discussion Paper Juni 1999

Pätzold, Jürgen (1998): Stabilisierungspolitik, 6. Auflage, Bern/Stuttgart/Wien.

Peacock, Alan (1993): Keynes und die Rolle des Staates. Zeitschrift für Wirtschaftspolitik 42 (1): $47 \mathrm{ff}$.

Pribram, Karl (1992): Geschichte des ökonomischen Denkens, Frankfurt am Main/New York.

Reinhoffer, Bernd (2005): Lehrkräfte geben Auskunft über ihren Unterricht. Ein systematisierender Vorschlag zur deduktiven und induktiven Kategorienbildung in der Unterrichtsforschung. In: Mayring, Philipp/Gläser-Zikuda, Michaela (Hg.), a.a.O.: $123 \mathrm{ff}$.

Risse, Thomas (1999): Multilaterale Entscheidungen unter den Bedingungen der Globalisierung: Wenn die Staatenwelt auf die Gesellschaftswelt trifft, Beitrag für die Deutsche Gesellschaft für Politikwissenschaft, http://www.deutsche-aussenpolitik.de/resources/seminars/gb/euracowa/document/ globalisierung.pdf (16.5.05).

Rodrik, Dani (1996): Why do more open economies have bigger governments?, NBER Working Paper 5537, April 1996.

Rosen, Harvey S./Windisch, Rupert (1997): Finanzwissenschaft I, München/Wien.

Rössler, Patrick (2005): Inhaltsanalyse, Konstanz.

Rotte, Ralph/Zimmermann, Klaus F. (1998): Fiscal restraints and the political economy of EMU. Public Choice 94 (3-4): 385ff. 
Rustemeyer, Ruth (1992): Praktisch-methodische Schritte der Inhaltsanalyse, Münster.

Sachverständigenrat zur Begutachtung der gesamtwirtschaftlichen Entwicklung (SVR) (1981): Investieren für mehr Beschäftigung!, Jahresgutachten 1981/82, Stuttgart/Mainz.

Samuelson, Paul A. (1971): Reflections on the Merits and Demerits of Monetarism. In: James J. Diamond (Hg.): Issues in Fiscal and Monetary Policy, Chicago: $7 \mathrm{ff}$.

Scharpf, Fritz W. (2000): Institutions in Comparative Policy Research. Comparative Political Studies 33 (6/7): 762ff.

Schatz, Klaus Werner (1988): Globalsteuerung und Angebotspolitik. In: Manfred E. Streit (Hg.): Wirtschaftspolitik zwischen ökonomischer und politischer Rationalität, Wiesbaden: $187 \mathrm{ff}$.

Schelkle, Waltraud (2005): The Political Economy of Fiscal Policy Coordination in EMU. From Disciplinarian Device to Insurance Arrangement. Journal of Common Market Studies 43 (2): $371 \mathrm{ff}$.

Scherrer, Christoph (2000): Das Spektrum möglicher Antworten. Globalisierung - eine Zwischenbilanz. Kommune 18 (7): $51 \mathrm{ff}$.

Schulte, Bernd (2001): EG-rechtliche Rahmenbedingungen für nationale Sozialpolitik. In: Winfried Schmähl (Hg.): Möglichkeiten und Grenzen einer nationalen Sozialpolitik in der Europäischen Union, Berlin: $34 \mathrm{ff}$.

Schumpeter, Joseph (1926): Theorie der wirtschaftlichen Entwicklung, 2. Auflage, München.

Schumpeter, Joseph (1943): Capitalism, Socialism and Democracy, New York.

Siebert, Horst (1998): Disziplinierung der nationalen Wirtschaftspolitik durch internationale Kapitalmobilität. In: Duwendag, Dieter (Hg.): Finanzmärkte im Spannungsfeld von Globalisierung, Regulierung und Geldpolitik, Berlin: $41 \mathrm{ff}$.

Sievert, Olaf (1982): Die angebotsorientierte Wirtschaftspolitik des Sachverständigenrates - Das Konzept für die achtziger Jahre?. In: Vogel, Otto (Hg.), a.a.O.: $37 \mathrm{ff}$.

Sinn, Hans-Werner (1995): Implikationen der vier Grundfreiheiten für eine nationale Fiskalpolitik. Wirtschaftsdienst 75 (5), $240 \mathrm{ff}$.

Skidelsky, Robert (1989): Keynes and the State. In: Helm, Dieter (Hg.): The Economic Borders of the State, Oxford: 144ff.

Smith, Adam (1996/1789): Der Wohlstand der Nationen. Eine Untersuchung seiner Natur und seiner Ursachen, hg. von Horst Claus Recktenwald, München.

Snowdon, Brian/Vane, Howard/Wynarczyk, Peter (2002): A modern guide to macroeconomics, 4. Auflage, Cheltenham. 
Söllner, Fritz (1999): Geschichte des ökonomischen Denkens, Berlin/ Heidelberg/New York.

Stemmler, Steve (2001): An Overview of Content Analysis. Practical Assessment Research \& Evaluation 7 (17), http://PAREonline.net/ getvn.asp?v=7\&n=17 (24.10.06).

Stiglitz, Joseph (1989): Finanzwissenschaft, München/Wien.

Strange, Susan (1996): The retreat of the state, Cambridge.

Stockhausen, Dirk H. (2002): Beihilfenrechtliche Grenzen einer nationalen Beschäftigungspolitik, Bonn.

Streb, Sebastian (2006): Von »leeren Stühlen« und »Sklerosen«. Zur Krisendynamik des europäischen Integrationsprozesses. FEI-Arbeitspapier Nr. 27, Marburg: $1 \mathrm{ff}$.

Streeck, Wolfgang (2004): Globalisierung - Mythos und Wirklichkeit, MPIfG Working Paper 4/04.

Sweezy, Paul M. (1986): Listen Keynesians!. In: Wattel, Harold L. (Hg.): The Policy Consequences of John Maynard Keynes, London: 39ff.

Tanzi, Vito (1997): The Changing Role of the State in the Economy. A Historical Perspective, IMF Working Paper 97/114, Washington D.C.

Tanzi, Vito (2002): Globalization and the Future of Social Protection. Scottish Journal of Political Economy 49 (1): 116ff.

Tanzi, Vito/Schuknecht, Ludger (2000): Public spending in the 20th century: a global perspective, Cambridge.

Theurl, Theresia (1999): Globalisierung als Selektionsprozeß ordnungspolitischer Paradigmen. In: Berg, Hartmut (Hg.): Globalisierung der Wirtschaft: Ursachen - Formen - Konsequenzen, Berlin: 23ff.

Treib, Oliver (2002): Wo (k)ein Wille ist, ist auch (k)ein Weg: Die politische Logik des Regierens im europäischen Mehrebenensystem, Beitrag für den MPG 2000+-Workshop »Politik und Recht unter den Bedingungen der Globalisierung und Dezentralisierung«, Köln, 28.29. November 2002, http://elaine.ihs.ac.at/ treib/download/Treib MPG2000Plus2002.pdf (03.07.07).

Tumlir, Jan (1983): International Economic Order and Democratic Constitutionalism. ORDO 34: 71ff.

Uhl, Susanne (2008): Die Transformation nationaler Steuersysteme in der Europäischen Union, Frankfurt am Main/New York.

Vaubel, Roland (1986): A public choice approach to international organization. Public Choice 51 (1): 39ff.

Vobruba, Georg (2003): Globalisierung ohne Wohlfahrtsstaaten? Globalisierungsdiskurs, zweite Runde. Zur Einführung. In: Almendinger, Jutta (Hg): Entstaatlichung und soziale Sicherheit, Opladen: 1061ff 
Vogel, Otto (Hg.) (1982): Wirtschaftspolitik der achtziger Jahre. Leitbilder und Strategien, Köln.

Wallace, Helen (2000): The Institutional Setting. Five Variations on a Theme. In: dies./Wallace, William: Policy-Making in the European Union, 4. Auflage, Oxford: $3 \mathrm{ff}$.

Wehlau, Diana (2006): Auf dem Weg in die Armut? Soziale Entwicklungen in der EU und sozialpolitische Handlungsmöglichkeiten. In: Etxezarreta, Miren et al. (Hg.): EuroMemo 2005, Hamburg: 56ff.

Weidenfeld, Werner (2002): Europa - aber wo liegt es? In: ders. (Hg.): a.a.O.: $15 \mathrm{ff}$.

Weidenfeld, Werner (Hg.) (2002): Europa-Handbuch, Bonn.

Weidenfeld, Werner (2006): Europäische Einigung im historischen Überblick. In: ders./Wessels, Wolfgang (Hg.): Europa von A bis Z. Taschenbuch der europäischen Integration, 9. Auflage, Bonn: $13 \mathrm{ff}$.

Werner, Welf (2004): Globalisierung und Globalisierungs-backlash. Ein Vergleich zur Zeit vor 1914. In: Ohr, Renate (Hg.), a.a.O.: 9ff.

Wessels, Wolfgang (2006): Europäischer Rat. In: Weidenfeld, Werner/ Wessels, Wolfgang (Hg.): Europa von A bis Z. Taschenbuch der europäischen Integration, 9. Auflage, Bonn: 207ff.

Wolf, Klaus-Dieter (1997): Entdemokratisierung durch Selbstbindung in der Europäischen Union. In: ders. (Hg.): Projekt Europa im Übergang?, Baden-Baden: $271 \mathrm{ff}$.

Ziegler, Bernd (1998): Geschichte des ökonomischen Denkens, München/Wien.

Ziltener, Patrick (1999): Strukturwandel der europäischen Integration. Die Europäische Union und die Veränderung von Staatlichkeit, Münster.

Zürn, Michael/Wolf, Dieter (1999): European Law and International Regimes: The Features of Law Beyond the Nation State. European Law Journal 5 (3): 272ff.

\section{Europäische Vorgaben}

50/2002/EG: Beschluss des Europäischen Parlaments und des Rates vom 7. Dezember 2001 zur Einführung eines Aktionsprogramms der Gemeinschaft zur Förderung der Zusammenarbeit der Mitgliedstaaten bei der Bekämpfung der sozialen Ausgrenzung. Amtsblatt L 10 vom 12/01/2002: $1 \mathrm{ff}$.

60/C 31/764: Entscheidung des Rates vom 9. März 1960 über die Koordinierung der Konjunkturpolitik der Mitgliedstaaten. Amtsblatt 31 vom 09/05/1960: 764. 
63/266/EWG: Beschluss des Rats vom 2. April 1963 über die Aufstellung allgemeiner Grundsätze für die Durchführung einer gemeinsamen Politik der Berufsausbildung. Amtsblatt 63 vom 20/04/1963: 1338ff.

64/246/EWG: Empfehlung des Rates vom 15. April 1964 an die Mitgliedstaaten zur Wiederherstellung des inneren und äußeren Gleichgewichts der Wirtschaftsentwicklung in der Gemeinschaft. Amtsblatt 64 vom 22/04/1964: 1029.

64/247/EWG: Beschluss des Rates vom 15. April 1964 über die Einsetzung eines Ausschusses für mittelfristige Wirtschaftspolitik. Amtsblatt 64 vom 22/04/1964: 1031ff.

64/299/EWG: Beschluss des Rates vom 8. Mai 1964 über die Zusammenarbeit zwischen den Verwaltungsstellen der Mitgliedstaaten auf dem Gebiet der Haushaltspolitik. Amtsblatt 64 vom 22/04/1964: 1205.

65/192/EWG: Empfehlung des Rates vom 8. April 1965 an die Mitgliedstaaten betreffend die Konjunkturpolitik im weiteren Verlauf des Jahres 1965. Amtsblatt P 65 vom 15/04/1965: $985 f$ f.

65/271/EWG: Entscheidung des Rates vom 13. Mai 1965 über die Harmonisierung bestimmter Vorschriften, die den Wettbewerb im Eisenbahn-, Straßen- und Binnenschiffsverkehr beeinflussen. Amtsblatt 88 vom 24/05/1965: $1500 \mathrm{ff}$.

66/161/EWG: Entscheidung des Rates vom 28. Februar 1966 über die Einführung eines Beratungsverfahrens auf dem Gebiet der Infrastruktur-Investitionen für den Verkehr. Amtsblatt 42 vom 08/03/1966: 583.

66/736/EWG: Empfehlung des Rates vom 22. Dezember 1966 an die Mitgliedstaaten über die Leitlinien der Konjunkturpolitik für das Jahr 1967. Amtsblatt B 241 vom 28/12/1966: 4059.

67/264/EWG: 1. Programm für die mittelfristige Wirtschaftspolitik (1966-1970), 11. April 1967. Amtsblatt 67 vom 25/04/1967: $1513 \mathrm{ff}$.

67/452/EWG: Empfehlung des Rates vom 11. Juli 1967 an die Mitgliedstaaten über die Leitlinien der Konjunkturpolitik für das zweite Halbjahr 1967 und die ersten konjunkturpolitischen Dispositionen für das Jahr 1968. Amtsblatt P 159 vom 18/07/1967: 6ff.

68/147/EWG : Empfehlung des Rates vom 9. März 1968 an die Mitgliedstaaten über die Konjunkturpolitik im Jahre 1968. Amtsblatt L 63 vom 12/03/1968: $5 f$.

68/310/EWG: Richtlinie des Rates zur Gewährung des gegenseitigen Beistands. Amtsblatt L 189 vom 01/08/1968: 13.

69/157/EWG: 2. Programm für die mittelfristige Wirtschaftspolitik, 12. Mai 1969. Amtsblatt L 129 vom 30/05/1969: $1 \mathrm{ff}$. 
69/227/EWG: Entscheidung des Rates vom 17. Juli 1969 über die Koordinierung der kurzfristigen Wirtschaftspolitik der Mitgliedstaaten. Amtsblatt L 183 vom 25/07/1969: 41.

69/262/EWG: Richtlinie des Rates vom 18. Juli 1969 über die Gewährung von Beihilfen für den Schiffbau. Amtsblatt L 206 vom 15/08/1969: 25ff.

70/192/EWG: Beschluss des Rates vom 6. März 1970 über das Verfahren für die Zusammenarbeit in Wirtschafts- und Währungsfragen. Amtsblatt L 59 vom 14/03/1970: 44.

70/532/EWG: Beschluss des Rates vom 14. Dezember 1970 zur Einsetzung des Ständigen Ausschusses für Beschäftigungsfragen der Europäischen Gemeinschaften. Amtsblatt L 273 vom 17/12/1970: $25 f$

70/C 136/19: Ratsbeschlüsse der 116. Tagung vom 8. und 9. Juni 1970. Amtsblatt C 136 vom 11/11/1970: 19.

71/107/EWG: 3. Programm für die mittelfristige Wirtschaftspolitik (1971-1975), 9. Februar 1971. Amtsblatt L 49 vom 01/03/1971: 5ff.

71/141/EWG: Entscheidung des Rates vom 22. März 1971 über die Verstärkung der Koordinierung der kurzfristigen Wirtschaftspolitik der Mitgliedstaaten der Europäischen Wirtschaftsgemeinschaft. Amtsblatt L 73 vom 27/03/1971: 12f.

71/371/EWG: Jahresbericht über die Wirtschaftslage der Gemeinschaft. Amtsblatt L 235 vom 16/11/1971: 13ff.

71/C 23/20: Arbeitsprogramm zur Durchführung von Art. 118 EWGV. Amtsblatt C 23 vom 08/03/1972: $20 \mathrm{ff}$.

71/C 28/01: Entschließung des Rates und der Vertreter der Regierungen der Mitgliedstaaten vom 22. März 1971 über die stufenweise Verwirklichung der Wirtschafts- und Währungsunion in der Gemeinschaft. Amtsblatt C 28 vom 27/03/1971: $1 \mathrm{ff}$.

71/C 81/05: Allgemeine Leitlinien zur Ausarbeitung eines gemeinschaftlichen Tätigkeitsprogramms auf dem Gebiet der Berufsausbildung. Amtsblatt C 81 vom 12/08/1971: $5 \mathrm{ff}$.

72/273/EWG: Richtlinie des Rates vom 20. Juli 1972 betreffend die Beihilfen für den Schiffbau. Amtsblatt L 169 vom 27/07/1972: 28ff.

72/C 38/03: Entschließung des Rates und der Vertreter der Regierungen der Mitgliedstaaten vom 21. März 1972 betreffend die Anwendung der Entschließung vom 22. März 1971 über die stufenweise Verwirklichung der Wirtschafts- und Währungsunion in der Gemeinschaft. Amtsblatt C 38 vom 18/04/1972: 3 f.

72/C 133/01: Jahresbericht über die Wirtschaftslage der Gemeinschaft. Amtsblatt C 133 vom 23/12/1972: $1 \mathrm{ff}$. 
72/C 133/12: Entschließung des Rates vom 5. Dezember 1972 über Maßnahmen zur Inflationsbekämpfung. Amtsblatt C 133 vom 23/12/1972: $12 \mathrm{ff}$.

73/C 75/01: Entschließung des Rates vom 14. September 1973 über weitere Maßnahmen zur Inflationsbekämpfung. Amtsblatt C 75 vom 19/09/1973: 1ff.

73/C 107/01: Entscheidung des Rates zum Jahresbericht über die Wirtschaftslage der Gemeinschaft. Amtsblatt C 107 vom 08/12/1973: 1ff.

73/C 116/22: Entschließung des Rates vom 17. Dezember 1973 über den Kampf gegen die Preissteigerung und über die Wahrung eines hohen Beschäftigungsniveaus in der Gemeinschaft. Amtsblatt C 116 vom 29/12/1973: 22f.

74/120/EWG: Entscheidung des Rates vom 18. Februar 1974 zur Erreichung eines hohen Grades an Konvergenz der Wirtschaftspolitik der Mitgliedstaaten der Europäischen Wirtschaftsgemeinschaft. Amtsblatt L 63 vom 05/03/74: 16ff.

74/121/EWG: Richtlinie des Rates vom 18. Februar 1974 über die Stabilität, das Wachstum und die Vollbeschäftigung in der Gemeinschaft. Amtsblatt L 63 vom 05/03/1974: $19 f$.

74/122/EWG: Beschluss des Rates vom 18. Februar 1974 zur Einsetzung eines Ausschusses für Wirtschaftspolitik. Amtsblatt L 63 vom 05/03/1974: $21 \mathrm{f}$.

74/374/EWG: Entscheidung des Rates vom 4. Juli 1974 über die Anpassung der wirtschaftspolitischen Leitlinien für 1974. Amtsblatt L 199 vom 22/07/1974: $1 \mathrm{ff}$.

74/C 07/02: Entschließung des Rates vom 14. Januar 1974 über die Koordinierung der einzelstaatlichen Politik und die Definition der Aktionen von gemeinschaftlichem Interesse im Bereich der Wissenschaft und Technologie. Amtsblatt C 7 vom 29/01/1974: $2 \mathrm{ff}$.

74/C 13/01: Entschließung des Rates vom 21. Januar 1974 über ein sozialpolitisches Aktionsprogramm. Amtsblatt C 13 vom 12/02/1974: $1 \mathrm{ff}$.

74/C 111/01: Entschließung des Rates vom 27. Juni 1974 betreffend den Vorschlag für eine Entscheidung des Rates zu Artikel 8 der Entscheidung des Rates vom 13. Mai 1965. Amtsblatt C 111 vom 23/09/1974: $1 \mathrm{f}$.

74/C 149/01: Entscheidung des Rates zum Jahresbericht über die Wirtschaftslage der Gemeinschaft. Amtsblatt C 149 vom 28/11/1974: $1 \mathrm{ff}$. 75/327/EWG: Entscheidung des Rates vom 20. Mai 1975 zur Sanierung der Eisenbahnunternehmen und zur Harmonisierung der Vorschriften über die finanziellen Beziehungen zwischen diesen Unternehmen und den Staaten. Amtsblatt L 152 vom 12/06/1975: 3ff. 
75/361/EWG: Entscheidung des Rates vom 16. Juni 1975 über die Anpassung der wirtschaftspolitischen Leitlinien. Amtsblatt L 162 vom 25/06/1975: $13 \mathrm{ff}$.

75/432/EWG: Richtlinie des Rates vom 10. Juli 1975 betreffend die Beihilfen für den Schiffbau. Amtsblatt L 192 vom 24/07/1975: 27ff.

75/787/EWG: Entscheidung des Rates vom 18. Dezember 1975 über die Änderung des Zeitplans für die Ausarbeitung des Jahresberichts über die wirtschaftliche Lage der Gemeinschaft. Amtsblatt L 330 vom 24/12/1975: 52ff.

75/C 297/01: Entscheidung des Rates zum Jahresbericht über die Wirtschaftslage der Gemeinschaft. Amtsblatt C 297 vom 29/12/1975: 1ff.

76/440/EWG: Entscheidung des Rates vom 30. April 1976 über die Anpassung der wirtschaftspolitischen Leitlinien für 1976. Amtsblatt L 119 vom 06/05/1976: $12 \mathrm{ff}$.

76/646/EWG: Entscheidung der Rates zur Wirtschaftspolitik und zur Ausarbeitung der Staatshaushalte für 1977. Amtsblatt L 229 vom 20/08/1976: 1ff.

76/916/EWG: Entscheidung des Rates vom 22. November 1976 zur Verabschiedung des Jahresberichts über die Wirtschaftslage der Gemeinschaft sowie zur Festlegung der wirtschaftspolitischen Leitlinien für 1977. Amtsblatt L 358 vom 29/12/1976: 1ff.

77/294/EWG: Beschluss des Rates und der im Rat vereinigten Vertreter der Regierungen der Mitgliedstaaten vom 14. März 1977 zur Genehmigung des 4. Programms für die mittelfristige Wirtschaftspolitik. Amtsblatt L 101 vom 25/04/1977: $1 \mathrm{ff}$.

77/340/EWG: Entscheidung des Rates vom 25. April 1977 über die Anpassung der wirtschaftspolitischen Leitlinien für 1977. Amtsblatt L 119 vom 12/05/1977: $11 \mathrm{ff}$.

77/492/EWG: Entscheidung des Rates vom 25. Juli 1977 über die Vorbereitung der Staatshaushalte für das Jahr 1978. Amtsblatt L 204 vom 10/08/1977: 6ff.

77/778/EWG: Entscheidung des Rates vom 21. November 1977 zur Verabschiedung des Jahresberichts über die Wirtschaftslage der Gemeinschaft sowie zur Festlegung der wirtschaftspolitischen Leitlinien für 1978. Amtsblatt L 323 vom 19/12/1977: $1 \mathrm{ff}$.

78/338/EWG: Richtlinie des Rates vom 4. April 1978 betreffend die Beihilfen für den Schiffbau. Amtsblatt L 98 vom 11/04/1978: 19ff.

78/658/EWG: Entscheidung des Rates vom 24. Juli 1978 über die Anpassung der Staatshaushalte und die Vorbereitung der Staatshaushalte im Rahmen der konzertierten Aktion der Gemeinschaft. Amtsblatt L 220 vom 11/08/1978: $27 \mathrm{ff}$. 
79/19/EWG: Entscheidung des Rates vom 18. Dezember 1978 zur Verabschiedung des Jahresberichts über die Wirtschaftslage der Gemeinschaft sowie zur Festlegung der wirtschaftspolitischen Leitlinien für 1979. Amtsblatt L 8 vom 12/01/1979: 16ff.

79/136/EWG: Entscheidung des Rates vom 6. Februar 1979 zur Änderung der Entscheidung 74/120/EWG zur Erreichung eines hohen Grades an Konvergenz der Wirtschaftspolitik der Mitgliedstaaten der Europäischen Wirtschaftsgemeinschaft. Amtsblatt L 35 vom 09/02/1979: 8ff.

80/67/EWG: Entscheidung des Rates vom 17. Dezember 1979 zur Verabschiedung des Jahresberichts über die Wirtschaftslage der Gemeinschaft sowie zur Festlegung der wirtschaftspolitischen Leitlinien für 1980. Amtsblatt L 17 vom 23/01/1980: $20 \mathrm{ff}$.

80/1265/EWG: Entscheidung des Rates vom 15. Dezember 1980 zur Verabschiedung des Jahresberichts über die Wirtschaftslage der Gemeinschaft (1980) sowie zur Festlegung der wirtschaftspolitischen Leitlinien für 1981. Amtsblatt L 375 vom 31/12/1980: 17ff.

80/C 168/01: Entschließung des Rates vom 27. Juni 1980 über Leitlinien für eine Arbeitsmarktpolitik der Gemeinschaft. Amtsblatt C 168 vom 08/07/1980: $1 \mathrm{ff}$.

81/363/EWG: Richtlinie des Rates vom 28. April 1981 betreffend die Beihilfen für den Schiffbau. Amtsblatt L 137 vom 23/05/1981: 39ff.

81/1056/EWG: Entscheidung des Rates vom 14. Dezember 1981 zur Verabschiedung des Jahresberichts über die Wirtschaftslage der Gemeinschaft und zur Festlegung der wirtschaftspolitischen Leitlinien für 1982. Amtsblatt L 385 vom 31/12/1981: $1 \mathrm{ff}$.

82/534/EWG: Beschluss des Rates und der im Rat vereinigten Vertreter der Regierungen der Mitgliedstaaten vom 28. Juli 1982 zur Genehmigung des 5. Programms für die mittelfristige Wirtschaftspolitik. Amtsblatt L 236 vom 11/08/1982: $10 \mathrm{ff}$.

82/857/EWG: Empfehlung des Rates vom 10. Dezember 1982 zu den Grundsätzen für ein gemeinsames Vorgehen betreffend die Altersgrenze. Amtsblatt L 357 vom 18/12/1982: $27 \mathrm{f}$.

82/880/EWG: Richtlinie des Rates vom 21. Dezember 1982 zur Änderung der Richtlinie 81/363/EWG betreffend die Beihilfen für den Schiffbau. Amtsblatt L 371 vom 30/12/1982: 46ff.

82/950/EWG: Entscheidung des Rates vom 17. Dezember 1982 zur Verabschiedung des Jahresberichts über die Wirtschaftslage der Gemeinschaft sowie zur Festlegung der wirtschaftspolitischen Leitlinien für 1983. Amtsblatt L 386 vom 31/12/1982: 1ff. 
82/C 186/01: Entschließung des Rates vom 12. Juli 1982 über eine Gemeinschaftsaktion zur Bekämpfung der Arbeitslosigkeit. Amtsblatt C 186 vom 21/07/1982: 1f.

83/674/EWG: Entscheidung des Rates vom 12. Dezember 1983 zur Verabschiedung des Jahresberichts über die Wirtschaftslage der Gemeinschaft sowie zur Festlegung der wirtschaftspolitischen Leitlinien für 1984. Amtsblatt L 378 vom 31/12/1983: 1ff.

83/C 166/01: Entschließung des Rates vom 2. Juni 1983 über Maßnahmen der Berufsbildung im Hinblick auf die Einführung der neuen Informationstechnologien. Amtsblatt C 166 vom 25/06/1983: 1.

83/C 193/02: Entschließung des Rates vom 11. Juli 1983 über die Berufsbildungspolitik in der Europäischen Gemeinschaft während der achtziger Jahre. Amtsblatt C 193 vom 20/07/1983: 2.

84/C 29/01: Entschließung des Rates vom 23. Januar 1984 zur Förderung der Beschäftigung von Jugendlichen. Amtsblatt C 29 vom 04/02/1984: $1 \mathrm{ff}$.

84/C 175/01: Schlussfolgerungen des Rates vom 22. Juni 1984 über ein mittelfristiges Aktionsprogramm der Gemeinschaft im Sozialbereich. Amtsblatt C 175 vom 04/07/1984: $1 \mathrm{ff}$.

84/C 184/01: Schlussfolgerungen des Rates vom 7. Juni 1984 betreffend den technologischen Wandel und soziale Veränderungen. Amtsblatt C 184 vom 11/07/1984: 1.

85/2/EWG: Richtlinie des Rates vom 18. Dezember 1984 zur Verlängerung der Geltungsdauer der Richtlinie 81/363/EWG über Beihilfen für den Schiffbau. Amtsblatt L 2 vom 03/01/1985: 13.

85/8/EWG: Beschluss des Rates vom 19. Dezember 1984 über gezielte Maßnahmen zur Bekämpfung der Armut auf Gemeinschaftsebene. Amtsblatt L 2 vom 03/01/1985: $24 f$.

85/105/EWG: Entscheidung des Rates vom 19. Dezember 1984 zur Verabschiedung des Jahresberichts über die Wirtschaftslage der Gemeinschaft. Amtsblatt L 45 vom 14/02/1985: $1 \mathrm{ff}$.

85/619/EWG: Entscheidung des Rates vom 20. Dezember 1985 zur Verabschiedung des Jahresberichts über die Wirtschaftslage in der Gemeinschaft und zur Festlegung wirtschaftspolitischer Leitlinien für 1986. Amtsblatt L 377 vom 31/12/1985: 1ff.

85/C 02/03: Entschließung des Rates vom 19. Dezember 1984 zur Bekämpfung der Langzeitarbeitslosigkeit. Amtsblatt C 2 vom 04/01/1985: 3ff.

85/C 165/02: Schlussfolgerungen des Rates vom 13. Juni 1985 über ein Programm für spezifische beschäftigungsfördernde Maßnahmen. Amtsblatt C 165 vom 04/07/1985: 1ff. 
86/667/EWG: Entscheidung des Rates vom 22. Dezember 1986 zur Verabschiedung des Jahresberichts über die Wirtschaftslage in der Gemeinschaft und Festlegung wirtschaftspolitischer Leitlinien für 1987. Amtsblatt L 385 vom 31/12/1986: $1 \mathrm{ff}$.

86/C 340/02: Entschließung des Rates vom 22. Dezember 1986 über ein Aktionsprogramm zur Förderung des Beschäftigungswachstums. Amtsblatt C 340 vom 31/12/1986: $2 \mathrm{ff}$.

87/167/EWG: Richtlinie des Rates vom 26. Januar 1987 über Beihilfen für den Schiffbau. Amtsblatt L 69 vom 12/03/1987: 55ff.

87/569/EWG: Beschluss des Rates vom 1. Dezember 1987 über ein Aktionsprogramm für die Berufsbildung Jugendlicher und zur Vorbereitung der Jugendlichen auf das Erwachsenen- und Erwerbsleben. Amtsblatt L 346 vom 10/12/1987: 31ff.

87/609/EWG: Entscheidung des Rates vom 22. Dezember 1987 zur Verabschiedung des Jahresberichts über die Wirtschaftslage in der Gemeinschaft und zur Festlegung wirtschaftspolitischer Leitlinien für 1988. Amtsblatt L 394 vom 31/12/1987: 1ff.

87/C 178/03: Schlussfolgerungen des Rates vom 26. Mai 1987 betreffend die berufliche Bildung der Frauen. Amtsblatt C 178 vom 07/07/1987: 3.

88/655/EWG: Entscheidung des Rates vom 21. Dezember 1988 zur Verabschiedung des Jahresberichts über die Wirtschaftslage in der Gemeinschaft und Festlegung wirtschaftspolitischer Leitlinien für 1989. Amtsblatt L 377 vom 31/12/1988: $1 \mathrm{ff}$.

88/C 333/01: Entschließung des Rates vom 16. Dezember 1988 zur Wiedereingliederung und Späteingliederung von Frauen in das Berufsleben. Amtsblatt C 333 vom 28/12/1988: 1f.

89/685/EWG: Entscheidung des Rates vom 21. Dezember 1989 zur Verabschiedung des Jahreswirtschaftsberichts 1989-1990 über die Wirtschaftslage in der Gemeinschaft und zur Festlegung der wirtschaftspolitischen Leitlinien der Gemeinschaft für 1990. Amtsblatt L 399 vom 30/12/1989: $1 \mathrm{ff}$.

89/C 148/01: Entschließung des Rates vom 5. Juni 1989 über die berufliche Weiterbildung. Amtsblatt C 148 vom 15/06/1989: $1 \mathrm{ff}$.

89/C 277/01: Entschließung des Rates und der im Rat vereinigten Minister für Sozialfragen vom 29. September 1989 über die Bekämpfung der sozialen Ausgrenzung. Amtsblatt C 277 vom 31/10/1989: 1.

90/141/EWG: Entscheidung des Rates vom 12. März 1990 zur Erreichung einer schrittweisen Konvergenz der Politiken und der wirtschaftlichen Ergebnisse während der ersten Stufe der Wirtschaftsund Währungsunion. Amtsblatt L 78 vom 24/03/1990: 23 f. 
90/267/EWG: Beschluss des Rates vom 29. Mai 1990 über ein Aktionsprogramm zur Förderung der beruflichen Weiterbildung in der Europäischen Gemeinschaft. Amtsblatt L 156 vom 21/06/1990: 1ff.

90/684/EWG: Richtlinie des Rates vom 21. Dezember 1990 über Beihilfen für den Schiffbau. Amtsblatt L 380 vom 31/12/1990: $27 f$.

91/387/EG: Beschluss des Rates vom 22. Juli 1991 zur Änderung des Beschlusses 87/569/EWG über ein Aktionsprogramm für die Berufsbildung Jugendlicher und zur Vorbereitung der Jugendlichen auf das Erwachsenen- und Erwerbsleben (PETRA). Amtsblatt L 214 vom 02/08/1991: 69ff.

91/440/EWG: Richtlinie des Rates vom 29. Juli 1991 zur Entwicklung der Eisenbahnunternehmen der Gemeinschaft. Amtsblatt L 237 vom 24/08/1991: $25 \mathrm{ff}$.

91/464/EWG: Entscheidung des Rates vom 29. Juli 1991 zur Verabschiedung des Jahresberichts 1990/91 über die Wirtschaftslage in der Gemeinschaft und zur Festlegung der wirtschaftspolitischen Leitlinien der Gemeinschaft für 1991. Amtsblatt L 252 vom 07/09/1991: $17 \mathrm{ff}$.

92/180/EWG: Entscheidung des Rates vom 25. Februar 1992 zur Verabschiedung des Jahreswirtschaftsberichts 1991/92 über die Wirtschaftslage in der Gemeinschaft und zur Festlegung der wirtschaftspolitischen Leitlinien der Gemeinschaft für 1992. Amtsblatt L 85 vom 31/03/1992: $1 \mathrm{ff}$.

92/241/EWG: Empfehlung des Rates vom 31. März 1992 zur Kinderbetreuung. Amtsblatt L 123 vom 08/05/1992: 16ff.

92/441/EWG: Empfehlung des Rates vom 24. Juni 1992 über gemeinsame Kriterien für ausreichende Zuwendungen und Leistungen im Rahmen der Systeme der sozialen Sicherung. Amtsblatt L 245 vom 26/08/1992: 46ff.

92/442/EWG: Empfehlung des Rates vom 27. Juli 1992 über die Annäherung der Ziele und der Politiken im Bereich des sozialen Schutzes. Amtsblatt L 245 vom 26/08/1992: 49ff.

92/C 49/03: Entschließung des Rates vom 21. Dezember 1992 über die Notwendigkeit einer Reaktion auf die ernste, sich verschlechternde Arbeitsmarktlage der Gemeinschaft. Amtsblatt C 49 vom 19/02/1993: 3ff.

93/258/EWG: Entscheidung des Rates vom 23. März 1993 zur Verabschiedung des Jahreswirtschaftsberichts 1993 und zur Festlegung der wirtschaftspolitischen Leitlinien der Gemeinschaft für 1993. Amtsblatt L 119 vom 14/05/1993: $1 \mathrm{ff}$. 
93/C 186/02: Entschließung des Rates vom 11. Juni 1993 über die Berufsbildung in den 1990er Jahren. Amtsblatt C 186 vom 08/07/1993: $3 \mathrm{ff}$.

93/C 343/01: Grundsatzerklärung des Rates der Europäischen Union und der im Rat vereinigten Minister für Sozialfragen vom 6. Dezember 1993 anläßlich des Abschlusses des Europäischen Jahres der älteren Menschen und der Solidargemeinschaft der Generationen. Amtsblatt C 343 vom 21/12/1993: $1 \mathrm{ff}$.

94/7/EG: Empfehlung des Rates vom 22. Dezember 1993 über die Grundzüge der Wirtschaftspolitik der Mitgliedstaaten und der Gemeinschaft. Amtsblatt L 7 vom 11/01/1994: 9ff.

94/480/EG: Empfehlung des Rates vom 11. Juli 1994 über die Grundzüge der Wirtschaftspolitik der Mitgliedstaaten und der Gemeinschaft. Amtsblatt L 200 vom 03/08/1994: 38ff.

94/819/EG: Beschluss des Rates vom 6. Dezember 1994 über ein Aktionsprogramm zur Durchführung einer Berufsbildungspolitik der Europäischen Gemeinschaft. Amtsblatt L 340 vom 29/12/1994: 8ff.

94/C 343/01: Entschließung des Rates vom 21. November 1994 zur Stärkung der Wettbewerbsfähigkeit der Gemeinschaftsindustrie. Amtsblatt C 343 vom 06/12/1994: $1 \mathrm{ff}$.

94/C 368/03: Entschließung des Rates vom 6. Dezember 1994 zu bestimmten Perspektiven einer Sozialpolitik der Europäischen Union: Ein Beitrag zur wirtschaftlichen und sozialen Konvergenz in der Union. Amtsblatt C 368 vom 23/12/1994: 6ff.

94/C 374/01: Entschließung des Rates vom 5. Dezember 1994 zur Qualität und Attraktivität beruflicher Bildung. Amtsblatt C 374 vom 30/12/1994: 1ff.

95/326/EG: Empfehlung des Rates vom 10. Juli 1995 zu den Grundzügen der Wirtschaftspolitik der Mitgliedstaaten und der Gemeinschaft. Amtsblatt L 191 vom 12/08/1995: 24ff.

95/C 207/07: Schlussfolgerungen des Rates vom 24. Juli 1995 zur entscheidenden Bedeutung der Qualität beruflicher Bildung. Amtsblatt C 207 vom 12/08/1995: 7f.

96/431/EG: Empfehlung des Rates vom 8. Juli 1996 über die Grundzüge der Wirtschaftspolitik der Mitgliedstaaten und der Gemeinschaft. Amtsblatt L 179 vom 18/07/1996: 46ff.

96/C 281/03: Mitteilung der Kommission: Leistungen der Daseinsvorsorge in Europa. Amtsblatt C 281 vom 26/09/1993: 3ff.

96/C 386/02: Entschließung des Rates und der im Rat vereinigten Vertreter der Regierungen der Mitgliedstaaten vom 2. Dezember 1996 zur Rolle der Sozialschutzsysteme bei der Bekämpfung der Arbeitslosigkeit. Amtsblatt C 386 vom 20/12/1996: 3ff. 
97/479/EG: Empfehlung des Rates vom 7. Juli 1997 über die Grundzüge der Wirtschaftspolitik der Mitgliedstaaten und der Gemeinschaft. Amtsblatt L 209 vom 02/08/1997: $12 \mathrm{ff}$.

97/C 236/01: Entschließung des Europäischen Rates über den Stabilitäts- und Wachstumspakt, Amsterdam, 17. Juni 1997. Amtsblatt C 236 vom 02/08/1997: 1f.

97/C 236/02: Entschließung des Europäischen Rates über Wachstum und Beschäftigung, Amsterdam, 16. Juni 1997. Amtsblatt C 236 vom 02/08/1997: $3 \mathrm{f}$.

98/454/EG: Empfehlung des Rates vom 6. Juli 1998 über die Grundzüge der Wirtschaftspolitik der Mitgliedstaaten und der Gemeinschaft. Amtsblatt L 200 vom 16/07/1998: 34ff.

98/C 30/01: Entschließung des Rates vom 15. Dezember 1997 zu den beschäftigungspolitischen Leitlinien für 1998. Amtsblatt C 30 vom 28/01/1998: $1 \mathrm{ff}$.

98/C 35/01: Entschließung des Europäischen Rates vom 13. Dezember 1997 über die wirtschaftspolitische Koordinierung in der dritten Stufe der WWU und zu den Artikeln 109 und 109b des EG-Vertrags. Amtsblatt C 35 vom 02/02/1998: $1 \mathrm{ff}$.

1692/96/EG: Entscheidung des Europäischen Parlaments und des Rates vom 23. Juli 1996 über gemeinschaftliche Leitlinien für den Aufbau eines transeuropäischen Verkehrsnetzes. Amtsblatt L 228 vom 09/09/1996: $1 \mathrm{ff}$.

1999/570/EG: Empfehlung des Rates vom 12. Juli 1999 über die Grundzüge der Wirtschaftspolitik der Mitgliedstaaten und der Gemeinschaft. Amtsblatt L 217 vom 17/08/1999: 34ff.

1999/C 69/02: Entschließung des Rates vom 22. Februar 1999 zu den beschäftigungspolitischen Leitlinien für 1999. Amtsblatt C 69 vom 12/03/1999: 2ff.

2000/228/EG: Beschluss des Rates vom 13. März 2000 über die Leitlinien für beschäftigungspolitische Maßnahmen der Mitgliedstaaten im Jahr 2000. Amtsblatt L 72 vom 21/03/2000: $15 \mathrm{ff}$.

2000/436/EG: Beschluss des Rates vom 29. Juni 2000 zur Einsetzung eines Ausschusses für Sozialschutz. Amtsblatt L 172 vom 12/07/ 2000: $26 f$.

2000/517/EG: Empfehlung des Rates vom 19. Juni 2000 betreffend die Grundzüge der Wirtschaftspolitik der Mitgliedstaaten und der Gemeinschaft. Amtsblatt L 210 vom 21/08/2000: 1ff.

2000/C 8/04: Entschließung des Rates vom 17. Dezember 1999 zur Entwicklung neuer Arbeitsweisen für die europäische Zusammenarbeit im Bereich der allgemeinen und beruflichen Bildung. Amtsblatt C 8 vom 12/01/2000: $6 f$. 
2000/C 8/05: Schlussfolgerungen des Rates vom 17. Dezember 1999 über den Ausbau der Zusammenarbeit zur Modernisierung und Verbesserung des Sozialschutzes. Amtsblatt C 8 vom 12/01/2000: $7 f$.

2001/63/EG: Beschluss des Rates vom 19. Januar 2001 über die Leitlinien für beschäftigungspolitische Maßnahmen der Mitgliedstaaten im Jahr 2001. Amtsblatt L 22 vom 24/01/2001: 18ff.

2001/483/EG: Empfehlung des Rates vom 15. Juni 2001 zu den Grundzügen der Wirtschaftspolitik der Mitgliedstaaten und der Gemeinschaft. Amtsblatt L 179 vom 02/07/2001: $1 \mathrm{ff}$.

2001/C 204/01: Entschließung des Rates vom 13. Juli 2001 über die Rolle der allgemeinen und beruflichen Bildung in der Beschäftigungspolitik. Amtsblatt C 204 vom 20/07/2001: 1f.

2002/39/EG: Richtlinie des Europäischen Parlaments und des Rates vom 10. Juni 2002 zur Änderung der Richtlinie 97/67/EG im Hinblick auf die weitere Liberalisierung des Marktes für Postdienste in der Gemeinschaft. Amtsblatt L 176 vom 05/07/2002: $21 \mathrm{ff}$.

2002/177/EG: Beschluss des Rates vom 18. Februar 2002 über die Leitlinien für beschäftigungspolitische Maßnahmen der Mitgliedstaaten im Jahr 2002. Amtsblatt L 60 vom 01/03/2002: $60 \mathrm{ff}$.

2002/549/EG: Empfehlung des Rates vom 21. Juni 2002 zu den Grundzügen der Wirtschaftspolitik der Mitgliedstaaten und der Gemeinschaft. Amtsblatt L 182 vom 11/07/2002: 1ff.

2002/C 13/02: Entscheidung des Rates vom 19. Dezember 2002 zur Förderung einer verstärkten europäischen Zusammenarbeit bei der beruflichen Bildung. Amtsblatt C 13 vom 18/01/2003: $2 \mathrm{ff}$.

2002/C 142/01: Mitteilung des Rates: Detailliertes Arbeitsprogramm zur Umsetzung der Ziele der Systeme der allgemeinen und beruflichen Bildung in Europa. Amtsblatt C 142 vom 14/06/2002: $1 \mathrm{ff}$.

2002/C 162/01: Entschließung des Rates vom 3. Juni 2002 über Qualifikation und Mobilität. Amtsblatt C 162 vom 06/07/2002: $1 \mathrm{ff}$.

2003/555/EG: Empfehlung des Rates vom 26. Juni 2003 zu den Grundzügen der Wirtschaftspolitik der Mitgliedstaaten und der Gemeinschaft (Zeitraum 2003-2005). Amtsblatt L 195 vom 01/08/2003: 1ff.

2003/578/EG: Beschluss des Rates vom 22. Juli 2003 über die Leitlinien für beschäftigungspolitische Maßnahmen der Mitgliedstaaten. Amtsblatt L 197 vom 05/08/2003: 13ff.

2003/C 175/02: Entschließung des Rates vom 15. Juli 2003 zum Sozialund Humankapital - Aufbau von Sozial- und Humankapital in der Wissensgesellschaft: Ausbildung, Beruf, sozialer Zusammenhalt und Geschlechterperspektive. Amtsblatt C 175 vom 24/07/2003: 3ff. 
2004/740/EG: Beschluss des Rates vom 4. Oktober 2004 über die Leitlinien für beschäftigungspolitische Maßnahmen der Mitgliedstaaten. Amtsblatt L 326 vom 29/10/2004: 45f.

14098/01: Rat (Beschäftigung und Soziales) (2001): Qualität und langfristige Finanzierbarkeit der Altersversorgungssysteme - Gemeinsamer Bericht über Zielsetzungen und Arbeitsmethoden im Bereich der Renten (gebilligt auf dem Europäischen Rat von Laeken, 14.15.12.2001), http://ue.eu.int/ueDocs/cms_Data/docs/pressData/de/ misc/DOC.68840.pdf (04.04.07).

14164/1/02: Rat (Beschäftigung und Soziales) (2002): Bekämpfung der Armut und der sozialen Ausgrenzung: gemeinsame Ziele für die zweite Runde der nationalen Aktionspläne, (gebilligt auf dem Europäischen Rat von Kopenhagen, 12-13.12.02), http://ec.europa.eu/ employment_social/social_inclusion/docs/counciltext_de.pdf (04.04.07).

14110/00: Rat (Beschäftigung und Soziales) (2000): Bekämpfung der Armut und sozialen Ausgrenzung, Festlegung von geeigneten Zielen, Brüssel (gebilligt auf dem Europäischen Rat von Nizza, 7.9.12.00), http://ec.europa.eu/employment_social/social_inclusion/ docs/approb_de.pdf (04.04.07).

CREST (2004): Report on the application of the open method of coordination in favour of the Barcelona research investment objective, http://ec.europa.eu/invest_in_research/pdf/download_en/crest_report _barcelona_research_investment_objective.pdf (24.05.06).

Einheitliche Europäische Akte, 1987.

Europäischer Rat (1976a): Schlussfolgerungen des Vorsitzes, Europäischer Rat Brüssel, 12.-13. 7.1976. In: Group of the Europeans People's Party (1990): Dossier: The European Council, Luxemburg: $79 \mathrm{ff}$.

Europäischer Rat (1976b): Schlussfolgerungen des Vorsitzes, Europäischer Rat Den Haag, 29.-30.11.1976. In: Group of the Europeans People's Party (1990): Dossier: The European Council, Luxemburg: $82 \mathrm{ff}$.

Europäischer Rat (1977): Schlussfolgerungen des Vorsitzes, Europäischer Rat Brüssel, 5.-6.12. 1977. In: Europäische Kommission: Bulletin der Europäischen Gemeinschaften 12-1977: $26 \mathrm{f}$.

Europäischer Rat (1978a): Schlussfolgerungen des Vorsitzes, Europäischer Rat Kopenhagen, 7.-8.4.1978. In: Europäische Kommission: Bulletin der Europäischen Gemeinschaften 4-1978: 11ff.

Europäischer Rat (1978b): Schlussfolgerungen des Vorsitzes, Europäischer Rat Bremen, 6.-7.7.1978. In: Europäische Kommission: Bulletin der Europäischen Gemeinschaften 6-1978: $17 \mathrm{ff}$. 
Europäischer Rat (1979a): Schlussfolgerungen des Vorsitzes, Europäischer Rat Paris, 12.-13.3.1979. In: Europäische Kommission: Bulletin der Europäischen Gemeinschaften 2-1979: 9ff.

Europäischer Rat (1979b): Schlussfolgerungen des Vorsitzes, Europäischer Rat Straßbourg, 21.-22.6.1979 in: Europäische Kommission: Bulletin der Europäischen Gemeinschaften 6-1979: 7ff.

Europäischer Rat (1979c): Schlussfolgerungen des Vorsitzes, Europäischer Rat Dublin, 29.-30.11.1979. In: Europäische Kommission: Bulletin der Europäischen Gemeinschaften 11-1979: 8ff.

Europäischer Rat (1980a): Schlussfolgerungen des Vorsitzes, Europäischer Rat Venedig, 12.-13.6.1980. In: Europäische Kommission: Bulletin der Europäischen Gemeinschaften 6-1980: 8ff.

Europäischer Rat (1980b): Schlussfolgerungen des Vorsitzes, Europäischer Rat Luxemburg, 1.-2.12.1980. In: Group of the Europeans People's Party (1990): Dossier: The European Council, Luxemburg: $153 \mathrm{ff}$.

Europäischer Rat (1981a): Schlussfolgerungen des Vorsitzes, Europäischer Rat Maastricht, 22.-23.3.1981. In: Europäische Kommission: Bulletin der Europäischen Gemeinschaften 3-1981: 7ff.

Europäischer Rat (1981b): Schlussfolgerungen des Vorsitzes, Europäischer Rat Luxemburg, 29.-30.6.1981. In: Europäische Kommission: Bulletin der Europäischen Gemeinschaften 6-1981: 7ff.

Europäischer Rat (1981c): Schlussfolgerungen des Vorsitzes, Europäischer Rat London, 26.-27.11.1981. In: Europäische Kommission: Bulletin der Europäischen Gemeinschaften 11- 1981: 7ff.

Europäischer Rat (1982a): Schlussfolgerungen des Vorsitzes, Europäischer Rat Brüssel, 29.-30.3.1982. In: Europäische Kommission: Bulletin der Europäischen Gemeinschaften 3-1982: $18 \mathrm{ff}$.

Europäischer Rat (1982b): Schlussfolgerungen des Vorsitzes, Europäischer Rat Brüssel, 28.-29.6.1982. In: Europäische Kommission: Bulletin der Europäischen Gemeinschaften 6-1982: 16ff.

Europäischer Rat (1982c): Schlussfolgerungen des Vorsitzes, Europäischer Rat Kopenhagen, 3.-4.12.1982. In: Europäische Kommission: Bulletin der Europäischen Gemeinschaften 12-1982: $10 \mathrm{ff}$.

Europäischer Rat (1983a): Schlussfolgerungen des Vorsitzes, Europäischer Rat Brüssel, 21.-22.3.1983. In: Europäische Kommission: Bulletin der Europäischen Gemeinschaften 3-1983: 18ff.

Europäischer Rat (1983b): Schlussfolgerungen des Vorsitzes, Europäischer Rat Stuttgart, 17.-19.6.1983. In: Europäische Kommission: Bulletin der Europäischen Gemeinschaften 6-1983: 19ff. 
Europäischer Rat (1983c): Feierliche Deklaration zur Europäischen Union. In: Europäische Kommission: Bulletin der Europäischen Gemeinschaften 6-1983: 26ff.

Europäischer Rat (1984): Schlussfolgerungen des Vorsitzes, Europäischer Rat Dublin, 3.-4.12.1984. In: Europäische Kommission: Bulletin der Europäischen Gemeinschaften 12-1984: $18 \mathrm{ff}$.

Europäischer Rat (1985a): Schlussfolgerungen des Vorsitzes, Europäischer Rat Brüssel, 29.-30.03.1985. In: Europäische Kommission: Bulletin der Europäischen Gemeinschaften 3-1985: $11 \mathrm{ff}$.

Europäischer Rat (1985b): Schlussfolgerungen des Vorsitzes, Europäischer Rat Mailand, 28.-29.06.1985. In: Europäische Kommission: Bulletin der Europäischen Gemeinschaften 6-1983: 13ff.

Europäischer Rat (1985c): Schlussfolgerungen des Vorsitzes, Europäischer Rat Luxemburg, 2.-3.12.1985. In: Europäische Kommission: Bulletin der Europäischen Gemeinschaften 12-1985: 8ff.

Europäischer Rat (1986a): Schlussfolgerungen des Vorsitzes, Europäischer Rat Den Haag, 26.-27.06.1986. In: Europäische Kommission: Bulletin der Europäischen Gemeinschaften 6-1986: 7ff.

Europäischer Rat (1986b): Schlussfolgerungen des Vorsitzes, Europäischer Rat London, 6.12.1986. In: Europäische Kommission: Bulletin der Europäischen Gemeinschaften 12-1986: 7ff.

Europäischer Rat (1987a): Schlussfolgerungen des Vorsitzes, Europäischer Rat Brüssel, 29.-30.6.1987. In: Europäische Kommission: Bulletin der Europäischen Gemeinschaften 6-1987: 8ff.

Europäischer Rat (1988a): Schlussfolgerungen des Vorsitzes, Europäischer Rat Hannover, 27.-28.6.1988. In: Europäische Kommission: Bulletin der Europäischen Gemeinschaften 6-1988: 164ff.

Europäischer Rat (1988b): Schlussfolgerungen des Vorsitzes, Europäischer Rat Rhodos, 2.-3.12.1988. In: Europäische Kommission: Bulletin der Europäischen Gemeinschaften 12-1988: 8ff.

Europäischer Rat (1989a): Schlussfolgerungen des Vorsitzes, Europäischer Rat Madrid, 26.-27.6.1989. In: Europäische Kommission: Bulletin der Europäischen Gemeinschaften 6-1989: 8ff.

Europäischer Rat (1989b): Gemeinschaftscharta der sozialen Grundrechte der Arbeitnehmer, verabschiedet auf dem Europäischen Rat Straßburg, 9.12.1989, http://www2.fh-fulda.de/CuRs/ normenarchiv/ internationalrecht/arbeitnehmersozialegrundrechte.htm (04.04.07).

Europäischer Rat (1990): Schlussfolgerungen des Vorsitzes, Europäischer Rat Rom, 27.-28.10.1990. In: Europäische Kommission: Bulletin der Europäischen Gemeinschaften 10-1990: 7ff. 
Europäischer Rat (1991): Schlussfolgerungen des Vorsitzes, Europäischer Rat Luxemburg, 28.-29.6.1991. In: Europäische Kommission: Bulletin der Europäischen Gemeinschaften 6-1991: 8ff.

Europäischer Rat (1992a): Schlussfolgerungen des Vorsitzes, Europäischer Rat Birmingham, 16.10.1992. In: Europäische Kommission: Bulletin der Europäischen Gemeinschaften 10-1992: 7ff.

Europäischer Rat (1992b): Schlussfolgerungen des Vorsitzes, Europäischer Rat Edinburgh, 11.-12.12.1992 (inkl. Erklärung des Europäischen Rates zur Förderung des wirtschaftlichen Aufschwungs in Europa). In: Europäische Kommission: Bulletin der Europäischen Gemeinschaften 12-1992: 8ff.

Europäischer Rat (1993a): Schlussfolgerungen des Vorsitzes, Europäischer Rat Kopenhagen, 21.-22.6.1993. In: Europäische Kommission: Bulletin der Europäischen Gemeinschaften 6-1993: 8ff.

Europäischer Rat (1993b): Schlussfolgerungen des Vorsitzes, Europäischer Rat Brüssel, 29.10.1993. In: Europäische Kommission: Bulletin der Europäischen Gemeinschaften 10-1993: $7 \mathrm{ff}$.

Europäischer Rat (1993c): Schlussfolgerungen des Vorsitzes, Europäischer Rat Brüssel, 10.-11.12.1993. In: Europäische Kommission: Bulletin der Europäischen Gemeinschaften 12-1993: 7ff.

Europäischer Rat (1994a): Schlussfolgerungen des Vorsitzes, Europäischer Rat Korfu, 24.- 25.6.1994. In: Europäische Kommission: Bulletin der Europäischen Gemeinschaften 6-1994: 8ff.

Europäischer Rat (1994b): Schlussfolgerungen des Vorsitzes, Europäischer Rat Essen, 9.-10.12.1994. In: Europäische Kommission: Bulletin der Europäischen Gemeinschaften 12-1994: $7 \mathrm{ff}$.

Europäischer Rat (1995a): Schlussfolgerungen des Vorsitzes, Europäischer Rat Cannes, 26.-27.6.1995. In: Europäische Kommission: Bulletin der Europäischen Gemeinschaften 6-1995: $10 \mathrm{ff}$.

Europäischer Rat (1995b): Schlussfolgerungen des Vorsitzes, Europäischer Rat Madrid, 15.-16.12.1995. In: Europäische Kommission: Bulletin der Europäischen Gemeinschaften 12-1995: 9ff.

Europäischer Rat (1996): Schlussfolgerungen des Vorsitzes, Europäischer Rat Dublin, 13.-14.12.1996. In: Europäische Kommission: Bulletin der Europäischen Union 12-1996: 9ff.

Europäischer Rat (1997a): Schlussfolgerungen des Vorsitzes, Europäischer Rat Amsterdam, 16.-17.6.1997. In: Europäische Kommission: Bulletin der Europäischen Union 6-1997: 8ff.

Europäischer Rat (1997b): Schlussfolgerungen des Vorsitzes, Sondertagung des Europäischen Rates über Beschäftigungsfragen, Luxemburg, 20.-21.11.1997. In: Europäische Kommission: Bulletin der Europäischen Union 11-1997: 7ff. 
Europäischer Rat (1997c): Schlussfolgerungen des Vorsitzes, Europäischer Rat Luxemburg, 12.-13.12.1997. In: Europäische Kommission: Bulletin der Europäischen Union 12-1997: Ziff. I.2ff.

Europäischer Rat (1998a): Schlussfolgerungen des Vorsitzes, Europäischer Rat Cardiff, 15.-16.6.1998. In: Europäische Kommission: Bulletin der Europäischen Union 6-1998: Ziff. I.2ff.

Europäischer Rat (1998b): Schlussfolgerungen des Vorsitzes, Europäischer Rat Wien, 11.-12.12.1998. In: Europäische Kommission: Bulletin der Europäischen Union 12-1998: Ziff. I.2ff.

Europäischer Rat (1999a): Schlussfolgerungen des Vorsitzes, Europäischer Rat Köln, 3.-4.6.1999. In: Europäische Kommission: Bulletin der Europäischen Union 6-1999: Ziff. I.2ff.

Europäischer Rat (1999b): Schlussfolgerungen des Vorsitzes, Europäischer Rat Helsinki, 10.-11.12.1999. In: Europäische Kommission: Bulletin der Europäischen Union 12-1999: Ziff. I.2ff.

Europäischer Rat (2000a): Schlussfolgerungen des Vorsitzes, Europäischer Rat Lissabon, 23.- 24.3.2000. In: Europäische Kommission: Bulletin der Europäischen Union 3-2000: Ziff. I.2ff.

Europäischer Rat (2000b): Schlussfolgerungen des Vorsitzes, Europäischer Rat Nizza, 7.-9.12.2000. In: Europäische Kommission: Bulletin der Europäischen Union 12-2000: Ziff. I.2ff.

Europäischer Rat (2001a): Schlussfolgerungen des Vorsitzes, Europäischer Rat Stockholm, 23.-24.3.2001. In: Europäische Kommission: Bulletin der Europäischen Union 3-2001: Ziff. I.2ff.

Europäischer Rat (2001b): Schlussfolgerungen des Vorsitzes, Europäischer Rat Göteborg, 15.-16.6.2001. In: Europäische Kommission: Bulletin der Europäischen Union 6-2001: Ziff. I.2ff.

Europäischer Rat (2001c): Schlussfolgerungen des Vorsitzes, Europäischer Rat Laeken, 14.-15.12.2001. In: Europäische Kommission: Bulletin der Europäischen Union 12-2001: Ziff. I.2ff.

Europäischer Rat (2002a): Schlussfolgerungen des Vorsitzes, Europäischer Rat Barcelona, 15.-16.3.2002. In: Europäische Kommission: Bulletin der Europäischen Union 3-2002: Ziff. I.2ff.

Europäischer Rat (2002b): Schlussfolgerungen des Vorsitzes, Europäischer Rat Kopenhagen, 12.-13.12.2002. In: Europäische Kommission: Bulletin der Europäischen Union 12-2002: Ziff. I.2ff.

Europäischer Rat (2003a): Schlussfolgerungen des Vorsitzes, Europäischer Rat Brüssel, 20.-21.3.2003. In: Europäische Kommission: Bulletin der Europäischen Union 3-2003: Ziff. I.2ff.

Europäischer Rat (2003b): Schlussfolgerungen des Vorsitzes, Europäischer Rat Thessaloniki, 19.-20.6.2003. In: Europäische Kommission: Bulletin der Europäischen Union 6-2003: Ziff. I.2ff. 
Europäischer Rat (2003c): Schlussfolgerungen des Vorsitzes, Europäischer Rat Brüssel, 16.-17.10.2003. In: Europäische Kommission: Bulletin der Europäischen Union 10-2003: Ziff. I-2ff.

Europäischer Rat (2003d): Schlussfolgerungen des Vorsitzes, Europäischer Rat Brüssel, 12.-13.12.2003. In: Europäische Kommission: Bulletin der Europäischen Union 12-2003: Ziff. I.2ff.

Europäischer Rat (2004): Schlussfolgerungen des Vorsitzes, Europäischer Rat Brüssel, 25.-26.3.2004. In: Europäische Kommission: Bulletin der Europäischen Union 3-2004: Ziff. I.2ff.

European Council (2007): Presidency Press Release of the Informal European Council Lisbon, 19.10.2007, http://www.eu2007.pt/ UE/vEN/Noticias_Documentos/20071019FINAL.htm (07. 11.07).

Konferenz der Staats- bzw. Regierungschefs (1961a): Kommunique des Treffens in Paris, 10.-11.2.1961. In: Europäische Kommission: Bulletin der Europäischen Wirtschaftsgemeinschaft 1-1961: $13 \mathrm{ff}$.

Konferenz der Staats- bzw. Regierungschefs (1961b): Kommunique des Treffens in Bonn, 19.7.1961. In: Europäische Kommission: Bulletin der Europäischen Wirtschaftsgemeinschaft 7/8-1961: 39ff.

Konferenz der Staats- bzw. Regierungschefs (1969): Kommunique des Treffens in Den Haag, 1.-2.12.1969. In: Europäische Kommission: Bulletin der Europäischen Gemeinschaften 1-1970: 12ff.

Konferenz der Staats- bzw. Regierungschefs (1972): Kommunique des Treffens in Paris, 19.-20.10.1972. In: Europäische Kommission: Bulletin der Europäischen Gemeinschaften 10-1972: 15ff.

Konferenz der Staats- bzw. Regierungschefs (1974): Kommunique des Treffens in Paris, 19.-20.10.1974. In: Europäisches Parlament: Bulletin 45/74: 4ff.

Konferenz der Vertreter der Regierungen der Mitgliedstaaten (2007a): Entwurf eines Vertrags zur Änderung des Vertrags über die Europäische Union und des Vertrags zur Gründung der Europäischen Gemeinschaft, CIG 1/1/07, REV 1, http://www.consilium.europa.eu/ uedocs/cmsUpload/ cg00001-re01.de07.pdf (22.10.07).

Konferenz der Vertreter der Regierungen der Mitgliedstaaten (2007b): Entwurf eines Vertrags zur Änderung des Vertrags über die Europäische Union und des Vertrags zur Gründung der Europäischen Gemeinschaft - Protokolle, CIG 2/1/07, REV 1, http://www.consilium. europa.eu/uedocs/ cmsUpload/cg00002re01.de07.pdf (22.10.07).

Rat (1959): Pressekommunique des Treffens der Finanzminister am 16. und 17.7.1959. In: Europäische Kommission: Bulletin der Europäischen Wirtschaftsgemeinschaft 3-1959: 39f. 
Rat (1967): Entschließung des Rates über die allgemeine Ausrichtung der Wirtschaftspolitik, Tagung vom 3.7.1967. In: Europäische Kommission: Bulletin der Europäischen Wirtschaftsgemeinschaft 9/10-1967: 49f.

Rat (1970): Beschluss über zweckmäßige Einzelheiten der in der Ratsentscheidung vom 17. Juli 1969 über die Koordinierung der kurzfristigen Wirtschaftspolitik der Mitgliedstaaten vorgesehenen Konsultationen. In: Europäische Kommission: 4. Gesamtbericht über die Tätigkeit der Europäischen Gemeinschaften, Brüssel: 88.

Rat (1971): Orientierungsdaten für die kurzfristige Wirtschaftspolitik, beschlossen auf der Sitzung am 15. Juni 1971. In: Europäische Kommission: Bulletin der Europäischen Gemeinschaften 7-1971: $14 \mathrm{ff}$.

Rat (1973): Mitteilung des Rates zu Sozialpolitik, 11.-12. Dezember 1973. In: Europäische Kommission: Bulletin der Europäischen Gemeinschaften 12-1973: 53ff.

Rat (1979): Entscheidung der Ratstagung vom 18. Juni 1979. In: Europäische Kommission: 13. Gesamtbericht über die Tätigkeit der Europäischen Gemeinschaften, Brüssel: 81f.

Rat (1983): Schlussfolgerungen der Ratstagung vom 11. Juli 1983 bezüglich der zweiten vierteljährlichen Prüfung der Wirtschaftslage. In: Europäische Kommission: Bulletin der Europäischen Gemeinschaften 7/8-1983: 16.

Vertrag zur Gründung der Europäischen Atomgemeinschaft, 1958.

Vertrag zur Gründung der Europäischen Gemeinschaft für Kohle und Stahl, 1952.

Vertrag zur Gründung der Europäischen Wirtschaftsgemeinschaft, 1958.

Vertrag zur Gründung der Europäischen Gemeinschaft in der Fassung von Maastricht, 1993.

Vertrag zur Gründung der Europäischen Gemeinschaft in der Fassung von Amsterdam, 1997.

Vertrag zur Gründung der Europäischen Gemeinschaft in der Fassung von Nizza, 2003.

Vertrag über die Europäische Union in der Fassung von Maastricht, 1993.

Vertrag über die Europäische Union in der Fassung von Amsterdam, 1997.

Vertrag über die Europäische Union in der Fassung von Nizza, 2003.

Vertrag über eine Verfassung für Europa, 2004. 
VO 165/65: Verordnung (EWG) des Rates vom 9. Dezember 1965 zur Verlängerung des Zeitraums, in dem die VO 17 des Rates auf den Eisenbahn-, Strassen- und Binnenschiffsverkehr keine Anwendung findet. Amtsblatt 210 vom 11/12/1965: 3141ff.

VO 659/1999: Verordnung (EG) des Rates vom 22. März 1999 über besondere Vorschriften für die Anwendung von Artikel 93 des EGVertrags. Amtsblatt L 83 vom 27/03/1999: $1 \mathrm{ff}$.

VO 994/98: Verordnung (EG) des Rates vom 7. Mai 1998 über die Anwendung der Artikel 92 und 93 des Vertrags zur Gründung der Europäischen Gemeinschaft auf bestimmte Gruppen horizontaler Beihilfen. Amtsblatt L 142 vom 14/05/1998: $1 \mathrm{ff}$.

VO 1002/67: Verordnung (EWG) des Rates vom 14. Dezember 1967 zur Verlängerung des Zeitraums, in dem die VO 17 des Rates auf den Eisenbahn-, Straßen- und Binnenschiffsverkehr keine Anwendung findet. Amtsblatt L 306 vom 16/12/1967: 1.

VO 1013/97: Verordnung (EG) des Rates vom 2. Juni 1997 über Beihilfen für bestimmte Werften, die zur Zeit umstrukturiert werden. Amtsblatt L 148 vom 06/06/1997: 1f.

VO 1017/68: Verordnung (EWG) des Rates vom 19. Juli 1968 über die Anwendung von Wettbewerbsregeln auf dem Gebiet des Eisenbahn-, Straßen- und Binnenschiffsverkehrs. Amtsblatt L 175 vom 23/07/1968: $1 \mathrm{ff}$.

VO 1100/89: Verordnung (EWG) des Rates vom 27. April 1989 zur Änderung der VO 1107/70 über Beihilfen im Eisenbahn-, Strassen- und Binnenschiffsverkehr. Amtsblatt L 116 vom 28/04/1989: 24.

VO 1107/70: Verordnung (EWG) des Rates vom 4. Juni 1970 über Beihilfen im Eisenbahn-, Straßen- und Binnenschiffsverkehr. Amtsblatt L 130 vom 15/06/1970: $1 \mathrm{ff}$.

VO 1191/69: Verordnung (EWG) des Rates vom 26. Juni 1969 über das Vorgehen der Mitgliedstaaten bei mit dem Begriff des öffentlichen Dienstes verbundenen Verpflichtungen auf dem Gebiet des Eisenbahn-, Straßen- und Binnenschiffsverkehrs. Amtsblatt L 156 vom 28/06/1969: $1 \mathrm{ff}$.

VO 1192/69: Verordnung (EWG) des Rates vom 26. Juni 1969 über gemeinsame Regeln für die Normalisierung der Konten der Eisenbahnunternehmen. Amtsblatt L 156 vom 28/06/ 1969: 8ff.

VO 1466/97: Verordnung (EG) des Rates vom 7. Juli 1997 über den Ausbau der haushaltspolitischen Überwachung und der Überwachung und Koordinierung der Wirtschaftspolitiken. Amtsblatt L 209 vom 02/08/1997: $1 \mathrm{ff}$. 
VO 1467/97: Verordnung (EG) des Rates vom 7. Juli 1997 über die Beschleunigung und Klärung des Verfahrens bei einem übermäßigen Defizit. Amtsblatt L 209 vom 02/08/ 1997: 6ff.

VO 1473/75: Verordnung (EWG) des Rates vom 20. Mai 1975 zur Änderung der VO 1107/70 über Beihilfen im Eisenbahn-, Straßen- und Binnenschiffsverkehr. Amtsblatt L 152 vom 12/06/1975: 1f.

VO 1540/98: Verordnung (EG) des Rates vom 29. Juni 1998 zur Neuregelung der Beihilfen für den Schiffbau. Amtsblatt L 202 vom 18/07/1998: $1 \mathrm{ff}$.

VO 3094/95: Verordnung (EG) des Rates vom 22. Dezember 1995 über Beihilfen für den Schiffbau. Amtsblatt L 332 vom 30/12/1995: 1ff.

VO 3578/92: Verordnung (EWG) des Rates vom 7. Dezember 1992 zur Änderung der VO 1107/70 über Beihilfen im Eisenbahn-, Strassenund Binnenschiffsverkehr. Amtsblatt L 364 vom 12/12/1992: 11f. 


\section{ABBILDUNGSVERZEICHNIS}

Abb. 1

Zusammenhang zwischen Staatsverständnis, staatlichen

Interventionsmöglichkeiten und staatlicher Handlungsfähigkeit

Abb. 2

Starke Handlungsfähigkeit

Abb. 3

Stärkung der Handlungsfähigkeit bei einem zurückhaltenden Staatsverständnis

Abb. 4

Stärkung der Handlungsfähigkeit bei einem interventionistischen Staatsverständnis 



$\begin{array}{ll}\text { BE } & \text { beschäftigungspolitische Vorgaben } \\ \text { Benelux } & \begin{array}{l}\text { Belgien, Niederlande, Luxemburg } \\ \text { beschäftigungs- und sozialpolitische Vorgaben }\end{array} \\ \text { BS } & \text { Bruttoinlandsprodukt } \\ \text { BSP } & \text { Bruttosozialprodukt } \\ \text { CELEX } & \begin{array}{l}\text { Communitatis Europeae LEX (Online Datenbank für } \\ \text { Europäisches Gemeinschaftsrecht) }\end{array} \\ \text { CW } & \text { The Collected Writings of John Maynard Keynes } \\ \text { EAG } & \text { Europäische Atomgemeinschaft } \\ \text { EAGV } & \text { Vertrag zur Gründung der Europäischen } \\ & \text { Atomgemeinschaft } \\ \text { EC } & \text { European Community } \\ \text { EEA } & \text { Einheitliche Europäische Akte } \\ \text { EG } & \text { Europäische Gemeinschaft } \\ \text { EGKS } & \text { Europäische Gemeinschaft für Kohle und Stahl } \\ \text { EGKSV } & \text { Vertrag zur Gründung der EGKS } \\ \text { EGV } & \text { Vertrag zur Gründung der Europäischen Gemeinschaft } \\ \text { EGV-A } & \text { EGV in der Fassung von Amsterdam } \\ \text { EGV-M } & \text { EGV in der Fassung von Maastricht } \\ \text { EGV-N } & \text { EGV in der Fassung von Nizza } \\ \text { EP } & \text { Europäisches Parlament } \\ \text { ER } & \text { Europäischer Rat } \\ \text { EU } & \text { Europäische Union/European Union } \\ \text { EuGH } & \text { Europäischer Gerichtshof } \\ \text { EUR-LEX } & \text { Online Datenbank für Europäisches Gemeinschaftsrecht } \\ \text { EUV } & \text { Vertrag über die Europäische Union }\end{array}$




$\begin{array}{ll}\text { EWGV } & \text { Vertrag zur Gründung der Europäischen } \\ \text { EWS } & \text { Wirtschaftsgemeinschaft } \\ \text { EZB } & \text { Europäisches Währungssystem } \\ \text { FuE } & \text { Furopäische Zentralbank } \\ \text { GATT } & \text { General Agreement on Tariffs and Trade } \\ \text { GATS } & \text { General Agreement on Trade in Services } \\ \text { GdW } & \text { Grundzüge der Wirtschaftspolitik } \\ \text { KMU } & \text { Kleine und mittelständische Unternehmen } \\ \text { NKM } & \text { Neue Klassische Makroökonomie } \\ \text { OMK } & \text { Offene Methode der Koordinierung } \\ \text { OMKincl } & \text { OMK im Bereich Armut und soziale Ausgrenzung } \\ \text { SOZ } & \text { sozialpolitische Vorgaben } \\ \text { SWP } & \text { Stabilitäts- und Wachstumspakt } \\ \text { TRIPS } & \text { Agreement on Trade-Related Aspects of } \\ & \text { Intellectual Property Rights } \\ \text { VerfV } & \text { Vertrag über eine Verfassung für Europa } \\ \text { VO } & \text { Verordnung } \\ \text { WI } & \text { wirtschaftspolitische Vorgaben } \\ \text { WTO } & \text { World Trade Organisation } \\ \text { WWU } & \text { Wirtschafts- und Währungsunion }\end{array}$




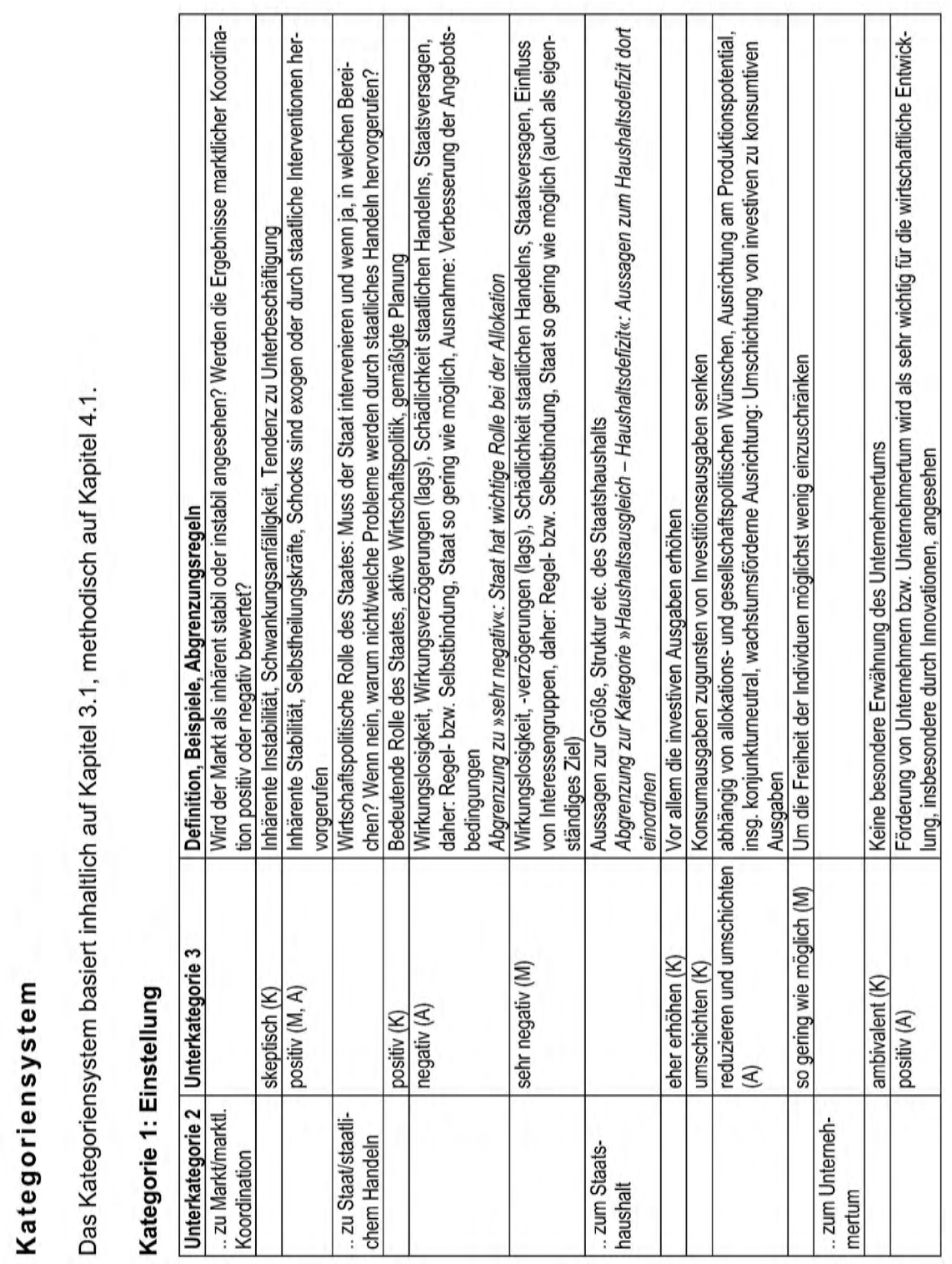




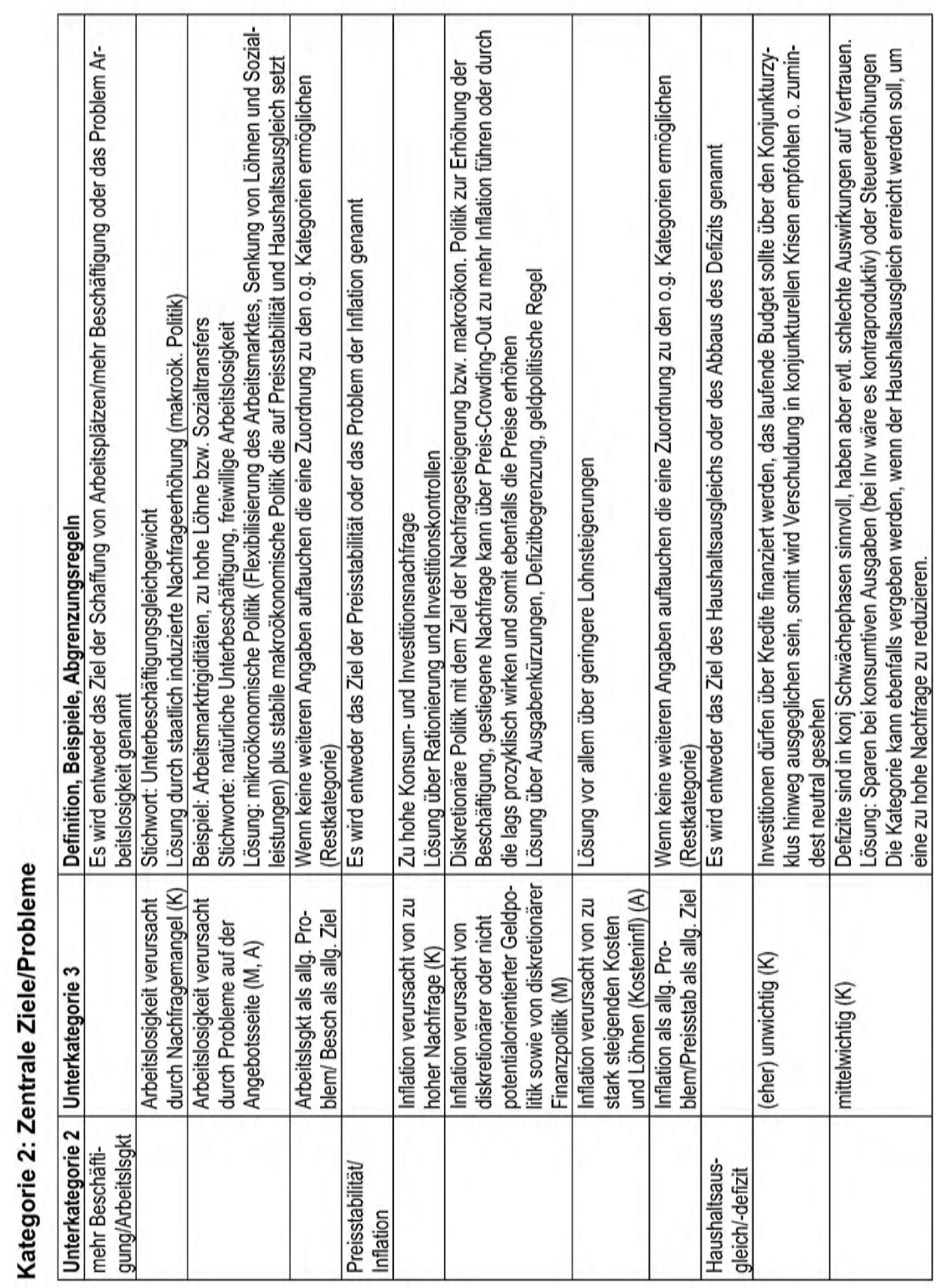




\begin{tabular}{|c|c|c|c|c|c|c|c|c|c|c|c|c|c|}
\hline 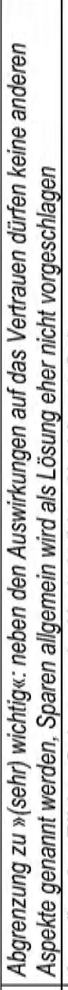 & 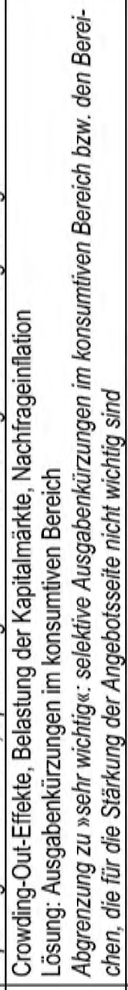 & 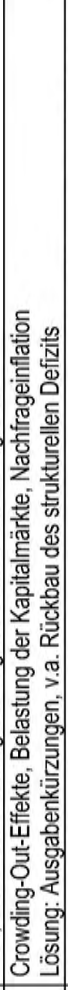 & 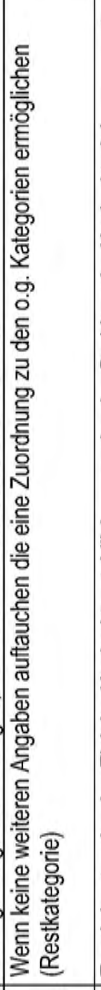 & 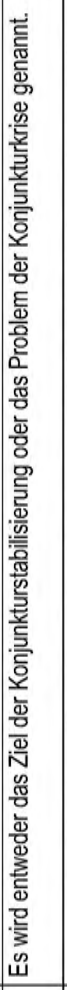 & 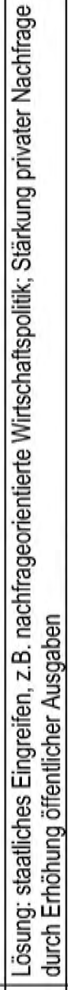 & 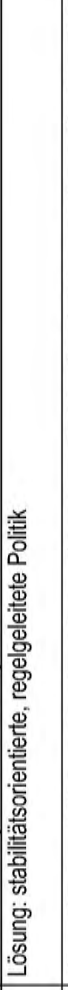 & 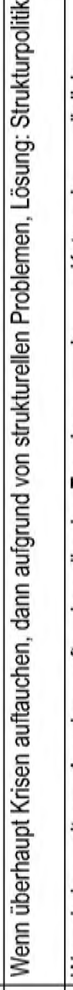 & 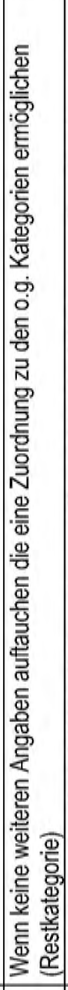 & 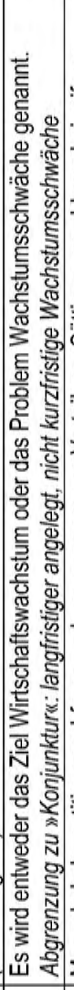 & 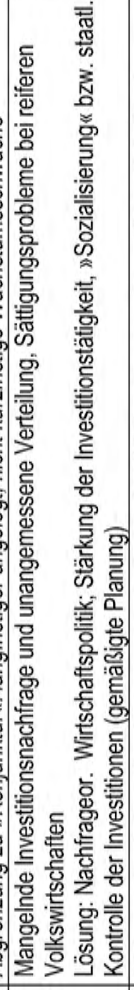 & 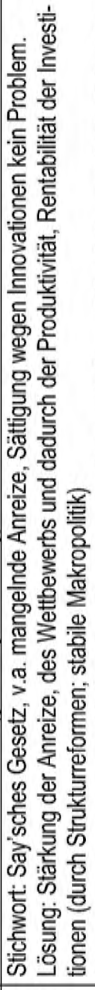 & 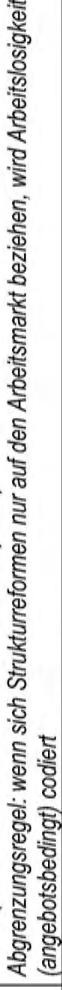 & 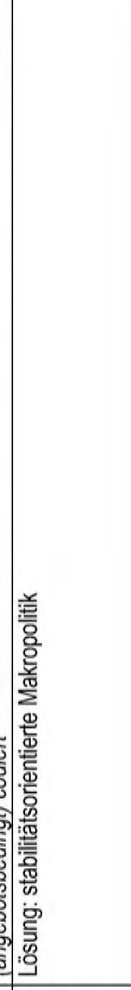 \\
\hline & $\begin{array}{l}\frac{1}{3} \\
\frac{0}{2} \\
\frac{20}{3} \\
\frac{0}{3}\end{array}$ & 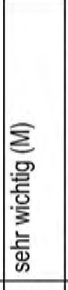 & 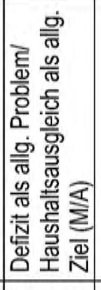 & & 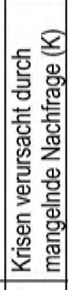 & 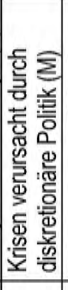 & 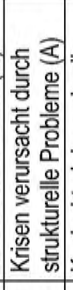 & 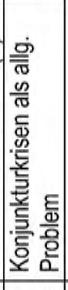 & & 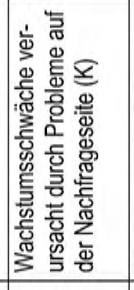 & 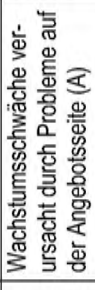 & & 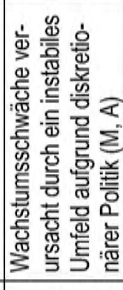 \\
\hline & & & & 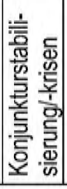 & & & & & 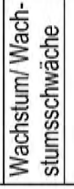 & & & & \\
\hline
\end{tabular}




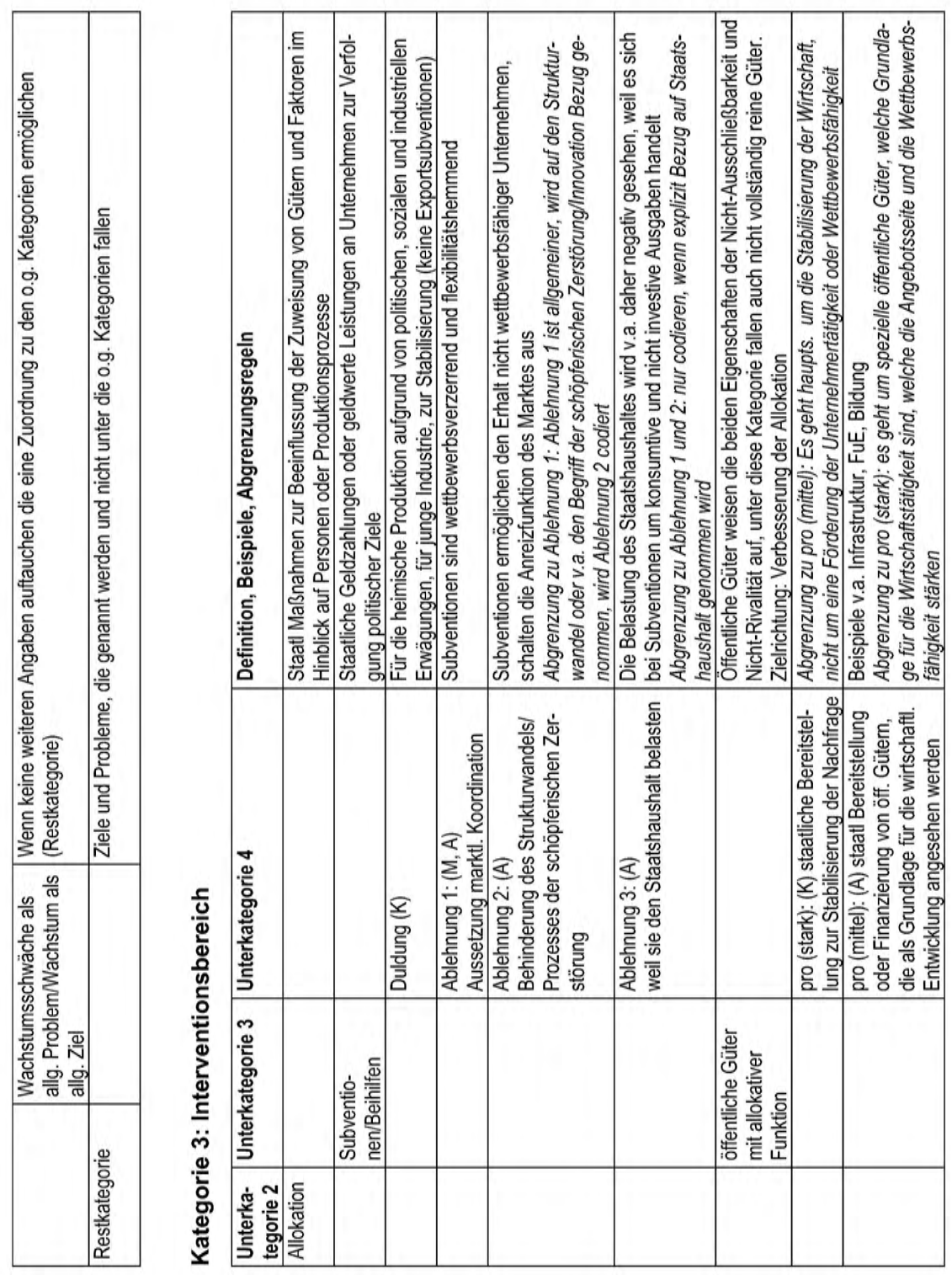




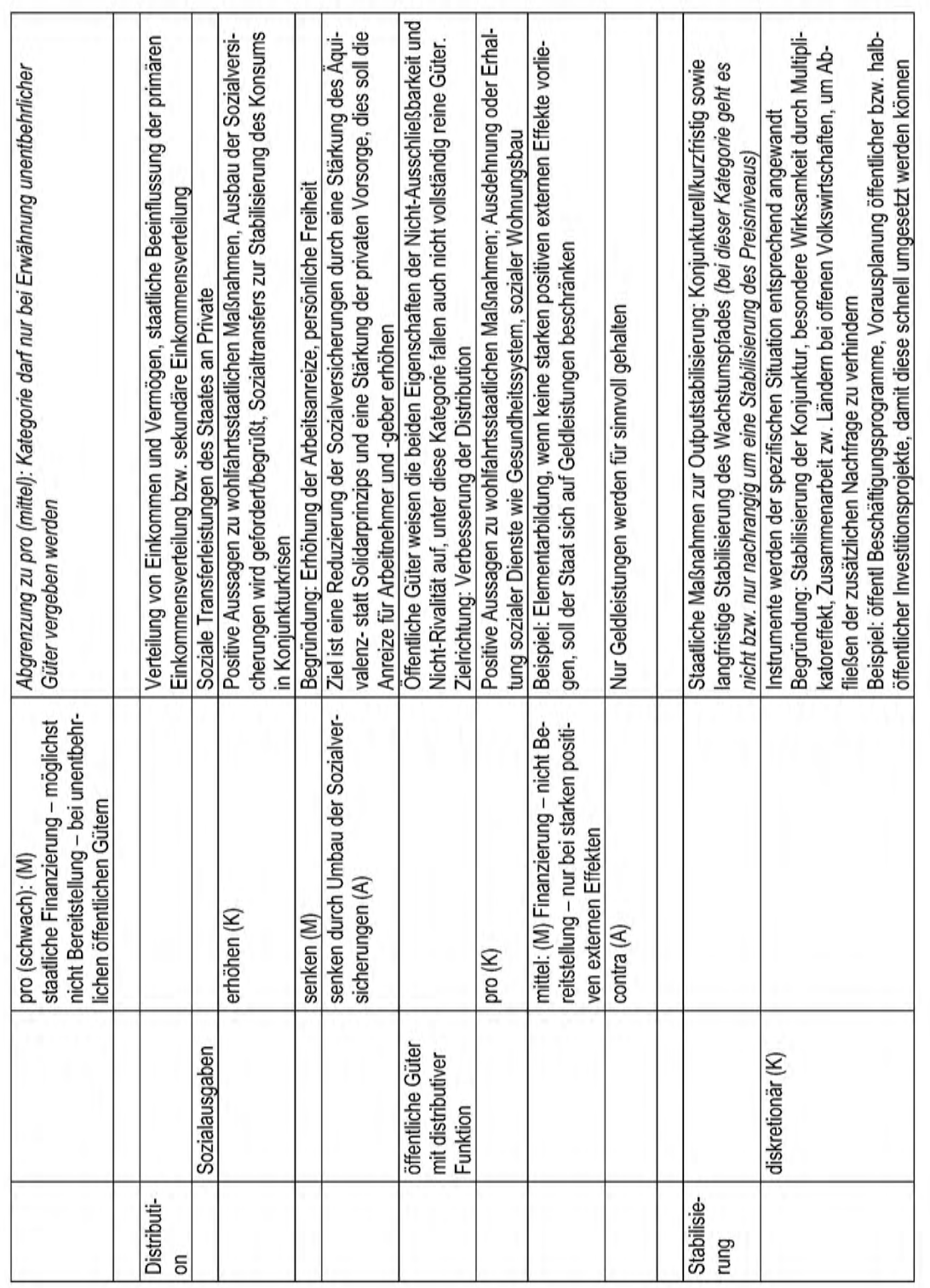




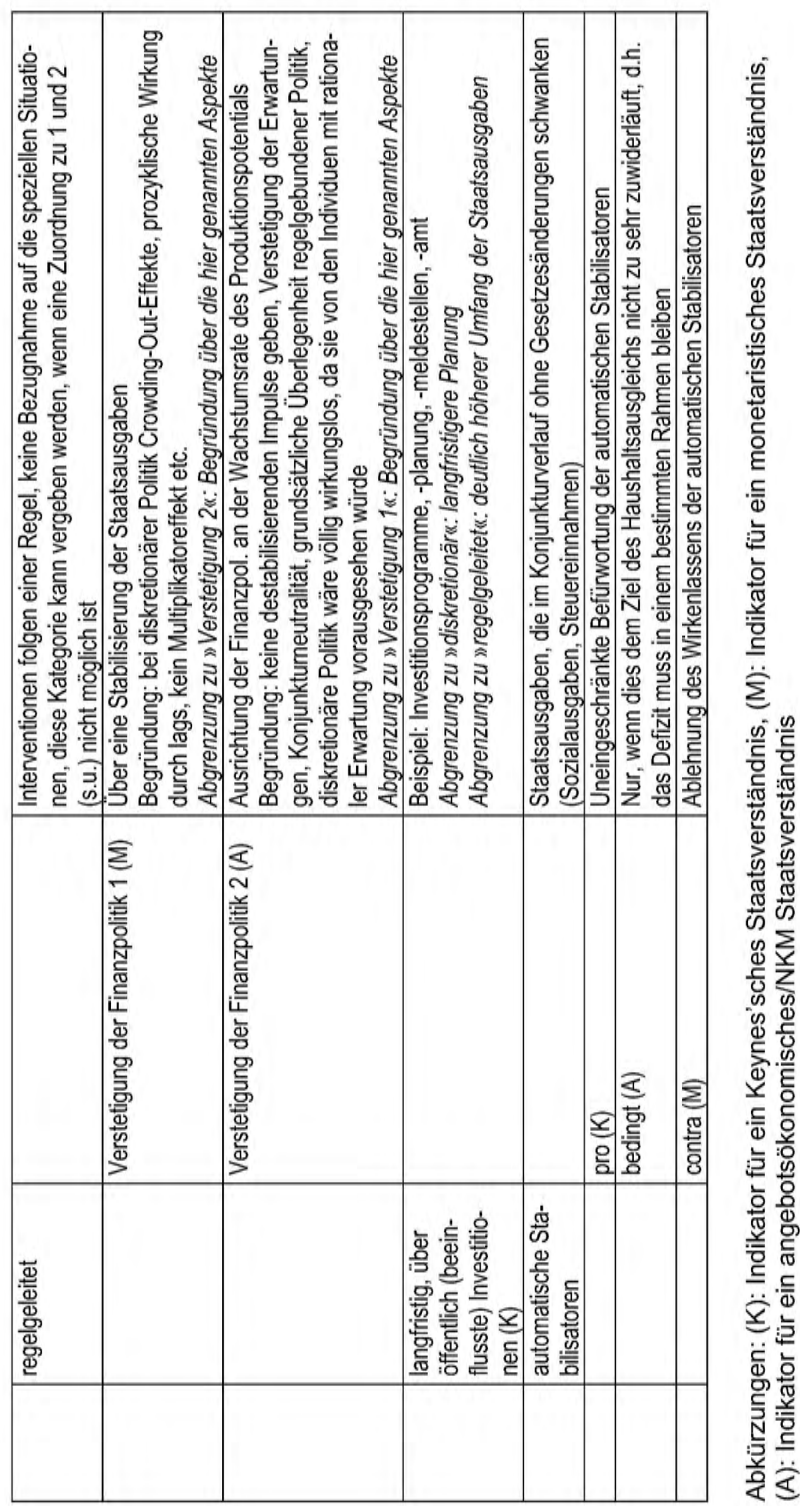




\section{DANKE}

Das Verfassen einer Doktorarbeit ist oftmals ein einsames Unterfangen - und doch sind so viele Menschen daran beteiligt, dass man kaum weiß, wo man mit dem Bedanken anfangen soll.

Ich danke meinen Gutachtern Prof. Dr. Arne Heise, Prof. Dr. Jörg Huffschmid und Prof. Dr. Leonhard Hajen für ihre kritischen Fragen, ihre konstruktiven Vorschläge und die oft bis in die Fußnoten reichende Betreuung. Das DFG-Graduiertenkolleg »Die Zukunft des Europäischen Sozialmodells« an der Universität Göttingen war die beste Arbeitsumgebung, die ich mir wünschen konnte. Ich möchte mich hierfür nicht nur bei der Deutschen Forschungsgemeinschaft und der Universität Göttingen bedanken, sondern vor allem bei denjenigen, die dieses Kolleg möglich gemacht haben, in erster Linie Prof. Dr. Ilona Ostner, Prof. Dr. Stephan Lessenich, Dr. Torsten Niechoj und Uschi Brand. Bedanken möchte ich mich auch bei all denen, die dort mit mir promoviert haben und von denen viele zu FreundInnen geworden sind: Doreen Müller, Oliver Nachtwey, Steve Schwarzer, Robert Fischer, Esther Ochoa-Fernández, Antonio Brettschneider, Christina May, Carina Siefken - um nur einige zu nennen.

Eine Doktorarbeit ist niemals möglich ohne das »Leben daneben«, wobei die Trennung oft nicht einfach ist. Ich danke ich stellvertretend für alle guten FreundInnen, die mich in dieser Zeit begleitet haben, Iris Peckl, Britta Wiesenthal, Susanne Uhl, Heike Ackermann, Tobias Kohl, Thomas Löding und Malte Klar. Gleiches gilt für meine Eltern, Schwestern und Großeltern. Schließlich möchte ich Thomas Herzog danken, der einen sehr langen Weg der Doktorarbeit mit mir gegangen ist und nun - wie viele andere, aber doch ganz besonders - mit mir weitergeht, in das Leben nach der Diss. 


\section{Global Studies}
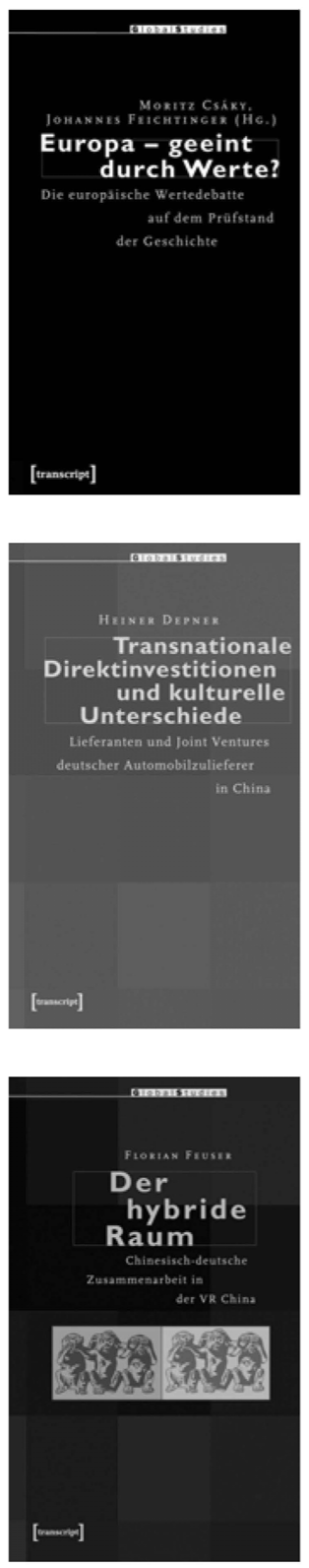

Moritz CsÁKY, Johannes Feichtinger (Hg.) Europa - geeint durch Werte? Die europäische Wertedebatte auf dem Prüfstand der Geschichte

2007, 218 Seiten, kart., 24,80€, ISBN 978-3-89942-785-I

\section{Heiner Depner}

Transnationale Direktinvestitionen und kulturelle Unterschiede Lieferanten und Joint Ventures deutscher Automobilzulieferer in China 2006, 240 Seiten, kart., 25,80€, ISBN $978-3-89942-567-3$

FLORIAN FEUSER

Der hybride Raum

Chinesisch-deutsche Zusammenarbeit in der VR China

2006, 344 Seiten, kart., 29,80€, ISBN 978-3-89942-58I-9 


\section{Global Studies}
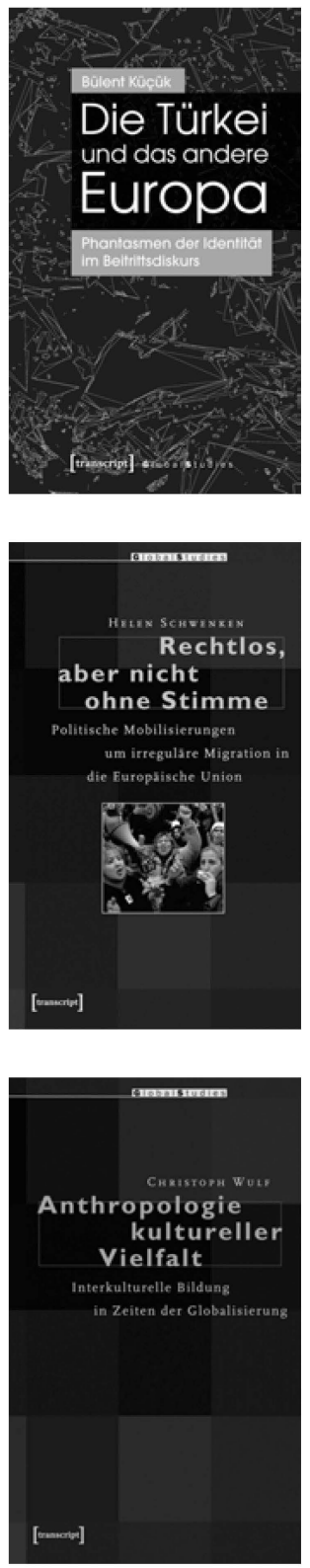

BÜLENT KüÇÜK

Die Türkei und das andere Europa Phantasmen der Identität im Beitrittsdiskurs

September 2008, 236 Seiten, kart., zahlr. Abb., 25,80€, ISBN 978-3-8376-IOI2-3

\section{Helen Schwenken}

Rechtlos, aber nicht ohne Stimme Politische Mobilisierungen um irreguläre Migration in die Europäische Union 2006, 374 Seiten, kart., 29,80€, ISBN 978-3-89942-516-I

Christoph Wulf Anthropologie kultureller Vielfalt Interkulturelle Bildung in Zeiten der Globalisierung 2006, I64 Seiten, kart., I7,80€, ISBN 978-3-89942-574-I 


\section{Global Studies}

Christian BERndT,

JoHANNES GlÜCKLER (HG.)

Denkanstöße zu einer anderen

Geographie der Ökonomie

2006, I72 Seiten, kart., $17,80 €$,

ISBN 978-3-89942-454-6

\section{Barbara Christophe}

Metamorphosen des Leviathan in einer post-sozialistischen

Gesellschaft

Georgiens Provinz zwischen

Fassaden der Anarchie

und regulativer Allmacht

2005, 264 Seiten, kart., 26,80€,

ISBN 978-3-89942-323-5

ANJA Frohnen

Diversity in Action

Multinationalität in globalen

Unternehmen am Beispiel Ford 2005, 246 Seiten, kart., 25,80€, ISBN 978-3-89942-377-8

\section{UlRich HeINZE}

Hautkontakt der Schriftsysteme Japan im Zeichen der

Globalisierung:

Geldflüsse und Werbetexte

2006, 208 Seiten, kart., 25,80€,

ISBN 978-3-89942-513-0

\section{Christian Kellermann}

Die Organisation

des Washington Consensus

Der Internationale

Währungsfonds und seine Rolle in der internationalen

Finanzarchitektur

2006, 326 Seiten, kart., $28,80 €$,

ISBN 978-3-89942-553-6
Lutz Leisering, Petra Buhr,

Ute Traiser-Diop

Soziale Grundsicherung in

der Weltgesellschaft

Monetäre Mindestsicherungs-

systeme in den Ländern

des Südens und des Nordens.

Weltweiter Survey und

theoretische Verortung

2006,342 Seiten, kart., 29,80€,

ISBN 978-3-89942-460-7

Ivo Mossig

Netzwerke der Kulturökonomie

Lokale Knoten und globale

Verflechtungen der Film-

und Fernsehindustrie in

Deutschland und den USA

2006, 228 Seiten, kart., 26,80€,

ISBN 978-3-89942-523-9

\section{Matthias Otten}

Interkulturelles Handeln in der globalisierten Hochschulbildung Eine kultursoziologische Studie 2006, 318 Seiten, kart., 28,80€, ISBN 978-3-89942-434-8

\section{GUdRUN QuenZeL}

Konstruktionen von Europa

Die europäische Identität und die Kulturpolitik der Europäischen Union 2005, 326 Seiten, kart., 28,80€, ISBN 978-3-89942-4I4-0

Shingo Shimada, Christian Tagsold

Alternde Gesellschaften im Vergleich

Solidarität und Pflege

in Deutschland und Japan

2006, I78 Seiten, kart., I8,80€, ISBN $978-3-89942-476-8$ 